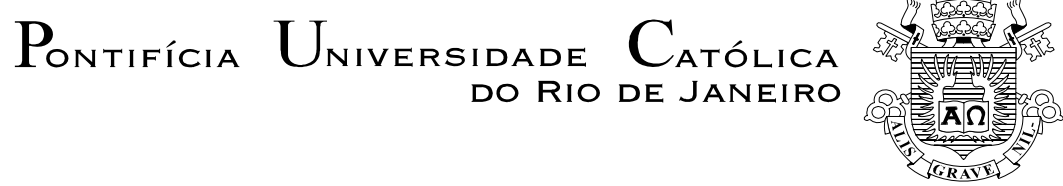

Sergio Luis Franklin Júnior Valuing Real Options for Network Investment
Decisions and Cost-Based Access Pricing

\author{
Tese de Doutorado
}

Thesis presented to the Programa de Pós-Graduação em Engenharia Industrial of the Departamento de Engenharia Industrial da PUC-Rio, as partial fulfillment of the requirements for the degree of Doutor.

Advisor: Prof. Nelio Domingues Pizzolato

Rio de Janeiro

Abril de 2013 


\title{
Valuing Real Options for Network Investment Decisions and Cost-Based Access Pricing
}

Thesis presented to the Programa de Pós-Graduação em Engenharia de Produção of the Departamento de Engenharia Industrial do Centro Técnico Científico da PUC-Rio, as partial fulfillment of the requirements for the degree of Doutor.

\author{
Prof. Nélio Domingues Pizzolato \\ Advisor \\ Departamento de Engenharia Industrial - PUC-Rio
}

Prof. Marco Antonio Guimarães Dias Petróleo Brasileiro - Rio de Janeiro

Prof. Luiz Eduardo Teixeira Brandão Departamento de Administração - PUC-Rio

Prof. Jorge Passamani Zubelli Instituto Nacional de Matemática Pura e Aplicada - IMPA

Prof. Luiz Guilherme Schymura de Oliveira Escola de Pós-Graduação em Economia - FGV

Dra. Maria Margarete da Rocha Mohelský FGV Projetos

Prof. José Eugenio Leal Coordinator of the Centro Técnico Científico da PUC-Rio 
All rights reserved.

\section{Sergio Luis Franklin Júnior}

Sergio Franklin is technical analyst at SUSEP (Superintendence of Private Insurance), where he works in the Solvency/Underwriting Division. Prior to SUSEP, Sergio worked as executive and principal consultant in a number of companies, including Telcordia Technologies, Analysys Consulting, and IBM, where he led consulting assignments in the areas of business strategy, corporate finance, regulatory economics and statistical modeling, in Brazil and abroad. He holds a master degree in Business Administration from the Institut Européen d'Administration des Affaires, Fontainebleau, France (Insead), and a graduate degree in Electrical Engineering from Pontifícia Universidade Católica, Rio de Janeiro, Brazil (PUC-Rio).

Ficha Catalográfica

Franklin Júnior, Sergio Luis

Valuing real options for network investment decisions and cost-based access pricing / Sergio Luis Franklin Júnior; advisor: Nélio Domingues Pizzolato. - 2013.

187 f. ; $30 \mathrm{~cm}$

Tese (doutorado) - Pontifícia Universidade Católica do Rio de Janeiro, Departamento de Engenharia Industrial, 2013.

Inclui bibliografia

1. Engenharia Industrial - Teses. 2. Opções reais. 3. Investimento sob incerteza. 4. Regulação. 5. Precificação. 6. Incerteza de demanda. 7. Incerteza tecnológica. 8. Incerteza de taxa de juros. 9. Preços baseados em custos. 10. Interconexão e acesso. I. Pizzolato, Nélio Domingues. II. Pontifícia Universidade Católica do Rio de Janeiro. Departamento de Engenharia Industrial. III. Título. 


\section{Acknowledgements}

I dedicate this thesis to my wife, Sania, and my children, Rodrigo and Luisa, whom I love and admire so much, and I thank them for their love, affection, incentive, support and understanding.

I thank my parents, Sergio and Eglantine, and my siblings Katia, Zico, Marco and Isabela, for their love, friendship, values and examples.

I thank my advisor, Professor Nelio Domingues Pizzolato, and Professor Madiagne Diallo, for their encouragement, advice and support.

I thank Professor Marco Antônio Guimarães Dias for the knowledge imparted in the courses on real options and game theory, and for the suggestions and discussions on the theory and practice of real options.

I thank Pontifícia Universidade Católica do Rio de Janeiro (PUC-Rio), where I obtained my bachelor's degree in eletrical engineering, and Institut Européen d'Administration des Affaires, France (Insead), where I took my master's degree, for the knowledge transmitted.

I thank the professors of all the examination boards for their critical support and patience to read and discuss my thesis and other works. 


\section{Academic production during the part-time doctoral program}

Franklin Jr., S. L., \& Diallo, M. (2010). Cost-based access pricing and regulatory challenges. Brazilian Journal of Operations and Production Management, 7(1), $37-51$.

Franklin Jr., S. L., \& Diallo, M. (2012). Valuing real options for network investment decisions and cost-based access pricing. The Engineering Economist, 57(4), 223-246.

Franklin Jr., S. L., \& Diallo, M. (2013). Real options and cost-based access pricing: Model and methodology. Telecommunications Policy.

Franklin Jr., S. L., Duarte, T. B., Neves, C. R., \& Melo E. F. L. (2012). A estrutura a termo de taxas de juros no Brasil: Modelos, estimação e testes. Economia Aplicada, 16(2), 255-290 (in Portuguese).

Franklin Jr., S. L., Neves, C. R., \& Melo E. F. L. (2012). Modelo padrão de cálculo do capital adicional baseado no risco de subscrição das sociedades de capitalização. Revista Brasileira de Risco e Seguro, 7(14), 83-114 (in Portuguese).

Melo E. F. L., Franklin Jr., S. L., \& Neves, C. R. (2012). Mensuração do risco de sorteio em títulos de capitalização. Revista Brasileira de Finanças, 10(2), 197-213 (in Portuguese).

Franklin Jr., S. L., \& Diallo, M. (2012). The option to delay network investment decision and its impact on the cost-based prices of regulated telecommunications services. In Proceeding of the Seventh Conference on Research in Options, Buzios, Brazil, December 7-13.

Franklin Jr., S. L., Melo E. F. L., \& Neves, C. R. (2013). Risk evaluation of companies offering raffle-linked savings plans. In Proceeding of the Sixth Brazilian Conference on Statistical Modelling in Insurance and Finance, Maresias, Brazil, March 24-28.

Duarte, T. B., Franklin Jr., S. L., Neves, C. R., \& Melo E. F. L. (2013). The Brazilian inflation coupon curve estimated using genetic algorithms. In Proceeding of the Sixth Brazilian Conference on Statistical Modelling in Insurance and Finance, Maresias, Brazil, March 24-28. 


\section{Abstract}

Franklin Júnior, Sergio Luis; Pizzolato, Nelio Domingues (Advisor). Valuing Real Options for Network Investment Decisions and CostBased Access Pricing. Rio de Janeiro, 2013. 187p. Doctoral Thesis Departamento de Engenharia Industrial, Pontifícia Universidade Católica do Rio de Janeiro.

With the goal of increasing competition in the telecommunications sector, regulatory authorities around the world have adopted cost-based prices for network interconnection and access services. The process of introducing competition has not been easy and many issues have arisen in recent years related to which facilities should be made available by the incumbent carriers, and on what terms and conditions. One of these issues, not yet addressed by the regulatory authorities, is the consideration of the value of the option to invest when calculating cost-based prices of regulated services. The pricing formula currently used by the regulators ignores the value of the option to productively invest at some time in the future. This thesis proposes a model and methodology for valuing the option to delay network investment decisions and calculating costbased prices of regulated telecommunications services, taking into account the demand and technological uncertainties in telecommunications networks. In a typical cost study, the telecommunications network is represented by a list of network elements specifically dimensioned to meet the forecast demand for all telecommunications services, where each network element is an identifiable part of the network infrastructure (e.g., the local loop), for which it can be assigned a single cost driver. Different network elements are subject to different demand and technological uncertainties. For example, switches and transmission equipment are subject to faster technological substitution than local loop and transmission facilities. In this thesis, I calculate the option value multiples for the decisions to invest in three main network elements, each representing a different part of the Brazilian fixed telecommunications network (subject to different technological and demand uncertainties), and estimate the impact of these option value multiples on the average unitary cost of each network element. This thesis innovates in several aspects. First, because different network elements are subject 
to different demand and technological uncertainties, a markup factor is calculated for each main network element. Second, the value of the option to invest in each network element is modeled as a function of two stochastic variables: the element's total variable profit and the cost of new investment in the element. Third, technological uncertainty is modeled using two complementary approaches: technology obsolescence of used equipment and technology evolution of new equipment. Fourth, the value of future replacement options is considered, allowing for the resizing of network capacity as equipment elements are replaced. The demand and technological uncertainties associated with each network element are modeled through the use of three stochastic processes: the flow of total variable profit (geometric Brownian motion), the depreciation of used asset (Poisson decay process), and the cost of modern equivalent asset (geometric Brownian motion). They all fit together into a neat and simple model that calculates the option value multiple for each network element. A constant riskfree interest rate has been assumed to derive the stochastic differential equations that the real option values must satisfy, although interest rate uncertainty has been investigated and interest rate volatilities have been calculated for different maturities/terms. This thesis proposes a method for constructing the Brazilian inflation coupon curve using a combination of traditional nonlinear optimization algorithm and a genetic algorithm specifically developed for that purpose. There has been a good deal of debate about which markup factor (if any) should be applied to the investment cost component of a network investment decision in order to reflect the value of the killed option. Some authors say the real option value is negligible and should be ignored, as in Pelcovits (1999), while others calculate markup values that are quite significant, as in Hausman (1999) and Pindyck (2005). This thesis shows that the markup values can be negligible for some network elements and quite significant for others. After applying the markup factors, network costs should be assigned to services on the basis of how much each service uses each network element. The impact of the option value multiples on the cost-based prices of regulated telecommunications services will depend on how much each service uses each network element. The proposed model and methodology address a problem left unsolved over the past 14 years and might become a landmark in regulatory cost modeling and cost-based access pricing. Although I focus on telecommunications, model and methodology can be 
adapted for application to other network industries as well.

\section{Keywords}

Real options; investment under uncertainty; regulation; costing; pricing; interconnection and access; demand uncertainty; technological uncertainty; interest rate uncertainty; cost-based prices; telecommunications. 


\section{Resumo}

Franklin Júnior, Sergio Luis; Pizzolato, Nelio Domingues (Advisor). Avaliando Opções Reais para Decisões de Investimento em Rede e Precificação de Acesso Baseado em Custos. Rio de Janeiro, 2013. 187p. Tese de Doutorado - Departamento de Engenharia Industrial, Pontifícia Universidade Católica do Rio de Janeiro.

Com o objetivo de estimular a competição no setor de telecomunicações, agências reguladoras do mundo todo têm adotado a regulação de preços baseados em custos para serviços de acesso e interconexão de redes. O processo de introdução da competição não tem sido fácil e muitos problemas têm surgido nos últimos anos relacionados com a definição de quais infraestruturas de rede devem ser disponibilizadas pela operadora incumbente (i.e., as atuais concessionárias de serviços de telecomunicações), e em que termos e condições. Um desses problemas, ainda não endereçado pelas agências reguladoras, é a consideração do valor da opção de investir na ocasião do cálculo de preços baseados em custos de serviços regulados. A fórmula de precificação atualmente usada pelos reguladores ignora o valor da opção de investir produtivamente em algum momento no futuro. Esta tese propõe um modelo e uma metodologia para a valoração da opção de postergar decisões de investimento em rede e para o cálculo de preços baseados em custos de serviços de telecomunicações regulados, levando em consideração as incertezas de demanda e tecnológica no setor de telecomunicações. Em um estudo de custos típico, a rede de telecomunicações é representada por uma lista de elementos de rede especificamente dimensionados para atender a previsão de demanda por serviços de telecomunicações, onde cada elemento de rede é uma parte identificável da infraestrutura de rede (por exemplo, o enlace de acesso local), para a qual pode ser designado um único direcionador de custos. Diferentes elementos de rede estão sujeitos a diferentes incertezas de demanda e tecnológica. Por exemplo, equipamentos de comutação e transmissão estão sujeitos a substituição tecnológica mais rápida do que enlaces de acesso local e linhas de transmissão. Nesta tese, múltiplos de valor de opção são calculados para decisões de investimento em três principais elementos de rede, cada um representando uma parte diferente da rede de telecomunicações fixa brasileira, e o impacto desses 
múltiplos sobre o custo unitário médio de cada elemento de rede é estimado. Esta tese inova em vários aspectos. Primeiro, porque diferentes elementos de rede estão sujeitos a diferentes incertezas de demanda e tecnológica, um fator de markup é calculado para cada elemento de rede principal. Segundo, o valor da opção de investir em cada elemento de rede é modelado como uma função de duas variáveis estocásticas: o fluxo de lucro variável total do elemento e o custo de novo investimento no elemento. Terceiro, a incerteza tecnológica é modelada por meio de duas abordagens complementares: obsolescência tecnológica de equipamento usado e evolução tecnológica de equipamento novo. Quarto, o valor das opções futuras de reposição é considerado, permitindo o redimensionamento da capacidade de rede na medida em que os equipamentos vão sendo substituídos. As incertezas de demanda e tecnológica associadas a cada elemento de rede são modeladas por meio de três processos estocásticos: o fluxo de lucro variável total (movimento geométrico Browniano), a depreciação de ativo usado (processo de Poisson), e o custo de ativo moderno equivalente (movimento geométrico Browniano). E todos se encaixam em um modelo elegante e simples que calcula o múltiplo de valor de opção para cada elemento de rede. Uma taxa de juros livre de risco constante foi assumida para derivar as equações diferenciais estocásticas que devem ser satisfeitas pelos valores das opções reais, apesar de a incerteza na taxa de juros ter sido investigada e a sua volatilidade ter sido calculada para diferentes maturidades/prazos. Esta tese propõe um método para a construção da curva de cupom de inflação no Brasil, usando uma combinação de algoritmo tradicional de otimização não-linear e um algoritmo genético especificamente desenvolvido para esta finalidade. Tem havido um grande debate sobre qual fator de markup (se algum) deve ser aplicado sobre o componente custo de investimento para refletir o valor da opção de espera extinta no momento da realização do investimento. Alguns autores dizem que o valor dessa opção real é desprezível e deve ser ignorado, como em Pelcovits (1999), enquanto que outros autores calculam fatores de markup que são muito significativos, como em Hausman (1999) e Pindyck (2005). Esta tese mostra que os fatores de markup podem ser desprezíveis para alguns elementos de rede e muito significativos para outros. Após a aplicação desses markups, os custos de rede devem ser atribuídos aos serviços de rede com base em quanto cada serviço usa cada elemento de rede. $\mathrm{O}$ impacto dos múltiplos de valor de opção sobre os preços baseados em custos de 
serviços de telecomunicações regulados vai depender de quanto cada serviço usa cada elemento de rede. $\mathrm{O}$ modelo e a metodologia aqui propostos endereçam um problema que permaneceu sem solução por mais de 14 anos e podem se tornar um marco em modelagem de custos regulatórios e precificação de acesso baseado em custos. Embora o foco desta tese tenha sido o setor de telecomunicações, o modelo e a metodologia podem ser adaptados para aplicação em outras indústrias de rede.

\section{Palavras-chave}

Opções reais; investimento sob incerteza; regulação; custeio; precificação; interconexão e acesso; incerteza de demanda; incerteza tecnológica; incerteza de taxa de juros; preços baseados em custos; telecomunicações. 


\section{Contents}

$\begin{array}{ll}\text { 1. Introduction and motivation } & 18\end{array}$

1.1. Presentation of the problem 18

1.2. Objectives of the thesis 19

$\begin{array}{ll}\text { 1.3. Organization of the thesis } & 19\end{array}$

2. Telecommunications access pricing: the Brazilian experience and challenges

2.1. Introduction 21

2.2. An overview of the regulatory environment 22

2.3. Interconnection and access pricing 25

2.3.1. Fixed call origination/termination and transit services 26

$\begin{array}{ll}\text { 2.3.2. Mobile call origination/termination services } & 27\end{array}$

2.3.3. Wholesale leased lines $\quad 28$

2.3.4. Local loop unbundling 30

$\begin{array}{ll}\text { 2.3.5. In summary } & 31\end{array}$

2.4. Service-based vs Facilities-based competition $\quad 32$

2.5. Implementing the pricing/costing mechanism 33

2.6. The option to delay network investment decisions 34

3. Access service costing 36

3.1. Introduction 36

3.2. The fully allocated cost (FAC) model $\quad 38$

3.3. The change of cost base from HCA to CCA 43

3.4. The long run incremental cost (LRIC) model 43

4. Real options and cost-based access pricing: model and methodology 48

4.1. Introduction $\quad 48$

4.2. Brief overview of the LRIC models 51

4.3. The real options model

4.3.1. Model assumptions

4.3.2. Value of the option to invest

4.3.3. Option value multiple $\quad 58$

4.4. The option value multiples for three main investment decisions 59

4.4.1. Parameter estimates for the Brazilian telecommunications market $\quad 60$

4.4.2. Option value multiples and sensitivity analyzes 62

4.5. Application of the real options model 65

5. Enhanced real options model and methodology 69

5.1. Introduction $\quad 69$

$\begin{array}{ll}\text { 5.2. The enhanced real options model } & 70\end{array}$

$\begin{array}{ll}\text { 5.2.1. Model assumptions } & 73\end{array}$

5.2.2. Value of the option to invest 76

5.2.3. Value of the installed project along with all future replacement options 
5.2.4. Option value multiple

5.3. Parameter estimates for the Brazilian telecommunications market 88

5.3.1. The flow of total variable profit stochastic variables $\left(\Pi_{t}\right) \quad 88$

5.3.2. The cost of investment stochastic variables $\left(I_{t}\right)$ and the correlation coefficient between $\Pi_{t}$ and $I_{t}$

5.3.3. The Poisson decay rates 91

5.4. The option value multiples for three main investment decisions 92

5.4.1. Option value multiples under the static LRIC pricing perspective 93

5.4.2. Option value multiples under the dynamic LRIC pricing perspective 101

6. Interest rate uncertainty and the Brazilian inflation coupon curve 104

$\begin{array}{ll}\text { 6.1. Introduction } & 104\end{array}$

6.2. The term structure of interest rates 105

6.3. Database for the IPCA coupon curve 108

6.4. Models to estimate the interest rate term structure 109

6.4.1. The model proposed by Nelson \& Siegel (1987) 110

6.4.2. The model proposed by Svensson (1994) 112

6.5. Estimation of the term structure parameters 114

6.5.1. Traditional nonlinear optimization methods 115

$\begin{array}{ll}\text { 6.5.2. Genetic algorithms } & 117\end{array}$

$\begin{array}{ll}\text { 6.6. Analysis of the Results } & 128\end{array}$

6.6.1. Estimation of the IPCA coupon, error analysis and interpolation $\quad 128$

6.6.2. Extrapolation of the IPCA coupon curve 132

6.6.3. Historic evolution of the parameters of the Svensson model 134

7. Conclusion and research perspectives 137

$\begin{array}{ll}\text { 7.1. Conclusion } & 137\end{array}$

7.2. Suggestions for future studies 139

$\begin{array}{ll}\text { References } & 140\end{array}$

Appendix A - Testing for the GBM model and estimating the drift and

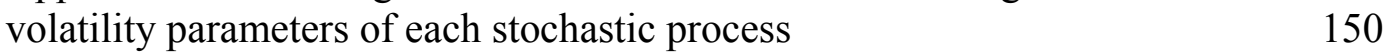

Appendix B - Actual cost and volume data 154

Appendix C - A note on exponential/Poisson decay 156

Appendix D - Proof that $\mu_{I \Delta}>\mu_{\Pi \Delta}$ (for $\Delta=\mathrm{A}, B, C$ ) 158

Annex A - Operational data and calculations for the demand stochastic variables

Annex B - Price indices and calculations for the cost of investment stochastic variables 


\section{List of figures}

Figure 1: The big picture: getting to unit costs 37

Figure 2: Schematic representation of PSTN resource consumption 37

Figure 3: Cost allocation process used in the FAC model 40

Figure 4: Sample of possible routes that can be taken by a local call 41

Figure 5: Contribution of a cost category to the LRIC of an increment 46

Figure 6: Option value multiple as a function of demand volatility 63

Figure 7: Option value multiple as a function of investment cost drift rate 64

Figure 8: Option value multiple as a function of the correlation coefficient $\rho_{\Pi \Delta, I \Delta}$ (enhanced real options model) 96

Figure 9: Option value multiple as a function of volatility parameters (enhanced real options model)

Figure 10: Option value multiple as a function of the variable profit drift rate (enhanced real options model)

Figure 11: Option value multiple as a function of the investment cost drift rate (enhanced real options model)

Figure 12: Option value multiple as a function of the average economic asset life (enhanced real options model)

Figure 13: Option value multiple as a function of the unit contribution margin drift rate (enhanced real options model)

Figure 14: Components of the yield curve (Nelson \& Siegel, 1987) 112

Figure 15: Operational flow chart of the genetic algorithm

Figure 16: Simulations of the genetic algorithm for different values of $\sigma$ for Dec. 30, 2010

Figure 17: Simulations of the genetic algorithm for different values of $\eta$ for Dec. 30, 2010

Figure 18: Examples of the distribution $\operatorname{Beta}(1, \alpha)$ for $\alpha=1,3$ and 6 
Figure 19: Simulations of the genetic algorithm for different values of $\alpha$ for Dec. 30, 2010

Figure 20: Simulations of the genetic algorithm for different values of $\pi$ for Dec. 30, 2010

Figure 21: Comparison of the weighted sum of squared errors in the 6 months before the date of model calibration

Figure 22: Comparison of the mean weighted squared error during the entire data series

Figure 23: Interpolation of the IRTS generated by each estimation method and the spot rates observed for each maturity (for Dec. 30, 2010)

Figure 24: Historic evolution and volatility of the discrete spot rates for different maturities

Figure 25: Extrapolation of the IRTS generated by each estimation method and the spot rates observed for each maturity (for Dec. 30, 2010)

Figure 26: Historic evolution of $\hat{\beta}_{0, t}$

Figure 27: Historic evolution of $\hat{\beta}_{1, t}$

Figure 28: Historic evolution of $\hat{\beta}_{2, t}$

Figure 29: Historic evolution of $\hat{\beta}_{3, t}$ 


\section{List of tables}

Table 1: Telecommunications statistics and market indicators 25

Table 2: Evolution of access pricing models 31

Table 3: Estimates calculated for the parameters of the real options base model

Table 4: Cost and volume data typically available for each network element

Table 5: Impact of the markup factor on the average unitary cost of each network element

Table 6: List of notations

Table 7: Economic asset lives and Poisson decay rates

Table 8: Estimates calculated for the parameters of the enhanced real options model under the static LRIC pricing perspective

Table 9: Option value multiples for the enhanced real options model

Table 10: Impact of the markup factor on the average unitary cost of each network element for the enhanced real options model (when $\rho_{\Pi \Delta, I \Delta}=0.5$ )

Table 11: Volatility of the spot rates for terms of 6 months, 5 years, 10 years and 50 years

Table 12: Volatility of the parameters obtained with each optimization method

Table 13: Empirical cumulative distribution of the $t$-student statistic under $H_{0}$

Table 14: Cost and volume information of $\mathrm{NE}_{\mathrm{A}}, \mathrm{NE}_{\mathrm{B}}$, and $\mathrm{NE}_{\mathrm{C}}$ 
1

\section{Introduction and motivation}

\section{1}

\section{Presentation of the problem}

The opening of the fixed telephony, mobile and data communications markets to competition, in conjunction with the subsequent reduction and elimination of entry barriers have allowed new telecommunications operators to launch their operations and develop. While traditional telecommunications business models required large amounts of money to be raised up-front in order to finance huge investment in network infrastructure, new business models are based on new entrants obtaining access to incumbents' essential facilities through interconnection and access agreements.

With the goal of increasing competition, regulatory authorities around the world have adopted cost-based prices for network interconnection and access services. Incumbent carriers have been required to share the use of their network facilities/equipment with rivals (competitive carriers) at the option of the rivals, who are free to utilize the facilities/equipment they choose when and for how long they wish. In other words, the incumbent carriers have been required by regulation to give a free option to the new entrants, where an option is the right but not the obligation to purchase the use of the incumbents' facilities/equipment.

In telecommunications networks, capital investments tend to be high so that a significant portion of the costs associated with products/services relates to capital costs, which are in large part sunk costs. ${ }^{1}$ When investment is sunk and future demand or cost conditions are uncertain, investment expenditures involve the exercising, or killing, of an option - the option to productively invest at some time in the future. Authors such as Hausman (1999), Alleman (2002) and Pindyck

\footnotetext{
${ }^{1}$ Sunk costs are costs that cannot be recovered if the economic activity ceases. In other words, if the economic return of such investment falls below competitive levels, the firm cannot shift the investment (e.g., assets) to other uses.
} 
$(2005,2007)$ suggest that the cost base to be used for calculating regulated access prices in telecommunications should include not only the actual cost of investment, but also the value of the real options that are extinguished by committing capital and building the network.

Network investment decisions have a cost component that has been overlooked by regulatory authorities, so that the total cost of such decisions (and, hence, the cost-based prices of regulated telecommunications services) has been underestimated. Regulators to date have not incorporated into their price setting the value of the options that are extinguished at the time of investment.

\section{2}

\section{Objectives of the thesis}

The main objective of this doctoral thesis is to develop a model and methodology for valuing the option to delay network investment decisions and calculating cost-based prices of regulated telecommunications services, taking into account the demand and technological uncertainties in telecommunications networks. Another objective is to investigate the interest rate uncertainty in Brazil for different maturities/terms and propose a method for constructing the Brazilian inflation coupon curve, although the impact of interest rate uncertainty on the option value multiples has been left as a future research topic.

\section{3}

\section{Organization of the thesis}

This thesis is organized into nine chapters. In this first chapter, I provide an introduction describing the objective of the doctoral research and its motivation. Chapters 2 and 3 show the state of the art in telecommunications access pricing and costing in Brazil. ${ }^{2}$ Chapter 4 describes the key aspects of the model/ methodology proposed for valuing the option to delay network investment

\footnotetext{
${ }^{2}$ The results presented in chapter 3 are partially published in the article Franklin Jr. \& Diallo (2010).
} 
decisions. ${ }^{3}$ In Chapter 5, I describe the enhanced model/methodology, calculate the option value multiples, perform sensitivity analyses and highlight key findings. ${ }^{4}$ In Chapter 6, I investigate the interest rate uncertainty in Brazil and propose a method for constructing the Brazilian inflation coupon curve. ${ }^{5}$ Chapter 7 concludes and provides some research perspectives. The thesis ends with the bibliographical references, appendices and annexes.

\footnotetext{
${ }^{3}$ The results presented in chapter 4 are partially published in the article Franklin Jr. \& Diallo (2013).

${ }^{4}$ The results presented in chapter 5 are partially published in the article Franklin Jr. \& Diallo (2012)

${ }^{5}$ The results presented in chapter 6 are partially published in the article Franklin Jr. et al. (2012).
} 


\section{Telecommunications access pricing: the Brazilian experience and challenges}

\section{1}

\section{Introduction}

The opening of the fixed, mobile and data communications markets to competition, together with the subsequent reduction and elimination of entry barriers, has allowed new telecommunications operators to launch and develop their operations. In the effort to promote service-based competition in telecommunications while also allowing for long term infrastructure competition, regulators in different parts of the world have adopted cost-based prices for network interconnection and access services. In this chapter, I provide an overview of the Brazilian regulatory framework for telecommunications, emphasizing the policies and models adopted for setting interconnection and access prices. I show how the regulations on interconnection and access pricing have evolved over time since the liberalization of the telecommunications sector and analyze the regulatory challenges associated with setting cost-based access prices in telecommunications networks, taking into account the value of the option that arises from the sunk cost nature of much telecommunications investments.

The rest of this chapter is organized as follows. The next section brings an overview of the Brazilian regulatory environment in telecommunications. Section 2.3 shows how the regulations on interconnection and access pricing have evolved over time. Section 2.4 discusses the choice between service-based and infrastructure-based competition. Section 2.5 addresses the implementation of the pricing/costing mechanism adopted. Section 2.6 discusses the need to consider the value of the delay options that are extinguished at the time of investment when calculating cost-based access prices in telecommunications. 


\section{2}

\section{An overview of the regulatory environment}

The liberalization process of the Brazilian telecommunications sector started in July 1997 with the approval by Congress of the General Telecommunications Law (National Congress, 1997), and followed with the privatization of the Telebras System $^{6}$ and the opening of the fixed and mobile phone and data communications markets to competition. A regulatory framework aimed at ensuring the gradual and permanent transition from a monopolistic system to a competitive system guided the process of liberalization. The state relinquished its role as service provider and instead concentrated exclusively on regulating services and stimulating market forces.

The development of this new institutional model was based on a set of goals that can be summarized in two main ideas: competition in the provision of telecommunications services and universal access to basic services. The introduction of competition required the establishment of an independent regulatory agency $\left(\right.$ Anatel $\left.^{7}\right)$, assigned with the mission of promoting fair competition, safeguarding the interests and rights of end-users and attracting private investment. The regulatory agency proved to be a key element in securing investor confidence with regard to the stability of the rules established for the sector.

Much of what exists today in terms of regulation in telecommunications deals with responses to market power and, therefore, associates the possession of market power with regulatory obligations with the purpose of restricting potential and actual abuses of market power and promoting effective competition. Considering that the former state monopoly providers (incumbent carriers) possessed significant market power, Anatel imposed one set of obligations on incumbent carriers and another on new entrants in order to give the latter the

\footnotetext{
${ }^{6}$ The group of state owned monopoly providers of telecommunications services in Brazil prior to the privatization of the telecommunications sector: Sistema Brasileiro de Telecomunicações S.A. (in Portuguese).

7 The Brazilian regulatory authority in telecommunications: Agência Nacional de Telecomunicações (in Portuguese).
} 
opportunity to launch their operations and develop. ${ }^{8}$

Among the rules and obligations that were imposed on all providers of telecommunications services of collective interest, ${ }^{9}$ the following deserve mention:

- Mandatory interconnection under non-discriminatory terms and conditions for all networks used to provide telecommunications services of collective interest.

- Satisfaction of reasonable requests for access to network facilities, such as cables, fibers, ducts, poles and towers, among others, under fair and nondiscriminatory conditions.

- Non-discriminatory rights-of-way under fair and reasonable prices and conditions.

- Quality goals specific to each telecommunications service.

Among the rules and obligations that were imposed exclusively on the incumbent carriers, the following deserve mention:

- Retail price control: intended to prevent abusive increases in retail prices charged to end-users.

- Wholesale price control: intended to prevent abusive tariffs for access and interconnection services.

- Universal service obligations: requirement for the incumbent carriers to meet a set of obligations related to the provision of universal service, as defined by the regulatory agency.

- Customer assistance: the incumbent carriers must ensure the continued expansion of their networks, within a reasonable timeframe, so as to provide services to anyone who requests them and is willing to pay commercial tariffs that cover the pertinent capital and operational costs.

\footnotetext{
${ }^{8}$ Asymmetric regulation has been adopted by regulators in many parts of the world as a mechanism to control market power in natural monopoly markets.

${ }^{9}$ The telecommunications services provided to the public in general.
} 
- Service continuity: the incumbent carriers cannot interrupt the provision of fixed telephone service, except in well-justified cases.

Providers of public telecommunications services have to formulate and make publicly available a Reference Interconnection Offer (RIO) (Anatel, 2005a) describing the terms and conditions for interconnection, along with all information needed to establish the interconnection. There are regulatory provisions aimed at preventing anticompetitive practices of cross-subsidization, price discrimination, improper use of information about competitors, delaying tactics, discriminatory use or withholding of information, quality discrimination, and undue requirements for the establishment of the interconnection agreement.

Table 1 shows some market statistics on how the telecommunications sector has evolved since its liberalization in 1997 until 2010 and 2011 (Anatel, 2012c). 
Table 1: Telecommunications statistics and market indicators

\begin{tabular}{|c|c|c|c|c|}
\hline MEASURES & UNITS & 1997 & 2010 & 2011 \\
\hline \multicolumn{5}{|l|}{ INDUSTRY GROWTH } \\
\hline $\begin{array}{l}\text { Total number of telephones (fixed } \\
\text { and mobile) }\end{array}$ & Million & 21.5 & 245.0 & 285.2 \\
\hline Total density (fixed and mobile) & $\begin{array}{l}\text { Number of telephones (fixed and mobile) per } \\
100 \text { inhabitants }\end{array}$ & 13.4 & 126.4 & 145.9 \\
\hline \multicolumn{5}{|l|}{ FIXED TELEPHONE SERVICE } \\
\hline Fixed access installed & Million & 18.8 & 62.0 & 64.7 \\
\hline Fixed access in service & Million & 17.0 & 42.1 & 43.0 \\
\hline Density of fixed telephony & $\begin{array}{l}\text { Number of fixed telephones in service per } \\
100 \text { inhabitants }\end{array}$ & 10.6 & 21.7 & 22.0 \\
\hline Rate of network digitalization & $\%$ & $67.8 \%$ & $99.9 \%$ & $99.9 \%$ \\
\hline Number of public payphones & Million & 0.5 & 1.1 & 1.0 \\
\hline Public payphone density & $\begin{array}{l}\text { Number of public payphones per } 1000 \\
\text { inhabitants }\end{array}$ & 3.2 & 5.7 & 5.2 \\
\hline \multicolumn{5}{|l|}{ PERSONAL MOBILE SERVICE } \\
\hline Mobile subscribers & Million & 4.6 & 202.9 & 242.2 \\
\hline Density of mobile telephony & $\begin{array}{l}\text { Number of mobile subscribers per } 100 \\
\text { inhabitants }\end{array}$ & 2.8 & 104.7 & 123.9 \\
\hline \multicolumn{5}{|l|}{ PAY TV } \\
\hline Pay TV subscribers & Million & 2.5 & 9.8 & 12.8 \\
\hline Density of pay TV service & $\begin{array}{l}\text { Number of pay TV subscribers per } 100 \\
\text { residences }\end{array}$ & 6.0 & 16.6 & 21.2 \\
\hline
\end{tabular}

\section{3}

\section{Interconnection and access pricing}

Access problems arise whenever the provision of a complete service to endusers requires the combination of two or more inputs, one of which is noncompetitive (Armstrong, 2002; Laffont \& Tirole, 2001; Valletti \& Estache, 1999; Noam, 2002). The services to which access is mandated in the Brazilian regulatory framework are:

- Fixed call origination/termination service (local fixed interconnection); 
- Transit service ${ }^{10}$ (long distance fixed interconnection);

- Mobile call origination/termination service (mobile interconnection);

- Wholesale leased lines;

- Local loop unbundling.

\subsection{1}

\section{Fixed call origination/termination and transit services}

Long distance carriers need access to call origination and termination services (at both ends of the call) for the purpose of completing end-to-end long distance calls. Also, fixed operators need access to call termination services of other fixed operators in order to complete off-net local fixed calls, and mobile operators need access to call termination services of fixed operators to complete mobile-fixed local calls. In all these situations, the telecommunications operator that provides the retail service (and receives the price paid by the end-user) needs to pay the operator that originates and/or terminates the call the local fixed interconnection tariff (TU-RL ${ }^{11}$ ). Long distance carriers may also need access to the transport network that brings the call from the point of interconnection to the local exchange that terminates the call. In that case, they also need to pay the long distance interconnection tariff (TU-RIU $\left.{ }^{12}\right)$.

After the privatization of the telecommunications sector, the TU-RL and TURIU were regulated by separate price-cap regimes that were not based on costs. In 2003, two Brazilian long distance carriers accused the three main vertically integrated incumbent carriers of engaging into anticompetitive practices of price discrimination and cross-subsidization, squeezing the long distance carriers' margins. The Secretariat of Economic Oversight of the Finance Ministry $\left(\mathrm{SEAE}^{13}\right)$ found that for several combinations of time of day, day of week and

\footnotetext{
${ }^{10}$ This is the transportation of the call from the point of interconnection to the local exchange.

${ }^{11}$ TU-RL is the acronym for the tariff of use of the local network: Tarifa de Uso de Rede Local (in Portuguese).

${ }^{12}$ TU-RIU is the acronym for the tariff of use of the inter-city network: Tarifa de Uso de Rede Interurbana (in Portuguese).

${ }^{13}$ SEAE - Secretaria de Acompanhamento Econômico do Ministério da Fazenda (in Portuguese).
} 
distance between parties the vertically integrated carriers actually set their long distance retail prices at levels below or slightly above the local fixed interconnection tariff, leveraging their market power in the access service to the long distance service market (see Bragança, 2005). ${ }^{14}$

Since the introduction of the new concession contracts in January 2006, the incumbents' TU-RL and TU-RIU ${ }^{15}$ have been set according to a retail-minus approach, where the minus is a percentage of the retail price of the fixed telephone service. Although this approach can prevent incumbent carriers from exposing new entrants to margin squeeze, it does not necessarily provide the right incentives for efficient investment in infrastructure. Starting in 2014, the fixed operators will cease paying other fixed operators for local calls made between networks (Anatel, 2012a) - a mechanism also used in other countries and known internationally as bill and keep.

In February 2007, Anatel determined that the maximum values of TU-RL, TURIU1, TU-RIU2 charged by incumbent carriers and fixed operators with significant market power (SMP) in the market of fixed interconnection services will be based on a LRIC model that will reconcile the results of the top-down LRIC-CCA model developed by the incumbent and SMP fixed operators and the bottom-up LRIC-CCA model developed by the regulator (Anatel, 2007, 2012a). ${ }^{16}$

\subsection{2}

\section{Mobile call origination/termination services}

Long distance carriers need access to call origination and termination services (at both ends of the call) for the purpose of completing end-to-end long distance calls. Also, mobile operators need access to call termination services of other mobile operators to complete off-net local mobile calls, and fixed operators need access to call termination services of mobile operators to complete fixed-mobile

\footnotetext{
${ }^{14}$ This case was forwarded to the Administrative Council for Economic Defense (CADE), which shelved it in 2005 for insufficient evidence. For details, see http://www.cade.gov.br/.

${ }^{15}$ Now split into two different tariffs: (i) TU-RIU1 when the call is transported between two local areas in the same numbering code area; and (ii) TU-RIU2 when the call is transported between two local areas in different numbering code areas.

${ }^{16}$ LRIC is the acronym for the long run incremental cost model/methodology. CCA is the acronym for the current cost accounting cost base. For details, see Chapter 3 .
} 
local calls. In all these situations, the telecommunications operator that provides the retail service (and receives the price paid by the end-user) needs to pay the operator that originates and/or terminates the call the mobile interconnection tariff $\left(\mathrm{VU}-\mathrm{M}^{17}\right)$.

After the privatization of the telecommunications sector, the incumbents' mobile interconnection tariffs were regulated according to a price-cap regime (above costs). Since 2001, after the third and fourth mobile operators entered the mobile market, the value of the VU-M has been subject to commercial negotiation between service providers. In practice, however, the free negotiation regime did not work out, and Anatel has often been asked to arbitrate the values of the mobile interconnection tariffs. Mobile operators have used the above cost mobile interconnection tariff to subsidize the costs of customer acquisition and mobile handsets, greatly increasing the penetration of mobile services and the percentage of mobile users with pre-paid services.

In July 2006, Anatel determined that the reference values of VU-M charged by the mobile operators with significant market power (SMP) in the market of mobile interconnection services will be based on a FAC model that will take into account the results of the FAC-HCA model developed by the SMP mobile operators and the FAC-CCA model developed by the regulator (Anatel, 2006). ${ }^{18}$

\subsection{3}

\section{Wholesale leased lines}

Retail and wholesale markets for dedicated capacity or leased lines are broadly parallel: (i) dedicated capacity or leased lines can be required by corporate clients to construct private networks and to link locations; or (ii) they may also be required by other telecommunications service providers to build their own networks, which in turn provide telecommunications services to retail clients. The incumbent carriers possess capillary networks that reach almost all places in their

\footnotetext{
${ }^{17}$ VU-M is the acronym for the value of use of the mobile network: Valor de Uso de Rede Móvel (in Portuguese).

${ }^{18} \mathrm{FAC}$ is the acronym for the fully allocated cost model/methodology. HCA is the acronym for the historical cost accounting cost base. CCA is the acronym for the current cost accounting cost base. For details, see Chapter 3.
} 
concession areas and enjoy the benefits of significant economies of scale and scope. Competitive service providers, on the other hand, need access to certain wholesale leased lines (in particular, to leased lines that cannot be economically duplicated) in order to provide telecommunications services to retail clients. These wholesale leased lines are denoted as standard EILD. ${ }^{19}$

After the privatization of the telecommunications sector, the incumbents' wholesale leased line tariffs were regulated according to a price cap regime, where the price caps were set at the costs measured and reported by the telecommunications operators using the technology available at that time (1996). The incumbent carriers offered discounts that varied according to a number of variables, such as transmission rate, distance, locality, term/volume commitments and network topology. The lack of a robust access regulation and a true cost-based model for pricing wholesale leased lines allowed the incumbent carriers to engage in anticompetitive practices of price discrimination and cross-subsidization, as well as other non-price anticompetitive practices, forcing retail competitors to margin squeeze and raising rivals' costs. ${ }^{20}$

In order to improve transparency and prevent anticompetitive practices, Anatel established new rules, terms and procedures with which telecommunications service providers with significant market power (SMP) in the wholesale leased line market must comply when providing standard EILD services (Anatel, 2005b, $2012 \mathrm{~b}$ ). Anatel also determined that the reference values charged for standard EILD services provided by telecommunications service providers with SMP will be based on a LRIC model that will reconcile the results of the top-down LRICCCA model developed by the SMP service providers and the bottom-up LRICCCA model developed by Anatel. The telecommunications service providers without SMP have no obligation with respect to the provision of wholesale leased lines to other telecommunications service providers.

\footnotetext{
${ }^{19}$ EILD is the acronym for the industrial exploration of leased lines (wholesale): Exploração Industrial de Linhas Dedicadas (in Portuguese).

${ }^{20}$ A number of cases were forwarded to the Administrative Council for Economic Defense and ended with consent decrees (TCCs - Termos de Compromissos de Cessação - in Portuguese) between CADE and the accused companies. For details, see http://www.cade.gov.br/.
} 


\subsection{4}

\section{Local loop unbundling}

Competitive service providers need access to physical local loop facilities to provide telecommunications services to end-users. Local loop unbundling happens when incumbent local carriers lease the local loop at wholesale prices to new entrants to enable the new entrants to provide a range of telecommunications services to retail clients. The General Telecommunications Law, approved in 1997, established that providers of public telecommunications services have to make their networks available for use by other public telecommunications service providers. However, at that time no regulation was established to determine the terms and conditions under which incumbent local carriers would have to provide unbundled access to local loops.

In May 2004, Anatel determined that the incumbent local carriers have to offer two different forms of local loop unbundling: full unbundling ${ }^{21}$ and line sharing. ${ }^{22}$ Anatel created standard operational procedures for the provision of local loop unbundling, and established maximum reference values (price caps) for the shared use of the local loop based on cost information provided by the incumbent carriers. Since then, the incumbent local carriers have had to make available on the Internet reference offers for unbundled access to the local loop under the supervisory control of Anatel. However, due to the asymmetry of information between regulator and regulated companies, the price caps were probably set too high (above cost), what can explain why competitive service providers have not contracted the provision of local loop unbundling from the incumbent carriers.

In June 2003, the Ministry of Communications established a set of public policies and directives determining (among other decisions) that the tariffs charged by incumbent carriers for fixed interconnection services and local loop unbundling will be based on a long-run cost model that will take into account the universal service obligations imposed on these carriers (Presidency, 2003).

\footnotetext{
${ }^{21}$ Unbundled access to all frequency spectrum of the local loop for the competitive provision of both voice and data services by third parties.

${ }^{22}$ Unbundled access to the high frequency spectrum of the local loop for the competitive provision of DSL services by third parties.
} 


\subsection{5}

\section{In summary}

The access tariffs charged for the services that qualify as essential facilities in Brazil (i.e., services to which access is mandated) will all be based on costs: either LRIC or FAC. The date when they will be based on costs will be determined by further resolutions. Table 2 provides an overview of how the regulations on interconnection and access tariffs have evolved over time since the start of liberalization process in 1997.

Table 2: Evolution of access pricing models

\begin{tabular}{|c|c|c|c|c|c|c|c|c|c|c|c|}
\hline Access Tariffs & Acces & Pricing & Model & & & & & & & & \\
\hline Year & 1997 & 1998 & 1999 & 2000 & 2001 & 2002 & 2003 & 2004 & 2005 & 2006 & $\begin{array}{l}\text { Adopted, but } \\
\text { not applied yet }\end{array}$ \\
\hline $\begin{array}{c}\text { Local fixed } \\
\text { interconnection }\end{array}$ & \multicolumn{9}{|c|}{ Price cap } & $\begin{array}{l}\text { Retail- } \\
\text { minus }\end{array}$ & $\begin{array}{l}\text { Cost based LRIC- } \\
\left.\text { CCA (TD\& BU }{ }^{23}\right)\end{array}$ \\
\hline Transit services & \multicolumn{9}{|c|}{ Price cap } & $\begin{array}{l}\text { Retail- } \\
\text { minus }\end{array}$ & $\begin{array}{l}\text { Cost based LRIC- } \\
\text { CCA (TD\& BU) }\end{array}$ \\
\hline $\begin{array}{c}\text { Mobile } \\
\text { interconnection }\end{array}$ & \multicolumn{10}{|c|}{ Price cap } & $\begin{array}{l}\text { Cost based FAC } \\
\left(\text { HCA\&CCA }^{24}\right)\end{array}$ \\
\hline $\begin{array}{c}\text { Wholesale leased } \\
\text { lines }\end{array}$ & \multicolumn{8}{|c|}{ Price cap } & \multicolumn{2}{|c|}{$\begin{array}{l}\text { New price cap, } \\
\text { terms and proc. }\end{array}$} & $\begin{array}{l}\text { Cost based LRIC- } \\
\text { CCA (TD \& BU) }\end{array}$ \\
\hline $\begin{array}{l}\text { Local loop } \\
\text { unbundling }\end{array}$ & \multicolumn{7}{|c|}{ No regulation } & \multicolumn{3}{|c|}{ Price cap } & $\begin{array}{l}\text { Based on a long } \\
\text { run cost model }\end{array}$ \\
\hline
\end{tabular}

${ }^{23}$ TD \& BU - Top-down and bottom-up reconciled.

${ }^{24} \mathrm{HCA} \& \mathrm{CCA}-\mathrm{HCA}$ and CCA reconciled. 


\section{4}

\section{Service-based vs Facilities-based competition}

There has been a great debate on whether regulatory regimes based on mandatory unbundling and the sharing of incumbents' facilities provide long-run welfare gains for consumers. Some studies show overall gains from mandatory unbundling (Clarke et al., 2004; Ford \& Pelcovits, 2002; Willig et al., 2002), while others show reduced investment and welfare losses in the long run (Crandall et al., 2004; Jorde et al., 2000). Other studies estimate the consumer welfare benefits of entry into local markets (Economides et al., 2008) and the impact of new entry on service prices (Knittel, 2004), as well as on variety of services (Greenstein \& Mazzeo, 2003).

The purpose of Anatel's recent regulations on cost-based access pricing is to promote service-based competition by ensuring new entrants' access to existing network facilities under conditions that enable them to compete with incumbent carriers. The key issue has been how to establish a pricing mechanism that ensures optimal competition and investment in network facilities (Prieger \& Heil, 2009).

- Service-based entry has low investment requirements (as it relies on access to the incumbents' networks) and can help competitive service providers quickly build up a subscriber base, and then move them over to their own facilities.

- Facilities-based entry, on the other hand, is more expensive for new entrants, but leads to more vigorous competition, because the competitors can provide their own innovative services (it only requires interconnection with incumbents).

To date, the competition in the Brazilian fixed telephone and broadband markets has been purely facilities-based. Through the end of the third quarter of 2012, the incumbent local carriers still had $68.9 \%$ of the fixed access lines in service, and $51.8 \%$ of the broadband accesses in service (Teleco, 2012). Competition is most visible, however, in the markets of mobile communications and long distance calls. 
The question now is how interconnection and access costs should be computed so as to promote service-based (retail) competition without reducing incentives to build new networks and/or upgrade existing ones. Cave (2006) proposes what is called the ladder of investment approach (LOI), which entails providing entrants, successively, with different levels of access (the rungs of the investment ladder), while inducing them to climb the ladder by setting access charges that increase over time or by withdrawing access obligations after some predetermined date. New entrants can climb the investment ladder step by step, starting from resale, which requires the least investment, then moving to the different forms of unbundled access to the local loop (bitstream, line sharing and full unbundling), which requires additional levels of investment, finally building their own network infrastructure, which costs the most.

Proponents of the LOI approach claim that such regulatory measures would make service-based entry and facility-based entry complements - instead of substitutes - in promoting competition. However, critics question the validity of key underlying assumptions and claim that the LOI approach still lacks some economic foundations (Bourreau et al., 2009).

\section{5}

\section{Implementing the pricing/costing mechanism}

Cost studies typically consist of a number of activities, such as defining the cost methodology and approach, gathering base input data, deriving needed cost study data, deriving network component costs and service costs, and validating these costs. In many telecommunications markets, the operators develop the cost studies, and the regulatory agency just evaluates and validates the study. In Brazil, Anatel will evaluate/validate the top-down cost studies prepared by the telecommunications operators, develop the respective bottom-up models and perform the top-down/ bottom-up reconciliation.

The implementation of such a pricing/costing mechanism will require an 
excessively high level of effort by the regulatory agency. ${ }^{25}$ In order to avoid unnecessary effort, cost study activities need to be carefully distributed between the regulatory authority and incumbent carriers. I suggest a few (non-exclusive) possibilities: (i) the regulator provides standard templates for the input cost study data, and the incumbent carriers gather all base data and derive the needed cost study data; (ii) the regulator develops the bottom-up cost models for key parts of the telecommunications network based on these standard templates; (iii) the topdown/bottom-up reconciliation is limited to the key parts of the telecommunications network, where the bottom-up LRIC model is used to investigate the top-down model and to compare outcomes and results.

\section{6}

\section{The option to delay network investment decisions}

In telecommunications networks, capital investments tend to be high, so that a significant portion of the costs associated with products/services relates to capital costs. Such investments are in large part irreversible - they involve sunk costs. Incumbent carriers have been required to share the use of their network facilities/ equipment with rivals (competitive carriers) at the option of the rivals, who are free to utilize the facilities/equipment they choose when and for how long they wish. In other words, the incumbent carriers have been required by regulation to give a free option to the new entrants, where an option is the right but not the obligation to purchase the use of the incumbents' facilities/equipment.

Future demand and technology are quite uncertain. New technologies periodically arrive on the market and strand old technologies. In the fixed network, copper distribution cables and digital circuit switches will soon be replaced by fiber cable and next generation network switches. In the mobile network, $2 \mathrm{G} / 3 \mathrm{G}$ technology will soon be replaced by $4 \mathrm{G}$ technologies. In the long term, the telecommunications network will evolve from a primarily voice network to a full service network that provides a full range of communications services,

\footnotetext{
${ }^{25}$ It should be noted that in Brazil there are four incumbent local exchange carriers (operating in demarcated areas), one long distance incumbent carrier (operating in the whole country), and eight mobile operators (operating in overlapped areas), while in most of other countries there is only one incumbent fixed carrier and just a few mobile operators.
} 
including voice and high-speed data services. Demand forecast should consider the impact of voice over broadband and fixed-mobile substitution on fixed line and traffic demand volumes. Incumbent carries can expect a broad substitution of wireline narrowband access by wireless, mobile and broadband access.

When investment is sunk and future demand or cost conditions are uncertain, investment expenditures involve the exercising, or killing, of an option - the option to productively invest at some time in the future. Authors such as Hausman (1999), Alleman (2002) and Pindyck $(2005,2007)$ suggest that the cost base to be used for calculating regulated access prices in telecommunications should include not only the actual cost of investment, but also the value of the real options that are extinguished by committing capital and building the network.

Network investment decisions have a cost component that has been overlooked by regulatory authorities, so that the total cost of such decisions (and, hence, the cost-based prices of regulated telecommunications services) has been underestimated. Regulators to date have not incorporated into their price setting the value of the options that are extinguished at the time of investment. 


\section{Access service costing}

\section{1}

\section{Introduction}

In Brazil, two different costing methodologies will be used to measure the costs of access services: long run incremental cost (LRIC) and fully allocated cost (FAC).

- FAC is an accounting-based approach that allocates total costs to services. It is usually based on audited costs of existing networks, and considers actual installed capacities and actual costs of operation. The concept of fully allocated costs implies a top-down costing system where all costs incurred are attributed to services based on pure activity-based costing (ABC) rules.

- $\quad$ LRIC is an economic approach based on the forward-looking costs of a network that is assumed to be efficient. It has been widely recognized as the costing methodology that best mirrors the effect of efficient competition in the market, although it may under-compensate incumbents because of its use of forward-looking $\operatorname{costs}^{26}$ (Salinger, 1998; Crandall, 2005). LRIC can be calculated using two different approaches: top-down or bottom-up.

o The top-down approach is based on the costs actually incurred by a telecommunications operator and the data appearing on its accounting system.

o The bottom-up approach establishes a number of assumptions on how an efficient operator would be structured to meet a given level of demand and what kind of cost would it incur in.

Both FAC and LRIC methodologies require the study of input data and allocation keys in order to apportion total operating and capital costs among the

\footnotetext{
${ }^{26}$ LRIC sets rental rates based on current or expected future equipment costs, rather than the historical costs that the incumbent actually paid for the equipment.
} 
products/services provided by the carrier. Figure 1 provides an overview of a cost study. $^{27}$

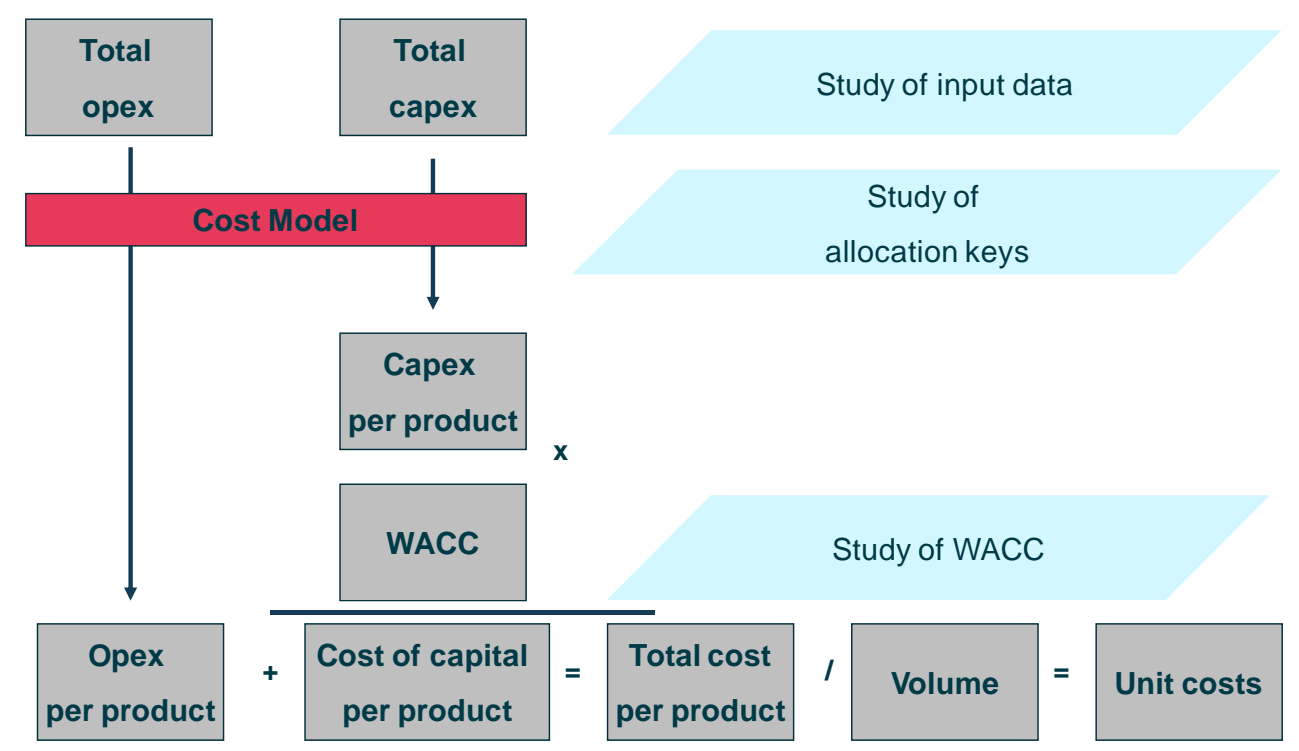

Figure 1: The big picture: getting to unit costs

A service cost study must identify the amount of network resources each service uses. When many products and services are provided over a common network platform, it may be difficult to isolate the investments and expenses used to support each service. Figure 2 shows a schematic representation of $\operatorname{PSTN}^{28}$ resource consumption by different services.

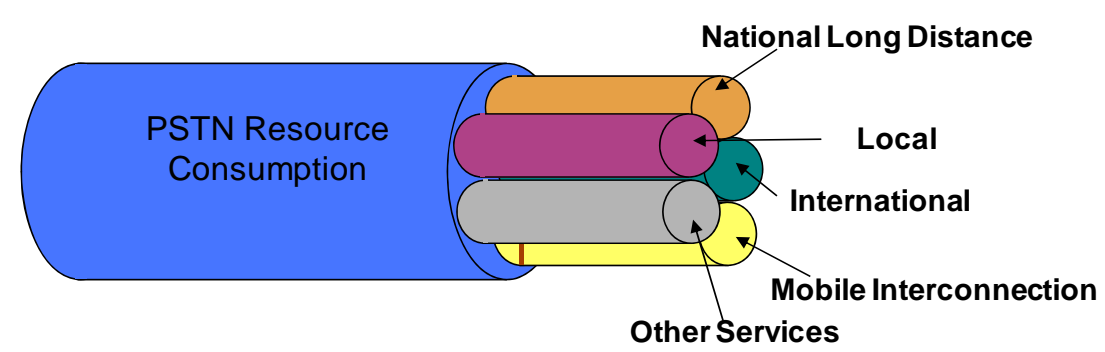

Figure 2: Schematic representation of PSTN resource consumption

The next section brings an overview of the fully allocated cost (FAC) methodology and shows how the investments and expenses used to support each service can be isolated. Section 3.3 describes the change of cost base from

\footnotetext{
${ }^{27}$ For details about these two costing methodologies, see Franklin Jr. \& Diallo (2010).

${ }^{28}$ PSTN is the acronym for public-switched telephone network.
} 
historical cost accounting (HCA) to current cost accounting (CCA). Section 3.4 describes the long run incremental cost methodology.

\section{2}

\section{The fully allocated cost (FAC) model}

The FAC methodology requires that all costs incurred be attributed to products/services based on pure activity-based costing (ABC) tools and techniques (Cooper \& Kaplan, 1991). Costs may be directly assigned to products/services or network elements (NEs), or can be allocated via activities (maintenance, customer service, etc.). The cost system should allocate costs, assets and liabilities to activities, network elements and products/services according to a transparent assignment and distribution method based on the causality principle. This method uses as its basis the cause of costs (referred to here as cost drivers), allowing the tracing and allocation of costs through the activities performed.

Costs can be classified in different ways:

- Directly attributable costs are caused and can be directly and unambiguously related to a service/product or network element. For example, access copper cables are directly attributable to the local loop element (and to the supply of the various access services), and an international gateway switch is directly attributable to the supply of international calls. Directly attributable costs can be fixed or can vary with service volumes.

- Indirectly attributable costs are shared by more than one service, but it is possible to allocate them across services on a non-arbitrary basis. An appropriate allocation method such as ABC can be used to spread indirectly attributable costs across products and services. For example, the costs of a cable repair team can be attributed to the copper cables and fiber cables they repair based on the time spent on each repair activity, and then allocated to the access and core services that use the cables. Indirectly attributable costs can be fixed or can vary with service volumes. 
- Fixed costs are costs that do not vary with the volume of a service. A billing system for some products may be considered a fixed cost - the computer and software is required for one or one million customers. This type of cost is a fixed cost but it may be directly attributable to the service that it was bought for.

- Variable costs are costs that vary with the volume of a service. For example, most media gateway costs (i.e., costs of IP concentrators supporting voice and broadband services) vary according to the number of access lines, although there are some fixed costs as well.

- Common costs are those costs for which no direct or indirect method of apportionment can be identified. It is, therefore, impossible to allocate these costs to products and services in a direct way. Once direct and indirect costs have been allocated to particular services on the basis of causality (using $\mathrm{ABC}$ ), the remaining costs should be allocated to products and services on some rational basis. Common costs include, for example, audit fees and the total costs of the office of the Chairman.

The cost/asset allocation process consists of a series of allocations to smaller and smaller groups (or cost pools) such that at the end all revenues, costs and capital employed are allocated to products/services. It typically includes intermediate stages of activities that enable a higher proportion of indirect costs to be allocated in an objective fashion to products/services. Figure 3 shows the cost centers and cost/asset allocation stages described in the Document for Separation and Allocation of Costs issued by Anatel. ${ }^{29}$

- Products and Services: cost center composed of the set of products/services that are pooled into Product Lines and Business Areas.

- Primary Plant: cost center made up of elements that perform network functions that are vital for the provision of telecommunications services and the costs ascribable to it (e.g., switches).

- Support Plant: cost center composed of infrastructure components that

\footnotetext{
${ }^{29}$ For details, see Anatel (2005c).
} 
support the primary plant (e.g., electric power plant).

- Support Functions: cost center composed of costs and assets related to functions that are not directly linked to the provision of telecommunications services, but that are required for the operation of the company (e.g., maintenance).

- Common Costs: cost center made up of costs and assets related to functions that have no causality relation with the provision of products/services, but are required for the operation of the company, in respect to which one was unable to find a rule for allocating the cost to other cost centers.

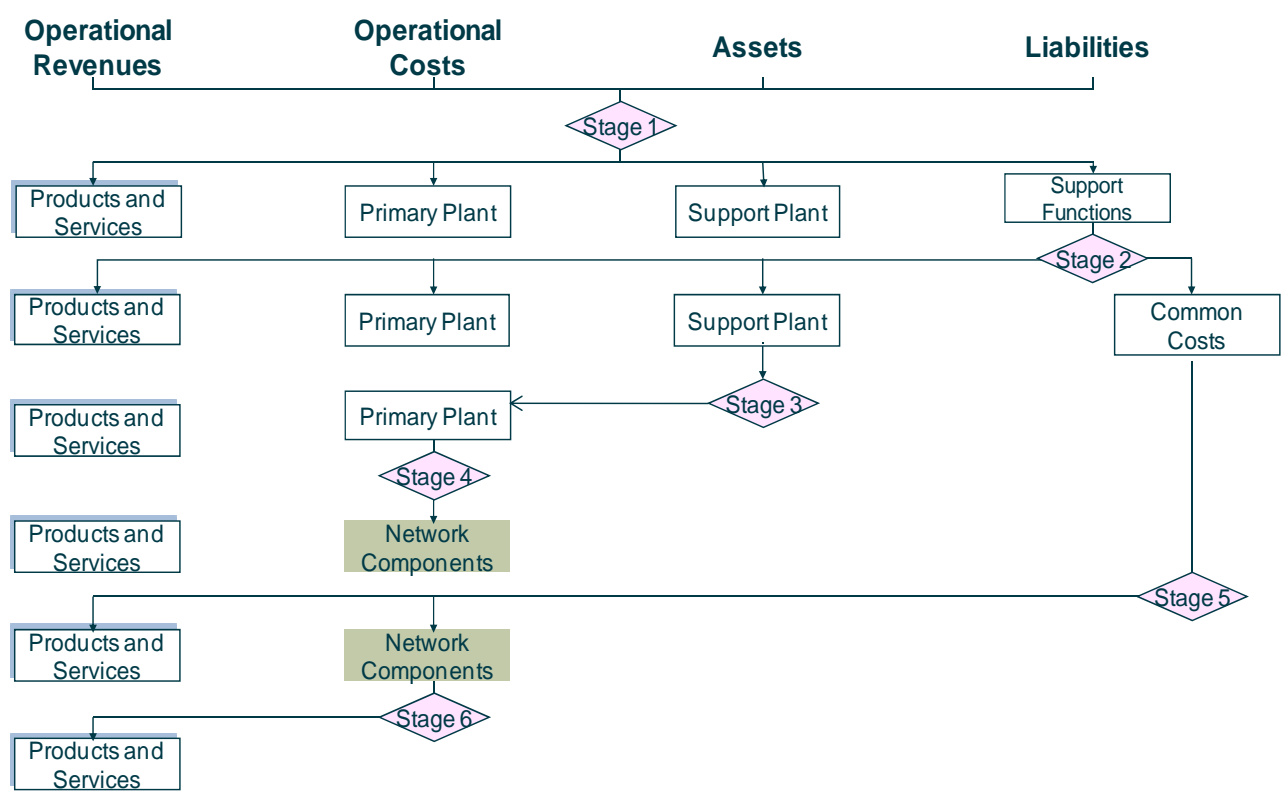

Figure 3: Cost allocation process used in the FAC model

Network elements form the building blocks of any network cost model. A key component of both the FAC and LRIC methodologies is the causal allocation of network element costs to services. The costs of the various network elements are allocated to the services according to the amount of network element resources each service uses. Routing factors are used to determine the extent to which each service causes the cost. For most network driven costs, this is dependent upon two factors: (i) the relative capacity consumed by a unit of demand of each service; (ii) the path through the network that the demand takes. 
The investment/costs associated with each network element (i.e., total operating and capital costs) need to be unitized according to the demand cost driver (or, routing factor volume) associated with the network element. Each service has a routing (or usage) profile indicating how the service uses each network element. Routing factors specify, for each type of service, the average use made of each network element. If $\mathrm{RF}_{\mathrm{i}, \Delta}$ denotes the amount of $\mathrm{NE}_{\Delta}$ resource consumption by Service $_{i}$, the routing factor (demand) volume of $\mathrm{NE}_{\Delta}$ in a given year is measured by the routing factor weighted demand on that network element, that is

$$
r v \Delta=\text { Routing Factor Volume of } \mathrm{NE}_{\Delta}=\sum_{\text {all services }(\mathrm{i})}\left(\text { Demand for Service } \mathrm{i}_{\mathrm{i}}\right) \mathrm{RF}_{\mathrm{i}, \Delta} .
$$

A simple illustrative example helps illustrate how routing factors are calculated. The example is for local calls, where traffic can take a number of different paths from the originating to the terminating party. Figure 4 shows a non-exhaustive list of routes that the traffic for local calls can take (routes 1, 2, 3 and 4). All customers are connected to either a remote or local switch. Depending on the route, different network components are used to process the call. For example, each minute of local call that passes through routes 1, 3 and 4 generates two minutes of host switch traffic, while each minute of local call that passes through route 2 generates one minute of host switch traffic.

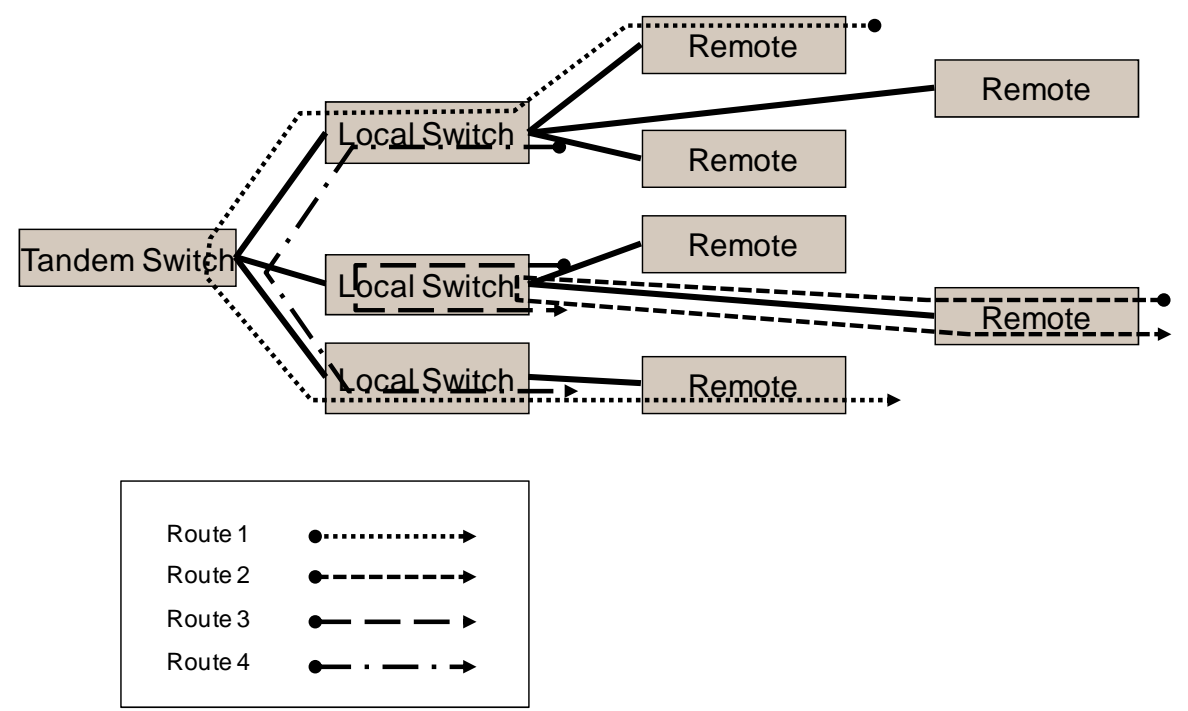

Figure 4: Sample of possible routes that can be taken by a local call 
The traffic for local calls can also take other routes not shown in Figure 4, and other network components are used to process the call that passes through each of these routes (e.g., transmission links). Other retail and wholesale services generate telecommunications traffic over these (and other) network components, usually over a different set of possible routes. For illustrative purpose, suppose that the traffic for local calls can only take routes $1,2,3$ and 4 , and the percentages of traffic that pass through these routes are respectively equal to $15 \%, 35 \%, 30 \%$ and $20 \%$. If Service ${ }_{1}$ is the local call service and $\mathrm{NE}_{\mathrm{B}}$ is a network element whose cost driver is host switch traffic, the routing factor $\mathrm{RF}_{1, \Delta}$ should be calculated as follows:

$$
\mathrm{RF}_{1, \mathrm{~B}}=0.15(2)+0.35(1)+0.30(2)+0.20 .(2)=1.65
$$

In the end, a routing factor matrix is needed to allocate network costs to network services on the basis of the traffic that each service generates on each network element. The unitary cost of each network element is calculated by dividing the total operating and capital costs by the annual routing factor volume, and then all network costs are assigned to network services on the basis of how much each service uses each NE:

$$
\begin{aligned}
& \text { Unitary Cost of } \mathrm{NE}_{\Delta}=\$ \frac{\text { Total Operating and Capital Costs }}{\text { Routing Factor Volume of } \mathrm{NE}_{\Delta}}, \\
& \text { Unitary Cost of Service }{ }_{\mathrm{i}}=\sum_{\text {all } \mathrm{NEs}(\Delta)}\left(\mathrm{RF}_{\mathrm{i}, \Delta}\right)\left(\text { Unitary Cost of } \mathrm{NE}_{\Delta}\right) .
\end{aligned}
$$

Joint and common costs are allocated to products/services and network elements on the basis of the EPMU (equiproportionate mark-up) method, i.e., in proportion to the sum of the directly attributable costs plus indirectly attributable costs that have been allocated to the product/service and network element. ${ }^{30}$

\footnotetext{
${ }^{30}$ Although the Ramsey pricing rule would be a better way of marking up prices to cover common costs (from the perspective of efficiency maximization), difficulties in obtaining reliable estimates of the elasticities of demand have made most regulatory authorities around the world consider the EPMU method as the most appropriate approach.
} 


\section{3}

\section{The change of cost base from HCA to CCA}

The current cost accounting (CCA) cost base considers the efficient utilization of resources, taking as basis the real network of the telecommunications operator. Excess capacity is excluded from the CCA valuation, where an asset is considered to have excess capacity if there is non-used capacity (above the acceptable safety margin) that is not expected to be used in a time horizon of three years.

The capital costs associated with a fixed asset is calculated by multiplying the asset's net current value by the company's weighted average cost of capital (WACC). The asset's net current value (i.e., its net current replacement cost) is derived from the asset's gross replacement cost, which is equal to the cost of replacing the existing asset by another of similar performance characteristics, based on modern equivalent technology - i.e., a modern equivalent asset (MEA) with the same service potential.

Depreciation expenses are adjusted to reflect the current value of the assets. The value of the depreciation expense under the CCA cost base is the difference between the net current value of the asset in the beginning of the period and the net current value of the asset at the end of the period. The economic asset lives used for the HCA and CCA cost bases are identical.

The impact of MEA over operational costs, such as the maintenance, space and energy costs needs to be reflected in the CCA cost base, so that appropriate adjustments need to be made to the operational costs.

\section{4}

\section{The long run incremental cost (LRIC) model}

The LRIC methodology combines a number of principles:

- Long run: In the long run, all capital inputs (and therefore all costs) vary due to a change in the volume or in the structure of production, in response to changes in demand. All investments are therefore considered as variable 
costs in the long run perspective, since all will require replacement at some time.

- Incremental: The incremental cost is the increase in total costs following the introduction of an additional product or service increment. The product/ service volume increment can take several forms. The increment may be defined as an additional unit of service, the entire output of a given service, a group of products/services, the total service, all services offered by the telecommunications operator, etc. With telecommunications services, it is often convenient to think of an increment as the entire output of a given service (such as total call volumes or total number of access lines). By adding or removing the entire service, the LRIC model can estimate the impact on total costs (i.e., the incremental cost for that specific service).

- Forward looking costs: Reflect the costs that a network service provider would incur were it to build a brand new network today, using modern equivalent assets (MEA). These costs are based on looking forward to anticipated levels of demand for network capacities and planning horizons for equipment installation necessary to run an efficient network. LRIC is estimated using forward looking economic costs because they mimic the cost base expected in a competitive market. The concept of forward looking costs requires that assets are valued using the cost of replacement with the MEA, since a competitive-market operator would use the MEA.

- Efficiently incurred costs: Inefficient costs should be excluded, since in a perfectly competitive market an operator would not be able to recover inefficiently-incurred costs. Practically, however, decisions made by the operator in the past cannot be judged against current standards of efficiency. In allowing only efficiently-incurred costs, therefore, the regulator usually demands reasonable efficiency.

o This assumes that the topology of the network is fixed and that the equipment at each node is optimized (efficient). This approach is referred to as scorched node because the costing approach accepts the existing numbers (and location) of switching nodes as given. 
o The alternative approach considers the costs of an idealistic network topology referred to as scorched earth. This scorched earth approach allows complete redesign of the network, without considering any past investment and existing node locations/numbers.

The method used to calculate the LRIC considers the costs that would be avoided in the long run by not producing one unit of increment (e.g., a product/service or a network element), given that costs can vary and some level of output already exists. With respect to the total cost of the company, the incremental cost of a given product/service is numerically equal to the savings that would be obtained had the product/service not been supplied. The total incremental cost of a product/service is the sum of the costs that would be avoided by not producing the product/service (the pure LRIC) and a mark-up in respect of joint/common costs. For details on the top-down LRIC convention, see for example BT Group (2011).

The LRIC model uses costs and asset values adjusted to the CCA basis and consolidated into cost and asset groups (or cost categories) of similar cost/asset types and identical cost drivers. The key component of the top-down LRIC analysis (and the main difference between FAC and LRIC methodologies) is the mapping and building of the cost-volume relationships (CVRs). The CVR is a curve that describes how the costs associated with a given cost category ( $y$-axis) varies according to the volume of its associated cost driver (x-axis). The appropriate cost measure is the long-run cost, which includes all costs that are present in this cost category (capital costs, operating costs, allocated indirect costs, etc.) stated on a long-run annualized cost basis.

The costs that would be avoided in the long run by not producing an increment (e.g., a product/service or a network element) are computed with reference to the CVR of each cost category by analyzing the impact of the product/service on the cost driver volume of each CVR - as illustrated in Figure 5. The processing sequence is determined by the CVR calculation hierarchy, which reflects the dependency between cost categories in such a way that independent categories (where cost drivers are linked to exogenous factors) are processed first, and thereafter the cost categories with first order dependency, second order 
dependency, and so on (where cost drivers are linked to endogenous factors) are processed. ${ }^{31}$ The incremental cost of each individual product/service (i.e., the pure LRIC) is derived by zeroing out the demand volumes associated with that product/service, identifying the reduction in the cost driver volume of each cost category, and reading out the $y$-axis of the CVR curve for the effect of these changes on the total costs of each cost category. Figure 5 shows the contribution of a cost category to the LRIC of an increment.

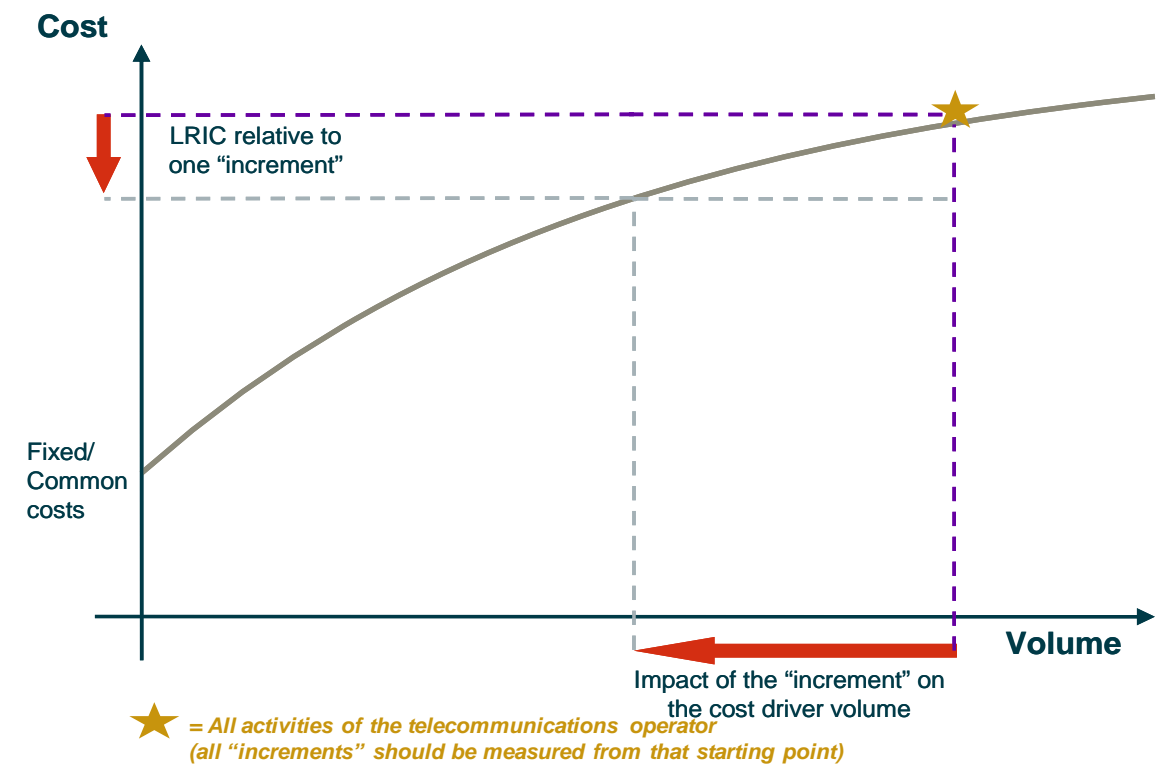

Figure 5: Contribution of a cost category to the LRIC of an increment

Each cost category needs a CVR associated with it. The CVRs can be estimated using technical economic models, simulations produced by engineering experts (mostly used for network cost categories), regression and statistical analysis. CVRs may be straight lines, convex curves or concave curves, depending on whether the cost category exhibits constant returns to scale, diseconomies of scale or economies of scale, respectively. ${ }^{32}$

The top-down cost/asset allocation process goes through a series of stages,

\footnotetext{
${ }^{31}$ Each cost category has a single cost driver, which may be linked to a factor that is either exogenous (e.g., number of access lines) or endogenous (e.g., the output of another CVR), so that the calculation of incremental costs should fit neatly into a recursive (or triangular) schema.

${ }^{32}$ If the CVR curve is concave, the total amount of variable costs allocated to products/services (i.e., the sum of the pure LRIC of all products/services that use that cost category) will be lower than the cost category's total amount of variable costs, what indicates the presence of joint/common costs.
} 
where activity based costing $(\mathrm{ABC})$ principles are typically used. In the end, the costs of the various network elements are allocated to the services according to the amount of network element resources each service uses. Network element costs, which are forecast to occur over the life of the investment, need to be converted into annual (or monthly) costs. Routing factors are used to determine the extent to which each service causes the cost. As shown in Section 3.2, for most network driven costs this is dependent upon two factors: (i) the relative capacity consumed by a unit of demand of each service; and (ii) the path through the network that the demand takes.

Joint costs are determined, for each cost category, by calculating the difference between the LRIC of a group of similar products/services (e.g., access services, traffic services, etc.) and the sum of the pure LRIC of each individual product/ service that belongs to that group. These costs are allocated proportionally based on the pure LRIC of each product/service forming the distributed LRIC of the products/services. Common costs are then allocated proportionally based on the distributed LRIC of each product/service, so that the total amount of costs allocated to products/services (i.e., the fully loaded LRIC) is exactly equal to the total amount of fixed and variable cost of all cost categories. 


\section{Real options and cost-based access pricing: model and methodology}

\section{1 \\ Introduction}

There is a fair body of work on valuing the option that arises out of firms being able to defer irreversible investment. Dixit \& Pindyck (1994) and Trigeorgis (1996) are the classic references on the theme. For a recent textbook treatment, see Dias (2013). There are also a number of studies on the need to consider sunk costs in the regulation of tariffs and return on capital in regulated sectors, such as the works of Salinger (1998), Small \& Ergas (1999), Alleman \& Noam (1999) and Hausman (1999). More recent studies, such as those of Alleman (2002), Hausman \& Myers (2002), Alleman \& Rappoport (2002), Dobbs (2004), Hori \& Mizuno (2006), Pindyck (2005, 2007), Evans \& Guthrie (2006), Clark \& Easaw (2007), Harmantzis \& Tanguturi (2007), Angelou \& Economides (2009) and Brandão \& Gomes (2011) have proposed the use of the real options methodology in a variety of applications, including capital budgeting, decision analysis, strategic planning, economic regulation and cost modeling.

In the decision analysis field of economic regulation, one of the earliest studies that addressed the relation between regulation and the option to delay was Teisberg (1993). The author analyzes a firm's decision to delay investment when it is faced with uncertain and asymmetric profit and loss restrictions due to regulation. She shows that the more uncertainty there is, the more regulation reduces the value of an investment project. Consequently, regulation can lead a firm to delay its investments.

Other references in that field include the works of Hausman (1999) and Hausman \& Myers (2002). These authors analyze access pricing methodologies and asymmetric regulation between incumbents and entrants in the telecommunications and railroad industries. They show that incumbent providers 
have been forced to grant to new entrants a free option, where such option is the right but not the obligation to purchase the use of incumbent's network. As a result, a markup factor must be applied to the investment cost component of costing methods in order to compensate incumbents for this option value.

Pindyck $(2005,2007)$ analyze the impact of network sharing agreements in the telecommunications industry. Pindyck (2007) shows that when there is entry, the entrant's expected gain is identical to the incumbent's expected loss, and suggests that in order to account for the option to delay value access prices should be set according to an $\mathrm{ECPR}^{33}$-based methodology. Pindyck (2005) develops a method to adjust the cost of capital in the TELRIC ${ }^{34}$ access pricing formula to account for the option to delay value.

Camacho \& Menezes (2009) examines a model of an investment decision in a network industry characterized by demand uncertainty, economies of scale and sunk costs. They find that, except under very specific conditions, an access price that accounts for the option to delay value is welfare-superior to the ECPR. The authors show that the extent to which the incumbent should be compensated for its option to delay depends upon market conditions (i.e., the nature of demand). Their work contrasts with Pindyck (2007) in showing that an access price that accounts for the option to delay value often yields higher welfare than the ECPR.

Among these papers, only two estimate the impact of real options on the costbased prices of regulated services using actual telecommunications data: Hausman (1999) modeled the uncertainties on output price and economic depreciation and estimated the markup factor to be applied to the investment cost component of an overall investment decision in the fixed network, while Pindyck (2005) modeled the uncertainty of demand for basic telephone services and proposed a markup on the weighted average cost of capital (WACC) of fixed network operators.

There has been a great debate about which option value multiple (if any) should be applied to the investment cost component to account for the value the delay option extinguished at the time of investment. Some authors say the real option

\footnotetext{
${ }^{33}$ EPCR - Efficient Component Pricing Rule.

${ }^{34}$ TELRIC - Total Element Long Run Incremental Cost - is a variant of the long run incremental cost (LRIC) methodology.
} 
value is negligible and should be ignored, as in Pelcovits (1999), while others calculate markup values that are quite significant, as in Hausman (1999) and Pindyck (2005). In a typical cost study, the telecommunications network is represented by a list of network elements specifically dimensioned to meet the forecast demand for all telecommunications services, where each network element is an identifiable part of the network infrastructure (e.g., the local loop), for which it can be assigned a single cost driver. Different network elements are subject to different demand and technological uncertainties. For example, switches and transmission equipment are more subject to fast technological substitution than local loop and transmission facilities.

Prior real options studies have modeled the investment project as a specific investment in the telecommunications network, such as the deployment of a large scale fixed network (as in Hausman, 1999), the deployment of a digital subscriber line network (as in Alleman \& Rappoport, 2002), the investment in an incremental unit of capacity for the provision of ancillary service (as in Pindyck, 2005), and the expansion of a $2.5 \mathrm{G}$ to a $3 \mathrm{G}$ wireless network (as in Harmantzis \& Tanguturi, 2007). To the best of my knowledge, no previous study has modeled the demand and technological uncertainties associated with each individual network element, and - in the decision analysis field of regulatory cost modeling - no prior study has excluded retail costs and revenues from the markup calculations for wholesale network services.

In this chapter, I propose a model and methodology for valuing the option to delay network investment decisions taking into account the demand and technological uncertainties in telecommunications networks. Option value multiples are calculated for investment decisions in three main network elements, each representing a different part of the Brazilian fixed telecommunications network, subject to different demand and technological uncertainties. This methodology can be applied to all network elements typically covered in a LRIC cost study.

This work innovates in two aspects: (i) it recognizes that different network elements are subject to different demand and technological uncertainties, so that a markup factor is calculated for each main network element; and (ii) retail costs 
and revenues are excluded from the markup calculations for wholesale network services. The investment project is defined as the purchase, installation and operation of a single network element, where each network element provides a hypothetical network service. The services provided by different network elements are combined to form a network service (e.g., interconnection, local loop unbundling, etc). The volume of service provided by a network element is given by the network element's cost driver volume measured in a given period (e.g., number of access lines, minutes of local traffic, number of call setups, minutes of long distance traffic, number of $2 \mathrm{MB}$ circuits, etc.). The uncertainties associated with each network element are modeled through the use of two stochastic processes: the flow of total variable profit (geometric Brownian motion) and the depreciation of used asset (Poisson decay process).

The rest of this chapter is organized as follows. The next section brings an overview of LRIC costing. Section 4.3 presents the proposed real options model and methodology. Section 4.4 calculates the option value multiples for the decisions to invest in three main network elements. Section 4.5 applies the real options model and methodology to a cost study using actual telecommunications data.

\section{2}

\section{Brief overview of the LRIC models}

The method used to calculate the LRIC considers the costs that would be avoided in the long run by not producing one unit of increment (e.g., a product/service or a network element), given that costs can vary and some level of output already exists. With respect to the total cost to the company, the incremental cost of a given product/service (the pure LRIC) is numerically equal to the savings that would be obtained had the product/service not been supplied. For clarity of exposition, I adopt in this thesis the top-down LRIC convention, but the model is equally valid for the bottom-up LRIC approach.

The cost/asset allocation process goes through a series of stages, where activity based costing $(\mathrm{ABC})$ principles are typically used. The telecommunications 
network is represented by a list of network elements carefully dimensioned to meet the demand forecasts, where a network element is an identifiable part of the network infrastructure (e.g., the local loop), loaded with all the directly and indirectly attributable costs, for which it can be assigned a single cost driver. The costs of the various network elements are allocated to network services according to the amount of network element resources each service uses.

In the final stage of the top-down cost/asset allocation process, the following information is typically available for each network element: (i) gross replacement cost (GRC); (ii) annualized capital cost; (iii) network operating expenses; (iv) allocated overhead expenses; and (v) routing factor volume.

\section{3}

\section{The real options model}

Network elements form the building blocks of any network cost model. Each network element is used to provide a unique hypothetical network service. The services provided by a number of network elements are combined to form a network service (e.g., interconnection, local loop unbundling, etc.), which is either sold to the incumbent carrier's retail business unit or to competing carriers. ${ }^{35}$

\subsection{1}

\section{Model assumptions}

Let $\mathrm{NE}_{\mathrm{i}}$ denote one of these network elements (i.e., the network element $i^{36}$ ) and $\Pi_{t}$ denote the flow of total variable profit at $t$ from the service provided by $\mathrm{NE}_{\mathrm{i}}$ (i.e., the flow of total profit ignoring the cost of capital needed to provide this service). I assume that the demand for the service provided by $\mathrm{NE}_{\mathrm{i}}, x_{t}$, follows geometric Brownian motion with drift and volatility parameters

\footnotetext{
35 The service provided by a network element should not be confused with any telecommunications retail or wholesale service. For example, one line of local access loop (the network element) should not be confused with one line of PSTN subscriber service (a retail service), nor with one line of full unbundling (a wholesale service).

${ }^{36}$ To keep the notation simple, the index $i$ has been omitted when no confusion arises.
} 
respectively given by $\alpha_{x}$ and $\sigma_{x}$,

$$
d x=\alpha_{x} x d t+\sigma_{x} x d z_{x} .
$$

The demand is expected to change with growth rate $\alpha_{x}$, so that $E\left[x_{t}\right]=x_{0} e^{\alpha_{x} t}$, where $x_{0}$ is the demand at the time of the cost study. Past historical demand is given by the total cost driver volume measured in a given period. The demand for the service provided by each network element can be measured in terms of minutes of traffic, call setups, access lines, or $2 \mathrm{MB}$ circuits

The choice of stochastic process to represent the uncertainties in real options valuation is usually not a trivial question. It can be supported by statistical tests and other theoretical considerations (see, for example, Ozorio et al., 2012). The GBM assumption has been adopted because it allows an analytical solution to the problem of finding the option value multiple for network investment decisions, and time-series data on demand volumes do not provide evidence against the GBM assumption (as shown in Appendix A).

LRIC prices are calculated from period to period considering the most efficient technology is employed, and this, in turn, causes the LRIC prices to fall over time (see, for example, Krouse, 2000). In this chapter, I assume that the unit contribution margin of $\mathrm{NE}_{\mathrm{i}}$ 's hypothetical network service (i.e., the LRIC price minus unit variable cost), $p$, is constant throughout the asset's lifetime. This is a common assumption in most telecommunications cost studies and represents the case when the output price and the unit variable cost are stepwise constant, and any change in the unit variable cost is offset by an identical change in the (regulated) output price.

As a result of that, the flow of total variable profit from the service provided by $\mathrm{NE}_{\mathrm{i}}, \Pi_{t}=p x_{t}$, follows geometric Brownian motion (GBM) with drift and volatility parameters respectively given by $\alpha_{\Pi}$ and $\sigma_{\Pi}$ :

$$
d \Pi=\alpha_{\Pi} \Pi d t+\sigma_{\Pi} \Pi d z_{\Pi},
$$

where 
$\alpha_{\Pi}=\alpha_{x}$ and $\sigma_{\Pi}=\sigma_{x}$.

I assume that the market is sufficiently complete so that the stochastic fluctuations in $\Pi_{t}$ are spanned by other assets in the economy. In other words, there are traded assets or portfolios of traded assets whose risks track or span the uncertainties in $\Pi_{t} \cdot{ }^{37}$ In this chapter, for simplicity of exposition, I assume that $\Pi_{t}$ is directly tradable, but it would be sufficient to assume that the risk dynamics of $\Pi_{t}$, namely the $d z_{\Pi}$ term in equation (4.2), could be replicated by some portfolio of traded assets.

Let $I_{t}$ denote the cost of investment in $\mathrm{NE}_{\mathrm{i}}$ at $t$. I assume that $I_{t}$ varies exponentially over time, so that $I_{t}=I_{0} e^{\alpha_{I} t}$ and $d I=\alpha_{I} I_{t} d t$, where $I_{0}$ is the investment cost at the time of the cost study. I assume that the economic depreciation of $\mathrm{NE}_{\mathrm{i}}$ is exponential or Poisson decay at rate $\lambda(\lambda>0)$ so that the event asset death follows Poisson process with rate $\lambda$ and the asset's lifetime, $T_{I O}$, has exponential distribution with parameter $\lambda$.

The fundamental equilibrium condition of the capital asset pricing model (CAPM) states that

$$
\mu_{\Pi}=r+\phi_{M} \sigma_{\Pi} \rho_{\Pi, M}
$$

where $\mu_{\Pi}$ is the total expected rate of return of the (directly tradable) asset $\Pi_{t}, r$ is the discount rate appropriate to riskless cash flows, $\rho_{\Pi, M}$ is the correlation coefficient between $\Pi_{t}$ and the whole market portfolio, $M_{t}$, and $\phi_{M}$ is the continuous-time market price of risk.

That asset is held by investors only if it provides a sufficiently high return, where part of that return comes in the form of expected capital appreciation and another part can come in the form of a dividend rate. Therefore, $\mu_{\Pi}=\alpha_{\Pi}+\delta_{\Pi}$, where $\mu_{\Pi}$ is the total expected return of $\Pi_{t}, \alpha_{\Pi}$ is the expected continuously

\footnotetext{
${ }^{37}$ If the market is incomplete, I would instead apply the minimum martingale measure or the minimum entropy measure - which depends on the preferences of the decision maker - in other to calculate the value of the options involved.
} 
compounded growth rate and $\delta_{\Pi}$ is the continuously compounded dividend rate ( $\delta_{\Pi}$ is assumed positive). ${ }^{38}$

\subsection{2}

\section{Value of the option to invest}

The flow of total variable profit produced at $t$ by the installed $\mathrm{NE}_{\mathrm{i}}$ is $\Pi_{t}=p x_{t}$, so that the value of the installed project, $V_{t}$, is given by

$$
\begin{aligned}
& V_{t}=V\left(\Pi_{t}\right)=E\left[\int_{0}^{T_{I O}} e^{-\mu_{\Pi} s} \Pi_{t+s} d s\right]=E\left[E\left[\int_{0}^{T_{I O}} e^{-\mu_{\Pi} s} \Pi_{t+s} d s \mid T_{I O}=t_{I O}\right]\right] \\
& =E\left[\int_{0}^{T_{T O}} e^{-\mu_{\Pi} s} E\left[\Pi_{t+s}\right] d s\right]=E\left[\int_{0}^{T_{I O}} e^{-\mu_{\Pi} s} \Pi_{t} e^{\alpha_{\Pi} s} d s\right] \\
& =E\left[\frac{\Pi_{t}\left(1-e^{-\left(\mu_{\Pi}-\alpha_{\Pi}\right) T_{I O}}\right)}{\mu_{\Pi}-\alpha_{\Pi}}\right]=\int_{0}^{\infty} \frac{\Pi_{t}\left(1-e^{-\delta_{\Pi} u}\right)}{\delta_{\Pi}} \lambda e^{-\lambda u} d u . \\
& \Rightarrow V\left(\Pi_{t}\right)=\frac{\Pi_{t}}{\left(\delta_{\Pi}+\lambda\right)}, \text { where } \delta_{\Pi}=\mu_{\Pi}-\alpha_{\Pi} .
\end{aligned}
$$

Let $F(\Pi, I, t)$ denote the value of the option to invest in $\mathrm{NE}_{\mathrm{i}}$. In this chapter, I assume that the investment option is available to the incumbent carrier in perpetuity and after the project/asset dies the incumbent carrier has no further rights (i.e., there is no replacement option). Following the steps of contingent claim valuation, consider a portfolio consisting of one unit of the option to invest in $\mathrm{NE}_{\mathrm{i}}$, which is worth $F(\Pi, I, t), m$ units short in the flow of total variable profit $(\Pi)$, and $n$ units short in the cost of new investment $(I)$. This is a dynamic portfolio; as $\Pi$ and $I$ change, $m$ and $n$ may change from one short interval of time to the next, so that the composition of the portfolio will change. However, over each infinitesimal interval of time $d t, m$ and $n$ are held fixed.

The value of that portfolio at $t$ is given by

\footnotetext{
${ }^{38} \delta_{\Pi}$ represents the extent to which the percentage change in $\Pi_{t}\left(\alpha_{\Pi}\right)$ falls short of the percentage return required on an investment of this risk class $\left(\mu_{\Pi}\right)$. For that reason, it is sometimes called rate of return shortfall (Dixit \& Pindyck, 1994).
} 


$$
\Gamma(\Pi, I, t)=F(\Pi, I, t)-m \Pi-n I .
$$

During the infinitesimal interval of time $[t, t+d t)$, the return on $\Gamma(\Pi, I, t)$ consists of two parts: the capital gain of $d F-m d \Pi-n d I$, and the dividend (or net cash flow) of $-m \delta_{\Pi} \Pi d t-n \delta_{I} I d t$, where $\delta_{\Pi}$ is the dividend rate of $\Pi_{t}$ and $\delta_{I}=r-\alpha_{I}:{ }^{39}$

$$
d \Gamma(\Pi, I, d t)=d F(\Pi, I, t)-m d \Pi-m \delta_{\Pi} \Pi d t-n d I-n\left(r-\alpha_{I}\right) I d t .
$$

Because the investment option is available in perpetuity, $F$ and $\Gamma$ can be expressed as functions of only $\Pi$ and $I\left(F_{t}=0\right)$. The Ito's Lemma gives

$$
d F=F_{\Pi} d \Pi+F_{I} d I+1 / 2 F_{\Pi \Pi}(d \Pi)^{2}
$$

Choosing $m=\partial F / \partial \Pi=F_{\Pi}$, the random terms in the return on $\Gamma(\Pi, I)$ are eliminated, making that portfolio riskless. Therefore, the return on $\Gamma(\Pi, I)$ during the infinitesimal interval $d t$ must be equal to the riskless return $r \Gamma(\Pi, I) d t$.

From the equations above, it follows that, over the region of the $(\Pi, I)$ space where it is optimal to hold the option unexercised, $F(\Pi, I)$ must satisfy the following partial differential equation:

$$
1 / 2 \sigma_{\Pi}^{2} \Pi^{2} F_{\Pi \Pi}+\left(r-\delta_{\Pi}\right) \Pi F_{\Pi}+\alpha_{I} I F_{I}-r F=0
$$

Because $\Pi_{t}$ and $I_{t}$ follow geometric Brownian motions and $V\left(\Pi_{t}\right)$ is a constant multiple of $\Pi_{t}, F\left(\Pi_{t}, I_{t}\right)$ is a convex homogeneous function of degree one in $\Pi_{t}$ and $I_{t} \cdot{ }^{40}$ Thus, I follow the procedure described in Dixit \& Pindyck (1994) to reduce the partial differential equation (4.5) to an ordinary differential equation by making

\footnotetext{
${ }^{39}$ In this chapter, the risk dynamics of $I_{t}$ can be replicated by the investment in the risk-free asset.

${ }^{40}$ See McDonald and Siegel (1986) for a proof that $F(V, I)$ is homogeneous of degree one in $V$ and $I$; since $V(\Pi)$ is a constant multiple of $\Pi, F(\Pi, I)$ is also homogeneous of degree one in $\Pi$ and $I$.
} 


$$
F(\Pi, I)=I F(\Pi / I, 1)=I f(\pi),
$$

where

$$
\left\{\begin{array}{l}
f=F / I, \text { is the value of the option per unit of investment, } \\
\pi=\Pi / I, \text { is the flow of total variable profit per unit of investment, }
\end{array}\right.
$$

and

$$
\left\{\begin{array}{l}
F_{\Pi}(\Pi, I)=f^{\prime}(\pi), F_{I}(\Pi, I)=f(\pi)-\pi f^{\prime}(\pi), \text { and } \\
F_{\Pi \Pi}(\Pi, I)=f^{\prime \prime}(\pi) / I
\end{array}\right.
$$

Substituting the equations above into the partial differential equation (4.5), leads to

$$
1 / 2 \sigma_{\Pi}^{2} \Pi^{2} f^{\prime \prime}(\pi) / I+\left(r-\delta_{\Pi}\right) \Pi f^{\prime}(\pi)+\alpha_{I} I\left(f(\pi)-\pi f^{\prime}(\pi)\right)-r F=0
$$

Simplifying the resulting equation, it follows that $f(\pi), 0 \leq \pi<\pi^{*}$ (where $\pi^{*}$ is the investment threshold), must satisfy the ordinary differential equation

$$
1 / 2 \sigma_{\Pi}^{2} \pi^{2} f^{\prime \prime}(\pi)+\left(r-\alpha_{I}-\delta_{\Pi}\right) \pi f^{\prime}(\pi)-\left(r-\alpha_{I}\right) f(\pi)=0 .
$$

The solution to that homogeneous second-order linear ordinary differential equation, valid over the range of $\pi$ for which it is optimal to hold the option unexercised $\left(0 \leq \pi<\pi^{*}\right)$, is

$$
f(\pi)=A_{1} \pi^{\beta_{1}}
$$

where

$A_{1}$ is a constant to be determined,

$$
\begin{aligned}
& \beta_{1}=1 / 2-\frac{\left(r-\alpha_{I}-\delta_{\Pi}\right)}{\sigma_{\Pi}^{2}}+\sqrt{\left[\frac{\left(r-\alpha_{I}-\delta_{\Pi}\right)}{\sigma_{\Pi}^{2}}-1 / 2\right]^{2}+\frac{2\left(r-\alpha_{I}\right)}{\sigma_{\Pi}^{2}}}(\geq 1), \text { and } \\
& \pi^{*}=(\Pi / I)^{*} \text { is the investment threshold. }
\end{aligned}
$$




\subsection{3}

\section{Option value multiple}

The value of $f(\pi)$ must satisfy the value-matching and smooth-pasting conditions with $\{v(\pi)-1\}$ at $\pi^{*}$. This leads to

$$
A_{1}\left(\pi^{*}\right)^{\beta_{1}}=\frac{\pi^{*}}{\left(\delta_{\Pi}+\lambda\right)}-1
$$

and

$$
\beta_{1} A_{1}\left(\pi^{*}\right)^{\beta_{1}-1}=\frac{1}{\left(\delta_{\Pi}+\lambda\right)}
$$

Solving equations (4.9) and (4.10) for the free boundary line separating the regions of waiting and investing in the $(\Pi, I)$ space:

$$
\pi^{*}=\left(\Pi / I^{*}=\frac{\beta_{1}}{\beta_{1}-1}\left(\delta_{\Pi}+\lambda\right)\right.
$$

For any given $I($ e.g., $I=\widehat{I})$, equations (4.4) and (4.11) lead to

$$
V\left(\Pi^{*}\right)=\frac{\Pi^{*}}{\left(\delta_{\Pi}+\lambda\right)}=\frac{\beta_{1}}{\beta_{1}-1} \hat{I}=m \hat{I}
$$

When the incumbent carrier invests in $\mathrm{NE}_{\mathrm{i}}$, it gets the installed project valued $V\left(\Pi^{*}\right)$. At that time, the incumbent carrier also gives up the opportunity or option to invest, which is valued $F\left(\Pi^{*}, \widehat{I}\right)$, so that the total cost of the project (direct cost plus opportunity cost of making the investment) is $\widehat{I}+F\left(\Pi^{*}, \widehat{I}\right)$. Thus, for any given $\hat{I}$ :

$$
V\left(\Pi^{*}\right)=\widehat{I}+F\left(\Pi^{*}, \widehat{I}\right)=\frac{\beta_{1}}{\beta_{1}-1} \widehat{I}
$$

Equations (4.8) to (4.10) give the value of the investment opportunity per unit of investment, $f(\pi)$, and the optimal investment rule (i.e., the critical value, $\pi^{*}$, 
at which is optimal to invest). Equation (4.12) states that at the investment threshold the value of the installed network element, $V\left(\Pi^{*}\right)$, is higher than the cost of investment, $\hat{I}$, by a factor of $\beta_{1} /\left(\beta_{1}-1\right)$.

Therefore, the ability to delay an irreversible investment expenditure invalidates the net present value (NPV) rule, so that the value of the installed $\mathrm{NE}_{\mathrm{i}}$ (at the investment threshold) must exceed the cost of investment by the factor $m=\beta_{1} /\left(\beta_{1}-1\right)$. This is the option value multiple for the decision to invest in $\mathrm{NE}_{\mathrm{i}}$, i.e., the markup factor that must be applied to the investment cost component in order to reflect the true cost of investment, considering both the cost of investment and the value of the real options involved.

From equations (4.8) and (4.12), it follows that (all other things held constant):

- The higher the volatility parameter of $\Pi_{t}\left(\sigma_{\Pi}\right)$ is, the higher the option value multiple $m$ is (increasing the incentives to wait to invest).

- The lower $\alpha_{I}$ is, the higher the option value multiple $m$ is (increasing the incentives to wait to invest).

- The lower $\alpha_{\Pi}$ is, the lower the option value multiple $m$ is (decreasing the incentives to wait to invest).

\section{4}

\section{The option value multiples for three main investment decisions}

In this section, I calculate the option value multiples for the decisions to invest in three main network elements of the Brazilian fixed telecommunications network: Local Access Loop $\left(\mathrm{NE}_{\mathrm{A}}\right)$; PSTN Host Switch/Duration Sensitive $\left(\mathrm{NE}_{\mathrm{B}}\right)$; and Host-Host Transmission $\left(\mathrm{NE}_{\mathrm{C}}\right)$. 


\subsection{1}

\section{Parameter estimates for the Brazilian telecommunications market}

Let $\Pi A_{t}, \Pi B_{t}$ and $\Pi C_{t}$ respectively denote the flow of total variable profit from the service provided by $\mathrm{NE}_{\mathrm{A}}$ (i.e., local access loop lines), $\mathrm{NE}_{\mathrm{B}}$ (i.e., minutes of host switch traffic) and $\mathrm{NE}_{\mathrm{C}}$ (i.e., minutes of host-host transport traffic). From equation (4.2), $\Pi A_{t}$ follows geometric Brownian motion with drift and volatility parameters given by $\alpha_{\Pi A}=\alpha_{x a}$ and $\sigma_{\Pi A}=\sigma_{x a}, \Pi B_{t}$ follows geometric Brownian motion with drift and volatility parameters given by $\alpha_{\Pi B}=\alpha_{x b}$ and $\sigma_{\Pi B}=\sigma_{x b}$, and $\Pi C_{t}$ follows geometric Brownian motion with drift and volatility parameters given by $\alpha_{\Pi C}=\alpha_{x c}$ and $\sigma_{\Pi C}=\sigma_{x c}$.

In order to find the demand drift and volatility estimates $\left(\hat{\alpha}_{x a}, \hat{\alpha}_{x b}, \hat{\alpha}_{x c}, \hat{\sigma}_{x a}\right.$, $\hat{\sigma}_{x b}$ and $\hat{\sigma}_{x c}$ ), I used publicly available quarterly time-series data on the number of access lines in service, minutes of local traffic and minutes of transport traffic in the Brazilian telecommunications market, and followed the procedure described in Appendix A. The operational data and calculations are shown in Annex A. ${ }^{41}$ The following estimates were obtained:

$$
\left\{\begin{array} { l } 
{ \hat { \alpha } _ { x a } = - 0 . 0 1 2 , } \\
{ \hat { \sigma } _ { x a } = 0 . 0 4 0 , }
\end{array} \quad \left\{\begin{array} { l } 
{ \hat { \alpha } _ { x b } = - 0 . 0 2 9 , } \\
{ \hat { \sigma } _ { x b } = 0 . 0 8 6 , }
\end{array} \quad \left\{\begin{array}{l}
\hat{\alpha}_{x c}=-0.034, \\
\hat{\sigma}_{x c}=0.082 .
\end{array}\right.\right.\right.
$$

The expected rates of return $\left(\mu_{\Pi A}, \mu_{\Pi B}\right.$ and $\left.\mu_{\Pi C}\right)$ were derived from the cost of capital typically used to discount cash flows from the investments in $\mathrm{NE}_{\mathrm{A}}, \mathrm{NE}_{\mathrm{B}}$ and $\mathrm{NE}_{\mathrm{C}}$. As most of the incumbent carriers' revenue comes from network access services, and most of the interexchange carriers' revenue comes from transport-related network services, the incumbent's cost of capital can be used to estimate $\mu_{\Pi A}$ and $\mu_{\Pi B}$, and the interexchange carrier's cost of capital can be used to estimate $\mu_{\Pi С}$. I used an average estimate of the post-tax real weighted average

\footnotetext{
41 Quarterly time-series data were kindly provided by Teleco (http://www.teleco.com). See Telebrasil and Teleco (2011) for yearly time-series data.
} 
cost of capital of incumbent and interexchange carriers equal to $9.0 \%{ }^{42}$ Thus, the values of $\hat{\delta}_{\Pi A}, \hat{\delta}_{\Pi B}$ and $\hat{\delta}_{\Pi C}$ were derived from the above considerations by making $\hat{\delta}_{\Pi A}=\hat{\mu}_{\Pi A}-\hat{\alpha}_{\Pi A}, \hat{\delta}_{\Pi B}=\hat{\mu}_{\Pi B}-\hat{\alpha}_{\Pi B}$ and $\hat{\delta}_{\Pi C}=\hat{\mu}_{\Pi C}-\hat{\alpha}_{\Pi C}$ :

$$
\left\{\begin{array} { l } 
{ \hat { \mu } _ { \Pi A } = 0 . 0 9 0 , } \\
{ \hat { \delta } _ { \Pi A } = 0 . 1 0 2 , }
\end{array} \quad \left\{\begin{array} { l } 
{ \hat { \mu } _ { \Pi B } = 0 . 0 9 0 , } \\
{ \hat { \delta } _ { \Pi B } = 0 . 1 1 9 , }
\end{array} \quad \left\{\begin{array}{l}
\hat{\mu}_{\Pi C}=0.090, \\
\hat{\delta}_{\Pi C}=0.124 .
\end{array}\right.\right.\right.
$$

Similarly, let $I A_{t}, I B_{t}$ and $I C_{t}$ respectively denote the cost of new investment in $\mathrm{NE}_{\mathrm{A}}$ (Local Access Loop), $\mathrm{NE}_{\mathrm{B}}$ (PSTN Host Switch/Duration Sensitive) and $\mathrm{NE}_{\mathrm{C}}$ (Host-Host Transmission). The drift rate estimates $\left(\hat{\alpha}_{I A}, \hat{\alpha}_{I B}\right.$ and $\left.\hat{\alpha}_{I C}\right)$ can be derived from historical price changes of modern equivalent equipments. Local loop investment costs, such as structure costs (e.g., poles, conduits), trenching, service area interface construction costs and the costs of placing the cable (copper or fiber) on the structure, are highly labor intensive. These costs have been constant or even increased over time, as opposed to switching and transmission network equipment prices, which have declined rapidly in the past few years. In this chapter, I used the estimates of $\hat{\alpha}_{I A}=0.00, \hat{\alpha}_{I B}=-0.09$ and $\hat{\alpha}_{I C}=-0.08$ (based on expert opinion).

For the risk-free interest rate, I used an estimate of $4.0 \%$ per year.

Table 3 summarizes the estimates calculated for the parameters of the real options base model.

\footnotetext{
${ }^{42}$ See, for example, Wikiwealth, 2012.
} 
Table 3: Estimates calculated for the parameters of the real options base model

\begin{tabular}{|c|c|c|c|c|c|}
\hline \multicolumn{2}{|c|}{ Local Access Loop } & \multicolumn{2}{|c|}{$\begin{array}{l}\text { Host Switch/ Duration } \\
\text { Sensitive }\end{array}$} & \multicolumn{2}{|c|}{ Host-Host Transmission } \\
\hline \multicolumn{2}{|c|}{ Parameters of $\Pi A_{t}$} & \multicolumn{2}{|c|}{ Parameters of $\Pi B_{t}$} & \multicolumn{2}{|c|}{ Parameters of $\Pi C_{t}$} \\
\hline$\hat{\alpha}_{\Pi A}$ & -0.012 & $\hat{\alpha}_{\Pi B}$ & -0.029 & $\hat{\alpha}_{\Pi C}$ & -0.034 \\
\hline$\hat{\sigma}_{\Pi A}$ & 0.040 & $\hat{\sigma}_{\Pi B}$ & 0.086 & $\hat{\sigma}_{\Pi C}$ & 0.082 \\
\hline$\hat{\mu}_{\Pi A}$ & 0.090 & $\hat{\mu}_{\Pi B}$ & 0.090 & $\hat{\mu}_{\Pi C}$ & 0.090 \\
\hline$\hat{\delta}_{\Pi A}$ & 0.102 & $\hat{\delta}_{\Pi B}$ & 0.119 & $\hat{\delta}_{\Pi C}$ & 0.124 \\
\hline \multicolumn{2}{|c|}{ Parameters of $I A_{t}$} & \multicolumn{2}{|c|}{ Parameters of $I B_{t}$} & \multicolumn{2}{|c|}{ Parameters of $I C_{t}$} \\
\hline$\hat{\alpha}_{I A}$ & 0.000 & $\hat{\alpha}_{I B}$ & -0.090 & $\hat{\alpha}_{I C}$ & -0.080 \\
\hline \multicolumn{2}{|c|}{ Risk-free interest rate } & \multicolumn{2}{|c|}{ Risk-free interest rate } & \multicolumn{2}{|c|}{ Risk-free interest rate } \\
\hline$\hat{r}$ & 0.040 & $\hat{r}$ & 0.040 & $\hat{r}$ & 0.040 \\
\hline
\end{tabular}

\subsection{2}

\section{Option value multiples and sensitivity analyzes}

From equations (4.8) and (4.12) and the parameter estimates shown in Table 3, the option value multiples calculated for the three investment decisions are as follows.

- For the investment decision in $\mathrm{NE}_{\mathrm{A}}$ (Local Access Loop): $m_{A}=1.01$.

- For the investment decision in $\mathrm{NE}_{\mathrm{B}}$ (PSTN Host Switch/Duration Sensitive): $m_{B}=1.25$.

- For the investment decision in $\mathrm{NE}_{\mathrm{C}}$ (Host-Host Transmission): $m_{C}=1.16$.

Figure 6 shows the sensitivity of the option value multiple $m_{\Delta}(\Delta=A, B, C)$ to 
the demand volatility $\sigma_{x \Delta}(\Delta=a, b, c)$, holding all other variables constant, where each volatility parameter varies in the range from half of the estimated value $\left(\hat{\sigma}_{x \Delta} / 2\right)$ to two times the estimated value $\left(2 \cdot \hat{\sigma}_{x \Delta}\right)$.
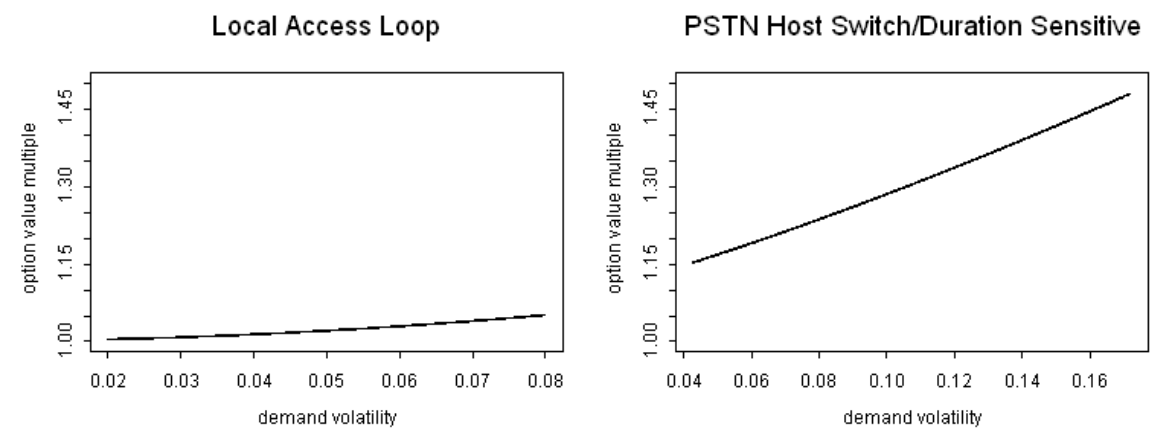

Host-Host Transmission

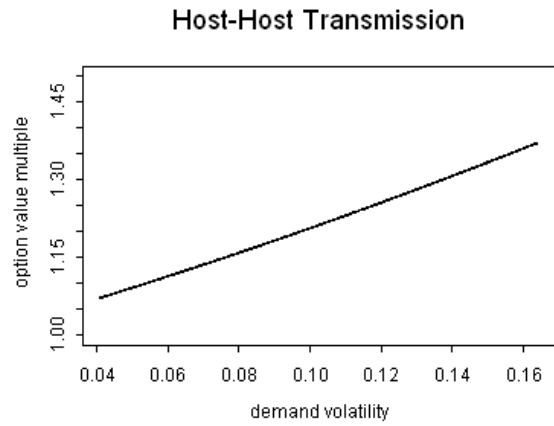

Figure 6: Option value multiple as a function of demand volatility

Figure 7 shows the sensitivity of the option value multiple $m_{\Delta}(\Delta=A, B, C)$ to the investment cost drift rate, holding all other variables constant, where each drift parameter varies in the range between the estimated value $\left(\hat{\alpha}_{I \Delta}\right) \pm 5 \%$. 

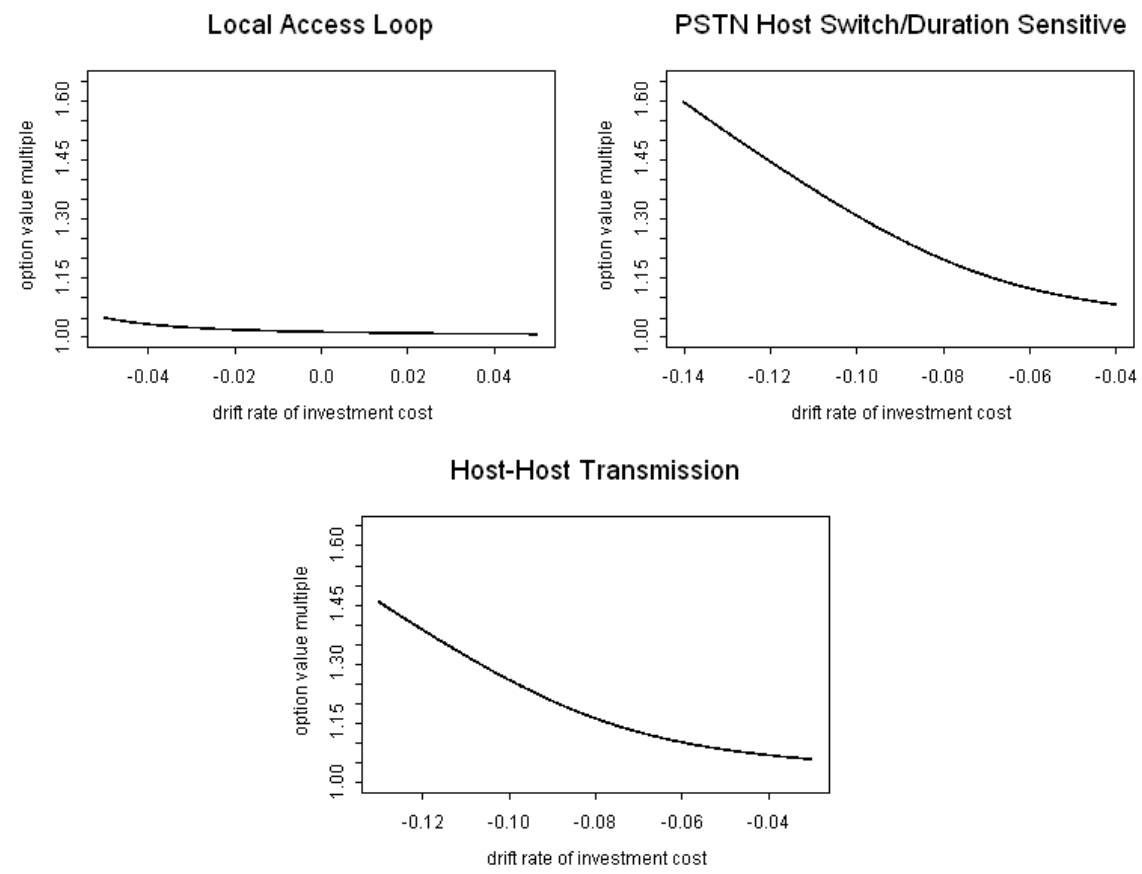

Figure 7: Option value multiple as a function of investment cost drift rate

It should be noted that:

- The option value multiple for the decision to invest in $\mathrm{NE}_{\mathrm{A}}$ is much lower than the option value multiples for the decisions to invest in $\mathrm{NE}_{\mathrm{B}}$ and $\mathrm{NE}_{\mathrm{C}}$. This can be explained by a combination of factors: (a) the demand uncertainty associated with the local access loop is much lower than the demand uncertainties associated with switching and transmission equipment; the lower the volatility of $\Pi A_{t}$ is, the lower the option value multiple is; (b) the drift rate of $I A_{t}$ is much higher than the drift rates of $I B_{t}$ and $I C_{t}$ (due to increasing labor costs); the higher the drift rate of $I A_{t}$ is, the lower the option value multiple is. These two factors combined reduce the option value multiple for the decision to invest in local access loop.

- The option value multiple is highly sensitive to the investment cost drift rate $\alpha_{I \Delta}(\Delta=A, B, C)$. The lower the drift rate is (or, the higher the decrease rate is), the higher the option value multiple is. 


\section{5}

\section{Application of the real options model}

The development of a LRIC cost model typically involves three steps: (i) estimate the investment in new equipment necessary to serve a predetermined level of demand; (ii) estimate the operating expenses required to operate the new equipment; and (iii) convert these costs, which are forecast to occur over the life of the investment, into annual (or monthly) costs. Total network operating and capital costs are calculated, and then apportioned to individual network elements, where each network element is an identifiable part of the network infrastructure to which a single cost driver can be assigned.

Each service has a routing (or usage) profile indicating how the service uses each network element. Routing factors specify, for each type of service, the average use made of each network element. ${ }^{43}$ If $\mathrm{RF}_{\mathrm{i}, \Delta}$ denotes the amount of $\mathrm{NE}_{\Delta}$ resource consumption by Service $_{\mathrm{i}}$, the routing factor (demand) volume of $\mathrm{NE}_{\Delta}$ $(\Delta=A, B, C)$ in a given year is measured by the routing factor weighted demand on that network element, that is

$r v \Delta=$ Routing Factor Volume of $\mathrm{NE}_{\Delta}=\sum_{\text {all services }(\mathrm{i})}\left(\right.$ Demand for Service $\left.\mathrm{i}_{\mathrm{i}}\right) \mathrm{RF}_{\mathrm{i}, \Delta} \cdot$

In the final stage of the top-down cost/asset allocation process, the cost and volume data typically available for each network element are as summarized in Table 4.

\footnotetext{
${ }^{43}$ See Section 3.2 for an illustrative example on how routing factors are calculated.
} 
Table 4: Cost and volume data typically available for each network element

\begin{tabular}{|l|l|l|}
\hline $\begin{array}{l}\text { Network } \\
\text { Element }\end{array}$ & \multicolumn{2}{|l|}{ Cost and volume information } \\
\hline NE & (i) Gross replacement cost & $\$ g \Delta$ \\
\cline { 2 - 3 } & (ii) Annualized capital cost & $\$ y \Delta$ \\
& (iii) Network operating expenses & $\$ z \Delta$ \\
\cline { 2 - 3 } & (iv) Allocated overhead expenses & $\$ w \Delta$ \\
\cline { 2 - 3 } & (v) Total operating and capital costs & $\$ y \Delta+z \Delta+w \Delta$ \\
& $\begin{array}{l}\text { (vi) Routing factor volume } \\
\end{array}$ & $r v \Delta$ \\
\hline $\begin{array}{l}\text { (i) The gross replacement cost of an asset measures the cost of replacing the existing asset by } \\
\text { another of similar performance characteristics, based on modern equivalent technology; (ii) The } \\
\text { annualized capital cost is the sum of the opportunity cost of capital and the economic } \\
\text { depreciation expenses; (iii) Network operating expenses are the network related expenses (e.g., } \\
\text { planning, maintenance, monitoring, etc) attributed to the network element using ABC-based } \\
\text { allocation; (iv) The allocated overhead expenses are general overheads attributed to the fixed } \\
\text { network; (v) Total operating and capital costs is the sum of the annualized capital cost (i.e., the } \\
\text { sum of the opportunity cost of capital and the economic depreciation expenses) and the annual } \\
\text { operating expenses; (v) the routing factor volume is the routing factor weighted demand (i.e., the } \\
\text { total demand volume for the service provided by the network element). }\end{array}$ \\
\hline
\end{tabular}

Current telecommunications cost models are based on the application of traditional discounted cash flow analysis. The cost-based prices of network services are calculated so as to make the expected present value of the net future cash flows from the service provided by each network element (NE) equal to the cost of investment in that NE. The unitary cost of each network element is calculated by dividing the total operating and capital costs by the annual routing factor volume,

$$
\text { Unitary Cost of } \mathrm{NE}_{\Delta}=\$ \frac{(y \Delta+z \Delta+w \Delta)}{r v \Delta} \text {. }
$$

Then, network costs are assigned to services on the basis of how much each service uses each NE,

$$
\text { Unitary Cost of Service }{ }_{\mathrm{i}}=\sum_{\operatorname{all} \mathrm{NEs}(\Delta)}\left(\mathrm{RF}_{\mathrm{i}, \Delta}\right)\left(\text { Unitary Cost of } \mathrm{NE}_{\Delta}\right) \text {. }
$$


In many regulatory environments, the regulated firm is allowed to collect revenue based on the costs faced by a hypothetical efficient replacement firm. In a world where firms have management flexibility to address uncertainties as they are resolved, the true cost of investment faced by a hypothetical efficient replacement firm should include not only the cost of investment in new assets, but also the value of the real options that are extinguished at the time of investment.

Therefore, in order to reflect the true investment cost, the option value multiple associated with each network investment decision must be applied to the investment cost component (i.e., to the gross replacement cost and/or annualized capital cost) of the respective network element. The true unitary cost of investment faced by a hypothetical efficient replacement firm is:

$$
\text { True Unitary Cost of } \mathrm{NE}_{\Delta}=\$ \frac{\left(m_{\Delta} y \Delta+z \Delta+w \Delta\right)}{r v \Delta},
$$

where $m_{\Delta}$ is the option value multiple associated with the investment decision in $\mathrm{NE}_{\Delta}$.

Table 5 shows the impact of the option value multiples on the average unitary cost of three network elements $\left(\mathrm{NE}_{\mathrm{A}}, \mathrm{NE}_{\mathrm{B}}\right.$ and $\left.\mathrm{NE}_{\mathrm{C}}\right)$, using the markup factors calculated in Section 4.4.2 $\left(m_{A}=1.01, m_{B}=1.25\right.$ and $\left.m_{C}=1.16\right)$ and actual cost and volume data of an incumbent telecommunications carrier, suitably modified to preserve the carrier's anonymity, for the project to build an IP/NGN network in a small metropolitan area (see Appendix B for the details on the actual cost and volume data used). 
Table 5: Impact of the markup factor on the average unitary cost of each network element

\begin{tabular}{|l|l|l|c|}
\hline \multirow{2}{*}{ Network Element } & \multicolumn{2}{|l|}{ Average Cost per Unit } \\
\cline { 2 - 4 } & Before the markup & After the markup & $\begin{array}{c}\% \\
\text { increase }\end{array}$ \\
\hline Local Access Loop & $\begin{array}{l}\text { US\$ 298.48 per line } \\
\text { (per year) }\end{array}$ & $\begin{array}{l}\text { US\$ 299.93 per line } \\
\text { (per year) }\end{array}$ & $0.5 \%$ \\
\hline $\begin{array}{l}\text { PSTN-Host Switch/ } \\
\text { Duration Sensitive }\end{array}$ & $\begin{array}{l}\text { US\$ 0.0035 } \\
\text { per minute }\end{array}$ & $\begin{array}{l}\text { US\$ 0.0039 } \\
\text { per minute }\end{array}$ & $12.0 \%$ \\
\hline $\begin{array}{l}\text { Host-Host } \\
\text { Transmission }\end{array}$ & $\begin{array}{l}\text { US\$ 0.0165 } \\
\text { per minute }\end{array}$ & $\begin{array}{l}\text { US\$ 0.0174 } \\
\text { per minute }\end{array}$ & $6.0 \%$ \\
\hline
\end{tabular}

The procedure described in Sections 4.3 and 4.4 can be applied to calculate the option value multiple associated with the investment decision in any other network element.

The impact of real options on the cost-based price of a regulated telecommunications service will depend on the network elements used by that service and the option value multiple calculated for each network investment decision.

The true unitary cost of a particular service $\left(\right.$ Service $\left._{\mathrm{i}}\right)$ is

$\sum_{\text {all } \mathrm{NEs}(\Delta)}\left(\mathrm{RF}_{\mathrm{i}, \Delta}\right)\left(\right.$ True Unitary Cost of $\left.\mathrm{NE}_{\Delta}\right)$. 


\section{Enhanced real options model and methodology}

\section{1}

\section{Introduction}

In this chapter, I propose an enhanced model/methodology for valuing the option to delay network investment decisions taking into account the demand and technological uncertainties in telecommunications networks. It takes the innovations introduced in Chapter 3 (i.e., it recognizes that different network elements are subject to different demand and technological uncertainties, so that a markup factor is calculated for each main network element, and excludes retail costs and revenues from the markup calculations for wholesale network services), and adds three other innovations/enhancements: (i) the option to invest in each network element is modeled as a function of two stochastic variables: the flow of total variable profit from the service provided by the network element, and the cost of new investment in that network element ${ }^{44}$; (ii) technological uncertainty is modeled through two different and complementary approaches: one for the technology obsolescence of used equipment, and another for the technology evolution of new modern equivalent equipment ${ }^{45}$; (iii) the study considers that when the used asset/equipment dies, the incumbent carrier gains a replacement option; that is, the option to invest in the modern equivalent network element of resized/adjusted capacity. The resized/adjusted capacity depends on the demand for the service provided by the network element at the time the option to invest becomes available ${ }^{46}$.

The uncertainties associated with each network element are modeled through the use of three stochastic processes: the flow of total variable profit (geometric

\footnotetext{
44 Prior real options studies considered the option value as a function of a single stochastic variable, either output price or demand.

45 None of the prior real options studies simultaneously addressed these two facts about technological uncertainty: the risk of technological obsolescence of used asset and the stochastic change in the cost of the modern equivalent asset of resized/adjusted capacity.

${ }^{46}$ None of the prior real options studies examined the impact of future replacement options on markup factors and cost-based access prices.
} 
Brownian motion), the depreciation of used asset (Poisson decay process), and the cost of new modern equivalent asset (geometric Brownian motion). They all fit together into a neat and simple model that calculates the option value multiple for each network element.

The rest of this chapter is organized as follows. The next section describes the enhanced model/methodology for valuing the option to delay network investment decisions and calculating cost-based access prices. Section 5.3 shows the estimates calculated for the parameters of the stochastic processes associated with three main network elements, each representing a different part of the Brazilian fixed telecommunications network. Section 5.4 calculates the option value multiples, performs sensitivity analyses and highlights key findings.

\section{2}

The enhanced real options model

For clarity of exposition, a notation table is provided below. 
Table 6: List of notations

\begin{tabular}{|c|c|}
\hline Notation $^{4 \prime}$ & Description \\
\hline $\mathrm{NE}_{\mathrm{i}}$ & Network Element $i$ \\
\hline $\mathrm{NE}_{\Delta}$ & Network Element $\Delta(\Delta=A, B, C)$ \\
\hline$\Pi_{t} ; \Pi \Delta_{t}$ & $\begin{array}{l}\text { Flow of total variable profit at } t \text { from the service provided by } \mathrm{NE}_{\mathrm{i}} / \\
\mathrm{NE}_{\Delta}(\Delta=A, B, C)\end{array}$ \\
\hline$\alpha_{\Pi} ; \alpha_{\Pi \Delta}$ & Drift parameter of the GBM $\Pi_{t} / \Pi \Delta_{t}(\Delta=A, B, C)$. \\
\hline$\sigma_{\Pi} ; \sigma_{\Pi \Delta}$ & Volatility parameter of the GBM $\Pi_{t} / \Pi \Delta_{t}(\Delta=A, B, C)$. \\
\hline$\mu_{\Pi} ; \mu_{\Pi \Delta}$ & $\begin{array}{l}\text { Expected rate of return of the directly tradable asset } \Pi_{t} / \Pi \Delta_{t} \\
(\Delta=A, B, C) .\end{array}$ \\
\hline$\delta_{\Pi} ; \delta_{\Pi \Delta}$ & Dividend rate of the directly tradable asset $\Pi_{t} / \Pi \Delta_{t}(\Delta=A, B, C)$. \\
\hline$I_{t} ; I \Delta_{t}$ & Cost of new investment in $\mathrm{NE}_{\mathrm{i}} / \mathrm{NE}_{\Delta}(\Delta=A, B, C)$ at $t$. \\
\hline$\alpha_{I} ; \alpha_{I \Delta}$ & Drift rate of the GBM $I_{t} / I \Delta_{t}(\Delta=A, B, C)$ \\
\hline$\sigma_{I} ; \sigma_{I \Delta}$ & Volatility parameter of the GBM $I_{t} / I \Delta_{t}(\Delta=A, B, C)$. \\
\hline$\mu_{I} ; \mu_{I \Delta}$ & $\begin{array}{l}\text { Expected rate of return of the directly tradable asset } I_{t} / I \Delta_{t} \\
(\Delta=A, B, C) .\end{array}$ \\
\hline$\delta_{I} ; \delta_{I \Delta}$ & Dividend rate of the directly tradable asset $I_{t} / I \Delta_{t}(\Delta=A, B, C)$. \\
\hline$x_{t} ; x \Delta_{t}$ & Demand for the service provided by $\mathrm{NE}_{\mathrm{i}} / \mathrm{NE}_{\Delta}$ at $t(\Delta=a, b, c)$. \\
\hline$\alpha_{x} ; \alpha_{x \Delta}$ & Drift parameter of the GBM $x_{t} / x \Delta_{t}(\Delta=a, b, c)$. \\
\hline$\sigma_{x} ; \sigma_{x \Delta}$ & Volatility parameter of the GBM $x_{t} / x \Delta_{t}(\Delta=a, b, c)$ \\
\hline$p_{t}$ & $\begin{array}{l}\text { Unit contribution margin of } \mathrm{NE}_{\mathrm{i}} \text { 's hypothetical network service } \\
\left(\Pi_{t}=p_{t} x_{t}\right)\end{array}$ \\
\hline$\alpha_{p} ; \alpha_{p \Delta}$ & Drift parameter of the zero-volatility GBM $p_{t} / p \Delta_{t}(\Delta=a, b, c)$ \\
\hline$q_{t}$ & $\begin{array}{l}\text { Stochastic price per unit of capacity of } \mathrm{NE}_{\mathrm{i}} \text { 's modern equivalent asset } \\
\left(I_{t}=q_{t} x_{t}\right)\end{array}$ \\
\hline$\lambda$ & Economic depreciation rate of $\mathrm{NE}_{\mathrm{i}}$ (i.e., the exponential/Poisson decay \\
\hline
\end{tabular}

${ }^{47}$ To keep the notation simple, the indexes $i$ and $\Delta$ have been omitted when no confusion arises. 


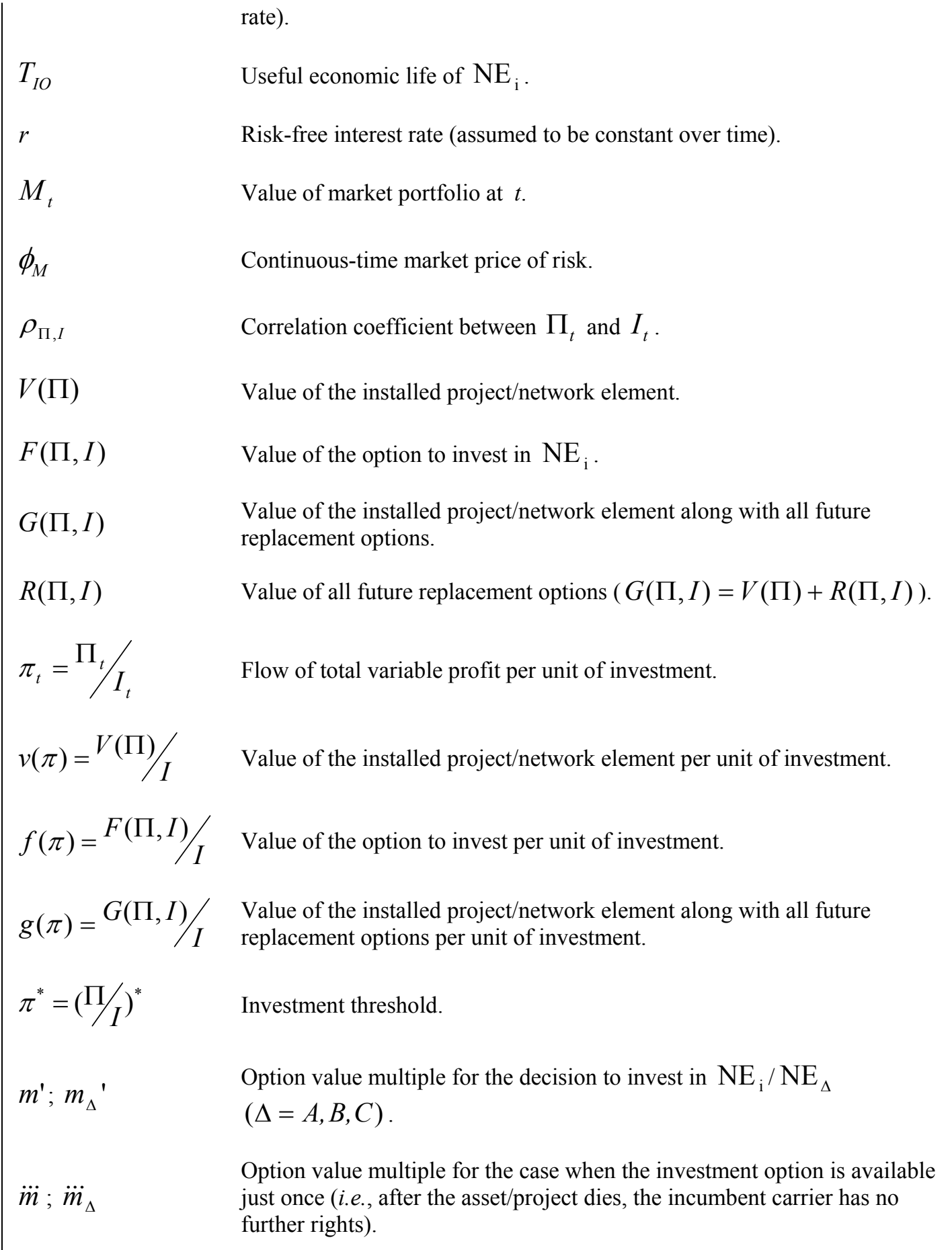




\section{2 .1}

\section{Model assumptions}

Let $\mathrm{NE}_{\mathrm{i}}$ denote one of these network elements (i.e., the network element $i^{48}$ ), $\Pi_{t}$ denote the flow of total variable profit at $t$ from the service provided by $\mathrm{NE}_{\mathrm{i}}$ (i.e., the flow of total profit ignoring the cost of capital needed to provide that service), and $I_{t}$ denote the cost of new investment in $\mathrm{NE}_{\mathrm{i}}$ at $t$ (i.e., the cost of the modern equivalent asset of resized/adjusted capacity). I assume that the demand for the service provided by $\mathrm{NE}_{\mathrm{i}}, x_{t}$, follows geometric Brownian motion with drift and volatility parameters respectively given by $\alpha_{x}$ and $\sigma_{x}$,

$$
d x=\alpha_{x} x d t+\sigma_{x} x d z_{x}
$$

where past historical demand is given by the total cost driver volume measured in a given period. $^{49}$

LRIC prices are calculated from period to period considering the most efficient technology is employed, and this, in turn, causes the LRIC prices to fall over time (see, for example, Krouse, 2000). In this chapter, I assume that the unit contribution margin of $\mathrm{NE}_{\mathrm{i}}{ }^{\prime} s$ hypothetical network service (i.e., the LRIC price minus unit variable cost), $p_{t}$, varies exponentially over time, so that $p_{t}=p_{0} e^{\alpha_{p} t}$ and $d p=\alpha_{p} p_{t} d t$. Therefore, the flow of total variable profit from the service provided by $\mathrm{NE}_{\mathrm{i}}, \Pi_{t}=p_{t} x_{t}$, follows geometric Brownian motion (GBM) with drift and volatility parameters respectively given by $\alpha_{\Pi}$ and $\sigma_{\Pi}$ :

$$
d \Pi=\alpha_{\Pi} \Pi d t+\sigma_{\Pi} \Pi d z_{\Pi},
$$

where

$$
\alpha_{\Pi}=\alpha_{x}+\alpha_{p} \text { and } \sigma_{\Pi}=\sigma_{x}
$$

The cost of new investment in $\mathrm{NE}_{\mathrm{i}}, I_{t}$, depends on two variables: (i) the

\footnotetext{
${ }^{48}$ To keep the notation simple, the index $i$ has been omitted when no confusion arises.

49 The demand for the service provided by each network element can be measured in terms of minutes of traffic, call setups, access lines, or $2 \mathrm{MB}$ circuits.
} 
stochastic price per unit of capacity of $\mathrm{NE}_{\mathrm{i}}$ 's modern equivalent asset; (ii) the capacity required to meet the stochastic demand for the service provided by $\mathrm{NE}_{\mathrm{i}}$. I assume that the investment in $\mathrm{NE}_{\mathrm{i}}$ displays no economies of scale and/or modularity effect, so that if $q_{t}$ denotes the stochastic price per unit of capacity of $\mathrm{NE}_{\mathrm{i}}$ 's modern equivalent asset and $x_{t}$ denotes the resized/adjusted capacity (as measured in terms of the demand for the service provided by $\mathrm{NE}_{\mathrm{i}}$ ), then $I_{t}=q_{t} x_{t}$. This assumption is consistent with cost-volume relationship curves that are straight lines passing through the origin. ${ }^{50}$

In this chapter, I assume that the cost of new investment in $\mathrm{NE}_{\mathrm{i}}$ (i.e., the cost of the modern equivalent equipment of resized/adjusted capacity), $I_{t}$, follows geometric Brownian motion (GBM) with drift and volatility parameters respectively given by $\alpha_{I}$ and $\sigma_{I}$,

$$
d I=\alpha_{I} I d t+\sigma_{I} I d z_{I}
$$

The GBM assumption has been adopted because it allows an analytical solution to the problem of finding the option value multiple for network investment decisions, and time-series data on demand volumes and cost of new investment do not provide evidence against the GBM assumption (as shown in Appendix A).

Note that an increase in the demand for the service provided by $\mathrm{NE}_{\mathrm{i}}\left(x_{t}\right)$ will cause an increase in the demand for the respective network element in order to build the required level of capacity. For a given supply curve, this will also cause an increase in the price per unit of capacity of $\mathrm{NE}_{\mathrm{i}}$ 's modern equivalent asset $\left(q_{t}\right)$. I assume that the supply curve moves stochastically according to the technological evolution of the modern equivalent equipment, and the correlation coefficients between $q_{t}$ and $x_{t}$ and between $q_{t}$ and the market portfolio $\left(M_{t}\right)$ are both positive; that is, $\rho_{q, x}=\operatorname{Corr}\left(\varepsilon_{q}, \varepsilon_{x}\right)>0$ and $\rho_{q, M}=\operatorname{Corr}\left(\varepsilon_{q}, \varepsilon_{M}\right)>0$.

Let $\rho_{\Pi, I}$ denote the correlation coefficient between $\Pi_{t}$ and $I_{t}$, so that

\footnotetext{
${ }^{50}$ Economies of scale and modularity effects can be introduced at the cost of making the algebra messier.
} 


$$
\rho_{\Pi, I}=\operatorname{Corr}\left(\varepsilon_{\Pi}, \varepsilon_{I}\right) \text {, and } d z_{\Pi} d z_{I}=\rho_{\Pi, I} d t
$$

I assume that the market is sufficiently complete so that the stochastic fluctuations in $\Pi_{t}$ and $I_{t}$ are spanned by other assets in the economy. In other words, there are traded assets or portfolios of traded assets, whose risks track or span the uncertainties in $\Pi_{t}$ and $I_{t} \cdot{ }^{51}$ In this chapter, for simplicity of exposition, I suppose that $\Pi_{t}$ and $I_{t}$ are directly tradable, but it would be sufficient to assume that the risk dynamics of $\Pi_{t}$ and $I_{t}$, namely the $d z_{\Pi}$ and $d z_{I}$ terms in equations (5.2) and (5.3), respectively, could be replicated by some portfolio of traded assets.

I assume that the economic depreciation of $\mathrm{NE}_{\mathrm{i}}$ is exponential or Poisson decay at rate $\lambda(\lambda>0)$ so that the event asset death follows Poisson process with rate $\lambda$. Therefore, the asset's lifetime, $T_{I O}$, has exponential distribution with parameter $\lambda$, and the asset's expected value declines exponentially at rate $\lambda$ (as shown in Appendix $\mathrm{C}$ ); that is, if $I O_{u}^{t}$ is the value at $t+u$ of an asset $\left(\mathrm{NE}_{\mathrm{i}}\right)$ bought at $t$, then $E\left[I O_{u}^{t}\right]=I_{t} e^{-\lambda u}(u \geq 0)$.

I also assume that the Poisson risk of asset death is fully diversifiable, or - in other words - the event asset death has correlation zero with the market portfolio. The emergence of new technologies can have profound impact on the economic depreciation profile (and economic life) of an installed network element $\left(\mathrm{NE}_{\mathrm{i}}\right)$, while not having such an impact on the price per unit of capacity of $\mathrm{NE}_{\mathrm{i}}$ 's modern equivalent asset $\left(q_{t}\right)$ or on the cost of new investment in $\mathrm{NE}_{\mathrm{i}}$ $\left(I_{t}=q_{t} x_{t}\right) .{ }^{52}$ The asset may come to the end of its economic life due to technology, competition and/or mortality factors.

The fundamental equilibrium condition of the capital asset pricing model

\footnotetext{
${ }^{51}$ If the market is incomplete, I would instead apply the minimum martingale measure or the minimum entropy measure - which depends on the preferences of the decision maker - in other to calculate the value of the options involved.

${ }^{52}$ This can be easily seen when one compares the depreciation profile of a network element with the time-series data on price of modern equivalent asset/network element (see, for example, EPT Luxembourg, 2007).
} 
(CAPM) states that

$$
\begin{aligned}
& \mu_{\Pi}=r+\phi_{M} \sigma_{\Pi} \rho_{\Pi, M}, \text { and } \\
& \mu_{I}=r+\phi_{M} \sigma_{I} \rho_{I, M},
\end{aligned}
$$

where $\mu_{\Pi}$ and $\mu_{I}$ are the total expected rates of return of the (directly tradable) assets $\Pi_{t}$ and $I_{t}$, respectively, $r$ is the discount rate appropriate to riskless cash flows, $\rho_{\Pi, M}$ is the correlation coefficient between $\Pi_{t}$ and the whole market portfolio $\left(M_{t}\right), \rho_{I, M}$ is the correlation coefficient between $I_{t}$ and the whole market portfolio $\left(M_{t}\right)$, and $\phi_{M}$ is the continuous-time market price of risk.

Those assets are held by investors only if they provide a sufficiently high return, where part of that return comes in the form of expected capital appreciation and another part may come in the form of a dividend rate. Therefore:

- $\mu_{\Pi}=\alpha_{\Pi}+\delta_{\Pi}$, where $\mu_{\Pi}$ is the total expected return of $\Pi_{t}, \alpha_{\Pi}$ is the expected continuously compounded growth rate, and $\delta_{\Pi}$ (assumed to be positive) is the continuously compounded dividend rate or the rate of return shortfall.

- $\mu_{I}=\alpha_{I}+\delta_{I}$, where $\mu_{I}$ is the total expected return of $I_{t}, \alpha_{I}$ is the expected continuously compounded growth rate, and $\delta_{I}$ (assumed to be positive) is the continuously compounded dividend rate or the rate of return shortfall.

\section{2 .2}

\section{Value of the option to invest}

The value of the installed project $\left(V_{t}\right)$ is a function of the flow of total variable profit $\left(\Pi_{t}=p_{t} x_{t}\right)$. As shown in Section 4.3.2,

$$
V\left(\Pi_{t}\right)=\frac{\Pi_{t}}{\left(\delta_{\Pi}+\lambda\right)}, \text { where } \delta_{\Pi}=\mu_{\Pi}-\alpha_{\Pi} .
$$


Let $F(\Pi, I, t)$ denote the value of the option to invest in $\mathrm{NE}_{\mathrm{i}}$. In this chapter, I assume that the investment option is available to the incumbent carrier in perpetuity and after the project/asset dies the incumbent carrier gets the original opportunity to invest in that network element back again (i.e., install the modern equivalent network element of resized/adjusted capacity). Following the steps of contingent claim valuation, consider a portfolio consisting of one unit of the option to invest in $\mathrm{NE}_{\mathrm{i}}$, which is worth $F(\Pi, I, t), m$ units short in the flow of total variable profit $(\Pi)$, and $n$ units short in the cost of new investment $(I)$. This is a dynamic portfolio; as $\Pi$ and $I$ change, $m$ and $n$ may change from one short interval of time to the next, so that the composition of the portfolio will be changed. However, over each infinitesimal interval of time $d t, m$ and $n$ are held fixed.

The value of that portfolio at $t$ is given by

$$
\Gamma(\Pi, I, t)=F(\Pi, I, t)-m \Pi-n I .
$$

During the infinitesimal interval of time $[t, t+d t)$ :

$$
d \Gamma(\Pi, I, t)=d F(\Pi, I, t)-m d \Pi-m \delta_{\Pi} \Pi d t-n d I-n \delta_{I} I d t
$$

Because I assumed that the option to invest is available in perpetuity, $F$ and $\Gamma$ can be expressed as functions of only $\Pi$ and $I\left(F_{t}=0\right)$. The Ito's Lemma gives

$$
d F=F_{\Pi} d \Pi+F_{I} d I+1 / 2 F_{\Pi \Pi}(d \Pi)^{2}+1 / 2 F_{I I}(d I)^{2}+F_{\Pi I}(d \Pi)(d I) .
$$

Substituting equation (5.10) into (5.9) and simplifying, leads to

$$
\begin{aligned}
& d \Gamma=\left(F_{\Pi}-m\right) d \Pi+\left(F_{I}-n\right) d I+1 / 2 F_{\Pi \Pi} \sigma_{\Pi}^{2} \Pi^{2} d t+1 / 2 F_{I I} \sigma_{I}^{2} I^{2} d t+ \\
& +F_{\Pi I} \sigma_{\Pi} \sigma_{I} \rho_{\Pi, I} \Pi I d t-m \delta_{\Pi} \Pi d t-n \delta_{I} I d t
\end{aligned}
$$

Choosing $m=\partial F / \partial \Pi=F_{\Pi}$ and $n=\partial F / \partial I=F_{I}$, the random terms in the return on $\Gamma(\Pi, I)$ are eliminated, making that portfolio riskless. Therefore, the return on $\Gamma(\Pi, I)$ during the infinitesimal interval $d t$ must be equal to the riskless return $r \Gamma(\Pi, I) d t$. 
From the equations above, it follows that, over the region of the $(\Pi, I)$ space where it is optimal to hold the option unexercised, $F(\Pi, I)$ must satisfy the following partial differential equation:

$$
\begin{aligned}
& 1 / 2\left(\sigma_{\Pi}^{2} \Pi^{2} F_{\Pi \Pi}+2 \rho_{\Pi, I} \sigma_{\Pi} \sigma_{I} \Pi I F_{\Pi I}+\sigma_{I}^{2} I^{2} F_{I I}\right)+\left(r-\delta_{\Pi}\right) \Pi F_{\Pi}+ \\
& +\left(r-\delta_{I}\right) I F_{I}-r F=0 .
\end{aligned}
$$

Because $\Pi_{t}$ and $I_{t}$ follow geometric Brownian motions and $V\left(\Pi_{t}\right)$ is a constant multiple of $\Pi_{t}, F\left(\Pi_{t}, I_{t}\right)$ is a convex homogeneous function of degree one in $\Pi_{t}$ and $I_{t} \cdot{ }^{53}$ Thus, I follow the procedure described in Dixit \& Pindyck (1994) to reduce the partial differential equation (5.11) to an ordinary differential equation by making

$$
F(\Pi, I)=I F(\Pi / I, 1)=I f(\pi),
$$

where

$$
\left\{\begin{array}{l}
f=F / I, \text { is the value of the option per unit of investment, } \\
\pi=\Pi / I, \text { is the flow of total variable profit per unit of investment, }
\end{array}\right.
$$

and

$$
\left\{\begin{array}{l}
F_{\Pi}(\Pi, I)=f^{\prime}(\pi), F_{I}(\Pi, I)=f(\pi)-\pi f^{\prime}(\pi), \\
F_{\Pi \Pi}(\Pi, I)=f^{\prime \prime}(\pi) / I, F_{I I}(\Pi, I)=\pi^{2} f^{\prime \prime}(\pi) / I, \text { and } \\
F_{\Pi I}(\Pi, I)=-\pi f^{\prime \prime}(\pi) / I .
\end{array}\right.
$$

Substituting equations (5.12) and (5.13) into the partial differential equation (5.11), leads to

$$
\begin{aligned}
& 1 / 2\left[\sigma_{\Pi}^{2} \Pi^{2} f^{\prime \prime}(\pi) / I+2 \rho_{\Pi, I} \sigma_{\Pi} \sigma_{I} \Pi I(-\pi) f^{\prime \prime}(\pi) / I+\sigma_{I}^{2} I^{2} \pi^{2} f^{\prime \prime}(\pi) / I\right]+ \\
& +\left(r-\delta_{\Pi}\right) \Pi f^{\prime}(\pi)+\left(r-\delta_{I}\right) I\left(f(\pi)-\pi f^{\prime}(\pi)\right)-r F=0 .
\end{aligned}
$$

\footnotetext{
${ }^{53}$ See McDonald and Siegel (1986) for a proof that $F(V, I)$ is homogeneous of degree one in $V$ and $I$; since $V(\Pi)$ is a constant multiple of $\Pi, F(\Pi, I)$ is also homogeneous of degree one in $\Pi$ and $I$.
} 
Simplifying the resulting equation, it follows that $f(\pi), 0 \leq \pi<\pi^{*}$ (where $\pi^{*}$ is the investment threshold), must satisfy the ordinary differential equation

$$
1 / 2\left(\sigma_{\Pi}^{2}-2 \rho_{\Pi, I} \sigma_{\Pi} \sigma_{I}+\sigma_{I}^{2}\right) \pi^{2} f^{\prime \prime}(\pi)+\left(\delta_{I}-\delta_{\Pi}\right) \pi f^{\prime}(\pi)-\delta_{I} f(\pi)=0
$$

The solution to that homogeneous second-order linear ordinary differential equation valid over the range of $\pi$ for which it is optimal to hold the option unexercised is

$$
f(\pi)=A_{1} \pi^{\beta_{1}}
$$

where $A_{1}$ is a constant to be determined and $\beta_{1}(>1)$ is the larger root of $Q E 1$ (shown below).

$$
\begin{gathered}
\text { QE1: } 1 / 2 \sigma_{T}^{2} \beta(\beta-1)+\left(\delta_{I}-\delta_{\Pi}\right) \beta-\delta_{I}=0 \\
\left(\text { where } \sigma_{T}^{2}=\sigma_{\Pi}^{2}-2 \rho_{\Pi, I} \sigma_{\Pi} \sigma_{I}+\sigma_{I}^{2}\right), \\
\beta_{1}=1 / 2-\frac{\left(\delta_{I}-\delta_{\Pi}\right)}{\sigma_{T}^{2}}+\sqrt{\left[\frac{\left(\delta_{I}-\delta_{\Pi}\right)}{\sigma_{T}^{2}}-1 / 2\right]^{2}+\frac{2 \delta_{I}}{\sigma_{T}^{2}}} .
\end{gathered}
$$

\section{2 .3}

\section{Value of the installed project along with all future replacement options}

Now, let $G(\Pi, I, t)$ denote the value of the installed $\mathrm{NE}_{\mathrm{i}}$ along with that of all future replacement options. Because I assumed that the stochastic fluctuations in $\Pi_{t}$ and $I_{t}$ are spanned by other assets in the economy and the event of project/ asset death has correlation zero with the market portfolio, I can take either the contingent claim approach or the dynamic programming perspective under the risk-neutral equivalent martingale measure $Q$. For ease of exposition, I now take the latter alternative.

First consider the region of the $(\Pi, I)$ space where $0 \leq \pi<\pi^{*}$. During the infinitesimal interval of time $[t, t+d t)$, the total variable profit from the service 
provided by $\mathrm{NE}_{\mathrm{i}}$ is $\Pi_{t} d t=p_{t} x_{t} d t$. Then, with probability $\lambda d t$, the current project will die and the firm will go back to holding the option worth $F(\Pi, I)$.

Therefore:

$$
\begin{aligned}
& G(\Pi, I, t)=\Pi d t+(1-\lambda d t) e^{-r d t} E^{Q}[G(\Pi, I, t)+d G]+ \\
& +\lambda d t e^{-r d t} E^{Q}[F(\Pi, I)+d F],
\end{aligned}
$$

where $r$ is the risk-free interest rate.

Under the risk-neutral equivalent martingale measure $Q$, the Ito's Lemma gives:

$$
\begin{aligned}
& d G^{Q}=G_{\Pi} d \Pi^{Q}+G_{I} d I^{Q}+1 / 2 G_{\Pi \Pi}\left(d \Pi^{Q}\right)^{2}+1 / 2 G_{I I}\left(d I^{Q}\right)^{2} \\
& +G_{\Pi I}\left(d \Pi^{Q}\right)\left(d I^{Q}\right), \\
& d F^{Q}=F_{\Pi} d \Pi^{Q}+F_{I} d I^{Q}+1 / 2 F_{\Pi \Pi}\left(d \Pi^{Q}\right)^{2}+1 / 2 F_{I I}\left(d I^{Q}\right)^{2} \\
& +F_{\Pi I}\left(d \Pi^{Q}\right)\left(d I^{Q}\right) .
\end{aligned}
$$

From the Girsanov theorem:

$$
d \Pi^{Q}=\left(r-\delta_{\Pi}\right) \Pi d t+\sigma_{\Pi} \Pi d z_{\Pi}^{Q} \text {, and } d I^{Q}=\left(r-\delta_{I}\right) I d t+\sigma_{I} I d z_{I}^{Q} .
$$

From equations (5.19), (5.20) and (5.21):

$$
\begin{aligned}
& E^{Q}[G(\Pi, I)+d G]=G(\Pi, I)+G_{\Pi}\left(r-\delta_{\Pi}\right) \Pi d t+G_{I}\left(r-\delta_{I}\right) I d t+ \\
& +1 / 2 G_{\Pi \Pi} \sigma_{\Pi}^{2} \Pi^{2} d t+1 / 2 G_{I I} \sigma_{I}^{2} I^{2} d t+G_{\Pi I} \sigma_{\Pi} \sigma_{I} \Pi I \rho_{\Pi, I} d t
\end{aligned}
$$

and

$$
\begin{aligned}
& E^{Q}[F(\Pi, I)+d F]=F(\Pi, I)+F_{\Pi}\left(r-\delta_{\Pi}\right) \Pi d t+F_{I}\left(r-\delta_{I}\right) I d t+ \\
& +1 / 2 F_{\Pi \Pi} \sigma_{\Pi}^{2} \Pi^{2} d t+1 / 2 F_{I I} \sigma_{I}^{2} I^{2} d t+F_{\Pi I} \sigma_{\Pi} \sigma_{I} \Pi I \rho_{\Pi, I} d t
\end{aligned}
$$

Substituting equations (5.22) and (5.23) into (5.18), leads to: 


$$
\begin{aligned}
& G(\Pi, I)=\Pi d t+(1-\lambda d t) e^{-r d t}\left[G(\Pi, I)+G_{\Pi}\left(r-\delta_{\Pi}\right) \Pi d t+\right. \\
& \left.+G_{I}\left(r-\delta_{I}\right) I d t+1 / 2 G_{\Pi \Pi} \sigma_{\Pi}^{2} \Pi^{2} d t+1 / 2 G_{I I} \sigma_{I}^{2} I^{2} d t+G_{\Pi I} \sigma_{\Pi} \sigma_{I} \Pi I \rho_{\Pi, I} d t\right]+ \\
& +\lambda d t e^{-r d t}\left[F(\Pi, I)+F_{\Pi}\left(r-\delta_{\Pi}\right) \Pi d t+F_{I}\left(r-\delta_{I}\right) I d t+1 / 2 F_{\Pi \Pi} \sigma_{\Pi}^{2} \Pi^{2} d t+\right. \\
& \left.+1 / 2 F_{I I} \sigma_{I}^{2} I^{2} d t+F_{\Pi I} \sigma_{\Pi} \sigma_{I} \Pi I \rho_{\Pi, I} d t\right] .
\end{aligned}
$$

Simplifying the resulting equation:

$$
\begin{aligned}
& 1 / 2\left(\sigma_{\Pi}^{2} \Pi^{2} G_{\Pi \Pi}+2 \rho_{\Pi, I} \sigma_{\Pi} \sigma_{I} \Pi I G_{\Pi I}+\sigma_{I}^{2} I^{2} G_{I I}\right)+\left(r-\delta_{\Pi}\right) \Pi G_{\Pi}+ \\
& +\left(r-\delta_{I}\right) I G_{I}-(r+\lambda) G+\Pi+\lambda F=0 .
\end{aligned}
$$

Again, as $G\left(\Pi_{t}, I_{t}\right)$ is a convex homogeneous function of degree one in $\Pi_{t}$ and $I_{t}$, the partial differential equation (5.24) can be reduced to an ordinary differential equation by making

$$
G(\Pi, I)=I G(\Pi / I, 1)=\operatorname{Ig}(\pi)
$$

where

$$
\left\{\begin{array}{l}
g=G / I, \text { is the value of the option per unit of investment, } \\
\pi=\Pi / I, \text { is the flow of total variable profit per unit of investment, }
\end{array}\right.
$$

and

$$
\left\{\begin{array}{l}
G_{\Pi}(\Pi, I)=g^{\prime}(\pi), G_{I}(\Pi, I)=g(\pi)-\pi g^{\prime}(\pi), \\
G_{\Pi \Pi}(\Pi, I)=g^{\prime \prime}(\pi) / I, G_{I I}(\Pi, I)=\pi^{2} g^{\prime \prime}(\pi) / I, \text { and } \\
G_{\Pi I}(\Pi, I)=-\pi^{g^{\prime \prime}}(\pi) / I .
\end{array}\right.
$$

Substituting equations (5.25) and (5.26) into (5.24), leads to

$$
\begin{aligned}
& 1 / 2\left[\sigma_{\Pi}^{2} \Pi^{2} g^{\prime \prime}(\pi) / I+2 \sigma_{\Pi} \sigma_{I} \Pi I \rho_{\Pi, I}(-\pi)^{g^{\prime \prime}(\pi)} / I+\sigma_{I}^{2} I^{2} \pi^{2} g^{\prime \prime}(\pi) / I\right]+ \\
& +\left(r-\delta_{\Pi}\right) \Pi g^{\prime}(\pi)+\left(r-\delta_{I}\right) I\left(g(\pi)-\pi g^{\prime}(\pi)\right)-(r+\lambda) G+\Pi+\lambda F=0 .
\end{aligned}
$$

Simplifying the resulting equation, it follows that $g(\pi), 0 \leq \pi \leq \pi^{*}$, must satisfy the ordinary differential equation 


$$
\begin{aligned}
& 1 / 2\left(\sigma_{\Pi}^{2}-2 \rho_{\Pi, I} \sigma_{\Pi} \sigma_{I}+\sigma_{I}^{2}\right) \pi^{2} g^{\prime \prime}(\pi)+\left(\delta_{I}-\delta_{\Pi}\right) \pi g^{\prime}(\pi)-\left(\delta_{I}+\lambda\right) g(\pi)+ \\
& +\pi+\lambda f=0
\end{aligned}
$$

This is a non-homogeneous second-order linear ordinary differential equation, and it is valid over the range $0 \leq \pi<\pi^{*}$. The solution for the homogeneous part is:

$$
g(\pi)=B_{1} \pi^{\beta^{\prime}}
$$

where $B_{1}$ is a constant to be determined and $\beta_{1}{ }^{\prime}(>1)$ is the larger root of $Q E 2$ (shown below).

$$
\begin{gathered}
\text { QE2: } 1 / 2 \sigma_{T}^{2} \beta(\beta-1)+\left(\delta_{I}-\delta_{\Pi}\right) \beta-\left(\delta_{I}+\lambda\right)=0 \\
\left(\text { where } \sigma_{T}^{2}=\sigma_{\Pi}^{2}-2 \rho_{\Pi, I} \sigma_{\Pi} \sigma_{I}+\sigma_{I}^{2}\right) \\
\beta_{1}{ }^{\prime}=1 / 2-\frac{\left(\delta_{I}-\delta_{\Pi}\right)}{\sigma_{T}^{2}}+\sqrt{\left[\frac{\left(\delta_{I}-\delta_{\Pi}\right)}{\sigma_{T}^{2}}-1 / 2\right]^{2}+\frac{2\left(\delta_{I}+\lambda\right)}{\sigma_{T}^{2}}} .
\end{gathered}
$$

Here, I can add on any particular solution of the full equation, and a simple substitution shows that $g(\pi)=\frac{\pi}{\left(\delta_{\Pi}+\lambda\right)}+f(\pi)$ satisfies that equation. ${ }^{54}$ Therefore, the solution for the non-homogeneous differential equation of second order (5.27), valid over the range $0 \leq \pi<\pi^{*}$, is

$$
g(\pi)=B_{1} \pi^{\beta_{1}^{\prime}}+\frac{\pi}{\left(\delta_{\Pi}+\lambda\right)}+f(\pi)
$$

Now, consider the region of the $(\Pi, I)$ space where $\pi>\pi^{*}$, and take again the dynamic programming perspective under the risk-neutral equivalent martingale measure $Q$. During the infinitesimal interval of time $[t, t+d t)$, the total variable profit from the service provided by $\mathrm{NE}_{\mathrm{i}}$ is $\Pi_{t} d t=p_{t} x_{t} d t$. Then, with probability $\lambda d t$, the current project will die; if that happens, the incumbent carrier will immediately exercise the option to invest again in that network element (as $\left.\pi>\pi^{*}\right)$

\footnotetext{
${ }^{54}$ This is the value of $g(\pi)$ for the case when the incumbent carrier never invests in that network element back again; i.e., once the project/asset dies, the investment option is held unexercised.
} 
Therefore:

$$
\begin{aligned}
& G(\Pi, I)=\Pi d t+(1-\lambda d t) e^{-r d t} E^{Q}[G(\Pi, I)+d G]+ \\
& +\lambda d t e^{-r d t} E^{Q}[G(\Pi, I)+d G-I-d I] .
\end{aligned}
$$

Again, under the risk-neutral equivalent martingale measure $Q$, the Ito's Lemma is applied for $d G^{Q}$ to reach equation (5.19), and the Girsanov theorem is applied for $d \Pi^{Q}$ and $d I^{Q}$ to reach to equation (5.22). Then, substituting equations (5.19) and (5.22) into (5.31), leads to

$$
\begin{aligned}
& G(\Pi, I)=\Pi d t+(1-r d t) G(\Pi, I)+G_{\Pi}\left(r-\delta_{\Pi}\right) \Pi d t+G_{I}\left(r-\delta_{I}\right) I d t+ \\
& +1 / 2 G_{\Pi \Pi} \sigma_{\Pi}^{2} \Pi^{2} d t+1 / 2 G_{I I} \sigma_{I}^{2} I^{2} d t+G_{\Pi I} \sigma_{\Pi} \sigma_{I} \Pi I \rho_{\Pi, I} d t-\lambda d t I
\end{aligned}
$$

Simplifying the resulting equation:

$$
\begin{aligned}
& 1 / 2\left(\sigma_{\Pi}^{2} \Pi^{2} G_{\Pi \Pi}+2 \rho_{\Pi, I} \sigma_{\Pi} \sigma_{I} \Pi I G_{\Pi I}+\sigma_{I}^{2} I^{2} G_{I I}\right)+\left(r-\delta_{\Pi}\right) \Pi G_{\Pi}+ \\
& +\left(r-\delta_{I}\right) I G_{I}+\Pi-r G-\lambda I=0 .
\end{aligned}
$$

I now take the same steps as above to reduce the partial differential equation in (5.32) to an ordinary differential equation. Substituting equations (5.25) and (5.26) into equation (5.32), leads to

$$
\begin{aligned}
& 1 / 2\left[\sigma_{\Pi}^{2} \Pi^{2} g^{\prime \prime}(\pi) / I+2 \sigma_{\Pi} \sigma_{I} \Pi I \rho_{\Pi, I}(-\pi)^{g^{\prime \prime}}(\pi) / I+\sigma_{I}^{2} I^{2} \pi^{2} g^{\prime \prime}(\pi) / I\right]+ \\
& +\left(r-\delta_{\Pi}\right) \Pi g^{\prime}(\pi)+\left(r-\delta_{I}\right) I\left(g(\pi)-\pi g^{\prime}(\pi)\right)+\Pi-r G-\lambda I=0 .
\end{aligned}
$$

Simplifying the resulting equation, it follows that $g(\pi), \pi>\pi^{*}$, must satisfy the ordinary differential equation

$$
\begin{aligned}
& 1 / 2\left(\sigma_{\Pi}^{2}-2 \rho_{\Pi, I} \sigma_{\Pi} \sigma_{I}+\sigma_{I}^{2}\right) \pi^{2} g^{\prime \prime}(\pi)+\left(\delta_{I}-\delta_{\Pi}\right) \pi g^{\prime}(\pi)-\delta_{I} g(\pi)+ \\
& +\pi-\lambda=0 .
\end{aligned}
$$

This is a non-homogeneous second-order linear ordinary differential equation, and it is valid over the range $\pi>\pi^{*}$. The solution for the homogeneous part is $g(\pi)=C_{2} \pi^{\beta_{2}}$, where $C_{2}$ is a constant to be determined and $\beta_{2}$ is the negative $(<0)$ root of $Q E 1$.

Here, I can add on any particular solution of the full equation, and a simple 
substitution shows that $g(\pi)=\frac{\pi}{\delta_{\Pi}}-\frac{\lambda}{\delta_{I}}$ satisfies that equation. ${ }^{55}$ Therefore, the solution of the non-homogeneous differential equation of second order (5.33), valid over the range $\pi>\pi^{*}$, is

$$
g(\pi)=C_{2} \pi^{\beta_{2}}+\frac{\pi}{\delta_{\Pi}}-\frac{\lambda}{\delta_{I}}
$$

\section{2 .4}

\section{Option value multiple}

The two branches of $g(\pi)$ must meet tangentially at $\pi^{*}$. Therefore:

$$
\begin{gathered}
g\left(\pi^{*}\right)=B_{1}\left(\pi^{*}\right)^{\beta_{1}}+\frac{\pi^{*}}{\left(\delta_{\Pi}+\lambda\right)}+A_{1}\left(\pi^{*}\right)^{\beta_{1}}=C_{2}\left(\pi^{*}\right)^{\beta_{2}}+\frac{\pi^{*}}{\delta_{\Pi}}-\frac{\lambda}{\delta_{I}}, \text { and } \\
g^{\prime}\left(\pi^{*}\right)=\beta_{1}^{\prime} B_{1}\left(\pi^{*}\right)^{\left(\beta_{1}{ }^{\prime}-1\right)}+\frac{1}{\left(\delta_{\Pi}+\lambda\right)}+\beta_{1} A_{1}\left(\pi^{*}\right)^{\left(\beta_{1}-1\right)}=\beta_{2} C_{2}\left(\pi^{*}\right)^{\left(\beta_{2}-1\right)}+\frac{1}{\delta_{\Pi}}
\end{gathered}
$$

Since $\pi^{*}=(\Pi / I)^{*}$ is the investment threshold, $f(\pi)$ must satisfy the valuematching and smooth-pasting conditions with $\{g(\pi)-1\}$ at $\pi^{*}$, which lead to

Value-matching:

$$
\begin{aligned}
& f\left(\pi^{*}\right)=A_{1}\left(\pi^{*}\right)^{\beta_{1}}=g\left(\pi^{*}\right)-1=B_{1}\left(\pi^{*}\right)^{\beta_{1}{ }^{\prime}}+\frac{\pi^{*}}{\left(\delta_{\Pi}+\lambda\right)}+f\left(\pi^{*}\right)-1 . \\
& \Rightarrow B_{1}\left(\pi^{*}\right)^{\beta_{1}{ }^{\prime}}+\frac{\pi^{*}}{\left(\delta_{\Pi}+\lambda\right)}=1 .
\end{aligned}
$$

Smooth-pasting:

$$
f^{\prime}\left(\pi^{*}\right)=\beta_{1} A_{1}\left(\pi^{*}\right)^{\left(\beta_{1}-1\right)}=g^{\prime}\left(\pi^{*}\right)=\beta_{1}^{\prime} B_{1}\left(\pi^{*}\right)^{\left(\beta_{1}^{\prime}-1\right)}+\frac{1}{\left(\delta_{\Pi}+\lambda\right)}+f^{\prime}\left(\pi^{*}\right)
$$

\footnotetext{
${ }^{55}$ This is the value of $g(\pi)$ for the case when every time the project/asset dies, the incumbent carrier immediately exercises the option to invest in the new modern equivalent network element that costs $I_{t}$.
} 


$$
\Rightarrow \beta_{1}^{\prime} B_{1}\left(\pi^{*}\right)^{\left(\beta_{1}^{\prime}-1\right)}+\frac{1}{\left(\delta_{\Pi}+\lambda\right)}=0 .
$$

There are now four equations (from (5.35) to (5.38)) to determine the four unknowns $A_{1}, B_{1}, C_{2}$ and $\pi^{*}$, and the values of $f(\pi)$ and $g(\pi)$ for any $\pi \geq 0$. Solving equations (5.37) and (5.38) for the free boundary line separating the regions of waiting and investing in the $(\Pi, I)$ space, leads to

$$
\pi^{*}=\left(\Pi / I^{*}=\frac{\beta_{1}^{\prime}}{\beta_{1}{ }^{\prime}-1}\left(\delta_{\Pi}+\lambda\right)\right.
$$

where $\beta_{1}{ }^{\prime}(>1)$ is the higher root of $Q E 2$.

I can now express, for any given $I \quad(e . g ., I=\widehat{I})$, the free boundary line in terms of the value of the installed network element:

$$
\begin{aligned}
& V\left(\Pi^{*}\right)=\frac{\Pi^{*}}{\left(\delta_{\Pi}+\lambda\right)}=\frac{1}{\left(\delta_{\Pi}+\lambda\right)} \frac{\beta_{1}{ }^{\prime}}{\beta_{1}{ }^{\prime}-1}\left(\delta_{\Pi}+\lambda\right) \widehat{I} . \\
& \Rightarrow V\left(\Pi^{*}\right)=\frac{\beta_{1}^{\prime}}{\beta_{1}{ }^{\prime}-1} \hat{I} \quad\left(\text { where } \beta_{1}{ }^{\prime}>1\right) .
\end{aligned}
$$

When the incumbent carrier invests in $\mathrm{NE}_{\mathrm{i}}$, it gets the installed project valued $V\left(\Pi^{*}\right)$, along with all future replacement options of $\mathrm{NE}_{\mathrm{i}}$. Together, the installed project and all future replacement options value $G\left(\Pi^{*}, \widehat{I}\right)$. If the value of all future replacement options is denoted by $R\left(\Pi^{*}, \widehat{I}\right)$, then $G\left(\Pi^{*}, \widehat{I}\right)=V\left(\Pi^{*}\right)+R\left(\Pi^{*}, \widehat{I}\right)$.

At that time, the incumbent carrier also gives up the opportunity or option to invest, which is valued $F\left(\Pi^{*}, \widehat{I}\right)$, so that the total cost of the project (direct cost plus opportunity cost of making the investment, net of all future replacement options $)$ is $\widehat{I}+F\left(\Pi^{*}, \widehat{I}\right)-R\left(\Pi^{*}, \widehat{I}\right)$.

In the free boundary line separating the waiting and investment regions in the $(\Pi, I)$ space: 


$$
G\left(\Pi^{*}, \widehat{I}\right)=V\left(\Pi^{*}\right)+R\left(\Pi^{*}, \widehat{I}\right)=\hat{I}+F\left(\Pi^{*}, \widehat{I}\right) .
$$

Thus, for any given $\widehat{I}$ :

$$
V\left(\Pi^{*}\right)=\widehat{I}+F\left(\Pi^{*}, \widehat{I}\right)-R\left(\Pi^{*}, \widehat{I}\right)=\frac{\beta_{1}{ }^{\prime}}{\beta_{1}^{\prime}-1} \widehat{I}=m^{\prime} \widehat{I} .
$$

The option value multiple for the decision to invest in $\mathrm{NE}_{\mathrm{i}}$ is $m^{\prime}=\beta_{1}^{\prime} /\left(\beta_{1}^{\prime}-1\right)$, where $\beta_{1}{ }^{\prime}(>1)$ is the higher root of $Q E 2$. This is the markup factor that must be applied to the investment cost component of $\mathrm{NE}_{\mathrm{i}}$ in order to reflect the true cost of investment considering both the cost of investment and the net value of the options involved.

From equations (5.29) and (5.41), it follows that (all other things held constant):

- The higher the economic depreciation rate is (i.e., the higher the Poisson decay rate $\lambda$ ), the lower the option value multiple is. This can be easily interpreted, as the value of an option to take an action depends on the degree of irreversibility of the action; the higher the depreciation rate, the less irreversible the investment decision is and the lower the option value multiple is.

- The higher the correlation coefficient $\rho_{\Pi, I}$ is, the lower $\sigma_{T}^{2}$ is and the lower the option value multiple $m^{\prime}$ is. All other things the same, a higher correlation between $d \Pi$ and $d I$ implies less uncertainty over the ratio $\Pi / I$ and thus a reduced option value multiple. ${ }^{56}$

- The higher the volatility parameter of either $\Pi_{t}$ or $I_{t}$ is (respectively, $\sigma_{\Pi}$ and $\sigma_{I}$ ), the higher $\sigma_{T}^{2}$ is and the higher the option value multiple $m^{\prime}$ is.

- The lower $\alpha_{I}$ is, the higher $\delta_{I}\left(=\mu_{I}-\alpha_{I}\right)$ is and the higher the option value multiple $m^{\prime}$ is. On the other hand, the lower $\alpha_{\Pi}$ is, the higher $\delta_{\Pi}$

\footnotetext{
${ }^{56}$ A positive correlation between $d \Pi$ and $d I$ (and thus, between $\varepsilon_{\Pi}$ and $\varepsilon_{I}$ ) is expected.
} 
$\left(=\mu_{\Pi}-\alpha_{\Pi}\right)$ is and the lower the option value multiple $m^{\prime}$ is. ${ }^{57}$

If the investment option were available just once (i.e., if after the asset/project dies, the incumbent carrier had no further rights), there would be a different free boundary line separating the investing and waiting decisions in the $(\Pi, I)$ space, and $f(\pi)$ would need to satisfy the value-matching and smooth-pasting conditions with $\{v(\pi)-1\}$ at $\pi^{\#}$ (the new investment threshold):

$$
\begin{aligned}
& A_{1}\left(\pi^{\#}\right)^{\beta_{1}}=\frac{\pi^{\#}}{\left(\delta_{\Pi}+\lambda\right)}-1 ; \beta_{1} A_{1}\left(\pi^{\#}\right)^{\beta_{1}-1}=\frac{1}{\left(\delta_{\Pi}+\lambda\right)} . \\
& \Rightarrow V\left(\Pi^{\#}\right)=\frac{\beta_{1}}{\beta_{1}-1} \widehat{I}
\end{aligned}
$$

Therefore:

$$
\underset{\text { (w/o replacement options) }}{V\left(\Pi^{\#}\right)}=\widehat{I}+\underset{\text { (w/o replacement options) }}{F\left(\Pi^{\#}, \widehat{I}\right)}=\frac{\beta_{1}}{\beta_{1}-1} \widehat{I}=\dddot{m} \widehat{I} .
$$

The change in markup value due to future replacement options may be written as

$$
\underset{\text { (w/o replacement options) }}{V\left(\Pi^{\#}\right)}-V\left(\Pi^{*}\right)=\left(\dddot{m}-m^{\prime}\right) \widehat{I} .
$$

From equations (5.17) and (5.29), it can be easily seen that $\beta_{1}{ }^{\prime}$ is always greater than $\beta_{1}$, and thus $m^{\prime}<\dddot{m}$. That is, the consideration that the option to invest is available to the incumbent carrier in perpetuity, so that after the asset/project dies the incumbent carrier gets the option to invest again in the modern equivalent version of that network element, lowers the option value multiple. I will get back to that point later in Section 5.4.

\footnotetext{
${ }^{57}$ It can be easily shown that if $\delta_{I}>0$ and $\lambda>0$, then $\partial \beta_{1}{ }^{\prime} / \partial \delta_{I}<0$, and if $\delta_{\Pi}>0$ and $\lambda>0$, then $\partial \beta_{1}{ }^{\prime} / \partial \delta_{\Pi}>0$. See assumptions on Section 5.2.1.
} 


\section{3}

\section{Parameter estimates for the Brazilian telecommunications market}

In this section, I estimate the parameters of the GBM and Poisson processes associated with three main network elements, each representing a different part of the Brazilian fixed telecommunications network: Local Access Loop $\left(\mathrm{NE}_{\mathrm{A}}\right)$; PSTN Host Switch/Duration Sensitive $\left(\mathrm{NE}_{\mathrm{B}}\right)$; and Host-Host Transmission $\left(\mathrm{NE}_{\mathrm{C}}\right)$.

\section{3 .1}

\section{The flow of total variable profit stochastic variables $\left(\Pi_{t}\right)$}

Let $\Pi A_{t}, \Pi B_{t}$ and $\Pi C_{t}$ respectively denote the flow of total variable profit from the service provided by $\mathrm{NE}_{\mathrm{A}}$ (i.e., local access loop lines), $\mathrm{NE}_{\mathrm{B}}$ (i.e., minutes of host switch traffic) and $\mathrm{NE}_{\mathrm{C}}$ (i.e., minutes of host-host transport traffic). From equation (5.2), $\Pi A_{t}$ follows geometric Brownian motion with drift and volatility parameters given by $\alpha_{\Pi A}=\alpha_{x a}+\alpha_{p a}$ and $\sigma_{\Pi A}=\sigma_{x a}, \Pi B_{t}$ follows geometric Brownian motion with drift and volatility parameters given by $\alpha_{\Pi B}=\alpha_{x b}+\alpha_{p b}$ and $\sigma_{\Pi B}=\sigma_{x b}$, and $\Pi C_{t}$ follows geometric Brownian motion with drift and volatility parameters given by $\alpha_{\Pi C}=\alpha_{x c}+\alpha_{p c}$ and $\sigma_{\Pi C}=\sigma_{x c}$.

In order to find the demand drift and volatility estimates $\left(\hat{\alpha}_{x a}, \hat{\alpha}_{x b}, \hat{\alpha}_{x c}, \hat{\sigma}_{x a}\right.$, $\hat{\sigma}_{x b}$ and $\hat{\sigma}_{x c}$ ), I used publicly available quarterly time-series data on the number of access lines in service, minutes of local traffic and minutes of transport traffic in the Brazilian telecommunications market, and followed the procedure described in Appendix A. The operational data and calculations are shown in Annex A. ${ }^{58}$ The following estimates were obtained (as shown in Section 4.4.1):

\footnotetext{
58 Quarterly time-series data were kindly provided by Teleco (http://www.teleco.com). See Telebrasil and Teleco (2011) for yearly time-series data.
} 


$$
\left\{\begin{array} { l } 
{ \hat { \alpha } _ { x a } = - 0 . 0 1 2 , } \\
{ \hat { \sigma } _ { x a } = 0 . 0 4 0 , }
\end{array} \quad \left\{\begin{array} { l } 
{ \hat { \alpha } _ { x b } = - 0 . 0 2 9 , } \\
{ \hat { \sigma } _ { x b } = 0 . 0 8 6 , }
\end{array} \quad \left\{\begin{array}{l}
\hat{\alpha}_{x c}=-0.034, \\
\hat{\sigma}_{x c}=0.082 .
\end{array}\right.\right.\right.
$$

The expected rates of return $\left(\mu_{\Pi A}, \mu_{\Pi B}\right.$ and $\left.\mu_{\Pi C}\right)$ were derived from the cost of capital typically used to discount cash flows from the investments in $\mathrm{NE}_{\mathrm{A}}, \mathrm{NE}_{\mathrm{B}}$ and $\mathrm{NE}_{\mathrm{C}}$. As most of the incumbent carriers' revenue comes from network access services, and most of the interexchange carriers' revenue comes from transport-related network services, the incumbent's cost of capital can be used to estimate $\mu_{\Pi A}$ and $\mu_{\Pi B}$, and the interexchange carrier's cost of capital can be used to estimate $\mu_{\Pi С}$. I used an average estimate of the post-tax real weighted average cost of capital of incumbent and interexchange carriers equal to $9.0 \%$. Thus, the values of $\hat{\delta}_{\Pi A}, \hat{\delta}_{\Pi B}$ and $\hat{\delta}_{\Pi C}$ were derived from the above considerations by making $\hat{\delta}_{\Pi A}=\hat{\mu}_{\Pi A}-\hat{\alpha}_{\Pi A}, \hat{\delta}_{\Pi B}=\hat{\mu}_{\Pi B}-\hat{\alpha}_{\Pi B}$ and $\hat{\delta}_{\Pi C}=\hat{\mu}_{\Pi C}-\hat{\alpha}_{\Pi C}$ (as shown in Section 4.4.1):

$$
\left\{\begin{array} { l } 
{ \hat { \mu } _ { \Pi A } = 0 . 0 9 0 , } \\
{ \hat { \delta } _ { \Pi A } = 0 . 1 0 2 , }
\end{array} \quad \left\{\begin{array} { l } 
{ \hat { \mu } _ { \Pi B } = 0 . 0 9 0 , } \\
{ \hat { \delta } _ { \Pi B } = 0 . 1 1 9 , }
\end{array} \quad \left\{\begin{array}{l}
\hat{\mu}_{\Pi C}=0.090, \\
\hat{\delta}_{\Pi C}=0.124 .
\end{array}\right.\right.\right.
$$

\section{3 .2}

\section{The cost of investment stochastic variables $\left(I_{t}\right)$ and the correlation coefficient between $\Pi_{t}$ and $I_{t}$}

Let $I A_{t}$ denote the cost of new investment in $\mathrm{NE}_{\mathrm{A}}$ (Local Access Loop), and $q a_{t}$ and $x a_{t}$ respectively denote the stochastic price per unit of capacity of the network element's modern equivalent asset and the resized/adjusted capacity measured in terms of its cost driver volume (i.e., the number of access lines in service); thus $I A_{t}=q a_{t} x a_{t}$. Similarly, the cost of new investment in $\mathrm{NE}_{\mathrm{B}}(\mathrm{PSTN}$ Host Switch/Duration Sensitive) and $\mathrm{NE}_{\mathrm{C}}$ (Host-Host Transmission), respectively denoted by $I B_{t}$ and $I C_{t}$, can be written as the product of the stochastic price per unit of capacity of the network element's modern equivalent 
equipment (respectively, $q b_{t}$ and $q c_{t}$ ) and the resized/adjusted capacity measured in terms of its cost driver volume (respectively, $x b_{t}$ and $x c_{t}$ ), so that $I B_{t}=q b_{t} x b_{t}$ and $I C_{t}=q c_{t} x c_{t}$.

From equation (5.3), the cost of new investment in $\mathrm{NE}_{\mathrm{A}}, \mathrm{NE}_{\mathrm{B}}$ and $\mathrm{NE}_{\mathrm{C}}$ follow, respectively, the geometric Brownian motions $d I A=\alpha_{I A} I A d t+\sigma_{I A} I A d z_{I A}, \quad d I B=\alpha_{I B} I B d t+\sigma_{I B} I B d z_{I B} \quad$ and $d I C=\alpha_{I C} I C d t+\sigma_{I C} I C d z_{I C}$. Although, time-series data on telecommunications equipment prices and local loop investment costs are not typically available in the public domain, equipment manufacturers and incumbent carriers usually keep historic records of network equipment price and capabilities over a number of years so that time-series data on the cost of new investment (i.e., the cost of the modern equivalent asset of resized/adjusted capacity) can be easily derived. Incumbent carriers often keep records of price offers from civil engineering firms for network extension projects and network underground work so that the investment/replacement cost associated with local loop plant can also be easily derived. As long as historic data on prices of modern equivalent assets/equipment are available, the procedure and formulas used for estimating the drift and volatility parameters of $I A_{t}, I B_{t}$ and $I C_{t}$ are analogous to the ones used for estimating the drift and volatility parameters of $x a_{t}, x b_{t}$ and $x c_{t}$.

In this chapter, I followed the procedure described in Appendix A and used price indices for switching and transmission equipment, obtained from the telecommunications equipment providers of a European incumbent carrier, to estimate $\alpha_{I B}, \alpha_{I C}, \sigma_{I B}, \sigma_{I C},{ }^{59}$ and the Brazilian national index for civil engineering cost, INCC-DI, ${ }^{60}$ to estimate $\alpha_{I A}$ and $\sigma_{I A}$. These indices were first adjusted to account for inflation and then adjusted to account for the change in the required level of capacity, so as to reflect the cost of new modern equivalent assets of resized/adjusted capacity. The price indices and calculations are shown

\footnotetext{
59 See EPT Luxembourg (2007) for the price indices used for switching and transmission equipment and EPT's approach to asset revaluation.

${ }^{60}$ INCC-DI is the acronym for the Brazilian national index for civil engineering cost: Índice Nacional de Custo da Construção - Disponibilidade Interna (in Portuguese).
} 
in Annex B. The following estimates were obtained:

$$
\left\{\begin{array} { l } 
{ \hat { \alpha } _ { I A } = 0 . 0 0 9 , } \\
{ \hat { \sigma } _ { I A } = 0 . 0 3 8 , }
\end{array} \quad \left\{\begin{array} { l } 
{ \hat { \alpha } _ { I B } = - 0 . 1 0 7 , } \\
{ \hat { \sigma } _ { I B } = 0 . 0 7 3 , }
\end{array} \quad \left\{\begin{array}{l}
\hat{\alpha}_{I C}=-0.087, \\
\hat{\sigma}_{I C}=0.089
\end{array}\right.\right.\right.
$$

In order to find the estimates of the dividend rates $\delta_{I A}, \delta_{I B}, \delta_{I C}$, I used estimates of the expected rates of return of the directly tradable assets $I A_{t}, I B_{t}$ and $I C_{t}$. Because I assumed positive correlations between $q \Delta_{t}$ and $x \Delta_{t}$ and between $q \Delta_{t}$ and the market portfolio (for $\Delta=a, b, c$ ), the required rate of return $\mu_{I \Delta}$ (for $\Delta=A, B, C$ ) must be higher than the required rate of return $\mu_{\Pi \Delta}$ (as shown in Appendix D). Thus, I used conservative estimates for the required rate of return on the directly tradable assets $I A_{t}, I B_{t}$ and $I C_{t}$ by making $\hat{\mu}_{I \Delta}$ equal to $\hat{\mu}_{\Pi \Delta}$, for $\Delta=A, B, C{ }^{61}$ The values of $\hat{\delta}_{I A}, \hat{\delta}_{I B}$ and $\hat{\delta}_{I C}$ were derived from the above considerations by making $\hat{\delta}_{I A}=\hat{\mu}_{I A}-\hat{\alpha}_{I A}, \hat{\delta}_{I B}=\hat{\mu}_{I B}-\hat{\alpha}_{I B}$ and $\hat{\delta}_{I C}=\hat{\mu}_{I C}-\hat{\alpha}_{I C}$ :

$$
\left\{\hat{\delta}_{I A}=0.081, \quad\left\{\hat{\delta}_{I B}=0.197, \quad\left\{\hat{\delta}_{I C}=0.177 .\right.\right.\right.
$$

I developed a sensitivity analysis for the correlation coefficient, $\rho_{\Pi \Delta, I \Delta}$ ( $\Delta=A, B, C)$, allowing the estimators to vary in the range from 0.0 to 1.0 :

$$
\left\{\hat{\rho}_{\Pi A, I A} \in[0.0,1.0], \quad\left\{\hat{\rho}_{\Pi B, I B} \in[0.0,1.0], \quad\left\{\hat{\rho}_{\Pi C, I C} \in[0.0,1.0]\right.\right.\right.
$$

\section{3 .3}

\section{The Poisson decay rates}

Let $\lambda_{A}, \lambda_{B}$ and $\lambda_{C}$ respectively denote the Poisson decay parameters of $\mathrm{NE}_{\mathrm{A}}$, $\mathrm{NE}_{\mathrm{B}}$ and $\mathrm{NE}_{\mathrm{C}}$, and let $T_{I O \Delta}$ and $n_{\Delta}(\Delta=A, B, C)$ respectively denote their random lifetimes and expected economic lives. The estimates of the decay rate parameters can be obtained from the estimates of economic lives, as follows:

\footnotetext{
${ }^{61}$ All other things the same, the higher $\mu_{I \Delta}$ is, the higher is $\delta_{I \Delta}$ is and the higher the option value multiple is. Therefore, as $\mu_{I \Delta}>\mu_{\Pi \Delta}, \hat{\mu}_{\Pi \Delta}$ is a conservative estimate of $\mu_{I \Delta}$.
} 


$$
E\left[T_{I O \Delta}\right]=n_{\Delta}=1 / \lambda_{\Delta}, \Delta=\mathrm{A}, \mathrm{B}, \mathrm{C}
$$

In this chapter, I used the average asset lives found in public and private reports shown in Table $7 .^{62}$

Table 7: Economic asset lives and Poisson decay rates

\begin{tabular}{|l|c|c|}
\hline Network Element & Economic Life $\left(n_{\Delta}\right)$ & Poisson Decay $\left(\lambda_{\Delta}\right)$ \\
\hline Local Access Loop & 15 & 0.067 \\
\hline $\begin{array}{l}\text { PSTN Host Switch/Duration } \\
\text { Sensitive }\end{array}$ & 8 & 0.125 \\
\hline Host-Host Transmission & 8 & 0.125 \\
\hline
\end{tabular}

\section{4}

\section{The option value multiples for three main investment decisions}

In this section, I initially take the static LRIC pricing perspective and assume that the unit contribution margin of the service provided by each network element is constant over time (i.e., $\alpha_{p a}=\alpha_{p b}=\alpha_{p c}=0$ ). This is a common assumption in most telecommunications cost studies and represents the case when the output price and the unit variable cost of the service provided by a network element are stepwise constant, and any change in the unit variable cost is offset by an identical change in the (regulated) output price. Thereafter, I examine the impact that the drift rates $\alpha_{p a}, \alpha_{p b}$, and $\alpha_{p c}$ have on the respective option value multiples.

\footnotetext{
${ }^{62}$ For an analysis of published data covering around 30 telecommunications operators, see PricewaterhouseCoopers (2001).
} 


\section{4 .1}

\section{Option value multiples under the static LRIC pricing perspective}

Table 8 shows the estimates calculated for the parameters of the stochastic processes associated with $\mathrm{NE}_{\mathrm{A}}, \mathrm{NE}_{\mathrm{B}}$ and $\mathrm{NE}_{\mathrm{C}}$ for the case when the unit contribution margin of the service provided by each network element is assumed to be constant over time (i.e., the static LRIC pricing perspective).

Table 8: Estimates calculated for the parameters of the enhanced real options model under the static LRIC pricing perspective

\begin{tabular}{|c|c|c|c|c|c|}
\hline \multicolumn{2}{|c|}{ Local Access Loop } & \multicolumn{2}{|c|}{$\begin{array}{c}\text { Host Switch/ Duration } \\
\text { Sensitive }\end{array}$} & \multicolumn{2}{|c|}{ Host-Host Transmission } \\
\hline \multicolumn{2}{|c|}{ Parameters of $\Pi A_{t}$} & \multicolumn{2}{|c|}{ Parameters of $\Pi B_{t}$} & \multicolumn{2}{|c|}{ Parameters of $\Pi C_{t}$} \\
\hline$\alpha_{\Pi A}=\alpha_{x a}$ & -0.012 & $\alpha_{\Pi B}=\alpha_{x b}$ & -0.029 & $\alpha_{\Pi C}=\alpha_{x c}$ & -0.034 \\
\hline$\sigma_{\text {ПА }}$ & 0.040 & $\sigma_{\Pi B}$ & 0.086 & $\sigma_{\Pi С}$ & 0.082 \\
\hline$\mu_{\Pi A}$ & 0.090 & $\mu_{\Pi B}$ & 0.090 & $\mu_{\Pi C}$ & 0.090 \\
\hline$\delta_{\Pi A}$ & 0.102 & $\delta_{\Pi B}$ & 0.119 & $\delta_{\Pi C}$ & 0.124 \\
\hline \multicolumn{2}{|c|}{ Parameters of $I A_{t}$} & \multicolumn{2}{|c|}{ Parameters of $I B_{t}$} & \multicolumn{2}{|c|}{ Parameters of $I C_{t}$} \\
\hline$\alpha_{I A}$ & 0.009 & $\alpha_{I B}$ & -0.107 & $\alpha_{I C}$ & -0.087 \\
\hline$\sigma_{I A}$ & 0.038 & $\sigma_{I B}$ & 0.073 & $\sigma_{I C}$ & 0.089 \\
\hline$\mu_{I A}$ & 0.090 & $\mu_{I B}$ & 0.090 & $\mu_{I C}$ & 0.090 \\
\hline$\delta_{I A}$ & 0.081 & $\delta_{I B}$ & 0.197 & $\delta_{I C}$ & 0.177 \\
\hline \multicolumn{2}{|c|}{ Poisson parameter } & \multicolumn{2}{|c|}{ Poisson parameter } & \multicolumn{2}{|c|}{ Poisson parameter } \\
\hline$\lambda_{A}$ & 0.067 & $\lambda_{B}$ & 0.125 & $\lambda_{C}$ & 0.125 \\
\hline
\end{tabular}


From equations (5.29) and (5.41) and the parameter estimates shown in Table 8, the option value multiples for the decisions to invest in $\mathrm{NE}_{\mathrm{A}}, \mathrm{NE}_{\mathrm{B}}$ and $\mathrm{NE}_{\mathrm{C}}$ can now be calculated. Table 9 shows the option value multiples, $m_{\Delta}{ }^{\prime}(\Delta=A, B, C)$, for three different values of $\rho_{\Pi \Delta, I \Delta}(0.0,0.5,1.0)$, together with the markup values for the case when the investment option is available just once (i.e., there is no replacement option) and the change in markup values due to the future replacement options.

Table 9: Option value multiples for the enhanced real options model

\section{Option value multiples for the right to invest in perpetuity}

\begin{tabular}{|l|c|c|c|l|l|l|l|l|l|l|l|}
\hline \multicolumn{2}{|l|}{ Local Access Loop } & \multicolumn{3}{l|}{$\begin{array}{l}\text { Host Switch/ Duration } \\
\text { Sensitive }\end{array}$} & \multicolumn{5}{l|}{ Host-Host Transmission } \\
\hline$\rho_{\Pi, I A}$ & 0.00 & 0.50 & 1.00 & $\rho_{\Pi B, I B}$ & 0.00 & 0.50 & 1.00 & $\rho_{\Pi C, I C}$ & 0.00 & 0.50 & 1.00 \\
\hline$m_{A}{ }^{\prime}$ & 1.05 & 1.03 & 1.00 & $m_{B}{ }^{\prime}$ & 1.41 & 1.37 & 1.32 & $m_{C}{ }^{\prime}$ & 1.33 & 1.28 & 1.24 \\
\hline
\end{tabular}

Option value multiples for the right to invest just once

\begin{tabular}{|c|c|c|c|c|c|c|c|c|c|c|c|}
\hline \multicolumn{4}{|c|}{ Local Access Loop } & \multicolumn{4}{|c|}{$\begin{array}{l}\text { Host Switch/ Duration } \\
\text { Sensitive }\end{array}$} & \multicolumn{4}{|c|}{ Host-Host Transmission } \\
\hline$\rho_{\Pi A, I A}$ & 0.00 & 0.50 & 1.00 & $\rho_{\Pi B, I B}$ & 0.00 & 0.50 & 1.00 & $\rho_{\Pi C, I C}$ & 0.00 & 0.50 & 1.00 \\
\hline$\dddot{m}_{A}$ & 1.06 & 1.03 & 1.00 & $\dddot{m}_{B}$ & 1.78 & 1.73 & 1.66 & $\dddot{m}_{C}$ & 1.59 & 1.51 & 1.47 \\
\hline \multicolumn{12}{|c|}{ Change in markup values due to future replacement options } \\
\hline \multicolumn{4}{|c|}{ Local Access Loop } & \multicolumn{4}{|c|}{$\begin{array}{l}\text { Host Switch/ Duration } \\
\text { Sensitive }\end{array}$} & \multicolumn{4}{|c|}{ Host-Host Transmission } \\
\hline$\rho_{\Pi A, I A}$ & 0.00 & 0.50 & 1.00 & $\rho_{\Pi B, I B}$ & 0.00 & 0.50 & 1.00 & $\rho_{\Pi C, I C}$ & 0.00 & 0.50 & 1.00 \\
\hline$\dddot{m}_{A}-m_{A}{ }^{\prime}$ & 0.01 & 0.00 & 0.00 & $\dddot{m}_{B}-m_{B}{ }^{\prime}$ & 0.37 & 0.36 & 0.34 & $\dddot{m}_{C}-m_{C}{ }^{\prime}$ & 0.26 & 0.23 & 0.22 \\
\hline
\end{tabular}


Table 10 shows the impact of the option value multiples on the average unitary cost of $\mathrm{NE}_{\mathrm{A}}, \mathrm{NE}_{\mathrm{B}}$ and $\mathrm{NE}_{\mathrm{C}}$, for the case when $\rho_{\Pi \Delta, I \Delta}=0.5$, using the cost and volume data shown in Appendix B.

Table 10: Impact of the markup factor on the average unitary cost of each network element for the enhanced real options model (when $\rho_{\Pi \Delta, I \Delta}=0.5$ )

\begin{tabular}{|l|l|l|c|}
\hline \multirow{2}{*}{ Network Element } & \multicolumn{2}{|l|}{ Average Cost per Unit } \\
\cline { 2 - 4 } & Before the markup & After the markup & $\begin{array}{c}\% \\
\text { increase }\end{array}$ \\
\hline Local Access Loop & $\begin{array}{l}\text { US\$ 298.48 per line } \\
\text { (per year) }\end{array}$ & $\begin{array}{l}\text { US\$ 302.83 per line } \\
\text { (per year) }\end{array}$ & $1.5 \%$ \\
\hline $\begin{array}{l}\text { PSTN-Host Switch/ } \\
\text { Duration Sensitive }\end{array}$ & $\begin{array}{l}\text { US\$ 0.0035 } \\
\text { per minute }\end{array}$ & $\begin{array}{l}\text { US\$ 0.0041 } \\
\text { per minute }\end{array}$ & $17.8 \%$ \\
\hline $\begin{array}{l}\text { Host-Host } \\
\text { Transmission }\end{array}$ & $\begin{array}{l}\text { US\$ 0.0165 } \\
\text { per minute }\end{array}$ & $\begin{array}{l}\text { US\$ 0.0182 } \\
\text { per minute }\end{array}$ & $10.4 \%$ \\
\hline
\end{tabular}

Figure 8 shows how each option value multiple, $m_{\Delta}{ }^{\prime}(\Delta=A, B, C)$, changes as a function of the correlation coefficient between $\Pi \Delta_{t}$ and $I \Delta_{t}$. It can be seen that (for $\left.\rho_{\Pi \Delta, I \Delta} \in[0.0,1.0]\right)$ :

- For the investment decision in $\mathrm{NE}_{\mathrm{A}}$ (Local Access Loop): $m_{A}{ }^{\prime} \in[1.00,1.05]$.

- For the investment decision in $\mathrm{NE}_{\mathrm{B}}$ (PSTN Host Switch/Duration Sensitive): $m_{B}{ }^{\prime} \in[1.32,1.41]$.

- For the investment decision in $\mathrm{NE}_{\mathrm{C}}$ (Host-Host Transmission): $m_{C}{ }^{\prime} \in[1.24,1.33]$. 

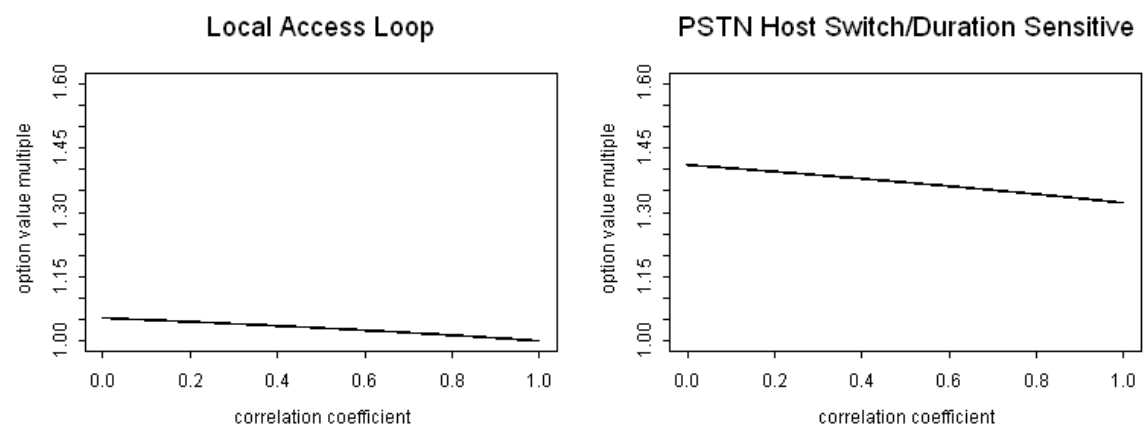

Host-Host Transmission

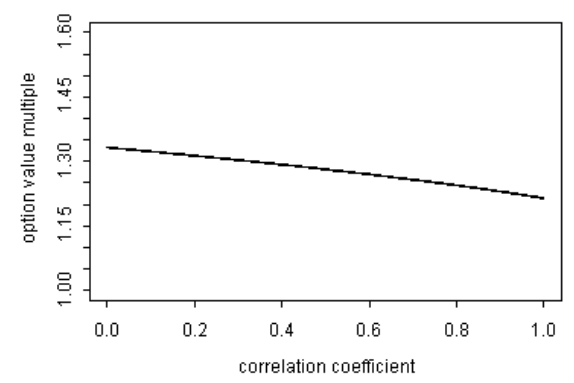

Figure 8: Option value multiple as a function of the correlation coefficient $\rho_{\Pi \Delta, I \Delta}$ (enhanced real options model)

Figure 9 shows how each option value multiple, $m_{\Delta}{ }^{\prime}(\Delta=A, B, C)$, changes as a function of the volatility parameter of $\Pi \Delta_{t}$ and $I \Delta_{t}$ (for the case when $\left.\rho_{\Pi \Delta, I \Delta}=0.5\right)$, where each volatility parameter varies in the range from half of the estimated value to two times the estimated value. 


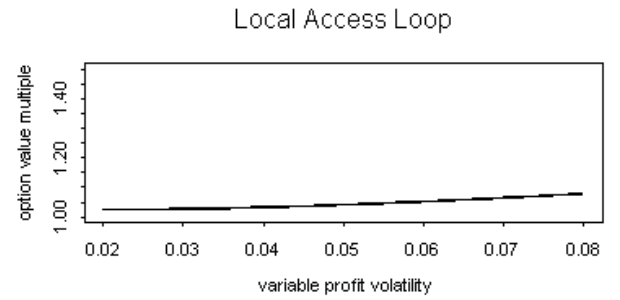

PSTN Host SimitchiDuration Sensitive

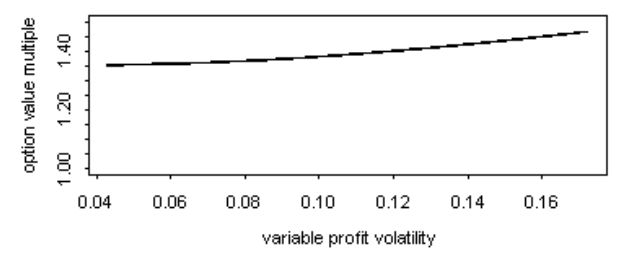

Host-Host Transmission

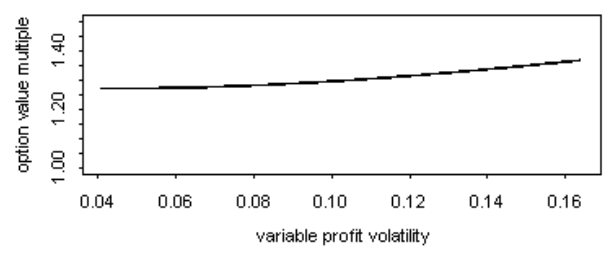

Local Access Loop

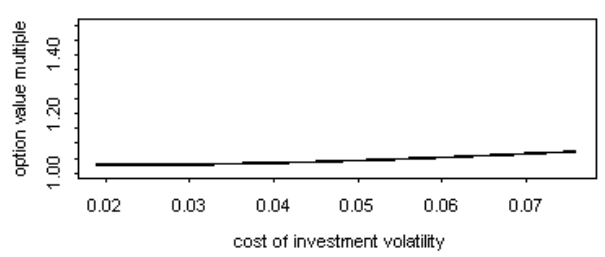

PSTN Host SwitchiDuration Sensitive

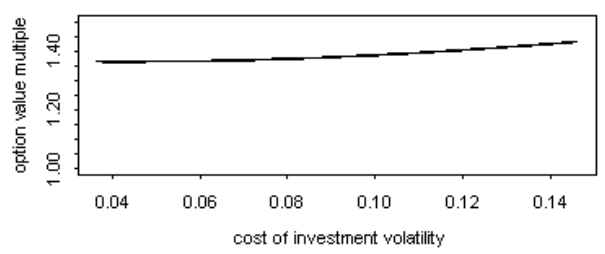

Host-Host Transmission

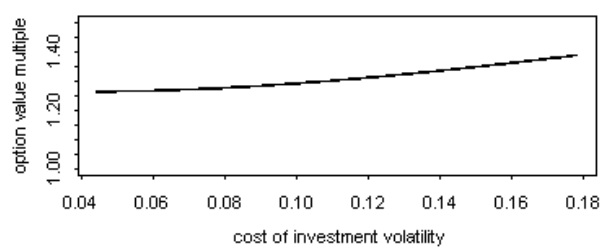

Figure 9: Option value multiple as a function of the volatility parameters (enhanced real options model)

Figures 10 and 11 show how each option value multiple, $m_{\Delta}{ }^{\prime}(\Delta=A, B, C)$, changes as a function of the variable profit drift rate, $\alpha_{\Pi \Delta}$ (which is equal to the demand drift rate if the unit contribution margin is constant), and the investment cost drift rate, $\alpha_{I \Delta}$, all other things held constant (for the case when $\rho_{\Pi \Delta, I \Delta}=0.5$ ). 


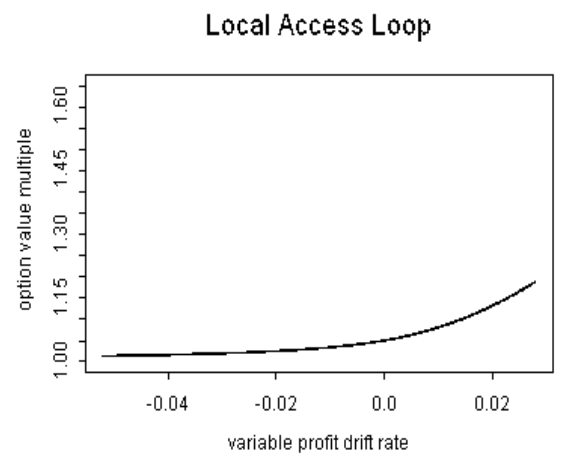

PSTN Host Switch/Duration Sensitive

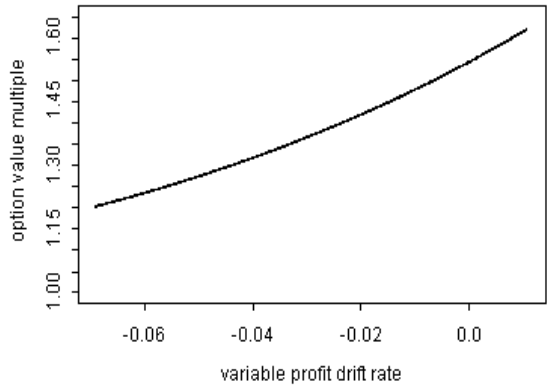

Host-Host Transmission

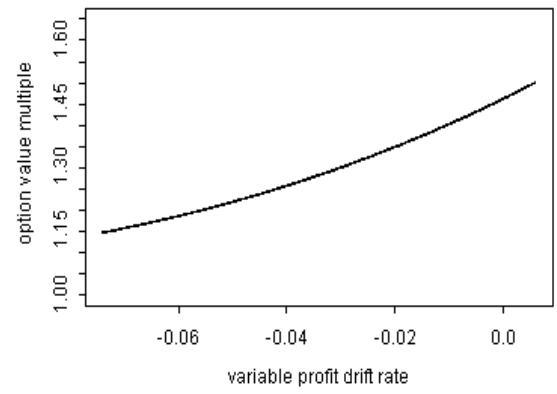

Figure 10: Option value multiple as a function of the variable profit drift rate (enhanced real options model)

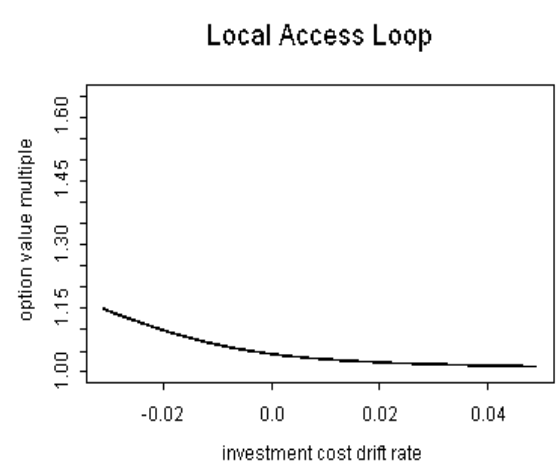

PSTN Host Switch/Duration Sensitive

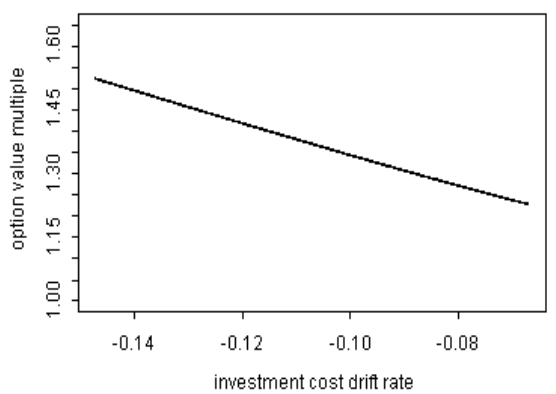

Host-Host Transmission

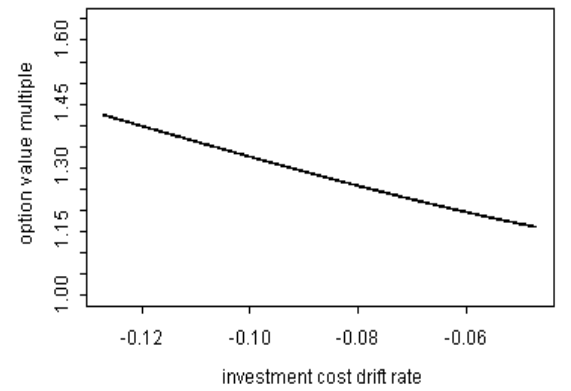

Figure 11: Option value multiple as a function of the investment cost drift rate (enhanced real options model) 
Figure 12 shows how each option value multiple, $m_{\Delta}{ }^{\prime}(\Delta=A, B, C)$, changes as a function of the average economic asset life, $n_{\Delta}$, all other things held constant (for the case when $\rho_{\Pi \Delta, I \Delta}=0.5$ ).
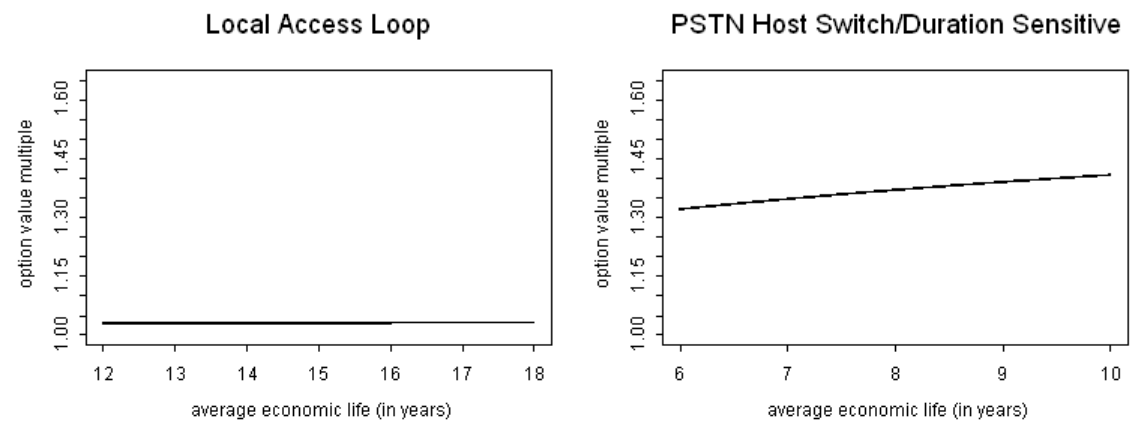

Host-Host Transmission

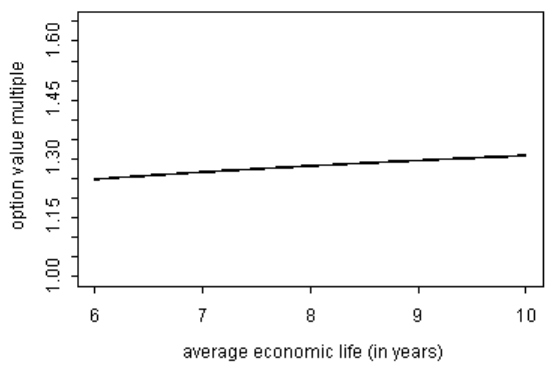

Figure 12: Option value multiple as a function of the average economic asset life (enhanced real options model)

It should be noted that:

- The option value multiple for the decision to invest in $\mathrm{NE}_{\mathrm{A}}$ is much lower than the option value multiples for the decisions to invest in $\mathrm{NE}_{\mathrm{B}}$ and $\mathrm{NE}_{\mathrm{C}}$. This can be explained by a combination of factors: (a) the demand and technological uncertainties associated with local access loop are much lower than the uncertainties associated with switching and transmission equipment; the lower the volatilities $\left(\sigma_{\Pi A}\right.$ and $\left.\sigma_{I A}\right)$ are, the lower the option value multiple is; (b) the drift rate of $I A_{t}$ is much higher than the drift rates of $I B_{t}$ and $I C_{t}$ (due to increasing labor costs); the higher the drift rate of $I A_{t}$ is, the lower $m_{A}{ }^{\prime}$ is. These two factors combined reduce the option value multiple for the decision to invest in local access loop. 
- As anticipated in section 5.2.4, for all network elements (i.e., for $\Delta=A, B, C)$ : the higher the correlation coefficient $\rho_{\Pi \Delta, I \Delta}$ is, the lower the option value multiple is; the higher the volatility parameter of either $\Pi \Delta_{t}$ or $I \Delta_{t}$ is, the higher the option value multiple is; the higher $\alpha_{\Pi \Delta}$ is, the higher the option value multiple is; the higher $\alpha_{I \Delta}$ is, the lower the option value multiple is; the higher $n_{\Delta}$ is (i.e., the lower the depreciation is), the higher the option value multiple is.

- While the change in markup value due to future replacement options of $\mathrm{NE}_{\mathrm{A}}$ is close to zero, the change in markup values due to future replacement options of $\mathrm{NE}_{\mathrm{B}}$ and $\mathrm{NE}_{\mathrm{C}}$ are quite significant. That can be explained by a combination of factors. First, note that the difference between $m_{A}$ and $m_{A}{ }^{\prime}$ is due to the introduction of the parameter $\lambda_{A}$ in the equation for $\beta_{1 A}{ }^{\prime}$. Then note that: (a) the higher the drift rate of $I A_{t}$ is, the higher $\beta_{1 A}{ }^{\prime}$ is; (b) the lower the drift rate of $\Pi A_{t}$ is, the higher $\beta_{1 A}{ }^{\prime}$ is. These two factors jointly increase $\beta_{1 A}{ }^{\prime}$ and make $\lambda_{A}$ less significant when compared to the other terms in equation (5.29), what makes the values of $m_{A}$ and $m_{A}{ }^{\prime}$ become closer to each other.

- The impact of future replacement options on the investment decisions on $\mathrm{NE}_{\mathrm{B}}$ and $\mathrm{NE}_{\mathrm{C}}$ are high, partly due to the demand and technological uncertainties associated with switching and transmission equipment, and partly due to the negative drift rate of the cost of investment in the respective modern equivalent assets. Telecommunications is an industry that undergoes changes with increasing rapidity, so that the depreciation rates of switching and transmission equipment will keep increasing in the next following years. An increase in the depreciation rate will cause a decrease in the option value multiple, but it will also make the value of future replacement options proportionally more relevant.

- The positive correlation between the flow of total variable profit and the cost of new investment makes the option value multiple less sensitive to 
changes in the volatility parameters. The lower the correlation coefficient is, the more sensitive the option value multiple is to changes in the volatility parameter.

- The option value multiples calculated for the enhanced real options model, $m_{\Delta}{ }^{\prime}(\Delta=A, B, C)$, are higher than the option value multiples calculated for the base model, $m_{\Delta}$ (compare Tables 5 and 10). This is due to the fact that $I \Delta_{t}(\Delta=A, B, C)$ are now uncertain and have lower drift rates (as they allow for the resizing of network capacity as equipment elements are replaced).

\section{4 .2}

\section{Option value multiples under the dynamic LRIC pricing perspective}

So far, it has been assumed that the unit contribution margin of $\mathrm{NE}_{\mathrm{i}}$ 's hypothetical network service is constant over time, an assumption made in most telecommunications cost studies. However, LRIC prices are calculated from period to period considering the most efficient technology is employed, and this, in turn, often causes LRIC prices and unit contribution margins to fall. The prices of electronics intensive products (e.g., switching and transmission equipment), have declined rapidly in the past few years. On the other hand, local loop costs, which are highly labor intensive, have been constant or even increased over time.

Krouse (2000) shows that the time path of LRIC prices depends on the effect of expected technical advance on investment and unit costs, and proposes an investment compatible LRIC pricing rule that ensures quasi-rents on earlier investments are not systematically expropriated. In particular, he shows that if technical advance takes place in a way that produces the same (constant) proportional decrease in invested capital and operating costs (per unit of output), then the period to period rate of change in the investment compatible LRIC price is exactly equal to the rate of technical advance.

In this thesis, I do not address the issues of dynamically competitive LRIC prices and investment compatible LRIC pricing rule. I show, however, how sensitive is the option value multiple to the drift rate of the unit contribution 
margin and the importance of carefully estimating the impact of technical advances on the prices of capital assets and unit operating costs. Figure 13 shows how each option value multiple, $m_{\Delta}^{\prime}(\Delta=A, B, C)$, changes as a function of the unit contribution margin drift rate, $\alpha_{p \Delta}(\Delta=a, b, c)$, for the case when $\rho_{\Pi \Delta, I \Delta}=0.5$ $(\Delta=A, B, C)$, where $\alpha_{p \Delta}$ vary in the range from zero (used in the static model for LRIC pricing) to the drift rate that makes $\alpha_{\Pi \Delta}=\alpha_{I \Delta}, \Delta=A, B, C .{ }^{63}$
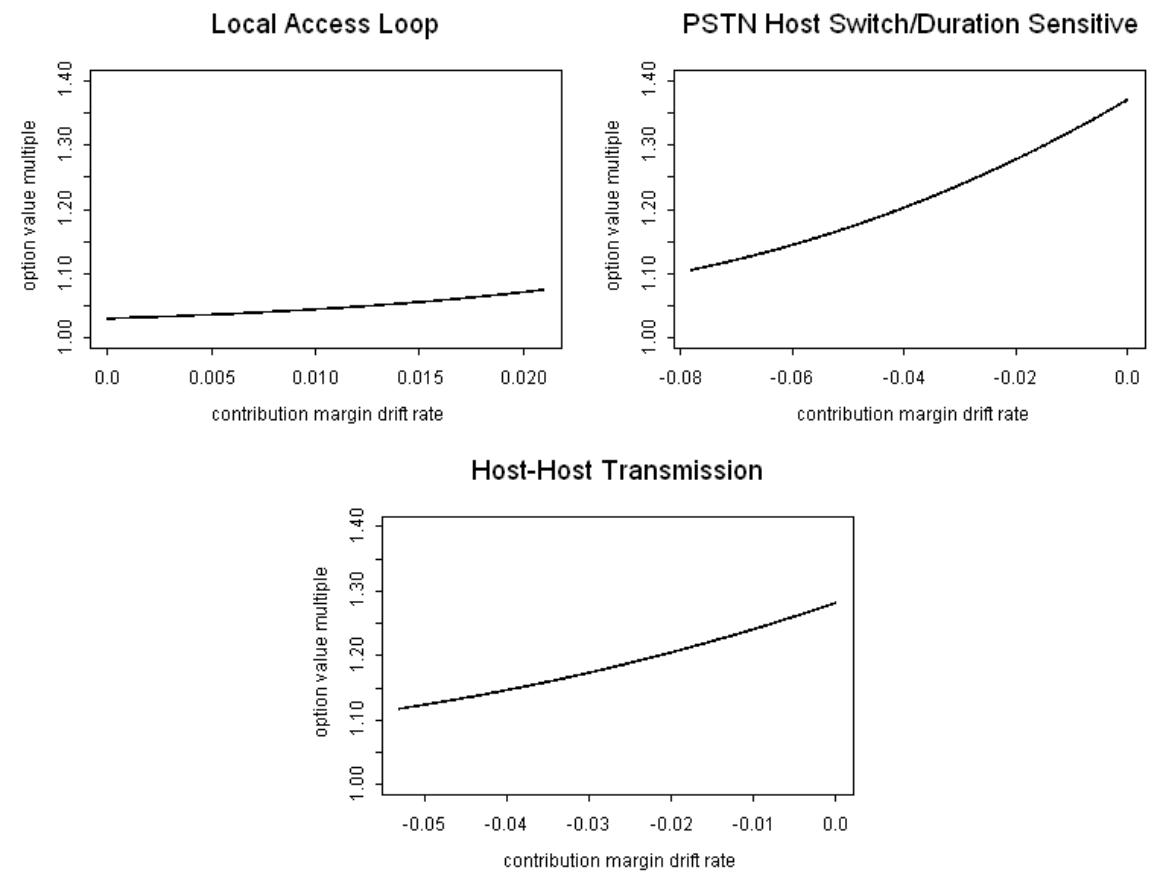

Figure 13: Option value multiple as a function of the unit contribution margin drift rate (enhanced real options model)

It should be noted that the option value multiple is highly sensitive to the unit contribution margin drift rate. In particular, if one takes the static LRIC pricing perspective and assumes that $\alpha_{p \Delta}$ is zero (for $\rho_{\Pi \Delta, I \Delta}=0.5$ ), the option value multiples are $m_{A}{ }^{\prime}=1.03, m_{B}{ }^{\prime}=1.37$ and $m_{C}{ }^{\prime}=1.28$ (as shown in Table 9), while

\footnotetext{
${ }^{63}$ Remember that $\Pi_{t}=p_{t} x_{t}$ (where $p_{t}$ is the unit contribution margin of $\mathrm{NE}_{\mathrm{i}}$ 's hypothetical network service and $x_{t}$ is the demand for the service provided by $\mathrm{NE}_{\mathrm{i}}$ ) and $I_{t}=q_{t} x_{t}$ (where $q_{t}$ is the stochastic price per unit of capacity). Therefore: $d \Pi=\left(\alpha_{x}+\alpha_{p}\right) \Pi d t+\sigma_{x} d z_{\Pi}$, and $d I=\left(\alpha_{x}+\alpha_{q}+\sigma_{q} \sigma_{x} \rho_{q, x}\right) I d t+\left(\sigma_{x} d z_{x}+\sigma_{q} d z_{q}\right) I$. The LRIC pricing rule that makes $\alpha_{\Pi}=\alpha_{I}$ is such that $\alpha_{p}=\alpha_{q}+\sigma_{q} \sigma_{x} \rho_{q, x}$.
} 
if one considers that LRIC prices decline over time and take the LRIC pricing rule that makes $\alpha_{\Pi \Delta}=\alpha_{І \Delta}, \Delta=A, B, C$, the option value multiples are $m_{A}{ }^{\prime}=1.07$, $m_{B}{ }^{\prime}=1.11$ and $m_{C}{ }^{\prime}=1.12$. 


\section{6 \\ Interest rate uncertainty and the Brazilian inflation coupon curve}

\section{1}

\section{Introduction}

So far a constant risk-free interest rate has been assumed to derive the stochastic differential equations that the real option values must satisfy. The basic motivation is that interest rates are typically more stable (and consequently less significant) than revenue and investment cost dynamics. However, it is known from empirical research that interest rates fluctuate a lot over time, so that interest rate uncertainty can create real options that have a significant effect on investment decisions.

The current extensive literature on irreversible investment decisions usually makes the assumption of constant risk-free interest rate. According to Hull (1997), the constant risk-free interest rate assumption may not be satisfactory in the case of a steeply upward or downward sloping yield curve, in which case it may be more appropriate to assume that the interest rate for future interval $\Delta t$ equals the current forward rate for that period. Ingersoll \& Ross (1992) shows that the interest rate uncertainty creates value to the option to defer an investment decision even for the simplest projects with deterministic cash flows. Alvarez \& Koskela (2002) builds on Ingersoll \& Ross (1992) and shows that, for irreversible investments, interest rate variability can be important from the standpoint of exercising real investment opportunities. Other authors such as Sandmann (1993), Ho, Stapleton \& Subrahmanyam (1997), Miltersen (2000) and Schulmerich (2010) discuss stochastic interest rate modeling in real options valuation. Schulmerich (2010) focuses on numerical real options pricing with interest rate uncertainty and provides in-depth insight into how a stochastically modeled interest rate influences the real options value in various cases common in practice. The approach in Schulmerich (2010) is different from that proposed by Hull 
(1997), since the former author models the complete term structure of interest rates (not just the short rate) via stochastic term structure models.

In this chapter, I investigate the interest rate uncertainty in Brazil for different maturities/terms and propose a method for constructing the term structure of the risk-free real interest rate (i.e., the risk-free nominal interest rate minus inflation), here called the Brazilian inflation coupon curve or the IPCA coupon curve ${ }^{64}$. To estimate the term structure parameters, I followed the procedure described in Franklin Jr. et al. (2012) and used a combination of traditional nonlinear optimization algorithm (the quasi-Newton method) and a genetic algorithm specifically developed for that purpose. The use of the genetic algorithm reduces the risk of false convergence ${ }^{65}$ and generates more stable time series for the model parameters. I propose the use of the Svensson model (Svensson, 1994) for interpolation and extrapolation of the IRTS (within a determined range of maturity periods) and the use of genetic algorithms in complement to a traditional nonlinear optimization algorithm for estimation of the model parameters.

The rest of this chapter is organized as follows. The next section describes the term structure of the risk-free real interest rate. Section 6.3 explains the choice of the database used to construct the Brazilian inflation coupon curve. Section 6.4 shows the term structure models proposed by Nelson \& Siegel (1987) and Svensson (1994). Section 6.5 describes the nonlinear optimization methods used to estimate the parameters of the Brazilian inflation coupon curve. Section 6.6 compares the results obtained with each estimation method.

\section{2}

\section{The term structure of interest rates}

The interest rate term structure (IRTS) is a central concept of financial and economic theory, used to price any set of cash flows (Fabozzi, 2006; Ray, 1992; Allen \& Kleinstein, 1991). It is represented by a set of points in the interest rate versus term space where each point $(t, r(t))$ corresponds to an interest rate $r(t)$,

\footnotetext{
${ }^{64}$ IPCA is the acronym for the Brazilian consumer price index: Índice Nacional de Preços ao Consumidor Amplo (in Portuguese).

${ }^{65}$ The risk that the optimization algorithm reaches a local minimum (quadratic error) rather than a global minimum.
} 
associated with a term (or maturity) $t$, with the rate obtained based on some security traded in a market (normally, a fixed-income security or interest rate derivative).

The spot interest rate associated with a given maturity $\tau$ can be interpreted as the return of a zero-coupon bond with maturity at $\tau$. The forward rates are the interest rates implied by the spot rates for future periods. The relation between the two can be illustrated by the equations below (the first used for rates compounded yearly and the second for continuous compounding):

$$
\begin{aligned}
& \left(1+R_{t, t+T}^{t}\right)^{T}=\prod_{k=0}^{T-1}\left(1+F R_{k}^{t}(1)\right), \text { and } \\
& e^{T y_{t}(T)}=e^{\sum_{k=0}^{T-1} F R c_{k}^{t}(1)},
\end{aligned}
$$

where

- $R_{t, t+T}^{t}$ is the annual spot rate compounded annually at $t$ for the period between $t$ and $t+T$,

- $y_{t}(T)$ is the annual spot rate compounded continuously (c.c.) at $t$ for maturity $T$,

- $F R_{k}^{t}(1)$ is the annual forward rate at $t$ for the period between years $t+k$ and $t+k+1$,

- $\quad F R c_{k}^{t}(1)$ is the annual forward rate c.c. at $t$ for the period between years $t+k$ and $t+k+1$

- $\quad T \in \mathrm{N}$ is the maturity (measured in years),

- $t \quad$ is the date of measuring the IRTS (i.e., the trading date).

The continuous-time interest rate can be converted into a discrete-time rate by applying the equations

$$
y_{t}(T)=\ln \left(1+R_{t, t+T}^{t}\right), \text { and }
$$




$$
F R c_{k}^{t}(1)=\ln \left\{1+F R_{k}^{t}(1)\right\}
$$

The IRTS can be described as a discount curve $P_{t}(\tau)$, a forward rate curve $f_{t}(\tau)$ or a spot rate curve $y_{t}(\tau)$. The equations below show how the discount, forward and spot rate functions, in continuous time, are interrelated, so that obtaining one of them leads to all the others: ${ }^{66}$

$$
\begin{aligned}
& P_{t}(\tau)=\exp \left\{-\tau y_{t}(\tau)\right\}=\exp \left\{-\int_{0}^{\tau} f_{t}(u) d u\right\}, \\
& f_{t}(\tau)=-\frac{1}{P_{t}(\tau)} P^{\prime}(\tau)=y_{t}(\tau)+\tau y_{t}^{\prime}(\tau), \text { and } \\
& y_{t}(\tau)=\frac{1}{\tau} \int_{0}^{\tau} f_{t}(u) d u=-\frac{1}{\tau} \ln P_{t}(\tau),
\end{aligned}
$$

where

- $P_{t}(\tau)$ is the present value at instant $t$ of US\$ 1 receivable at $t+\tau$,

- $f_{t}(\tau)$ is the forward rate (instantaneous) at $t$ for term $\tau$,

- $y_{t}(\tau)$ is the spot rate (continuously compounded) at $t$ for term $\tau$.

The risk-free IRTS, also called the base curve, must be constructed from market data concerning bonds considered to be free of credit and liquidity risks. ${ }^{67}$ Over time, the base curve can fluctuate in different ways, as a result of different shocks on the interest rates associated with each maturity period. It is the variability of the IRTS over the time that makes fixed-income instruments subject to market risk. $^{68}$

\footnotetext{
${ }^{66}$ Although the most common practice is to use discrete rates, the algebra involved in the mathematical equations is easier when working with instantaneous rates compounded continuously.

${ }^{67}$ Fixed-income instruments in general subject their holders to three types of risk: market risk, credit risk and liquidity risk.

${ }^{68}$ In this context, the market risk only applies to the investments that have holding horizons different than the maturities of the bonds acquired.
} 


\section{3}

\section{Database for the IPCA coupon curve}

The choice of the database to construct the risk-free IRTS necessarily entails choosing the financial market instruments considered to be free of credit and liquidity risk. For this the international literature suggests the use of the market quotations of government bonds, which theoretically have the lowest credit risk because of governments' ability to levy taxes and/or issue money to pay their debts. In the Brazilian market, characterized by a scarcity of pre-fixed bonds and low liquidity of the secondary market, a better representation of the risk-free IRTS in local currency (reais) can be constructed based on the implicit rates of derivative financial instruments.

In moments of economic instability, the estimated yield curves constructed based on federal bonds and those estimated based on derivatives can differ. ${ }^{69}$ Nevertheless, in periods of economic stability, the two curves practically coincide (Fraletti, 2004). With an increased number of trades (and liquidity) in the secondary market for federal bonds, which has been occurring in recent years, the two curves tend to become equal.

The period studied runs from September 2003 to December 2010. In choosing the most appropriate database, consideration was given to the risk-free financial instrument with highest market liquidity, the number of vertices provided by each instrument and the maturity of the last liquid point of each curve. ${ }^{70}$ The database for the IPCA coupon curve is formed by the unit prices of National Treasury Notes - Series B (NTN-B), calculated by the Brazilian Association of Financial and Capital Market Entities (Anbima), according to its own method, ${ }^{71}$ considering not only the trades between market participants, but also data sent directly by a

\footnotetext{
${ }^{69}$ An investment directly in federal bonds requires committing liquid resources until the maturity date, while an investment in derivatives only involves contracting rates, without intertemporal exchange of cash flow, and presents lower liquidity risk (associated with the investor's uncertainty regarding the need for liquid resources over time).

${ }^{70}$ Differences in taxation on capital gains and interest income or in bonds with different maturity periods were not considered. These tax differences are difficult to isolate from the sample and do not have a significant impact on the estimated IRTS.

71 Details of Anbima's method can be found at http://www.andima.com.br/comites/arqs/com_anexo_6.pdf.
} 
selected sample of market informants/participants. ${ }^{72}$

NTN-Bs are post-fixed bonds whose nominal value is updated monthly based on the variation in prices reflected by the IPCA. These bonds pay coupon interest twice a year and the principal is repaid on the maturity date. The effective annual yield of these bonds is based on 252 business days per year. From this rate, the price (observed) of each bond at time $t$ is calculated according to the following relation: ${ }^{73}$

$$
P_{N T N-B, i}=\sum_{j=1}^{k_{i}} \frac{1}{\left(1+R_{t, t+\tau_{j, i}}^{t}\right)^{\tau_{j, i} / 252}} F_{j, i},
$$

where

- $P_{N T N-B, i}$ is the observed (calculated) price of the NTN-B with index $i$,

- $k_{i} \quad$ is the number of payments of this NTN-B (coupon and principal),

- $F_{j, i} \quad$ is the $j$-th payment of this NTN-B,

- $\tau_{j, i} \quad$ is the term (in business days) of the $j$-th payment of this NTN-B,

- $R_{t, t+\tau_{j, i}}^{t}$ is the effective annual yield, based on 252 business days, at $t$ for the period between $t$ and $t+\tau_{j, i}$.

\section{4}

\section{Models to estimate the interest rate term structure}

The IRTS is not directly observable in practice, so it needs to be estimated based on market quotations of bonds or derivatives, available for a finite number of maturities (i.e., the observed data points of the curve). From this discrete set of

\footnotetext{
${ }^{72}$ These data are first submitted to a series of filters, formulated by Anbima, to eliminate errors and distortions (errors of data input, format of the rate, time of generation and/or attempts to manipulate rates). The market data are from the last trading day of each month.

${ }^{73}$ This equation can be deduced by applying the discount function (equation (6.5)) converted to the discrete form (equation (6.3)) for the bond's cash flow.
} 
points, a continuous curve/function can be constructed that approximately fits the observed data, using interpolation techniques, from which the value of the curve/function at points outside the known zone can be estimated by extrapolation techniques.

The most common procedure to estimate the term structure is first to impose a functional form with $K$ parameters for the discount function $P_{t}(\tau)$, the spot rate $y_{t}(\tau)$ or the forward rate $f_{t}(\tau)$. The functional forms can be polynomial (Chambers et al., 1984), spline (McCulloch, 1975; Litzenberger \& Rolfo, 1984; Fisher et al., 1995), exponential (Nelson \& Siegel, 1987; Svensson, 1994 ${ }^{74}$ ), or a combination of these or other functions (Smith \& Wilson, 2001; Barrie \& Hibbert, $2008^{75}$ ). Next, the $K$ parameters are estimated (by minimizing the sum of the squares of the difference between the curve's estimated and observed data points) or determined (by assembling a system of $K$ equations to calculate the $K$ parameters).

The most prominent methods, used by many central banks, are those proposed by Nelson \& Siegel (1987) and Svensson (1994).

\subsection{1}

\section{The model proposed by Nelson \& Siegel (1987)}

The model of Nelson \& Siegel establishes a functional form with four parameters that seeks to approximate the term structure curve by a sum of exponential functions. It is a parametrically parsimonious model that generates term structures with shapes very near those observed in the market (curves that are monotonically increasing, decreasing or humped).

The forward rates $f_{t}(\tau)$ of this model are given by the equation

\footnotetext{
${ }^{74}$ Svensson imposes a parametric form with six parameters while Nelson-Siegel imposes one with four parameters.

${ }^{75}$ Smith-Wilson uses the sum of an exponential term for the long-run asymptotic behavior of the discount function and a linear combination of $\mathrm{N}$ kernel functions (where $\mathrm{N}$ is the number of data points observed in the liquid part of the yield curve); Barrie-Hibbert uses cubic splines for the liquid part of the curve and Nelson-Siegel for the extrapolated part.
} 


$$
f_{t}(\tau)=\beta_{0, t}+\beta_{1, t} e^{-\lambda_{t} \tau}+\beta_{2, t} \lambda_{t} \tau e^{-\lambda_{t} \tau}
$$

The spot rates $y_{t}(\tau)$ can be calculated from equations (6.7) and (6.9):

$$
y_{t}(\tau)=\beta_{0, t}+\beta_{1, t}\left(\frac{1-e^{-\lambda_{t} \tau}}{\lambda_{t} \tau}\right)+\beta_{2, t}\left(\frac{1-e^{-\lambda_{t} \tau}}{\lambda_{t} \tau}-e^{-\lambda_{t} \tau}\right) .
$$

The parameter $\lambda_{t}$ measures the pace of decay of the IRTS: small values of $\lambda_{t}$ produce smoother (more gradual) decay and for this reason a better fit for longer term structure periods, while large values of $\lambda_{t}$ produce faster decay and a better fit for shorter periods. The parameter $\lambda_{t}$ also determines the period when the loading at $\beta_{2, t}$ reaches the maximum value.

The parameters $\beta_{0, t}, \beta_{1, t}, \beta_{2, t}$ can be interpreted as short-, medium- and longterm latent dynamic factors, respectively, of the term structure, and the terms that multiply these factors are called the factor loadings:

- The loading that multiplies the parameter $\beta_{0, t}$ is equal to one, a constant, and does not decay to zero as the maturity period increases, so that $\beta_{0, t}$ can be seen as a long-term factor.

- The loading that multiplies the parameter $\beta_{1, t}$ is given by a function that starts at one and decays rapidly and monotonically to zero with increasing maturity period, so that $\beta_{1, t}$ can be seen as a short-term factor: if $\beta_{1, t}<0$, the curve is increasing in the short run while if $\beta_{1, t}>0$ the curve is decreasing.

- The loading that multiplies the parameter $\beta_{2, t}$ is given by a function that starts at zero (and hence is not short-term), assumes positive values in the medium term and decays to zero when the maturity tends to infinity (and hence is not long-term), so $\beta_{2, t}$ can be seen as a medium-term factor: if $\beta_{2, t}<0$, the curve has a downward hump (U shape), while if $\beta_{2, t}>0$, has an upward hump (inverted U shape). 
Figure 14 illustrates the factor loadings and permits observing that with an appropriate choice of the model parameters, one can generate a variety of yield curves with monotonic and arched shapes. The three parameters $\beta_{0, t}, \beta_{1, t}, \beta_{2, t}$ can be interpreted as the level, slope and curvature, respectively (Diebold \& Li, 2006).

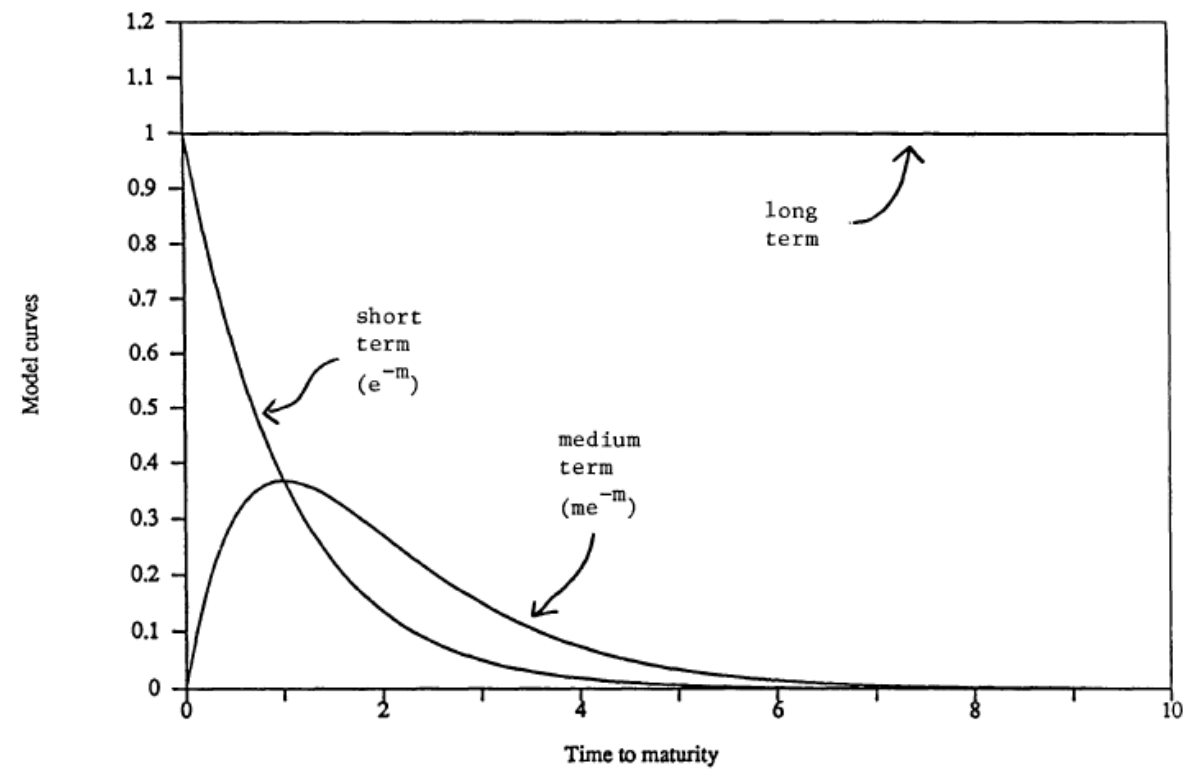

Figure 14: Components of the yield curve (Nelson \& Siegel, 1987)

The short- and long-term spot rates can be obtained by taking the limit of equation (6.10) when the period tends to zero or infinity, respectively: $\lim _{\tau \rightarrow 0} y_{t}(\tau)=\beta_{0, t}+\beta_{1, t}$ and $\lim _{\tau \rightarrow \infty} y_{t}(\tau)=\beta_{0, t}$. The way the transition between the short- and long-term rates occurs is determined by the parameters $\beta_{2, t}$ and $\lambda_{t}$.

For the function $y_{t}(\tau)$ to make economic sense, the parameters of the NelsonSiegel model must also satisfy the following constraints: $\lambda_{t}>0 ; \beta_{0, t}>0$; $\beta_{0, t}+\beta_{1, t}>0 .^{76}$

\section{4 .2}

\section{The model proposed by Svensson (1994)}

The model proposed by Svensson extends that of Nelson \& Siegel with the

\footnotetext{
${ }^{76}$ The nominal interest rates in the economy are necessarily positive, and during a period of economic stability, such as that studied here, the inflation coupon rates should also be positive.
} 
addition of a new exponential term to the yield curve, containing two additional parameters $\left(\beta_{3, t}\right.$ and $\left.\lambda_{2, t} ; \lambda_{2, t}>0\right)$, allowing a second hump in the curve: ${ }^{77}$

$$
f_{t}(\tau)=\beta_{0, t}+\beta_{1, t} e^{-\lambda_{1, t} \tau}+\beta_{2, t} \lambda_{1, t} \tau e^{-\lambda_{1, t} \tau}+\beta_{3, t} \lambda_{2, t} \tau e^{-\lambda_{2, t} \tau}
$$

The spot rates $y_{t}(\tau)$ can be calculated from equations (6.7) and (6.11):

$$
y_{t}(\tau)=\beta_{0, t}+\beta_{1, t}\left(\frac{1-e^{-\lambda_{1, t} \tau}}{\lambda_{1, t} \tau}\right)+\beta_{2, t}\left(\frac{1-e^{-\lambda_{1, t} \tau}}{\lambda_{1, t} \tau}-e^{-\lambda_{1, t} \tau}\right)+\beta_{3, t}\left(\frac{1-e^{-\lambda_{2, t} \tau}}{\lambda_{2, t} \tau}-e^{-\lambda_{2, t} \tau}\right) .
$$

Here the term structure factors have an interpretation for level (or long term), $\beta_{0, t}$, slope (or short term), $\beta_{1, t}$, and curvatures (or medium terms), $\beta_{2, t}$ and $\beta_{3, t}$. The parameters $\lambda_{1, t}$ and $\lambda_{2, t}$ characterize the decay velocities of the medium-term components of the curve, determining where the loadings that multiply the factors $\beta_{2, t}$ and $\beta_{3, t}$ reach their maximum values. Svensson's model is identical to that of Nelson \& Siegel when $\beta_{3, t}=0$ or $\lambda_{1, t}=\lambda_{2, t}$.

Taking the limit of the above equation: $\lim _{\tau \rightarrow 0} y_{t}(\tau)=\beta_{0, t}+\beta_{1, t}$ (short term) and $\lim _{\tau \rightarrow \infty} y_{t}(\tau)=\beta_{0, t}$ (long term). ${ }^{78}$ The parameters $\lambda_{1, t}$ and $\lambda_{2, t}$, associated with the exponential functions, capture the speed of the transition between the short- and long-term rates and the distortions (humps) in the curve.

For the function $y_{t}(\tau)$ to make economic sense, the parameters of Svensson's model must satisfy the following constraints:

$$
\lambda_{1, t}>0, \lambda_{2, t}>0, \beta_{0, t}>0, \text { and } \beta_{0, t}+\beta_{1, t}>0
$$

Svensson's model proposes a simple functional form to describe the entire interest rate term structure, with only six parameters. The equation's format permits a smooth and flexible structure that accommodates various IRTS shapes observed in practice (Anbima, 2010). For this reason, this model is widely used to interpolate yield curves, and it can also be used to extrapolate from these curves

\footnotetext{
${ }^{77}$ For this reason, in situations where the curve has a more complex form, Svensson's model can be significantly better than the Nelson-Siegel model.

${ }^{78}$ This result also holds for the Nelson-Siegel model.
} 
within a certain range of maturities beyond the last vertex available in the database. ${ }^{79}$

\section{5}

\section{Estimation of the term structure parameters}

The first step to estimate the model parameters is to define whether the object of the estimation is the price of the bond or its spot or forward interest rate. The price of financial instruments with short maturities is less sensitive to interest rate variations than is the price of those with long maturities: small changes in the price of short-term instruments mean large variations in the effective interest rate (return), the contrary of what happens with long-term instruments. So, the procedure for minimizing the sum of the squared errors of the spot rates has a heteroscedastic effect on the errors of the bond prices (high errors for the prices of bonds with long maturities), while the procedure for minimizing the sum of the squared errors of the bond prices has a heteroscedastic effect on the errors of the spot rates (high errors for the short-term spot rates). A way to correct the problem of heteroscedasticity in the spot rates is to weight the quadratic error of the price of each bond by the inverse of the Macaulay duration, giving more relevance to the errors of short-term bonds.

Depending on the object of estimation, the residuals/errors in the prices and interest rates can be homoscedastic or heteroscedastic: if the object is the price, the residuals will be homoscedastic in the prices and heteroscedastic in the rates; if the object is the spot rate, the residuals will be homoscedastic in the rates and heteroscedastic in the prices. ${ }^{80}$

(i) If the object of estimation is the bond's price, the discount function $P_{t}(\tau)$ is estimated for each trading day so as to minimize the sum of the squared errors of the prices (estimated and observed) of a set of risk-free federal bonds. In other words, for a determined set of parameters (initial solution),

\footnotetext{
${ }^{79}$ The database used for the IPCA coupon curve, for example, contains bonds with maturities of up to 40 years.

${ }^{80}$ In general, the desired result is for the IRTS to be homoscedastic in spot rates.
} 
the discount function is used to calculate the estimated price of each bond, according to equation (6.5), and an optimization algorithm is executed for the purpose of minimizing the sum of the squared errors between the estimated and observed prices for each bond.

(ii) If the object of estimation is the interest rate, the spot rate function $y_{t}(\tau)$ is estimated for each trading day so as to minimize the sum of the squared errors of the spot rates (estimated and observed). In other words, for a determined set of parameters (initial solution), the spot rate is estimated for each observed point on the yield curve according to the model's equation, ${ }^{81}$ and an optimization algorithm is executed for the purpose of minimizing the sum of the squared errors between the estimated and observed rates.

Here the IPCA coupon curve was constructed based on the market prices of NTN-Bs, using the price of each bond as the object of estimation and minimizing the sum of squared errors weighted by the inverse of the bond's Macaulay duration. The yield curves were estimated by applying the Svensson model and using two different procedures: (i) a traditional nonlinear optimization method (quasi-Newton); and (ii) a combination of a genetic algorithm and the quasiNewton method. ${ }^{82}$

\subsection{1}

\section{Traditional nonlinear optimization methods}

A general problem of nonlinear optimization is finding a vector $\bar{\phi}$ that maximizes (or minimizes) a function $f(\bar{\phi}), \bar{\phi}=\left[\begin{array}{llll}\phi_{1}, & \phi_{2}, & \ldots & \phi_{q}\end{array}\right]^{T} \in \mathfrak{R}^{q}$, subject to a series of constraints expressed in the following form:

$$
\begin{aligned}
& c_{i}(\bar{\phi})=0, i=1, \ldots, p, \\
& c_{i}(\bar{\phi}) \geq 0, i=p+1, \ldots, n .
\end{aligned}
$$

To estimate the parameters of the Svensson model for the IPCA coupon curve,

\footnotetext{
${ }^{81}$ Equations (6.10) and (6.12) for the Nelson-Siegel and Svensson models, respectively.

${ }^{82}$ For details, see Franklin Jr. et al. (2012).
} 
the optimization problem may be defined as: ${ }^{83}$

$$
\text { Minimize }\left\{\sum_{i=1}^{N_{t}} w_{i}\left(P_{N T N-B, i}-\sum_{j=1}^{k_{i}} \exp \left[-\tau_{j, i} y_{t}\left(\tau_{j, i}\right)\right] F_{j, i}\right)^{2}\right\} \text {, }
$$

subject to the constraints $\left\{\lambda_{1, t}>0 ; \lambda_{2, t}>0 ; \beta_{0, t}>0 ; \beta_{0, t}+\beta_{1, t}>0\right\}$,

where

- $P_{N T N-B, i}$ is the observed price of the NTN-B with index $i$,

- $k_{i}$ is the number of payments of the NTN-B $i$ (coupons and principal),

- $F_{j, i}$ is the $j$-th payment of NTN-B $i$,

- $\tau_{j, i}$ is the term (in business days) when the $j$-th payment of NTN-B $i$ occurs,

- $\quad N_{t}$ is the number of NTN-Bs traded/observed on the trading date $(t)$,

- $y_{t}\left(\tau_{j, i}\right)$ is the estimated spot rate on day $t$ for the period between $t$ and $t+\tau_{j, i}($ for the Svensson model, see equation (6.12)),

- $w_{i}$ is the inverse of the duration of NTN-B $i\left(w_{i}=1 /\right.$ duration $\left._{i}\right)$.

In general, traditional nonlinear optimization algorithms do not guarantee finding a global optimum for the problem. Instead, on most occasions they only lead to a local optimum ${ }^{84}$ (Bertsekas, 1999). In particular, the high nonlinearity of the function in (6.14) means there is a high risk of false convergence (when the optimization algorithm finds a local optimum, instead of a global optimum), and the result of the optimization is very sensitive to the initial feasible solution.

\footnotetext{
${ }^{83}$ To simplify the notation, the index $t$ (referring to the trading date of the bond) was suppressed for the majority of the terms of the objective function. It was only maintained in situations where its omission would impair comprehension.

${ }^{84}$ Only when the objective function and problem's constraints satisfy certain specific properties can there be assurance of reaching the global optimum of a nonlinear optimization problem.
} 


\section{5 .2}

\section{Genetic algorithms}

Genetic algorithms (GAs), introduced by Holland (1975), are heuristic techniques of global optimization based on the mechanisms of genetics and natural selection. They need three characteristics, also called genetic operators: selection, recombination (cross-over) and mutation (Mitchell, 1998). This is an alternative method of nonlinear optimization that has become more popular with the advance of computational speed.

The construction of a genetic algorithm starts with the creation of a chromosomal representation. The most common such representation is the binary codification (Dawid, 1999; Arifovic \& Gencay, 2000), which is based on the decomposition of each number into a chain of binary code. ${ }^{85}$ An alternative chromosome representation is the real codification, proposed by Davis (1989), which is the most appropriate for parameter optimization problems with values in the continuous domain (Davis, 1991; Wright, 1991; Eshelman \& Shaffer, 1993; Herrera et al., 1998).

In this work real codification was used, whereby each chromosome is a vector of real numbers and each element of this vector (gene) represents a variable of the optimization problem. A genetic algorithm was developed in SPlus v.8.1 specifically tailored to estimate the parameters of the Svensson model (see Franklin Jr. et al., 2012). This GA was based on the work of Gimeno \& Nave (2006) of the Central Bank of Spain, and introduced a new mutation (evolutionary) operator, with the objective of expanding the search space to attain the optimal global solution, along with new initialization parameters to adjust the search algorithm to the characteristics of the problem in question. The aim of developing this GA was to exploit the information accumulated (in each iteration) and guide the algorithm's subsequent searches to appropriate sub-spaces in search of the optimal global solution (or region). The flow chart in Figure 15 illustrates the operation of the GA (see Dias, 2005).

\footnotetext{
${ }^{85}$ The analogy with genetics is immediate: a chromosome is a sequence of genes. In the binary representation, each gene corresponds to a bit (which can assume the value zero or one). The concept represented by each bit and set of bits is inherent to the representation adopted by the GA.
} 


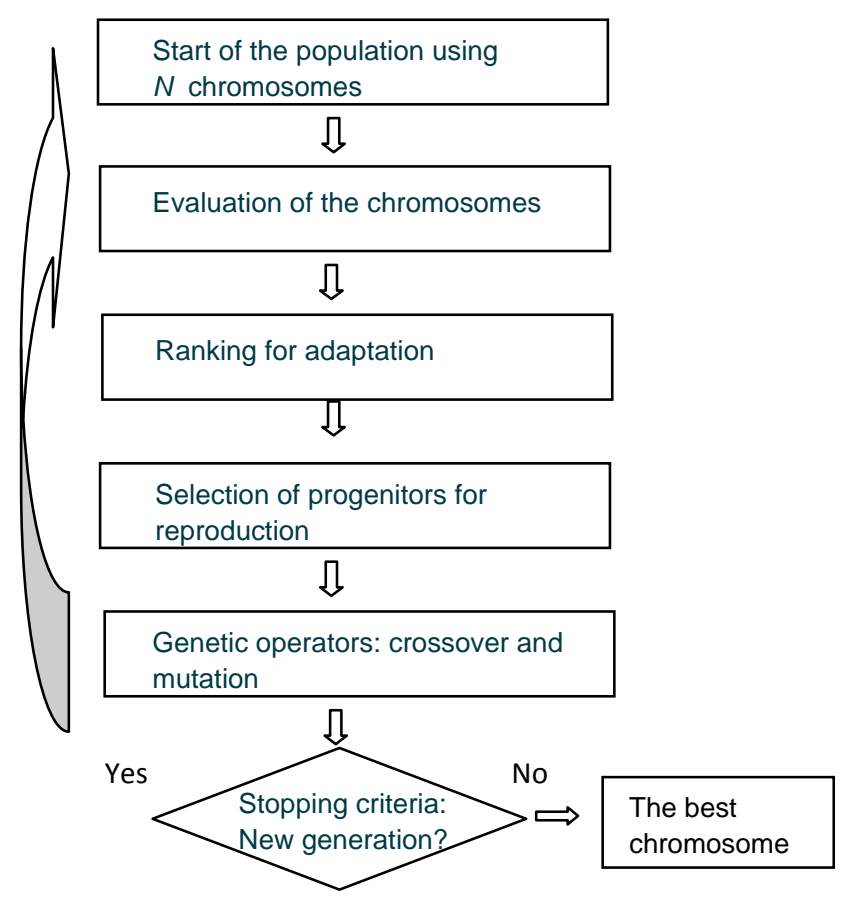

Figure 15: Operational flow chart of the genetic algorithm

Populations of individuals (chromosomes) are created and submitted to the genetic operators. Each chromosome is assessed, according to the function that evaluates the degree of adequacy of this chromosome as a potential solution to the optimization problem. The chromosomes are ordered and the progenitors are selected randomly according to a probability distribution function that attributes greater probability of recombination to the chromosomes receiving the best evaluation. The recombination and mutation operators act to compose the daughter chromosomes and to introduce (random) diversity in their genes. New generations are created and evaluated. The GA processes each generation of chromosomes, representing the solution search space, and uses the three genetic operators (selection, recombination and mutation) as a way to iteratively evolve feasible solutions in search of the optimal solution to the optimization problem.

The evolutionary algorithms, ${ }^{86}$ in general, do not assure obtaining the best possible result in all their executions. They are good to scan the entire space in search of the optimal solution, but have drawbacks for local fine tuning, that is, to

\footnotetext{
${ }^{86}$ Genetic algorithms are a branch of evolutionary algorithms.
} 
find the local optimal point within the global optimal region. ${ }^{87}$ In this work, a combination of genetic algorithm and traditional nonlinear optimization algorithm (quasi-Newton) was used to estimate the IPCA coupon curve.

\section{Chromosome representation}

The chromosome representation adopted here considers each individual/ chromosome to be a candidate to solve the optimization problem, where each chromosome $(\bar{\phi})$ is a vector of six real numbers $\left(\bar{\phi} \in \mathfrak{R}^{6}\right)$ and each element of this vector (gene) represents the value attributed to a parameter of the Svensson model. $^{88}$

A generation of the population consists of $N$ chromosomes and corresponds to an iteration of the GA. Therefore, the $N$ individuals of the $k$-th generation of the population can be represented as follows: ${ }^{89}$

$$
\begin{aligned}
& \bar{\phi}_{i}^{k}=\left[\begin{array}{llllll}
\beta_{0, i}^{k} & \beta_{1, i}^{k} & \beta_{2, i}^{k} & \beta_{3, i}^{k} & \lambda_{1, i}^{k} & \lambda_{2, i}^{k}
\end{array}\right]^{T} \\
& (i=1, \ldots, N) \\
& (k=1,2, \ldots) .
\end{aligned}
$$

\section{Initialization of the population}

The population starts with the generation of $N$ individuals from random variations produced for the species generating chromosome $\left(\bar{\phi}^{*}\right)$, thus forming the population's first generation $(k=1)$,

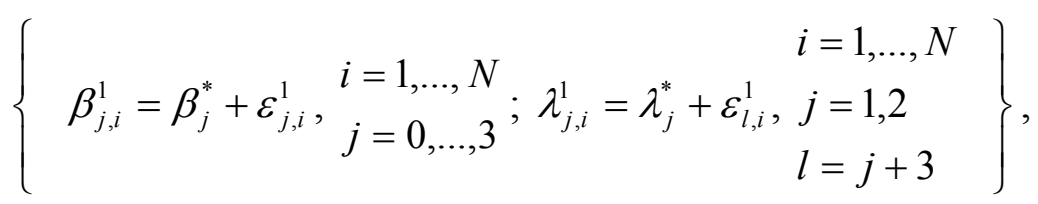

where

\footnotetext{
${ }^{87}$ Holland (1975) suggested that the GA should be used as a pre-processor to carry out an initial search, before passing the search process to a system that can employ domain knowledge to guide the local search.

${ }^{88}$ The genes are thus the variables of the optimization problem, and the chromosome/individual (set of genes) is a solution candidate.

${ }^{89}$ In this work, $\mathrm{N}=1,000$.
} 
- $\quad \beta_{j}^{*}$ and $\lambda_{j}^{*}$ are the values attributed to the genes of the species generating chromosome,

- $\varepsilon_{j, i}^{1} \sim N\left(0, \sigma_{j}^{0}\right)$.

The initial population can be represented in matrix notation as follows.

Species generating chromosome:

$\bar{\phi}^{*}=\left[\begin{array}{llllll}\beta_{0}^{*} & \beta_{1}^{*} & \beta_{2}^{*} & \beta_{3}^{*} & \lambda_{1}^{*} & \lambda_{2}^{*}\end{array}\right]^{T}$.

Random vector:

$\bar{\varepsilon}_{i}^{1}=\left[\begin{array}{llllll}\varepsilon_{0, i}^{1} & \varepsilon_{1, i}^{1} & \varepsilon_{2, i}^{1} & \varepsilon_{3, i}^{1} & \varepsilon_{4, i}^{1} & \varepsilon_{5, i}^{1}\end{array}\right]^{T}$

$(i=1, \ldots, N)$.

First generation of $N$ individuals:

$\bar{\phi}_{i}{ }^{1}=\left[\begin{array}{llllll}\beta_{0, i}^{1} & \beta_{1, i}^{1} & \beta_{2, i}^{1} & \beta_{3, i}^{1} & \lambda_{1, i}^{1} & \lambda_{2, i}^{1}\end{array}\right]^{T}$
$(i=1, \ldots, N)$.

$\bar{\phi}_{i}^{1}=\bar{\phi}^{*}+\bar{\varepsilon}_{i}^{1}|\operatorname{or}\rangle\left[\begin{array}{c}\beta_{0, i}^{1} \\ \beta_{1, i}^{1} \\ \beta_{2, i}^{1} \\ \beta_{3, i}^{1} \\ \lambda_{1, i}^{1} \\ \lambda_{2, i}^{1}\end{array}\right]=\left[\begin{array}{c}\beta_{0}^{*} \\ \beta_{1}^{*} \\ \beta_{2}^{*} \\ \beta_{3}^{*} \\ \lambda_{1}^{*} \\ \lambda_{2}^{*}\end{array}\right]+\left[\begin{array}{c}\varepsilon_{0, i}^{1} \\ \varepsilon_{1, i}^{1} \\ \varepsilon_{2, i}^{1} \\ \varepsilon_{3, i}^{1} \\ \varepsilon_{4, i}^{1} \\ \varepsilon_{5, i}^{1}\end{array}\right]$.

To expand the search space and reduce the number of iterations of the GA, two initial chromosomes (generators of the species) were chosen by complementary procedures: the first based on past data, using as initial values the optimal values for the parameters of the IRTS of the last business day of the previous month; and the second, based on current data, using as initial values the information on the interest rates of federal bonds on each trading day. ${ }^{90}$ Half of the individuals were

${ }^{90}$ For this second procedure, $\beta_{0}^{*}$ is the internal rate of return (IRR) of the public bond with longest maturity, $\beta_{1}^{*}$ is the difference between the IRR of the bond with shortest maturity and the 
generated by each procedure.

Thus, two initial chromosomes were created $\left(\bar{\phi}^{* 1}\right.$ and $\left.\bar{\phi}^{* 2}\right)$, and the first generation of individuals was composed of

$$
\left\{\bar{\phi}_{i}{ }^{1}=\bar{\phi}^{*_{1}}+\bar{\varepsilon}_{i}^{1} ; i=1, \ldots . N / 2\right\} \text { and }\left\{\bar{\phi}_{i}^{1}=\bar{\phi}^{*_{2}}+\bar{\varepsilon}_{i}^{1} ; i=N / 2+1, \ldots, N\right\} .
$$

The random vectors $\bar{\varepsilon}_{i}^{k}$ allow the introduction of diversity in the initial population $(k=1)$ and calibration of the magnitude of mutations in future generations $(k \geq 2) .{ }^{91}$ The standard deviation $\sigma_{j}^{0}$ of the random term associated with each gene $(j)$ depends on the initial value assigned to that gene and on the parameter $\sigma$ used to calibrate the model.

For chromosomes generated from $\bar{\phi}^{* 1}$ :

$$
\sigma_{0}^{0}=\sigma_{1}^{0}=\sigma \beta_{0}^{*_{1}} ; \sigma_{2}^{0}=\sigma\left|\beta_{2}^{*_{1}}\right| ; \sigma_{3}^{0}=\sigma\left|\beta_{3}^{*_{1}}\right| ; \sigma_{4}^{0}=\sigma \lambda_{1}^{*_{1}} ; \sigma_{5}^{0}=\sigma \lambda_{2}^{*_{1}} .
$$

In turn, for chromosomes generated from $\bar{\phi}^{* 2}$ :

$$
\sigma_{0}^{0}=\sigma_{1}^{0}=\sigma \beta_{0}^{*_{2}} ; \sigma_{2}^{0}=\sigma_{3}^{0}=\sigma\left|\beta_{1}^{* 2}\right| ; \sigma_{4}^{0}=\sigma \lambda_{1}^{* 1} ; \sigma_{5}^{0}=\sigma \lambda_{2}^{* 1}
$$

The greater the standard deviation $(\sigma)$ is, the greater the diversity of the initial population and the higher magnitude of the mutations are: a small value of $\sigma$ increases the risk of false convergence (when the algorithm finds a local rather than a global minimum); a large value of $\sigma$ expands the search space and the number of iterations necessary to reach the global minimum.

Simulations of the GA were carried out for different values of $\sigma$. In choosing the value to construct the yield curve, consideration was given to the optimal value of the objective function (lowest value of the weighted sum of squared errors) and the number of iterations (generations) necessary to reach the

IRR of the bond with the longest maturity, $\beta_{2}^{*}=\beta_{3}^{*}=0$ (curves without humps) and $\lambda_{1}^{*}$ and $\lambda_{2}^{*}$ are the same values adopted in the first procedure.

${ }^{91}$ The impact of $\sigma$ on the magnitude of the mutation will be seen later in this Section. 
minimum. ${ }^{92}$ In particular, the value of $\sigma$ for the IPCA coupon curve was chosen from the simulations presented in Figure $16 .^{93}$
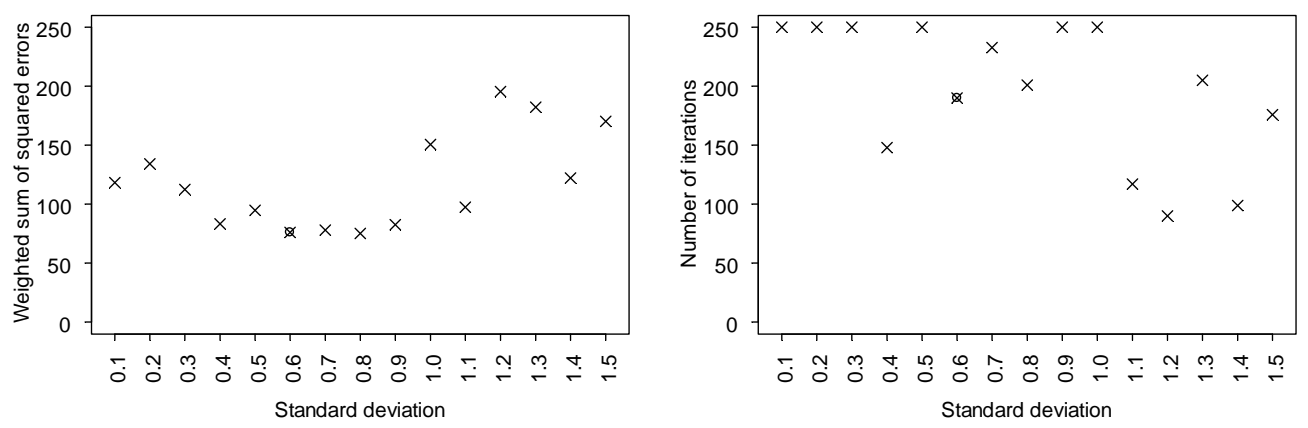

Figure 16: Simulations of the genetic algorithm for different values of $\sigma$ for Dec. 30, 2010

Not all randomly generated chromosomes are valid (feasible) solutions for an optimization problem. For a chromosome to be feasible, it must satisfy the conditions expressed in (6.13). The GA thus tests whether each of the chromosomes generated $(i=1, \ldots, N)$ satisfies the feasibility conditions, and if not, it generates new random values for the respective parameters (genes), until an initial generation is obtained with $N$ feasible chromosomes.

\section{Selection}

In this phase, the GA selects, for each generation $(k)$, the individuals/ chromosomes with highest quality and hence most appropriate for reproduction. For this it is necessary to define a measure to quantify the quality of each of the $N$ chromosomes of this generation.

A natural measure for the quality of a chromosome (as a candidate solution of the optimization problem) is the value of the objective function given by equation (6.14), substituting the parameters of the Svensson model with the respective genes of each chromosome. The lower the value of the objective function, the better the model will fit the observed data. Here, this quality measure is called the mortality index (MI) of the chromosome, such that the lower this $M I$ is, the better the chromosome's quality is, and the higher will be its chance of survival

\footnotetext{
${ }^{92}$ For purposes of calibration of the GA's parameters $(\sigma, \eta, \alpha, \pi)$, the number of iterations was limited to 250 and priority was given to the parameters that generated the lowest weighted sum of squared errors on December 30, 2010 (the GA calibration date).

${ }^{93}$ The value chosen for $\sigma$ (after the simulations) was 0.6.
} 
(reproduction), analogous to the process of natural selection, characterized by the expression survival of the fit enough (Scott, 2009).

Thus, for the IPCA coupon curve, the mortality index of a chromosome is given by

$$
M I=\left\{\sum_{i=1}^{N_{t}} w_{i}\left(P_{N T N-B, i}-\sum_{j=1}^{k_{i}} \exp \left[-\tau_{j, i} y_{t}\left(\tau_{j, i}\right)\right] F_{j, i}\right)^{2}\right\}
$$

The GA then creates a list of chromosomes, ranking them according to its $M I$ value (from lowest to highest value), and selects a number $M=N \eta$ of surviving chromosomes, where $\eta$ is the percentage of chromosomes that survive in each generation/iteration of the algorithm: a low value of $\eta$ can make the convergence process very slow, while a high value of $\eta$ increases the risk of false convergence.

Simulations of the GA were carried out for different values of $\eta$. In choosing the value to construct the yield curve, consideration was given to the optimal value of the objective function (lowest value of the weighted sum of squared errors) and the number of iterations (generations) necessary to reach the minimum. In particular, the value of $\eta$ for the IPCA coupon curve was selected from the simulations presented in Figure $17 .{ }^{94}$
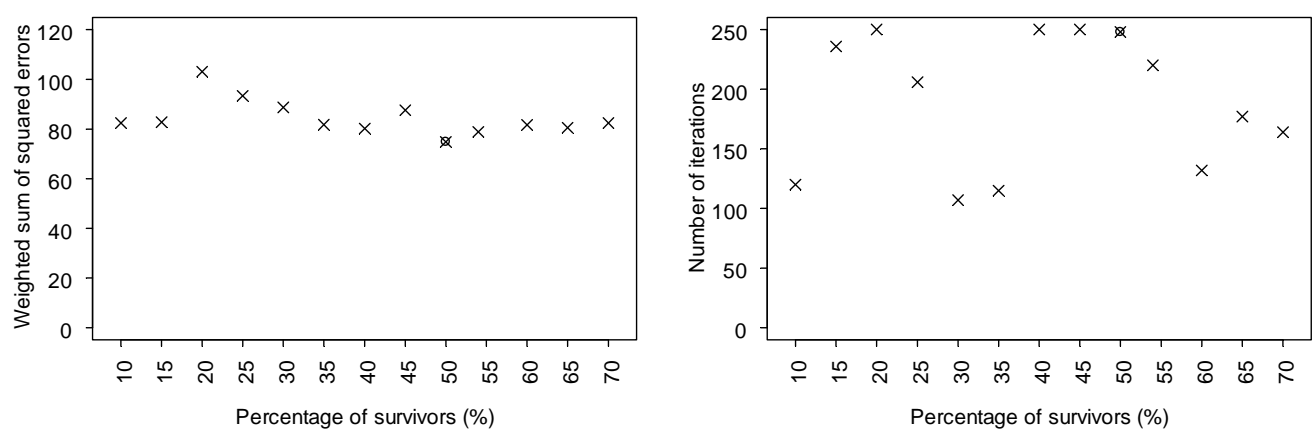

Figure 17: Simulations of the genetic algorithm for different values of $\eta$ for Dec. 30, 2010

Therefore, the ordered list of surviving chromosomes of generation $k$ (before the selection operator) was $\left\{\bar{\phi}_{1}^{k}, \bar{\phi}_{2}^{k}, \ldots, \bar{\phi}_{M}^{k}, \bar{\phi}_{M+1}^{k}, \ldots, \bar{\phi}_{N}^{k}\right\}$, while after the selection

\footnotetext{
${ }^{94}$ The value chosen for $\eta$ (after the simulations) was $50 \%$.
} 
operator the list of chromosomes declined to $\left\{\bar{\phi}_{1}^{k+1}, \bar{\phi}_{2}^{k+1}, \ldots, \bar{\phi}_{M}^{k+1}\right\}$ and the recombination and mutation operators entered the fray to improve the next generation's chromosomes $(k+1)$ and evolve the viable solution toward the global optimum of the optimization problem.

\section{Recombination}

The recombination operator acts first, adding $N(1-\eta)$ new chromosomes to generation $k+1$ of the population. For this, it selects the progenitor chromosomes ( $r$ and $s$ ) of generation $k$, attributing a higher probability of selection to those with lower MI (better quality). A random sample is generated $\left\{\xi_{i}, i=1,2, \ldots, 2 N(1-\eta)\right\}$ from a random variable $\xi$ with distribution $\operatorname{Beta}(1, \alpha)$, and for each pair of elements of the sample, the indices are calculated to rank the progenitor chromosomes, making $r=\xi_{i} N$ and $s=\xi_{j} N(i \neq j)$. Each gene of the daughter chromosome $\left(\bar{\phi}_{q}^{k+1}\right)$ is then generated by a linear combination of the respective genes of the two progenitor chromosomes:

$$
\bar{\phi}_{q}^{k+1}=D_{6 x 6} \bar{\phi}_{r}^{k}+\left(\mathrm{I}_{6}-D_{6 x 6}\right) \bar{\phi}_{s}^{k},
$$

where

- $D_{6 x 6}$ is a diagonal matrix of dimension 6, where $d_{i, j}=\left\{\begin{array}{l}\psi_{i}, \text { if } i=j, \\ 0, \text { if } i \neq j,\end{array}\right.$

- $\bar{\psi}$ is a column vector of size 6 , generated by independent and identically distributed random variables with uniform distribution in the interval $[0,1]$,

- $\mathrm{I}_{6}$ is the identity matrix.

Note that $\xi \sim \operatorname{Beta}(1, \alpha)$ is a continuous real random variable that can assume values in the interval $[0,1]$, and the greater the value of $\alpha$, the higher the probability of choosing progenitors with lower $M I$ (better quality). Figure 18 shows the probability density function of the distribution $\operatorname{Beta}(1, \alpha)$ for three values of $\alpha$. 

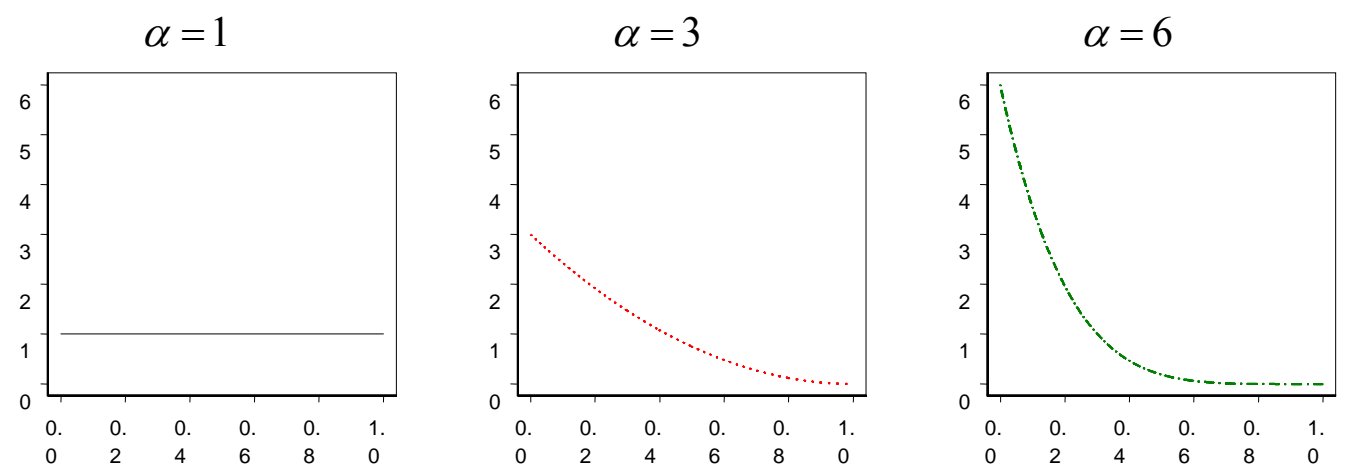

Figure 18: Examples of the distribution $\operatorname{Beta}(1, \alpha)$ for $\alpha=1,3$ and 6

The parameter $\alpha$ can be interpreted as an attractiveness index given to the chromosomes with the best genes: a low value of $\alpha$ indicates a weak preference for chromosomes of higher quality, what can make the convergence process very slow, while a high value of $\alpha$ reduces the diversity of each generation and increases the risk of false convergence.

Simulations of the GA were carried out for different values of $\alpha$. In choosing the value to construct the yield curve, consideration was given to the optimal value of the objective function (lowest value of the weighted sum of squared errors) and the number of iterations (generations) necessary to reach the minimum. In particular, the value of $\alpha$ for the IPCA coupon curve was selected from the simulations presented in Figure 19. ${ }^{95}$
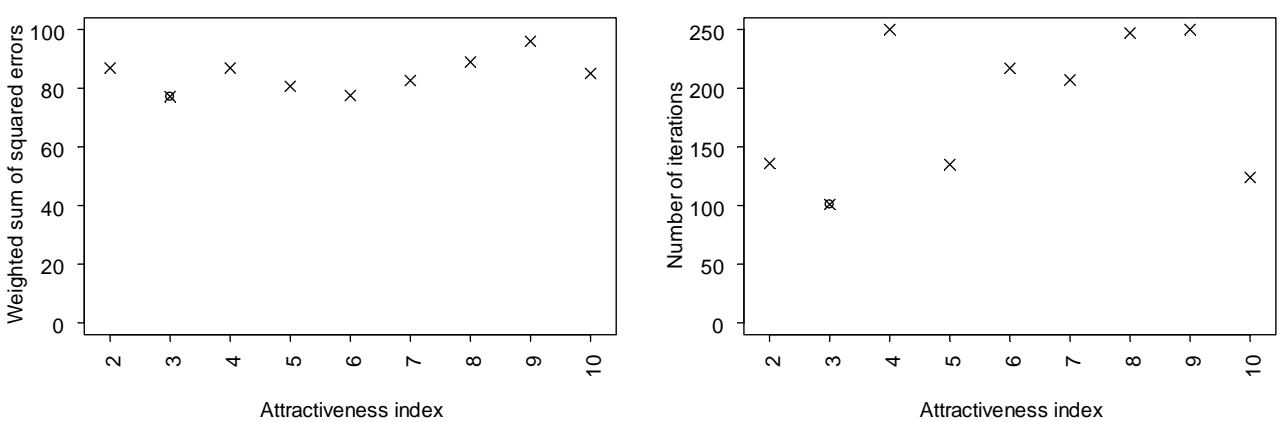

Figure 19: Simulations of the genetic algorithm for different values of $\alpha$ for Dec. 30, 2010

\footnotetext{
${ }^{95}$ The value selected for $\alpha$ (after the simulations) was 3 .
} 


\section{Mutation}

The mutation operator does its work just after the recombination operator, with the purpose of keeping the solution from evolving to a local optimum, by introducing random variations in the chromosomes' genes and testing the quality of the mutant chromosomes.

Each gene $\left(\beta_{j, i}^{k+1}\right.$ and $\left.\lambda_{j, i}^{k+1}\right)$ of each chromosome $\left(\bar{\phi}_{i}^{k+1}\right)$ of the new generation $(k+1)$ can undergo a mutation with probability $\pi$. When a mutation happens, a random variable $\varepsilon_{j, i}^{k} \sim N\left(0, \sigma_{j}^{k}\right)$ is added to gene $j$ of chromosome $i$, the quality of the mutant chromosomes is tested and the list of chromosomes of generation $(k+1)$ is reordered, being the case that for the surviving chromosomes of the preceding generation, $\left\{\bar{\phi}_{1}^{k+1}, \bar{\phi}_{2}^{k+1}, \ldots, \bar{\phi}_{M}^{k+1}\right\}$, the mutation will only have an effect if the mutant chromosome has better quality than the original one.

For each new chromosome generated, the GA tests whether it satisfies the feasibility conditions expressed in (6.13), and if not, it selects new progenitor chromosomes to generate a new daughter chromosome, repeating the process until obtaining a total of $N$ feasible chromosomes in generation $k+1$ : $\left\{\bar{\phi}_{1}^{k+1}, \bar{\phi}_{2}^{k+1}, \ldots, \bar{\phi}_{M}^{k+1}, \bar{\phi}_{M+1}^{k+1}, \ldots, \bar{\phi}_{N}^{k+1}\right\}$.

The occurrence of mutation in different genes of a single chromosome are statistically independent events, so that a given chromosome can undergo mutation in zero, one, two, three... genes. A low value of $\pi$ increases the risk of false convergence, while a high value of $\pi$ can make the convergence process very slow and even uncertain.

As before, simulations of the GA were carried out for different values of $\pi$. In selecting the value for constructing the yield curve, consideration was given to the optimal value of the objective function (lowest value of the weighted sum of squared errors) and the number of iterations (generations) necessary to reach the minimum. As an illustration, the value of $\pi$ for the IPCA coupon curve was chosen based on the simulations presented in Figure 20. ${ }^{96}$

\footnotetext{
${ }^{96}$ The value chosen for $\pi$ (after the simulations) was $45 \%$.
} 

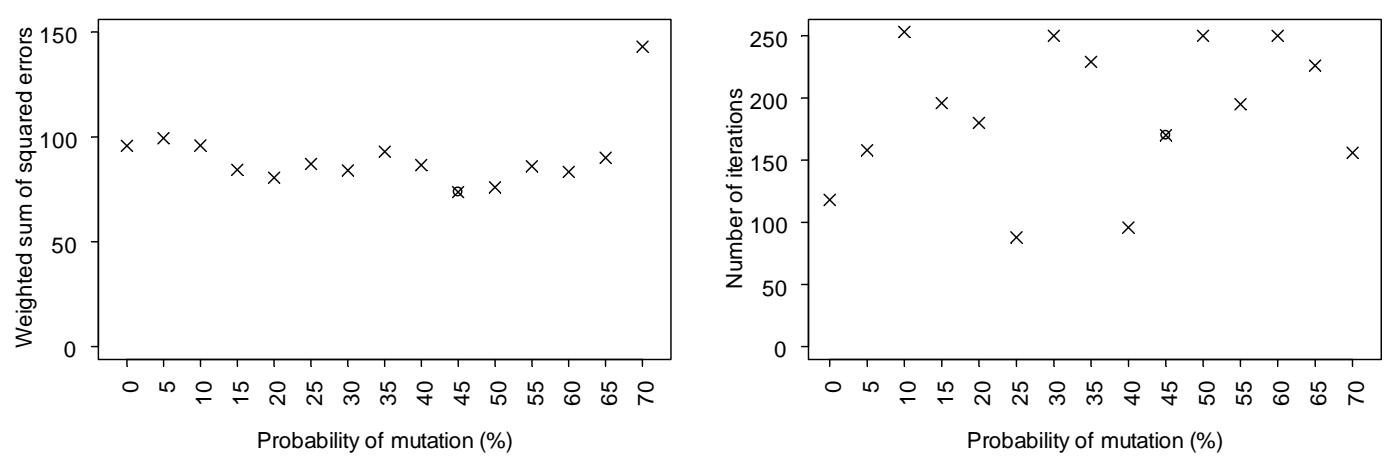

Figure 20: Simulations of the genetic algorithm for different values of $\pi$ for Dec. 30, 2010

The magnitude of each mutation can be increased with the number of iterations (generations) to keep the GA from being trapped at a local minimum point. In this work, we opted to make the standard deviation of the random term, which is added to the mutant gene, increase by $1 \%$ with each iteration. In other words:

$$
\begin{array}{r}
\sigma_{j}^{k}=\sigma_{j}^{k-1}(1.01), \quad j=0, \ldots, 5 \\
k=1,2, \ldots
\end{array}
$$

Therefore, an alternate way to represent chromosome $i$ of generation $k$, often used in the (broader) field of evolutionary algorithms, is through a pair of vectors,

$$
\overline{\bar{v}}_{i}^{k}=\left(\bar{\phi}_{i}^{k}, \bar{\sigma}_{i}^{k-1}\right)
$$

where

- $\bar{\phi}_{i}^{k}$ represents a point in the search space of the optimal solution,

- $\bar{\sigma}_{i}^{k-1}$ is a vector of standard deviations calculated iteratively ${ }^{97}$ (see equation (6.21)).

The objective of the GA simulations demonstrated in Figures 16, 17, 19 and 20 was, respectively, to find values of $\sigma, \eta, \alpha$ and $\pi$ that generate the lowest value of the objective function in a reasonable number of iterations (under 250). Small variations in the parameters do not change the final result of the combination of the genetic algorithm and the quasi-Newton method. In other words, small alterations in the parameters do not affect the capacity of the genetic algorithm to

\footnotetext{
${ }^{97}$ Used to initialized the population (when $k=1$ ), as presented in equation (6.16), and to specify the magnitude of each mutation (when $k \geq 2$ ), according to equation (6.21).
} 
reach the region of the global minimum of the objective function. For each simulation, only one of the GA's parameter was changed (all others were held fixed). ${ }^{98}$

\section{Stopping criterion}

Once the generational evolution is completed and after testing the viability of each new chromosome, the GA iteratively repeats the selection, recombination and mutation processes until reaching a steady state for the species' evolution (when new generations are not capable of introducing genetic improvements), thus reaching the region of global optimal point. ${ }^{99}$

The stopping criterion adopted here was obtainment of a series of 100 generations (iterations of the algorithm) without a change in any of the genes (parameters) of the chromosome (solution candidate) with the best quality (lowest value of the objective function). The genetic algorithm is used as a pre-processor to carry out the initial search for the global minimum region/point, and then the optimal solution found with the GA is used as initial solution in a traditional nonlinear optimization algorithm (quasi-Newton) to reach the local (and global) minimum.

\section{6}

\section{Analysis of the Results}

\subsection{1}

\section{Estimation of the IPCA coupon, error analysis and interpolation}

The IPCA coupon curve was estimated for the last business day of each month, between September 2003 and December 2010 (88 months). For each of these days (for each trading day, $t$ ), the parameters of the Svensson model were estimated by

\footnotetext{
${ }^{98}$ It should be noted that the genetic algorithm developed by Franklin Jr. et al. (2012) introduced a new mutation operator, unlike that proposed by Gimeno \& Nave (2006), and new initialization parameters.

${ }_{99}$ As said before, the evolutionary algorithms can present difficulties to find the local minimum point within the global minimum region (local fine tuning). For this reason, a combination of genetic with traditional nonlinear optimization algorithms was used in this work.
} 
means of a combination of genetic (GA) and quasi-Newton (QN) algorithms, obtaining the ordinary least squares estimators $\hat{\beta}_{0, t}, \hat{\beta}_{1, t}, \hat{\beta}_{2, t}, \hat{\beta}_{3, t}, \hat{\lambda}_{1, t}$ and $\hat{\lambda}_{2, t}$.

The estimate of the annual spot rate compounded continuously at $t$ for term $\tau$ can be obtained from equation (6.12):

$$
\hat{y}_{t}(\tau)=\hat{\beta}_{0, t}+\hat{\beta}_{1, t}\left(\frac{1-e^{-\hat{\lambda}_{1, t} \tau}}{\hat{\lambda}_{1, t} \tau}\right)+\hat{\beta}_{2, t}\left(\frac{1-e^{-\hat{\lambda}_{1, t} \tau}}{\hat{\lambda}_{1, t} \tau}-e^{-\hat{\lambda}_{1, t} \tau}\right)+\hat{\beta}_{3, t}\left(\frac{1-e^{-\hat{\lambda}_{1, t} \tau}}{\hat{\lambda}_{2, t} \tau}-e^{-\hat{\lambda}_{2, t} \tau}\right) .
$$

The discrete spot rate compounded annually is obtained from equation (6.3):

$$
\hat{R}_{t, t+\tau}^{t}=\exp \left(\hat{y}_{t}(\tau)\right)-1
$$

For December 30, 2010, the estimators of the parameters of the Svensson model obtained by combining the genetic and quasi-Newton algorithms for the IPCA coupon were the following:

$$
\begin{cases}\hat{\beta}_{0}=0.04829 ; & \hat{\beta}_{1}=-0.03660 ; \\ \hat{\lambda}_{1}=1.876257 ; & \hat{\beta}_{2}=0.19271 .\end{cases}
$$

The evolution of the weighted sum of squared errors obtained with the estimation of the IRTS, using each estimation method (only the quasi-Newton algorithm (QN) and a combination of the genetic and quasi-Newton algorithms $(\mathrm{GA}+\mathrm{QN}))$, during the last six months before the date of calibrating the GA (December 30, 2010), is presented in Figure 21. The evolution of the mean weighted squared error (equal to the weighted sum of squared errors divided by the number of public bonds sold on each trading day) over the entire period studied (from September 2003 to December 2010) is presented in Figure 22.

The combined GA + QN method was consistently better than the traditional QN estimation method, and on some dates the application of the GA significantly improved the result of the estimation. The reason is that in employing the GA as a pre-processor for initial search for the global optimal region/point and then the quasi-Newton for the final search to pin it down, jumps between local minima are 
avoided, improving the curve fitting to the market data. ${ }^{100}$

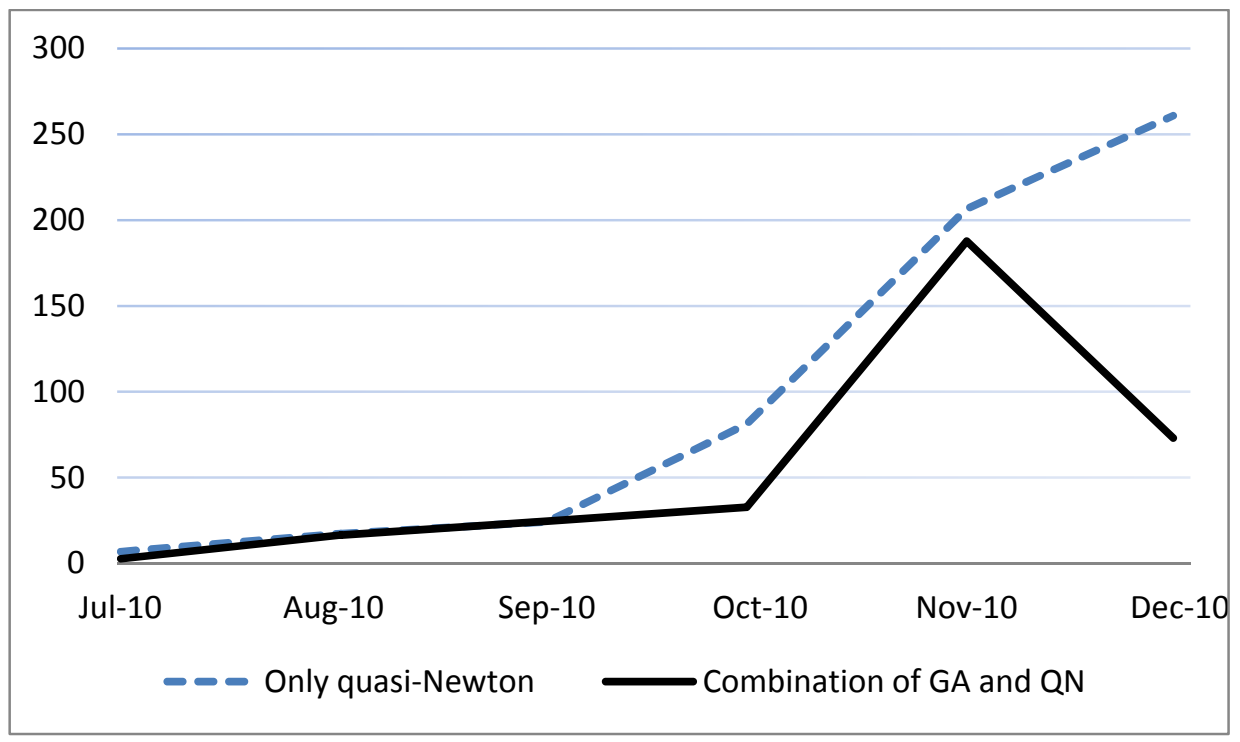

Figure 21: Comparison of the weighted sum of squared errors in the 6 months before the date of model calibration

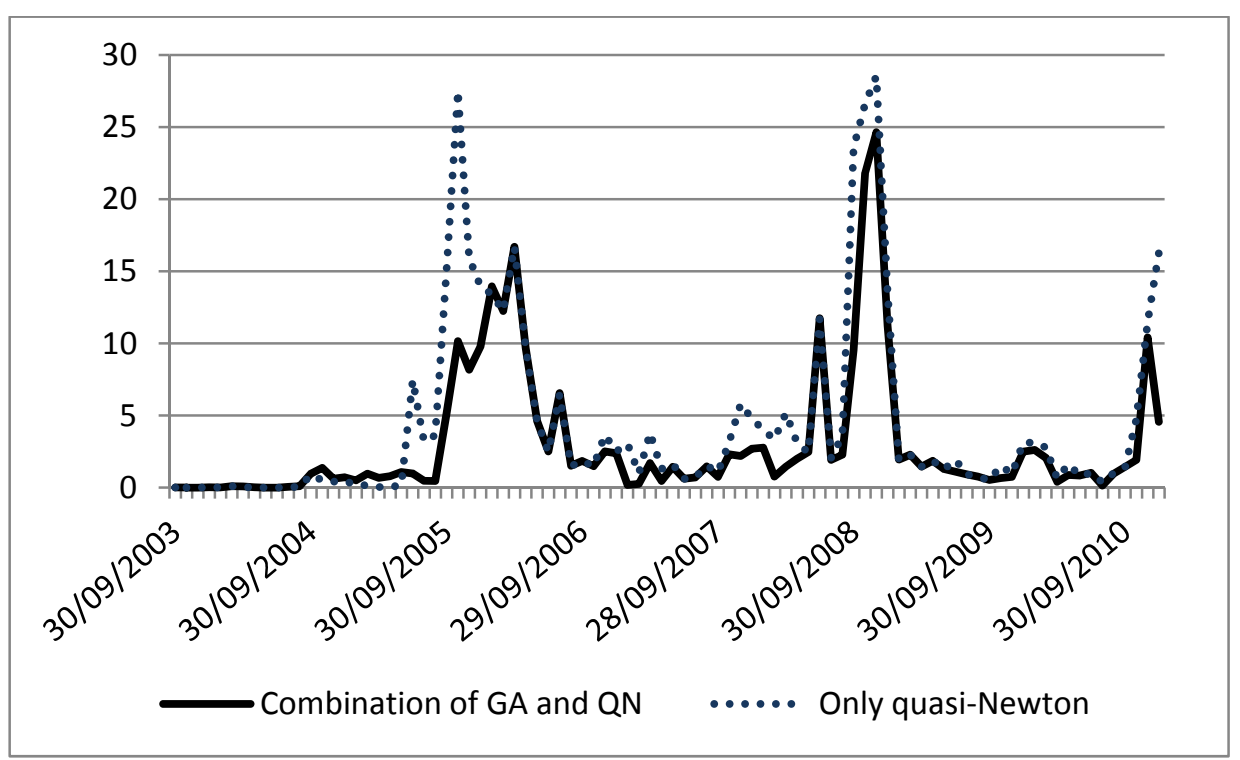

Figure 22: Comparison of the mean weighted squared error during the entire data series

The interpolation of the IRTS is obtained by replacing the parameters of the Svensson model (in equation (6.12)) by the estimated values found using each estimation method. The IRTSs generated by each estimation method, ${ }^{101}$ for December 30, 2010 and for terms from 6 months to 40 years, are demonstrated in

\footnotetext{
${ }^{100}$ The parameters of the GA $(\sigma, \eta, \alpha, \pi)$ were calibrated for December 30, 2010, one of the trading days with a significant improvement in the model's estimation.

${ }^{101}$ The continuous-time rates were converted to discrete annual rates.
} 
Figure 23, together with the observed spot rates, obtained by applying the bootstrap technique. ${ }^{102}$

Note that application of GA permits a significantly improved fit of the curve to the market data. Besides this, the weighting of the quadratic error of each bond by the inverse of the Macaulay duration made the residuals of the spot rate homoscedastic (as anticipated in Section 6.5).

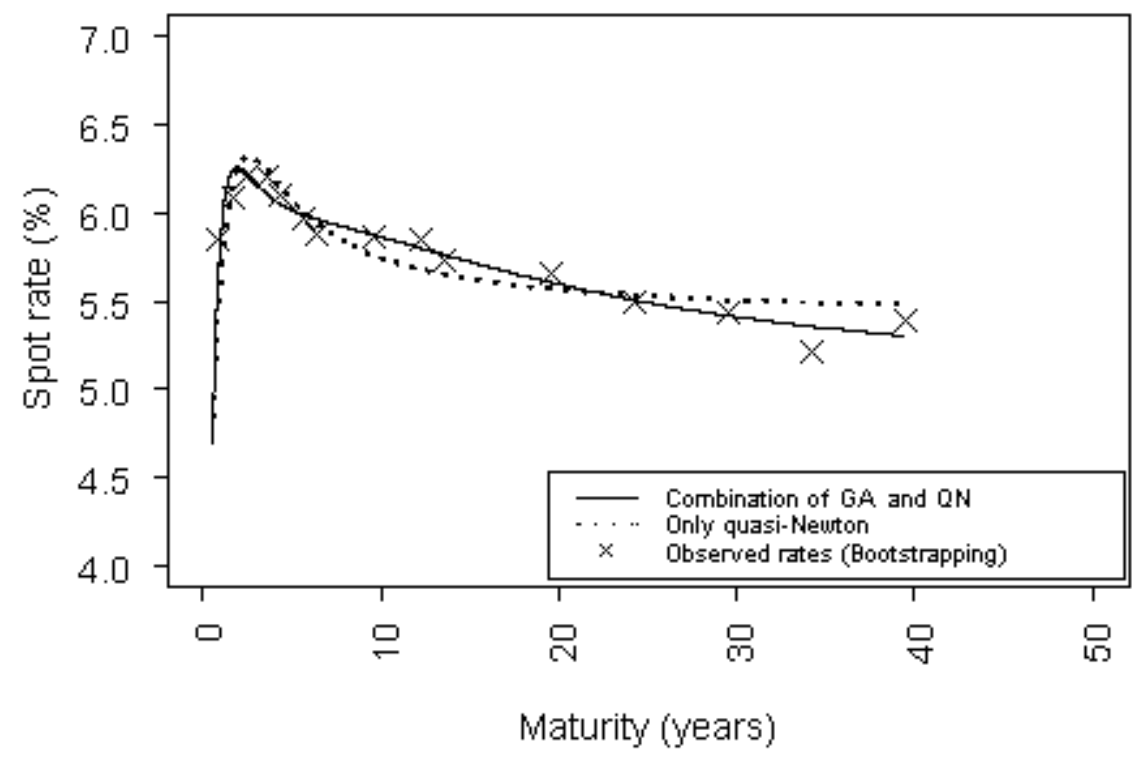

Figure 23: Interpolation of the IRTS generated by each estimation method and the spot rates observed for each maturity (for Dec. 30, 2010)

The historic evolution and volatility of the discrete spot rates for terms of 6 months, 5 years, 10 years and 50 years (extrapolated in the last case ${ }^{103}$ ) are illustrated, respectively, in Figure 24 and in Table 11. There is a peak in all these rates in the period between September 2008 and January 2009, the period of the worst effect of the subprime crisis (precipitated by the failure of Lehman Brothers in the United States). ${ }^{104}$ It can be seen that the volatility of the discrete spot rate, $R_{t, t+\tau}^{t}$, diminishes with increasing maturity $(\tau)$, which is consistent with wellknown theoretical models of the term structure (Vasicek, 1977). These models

\footnotetext{
${ }^{102}$ The bootstrap technique consists of treating bonds with coupon as being combinations of isolated zero-coupon bonds and in this way determining, through recursive techniques, the spot rate for different maturity terms.

${ }^{103}$ See Section 6.6.2.

${ }^{104}$ To calculate the volatility, an unbiased estimator of the standard deviation of the discrete spot rate was used. The standard deviation was calculated for the interest rate curve of the model, since for different trading days, the maturities of the bonds used to construct each curve are different.
} 
show that the long-term forward rate should converge to a determined limit value and the volatility of the rates should converge to zero when the maturity tends to infinity. In the case of the Svensson model, the long-term forward rate can be obtained by taking the $\operatorname{limit} \lim _{\tau \rightarrow \infty} y_{t}(\tau)=\beta_{0, t}$, and for December 30 , this produces $\hat{y}_{30 / 12 / 2010}(\infty)=4,83 \%$ (continuous rate) and $\hat{R}_{30 / 12 / 2010, \infty}^{30 / 12 / 2010}=4,95 \%$ (discrete rate).

Table 11: Volatility of the spot rates for terms of 6 months, 5 years, 10 years and 50 years

\begin{tabular}{|l|l|l|l|l|}
\hline Date & 0.5 year & 5 years & 10 years & 50 years \\
\hline Volatility (unitary rate) & 0.02097 & 0.01249 & 0.00964 & 0.00883 \\
\hline
\end{tabular}

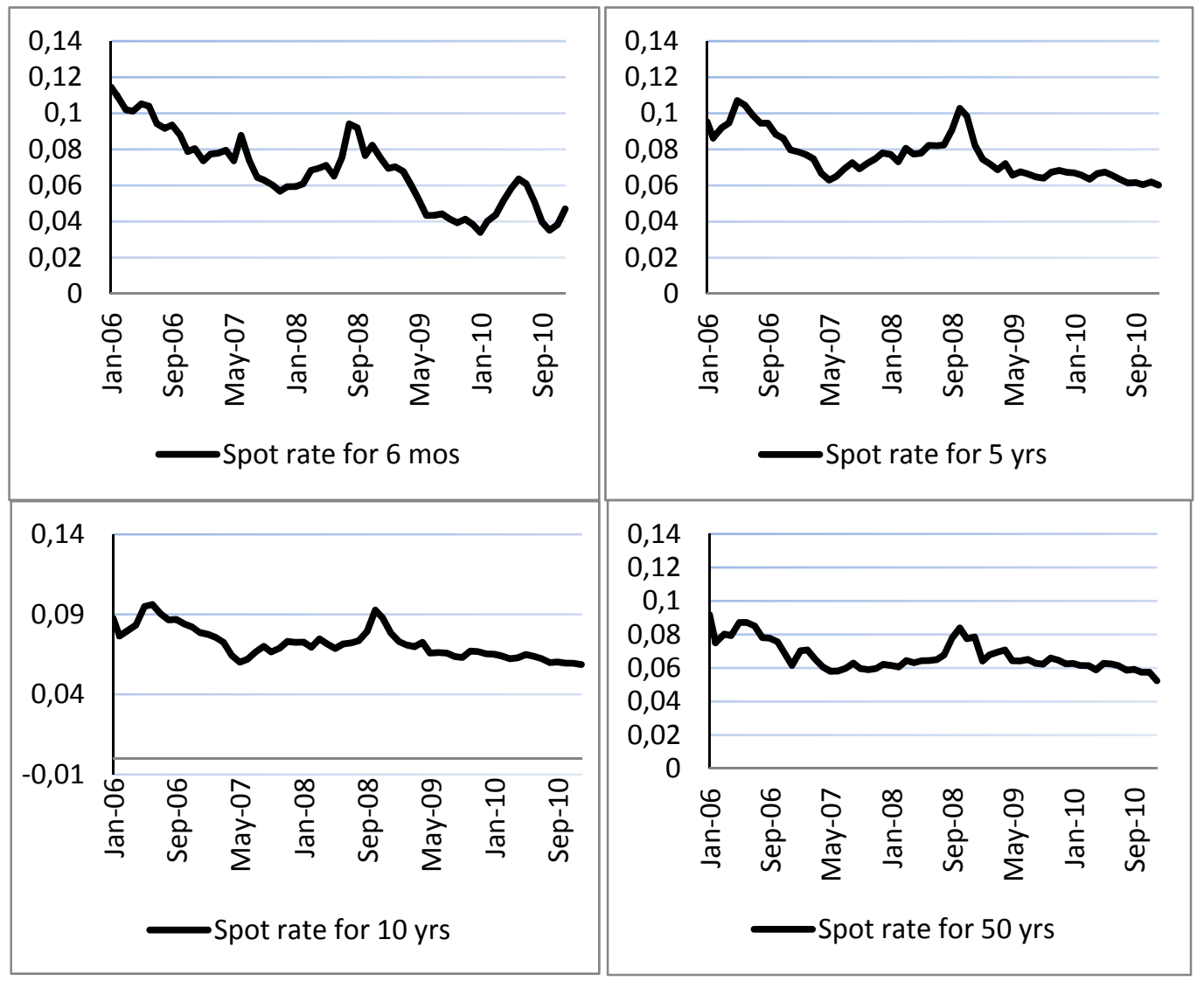

Figure 24: Historic evolution and volatility of the discrete spot rates for different maturities

\section{6 .2}

\section{Extrapolation of the IPCA coupon curve}

Previous studies in Brazil (e.g., Varga, 2009) show that many of the models commonly used to interpolate the term structure do not permit a reasonable 
extrapolation (in the economic sense), because they occasionally lead to indefinitely growing or negative rates. This is the case, for example, of the cubic spline, exponential and simple linear interpolation models. In contrast, smoothing models (e.g., Nelson-Siegel and Svensson) and flat forward models do not lead to unreasonably large or negative spot rates, so they can be used for extrapolation of the term structure. ${ }^{105}$

The international literature also suggests other methods for IRTS interpolation and extrapolation, with the standouts being the methods proposed by Barrie $\&$ Hibbert (2008) and Smith \& Wilson (2001). The former applies cubic spline for the liquid part and Nelson-Siegel for the extrapolated part of the term structure, and the latter models the discount function $\left(P_{t}(\tau)\right)$ as a sum of exponential functions (or kernel functions). These two methods depend on the specification of an extremely long-term forward rate, or ultimate forward rate (UFR) for extrapolation of the yield curve.

The UFR is, by definition, the forward rate implicit in the risk-free IRTS for infinite (or very long) maturity, and must be determined by means of macroeconomic methods. The most important macroeconomic factors used to explain the long-term forward rates are expected inflation over the long run and the expected real interest rate over the long term. From a theoretical standpoint, at least two other components can be said to exist: the nominal term premium and the nominal convexity effect expected over the long term. The adoption of premises about these expectations in Brazil is very tenuous.

In this work, we decided to use a uniform approach for interpolation and extrapolation of the IRTS (with the Svensson model), to avoid the use of a macroeconomic variable exogenous to the model, whose specification would be somewhat controversial and arbitrary. So, the extrapolation was performed using the Svensson model adjusted by the combination of the genetic and quasi-Newton algorithm methods.

The extrapolation of the IRTS beyond the last vertex available in the database is shown in Figure 25, for December 30, 2010. Note that from the results of the rates

\footnotetext{
${ }^{105}$ For example, European central banks and the Brazilian Central Bank use, respectively,
} Svensson and flat forward models to extrapolate the IRTS. 
extrapolated out to 50 years, shown in Figure 25, and from the volatility analysis presented in the previous section, the proposed model seems appropriate for extrapolating the IRTS.

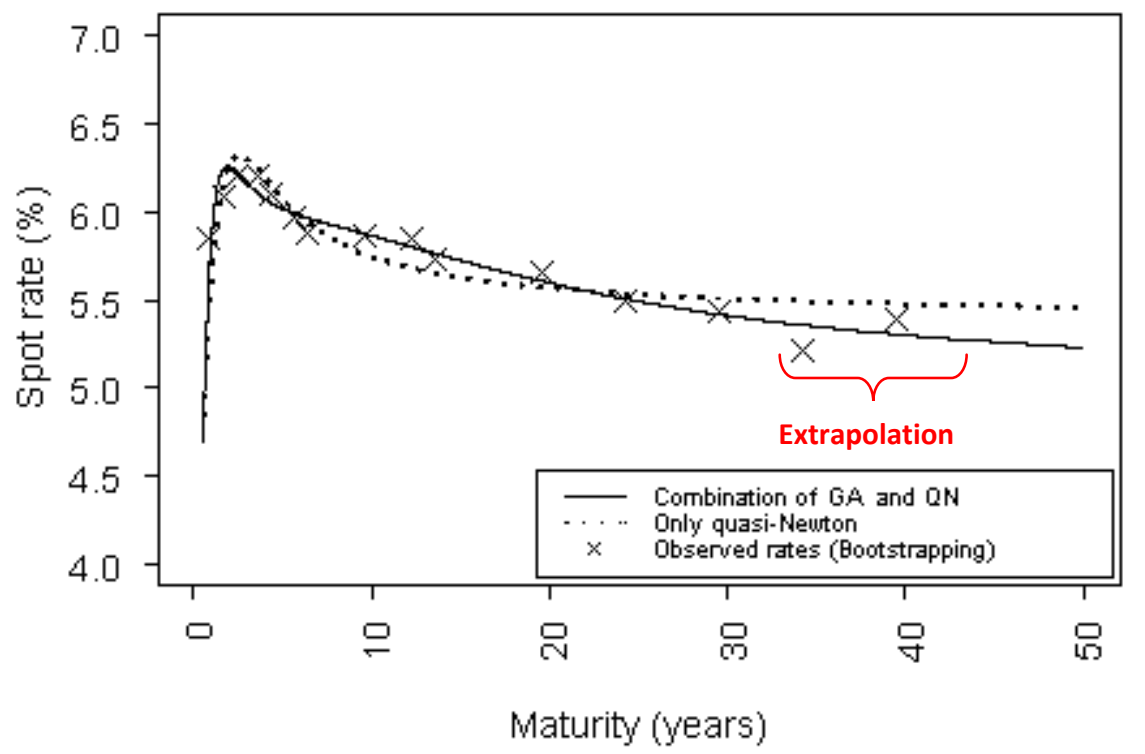

Figure 25: Extrapolation of the IRTS generated by each estimation method and the spot rates observed for each maturity (for Dec. 30, 2010)

\subsection{3}

\section{Historic evolution of the parameters of the Svensson model}

The use of genetic algorithms in complement to traditional nonlinear optimization algorithms resulted in more stable estimators for the Svensson model over time. This result is particularly important when one wants an economic interpretation of the estimated values of the Svensson model's parameters. ${ }^{106}$

The historic evolutions of the estimators obtained with the combination of the genetic and quasi-Newton algorithms $(\mathrm{GA}+\mathrm{QN})$ and only with the quasi-Newton (QN) method are shown in Figures 26, 27, 28 and 29. The volatility of the estimators obtained by each method is presented in Table 12 .

The combined method $(\mathrm{GA}+\mathrm{QN})$ generated more stable series for the

${ }^{106}$ The factors of the term structure have interpretations of level (or long term), $\beta_{0, t}$, slope (or short term), $\beta_{1, t}$, and curvatures (or medium terms), $\beta_{2, t}$ and $\beta_{3, t}$. The parameters $\lambda_{1, t}$ and $\lambda_{2, t}$ characterize the decay speeds of the medium-term components of the yield curve. 
estimators of the factors for level $\left(\beta_{0, t}\right)$, slope $\left(\beta_{1, t}\right)$ and curvatures $\left(\beta_{2, t}\right.$ and $\left.\beta_{3, t}\right)$, as well as for the set of decay speeds $\left\{\lambda_{1, t}, \lambda_{2, t}\right\}$. In particular, note that the estimators of $\beta_{2, t}$ and $\beta_{3, t}$ generated by the QN method present opposite/mirrored jumps that tend to cancel each other for proximate values of $\lambda_{1, t}$ and $\lambda_{2, t}$.

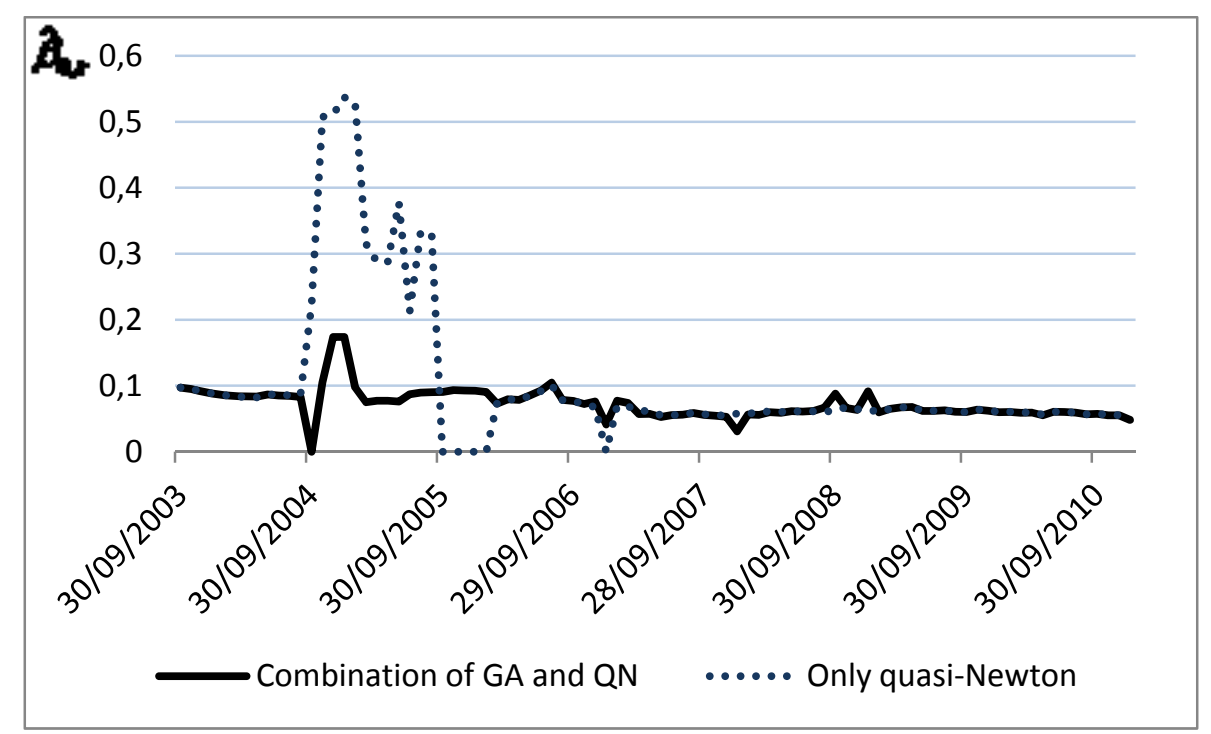

Figure 26: Historic evolution of $\hat{\beta}_{0, t}$

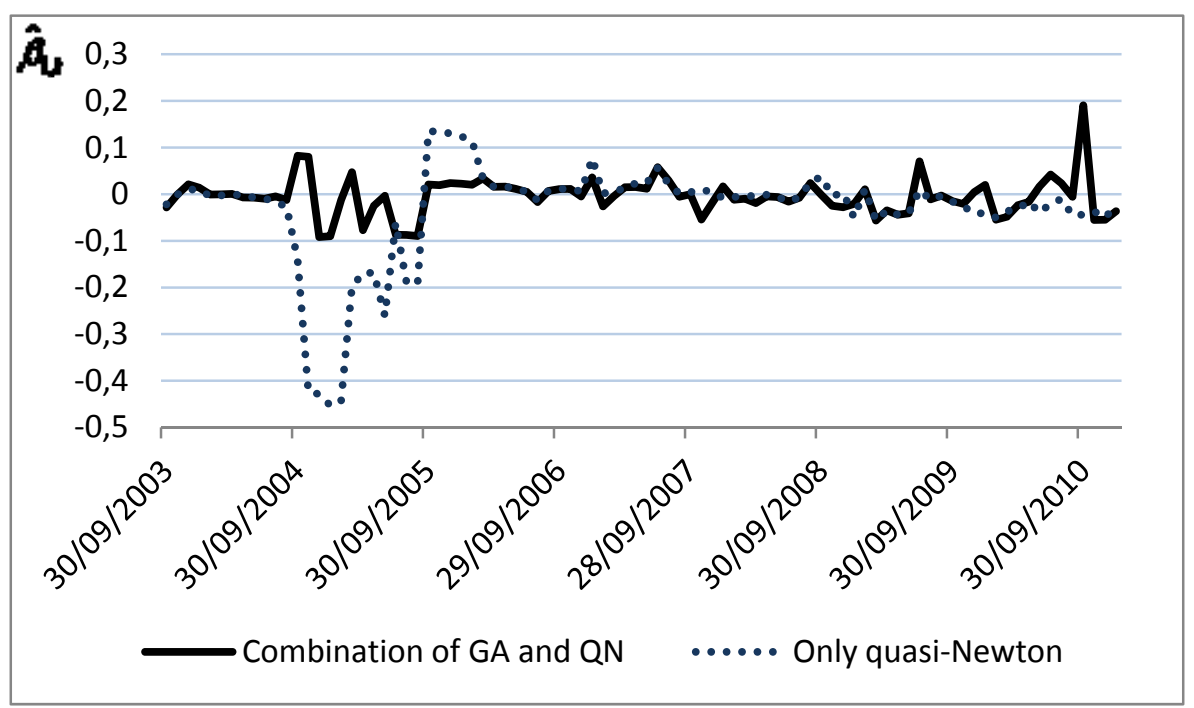

Figure 27: Historic evolution of $\hat{\beta}_{1, t}$ 


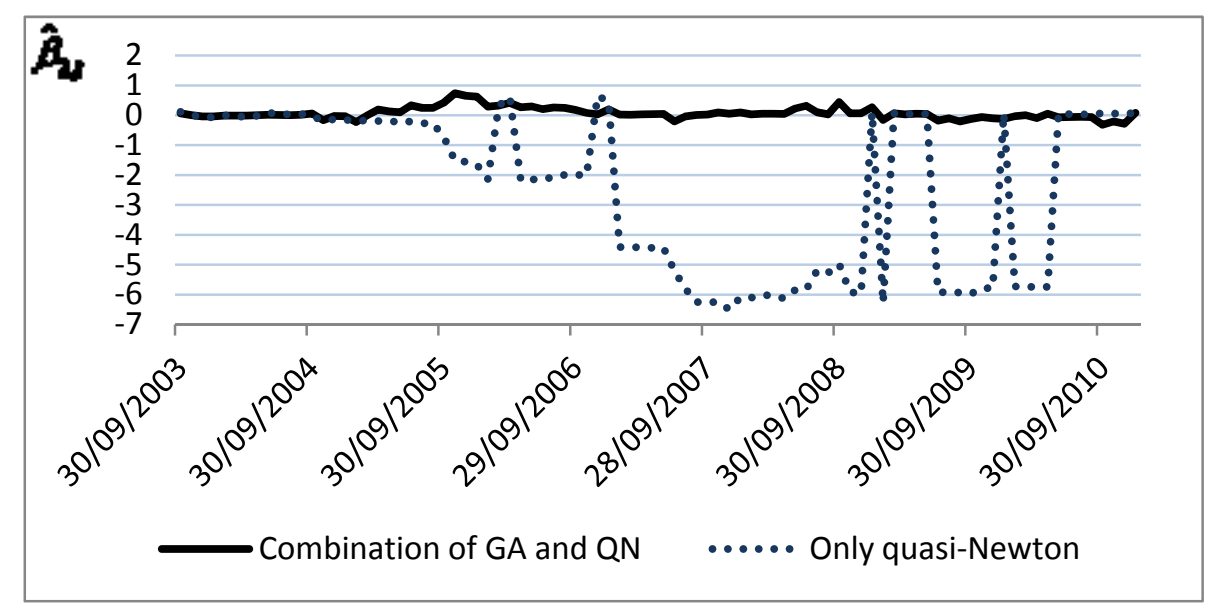

Figure 28: Historic evolution of $\hat{\beta}_{2, t}$

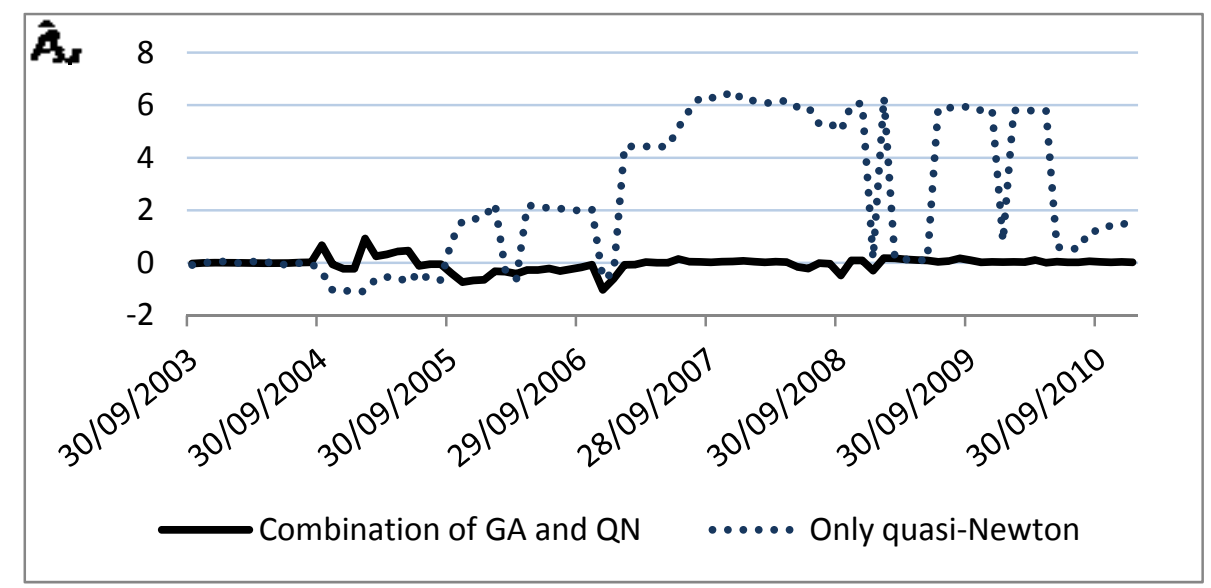

Figure 29: Historic evolution of $\hat{\beta}_{3, t}$

Table 12: Volatility of the parameters obtained with each optimization method

\begin{tabular}{|l|l|l|l|l|l|l|}
\hline Volatility & $\hat{\beta}_{0, t}$ & $\hat{\beta}_{1, t}$ & $\hat{\beta}_{2, t}$ & $\hat{\beta}_{3, t}$ & $\hat{\lambda}_{1, t}$ & $\hat{\lambda}_{2, t}$ \\
\hline QN & 0.116 & 0.110 & 2.681 & 2.734 & 0.407 & 47.310 \\
\hline GA + QN & 0.023 & 0.041 & 0.192 & 0.268 & 3.824 & 1.829 \\
\hline
\end{tabular}




\section{Conclusion and research perspectives}

\section{1}

\section{Conclusion}

In this thesis, I propose a model and methodology for valuing the option to delay network investment decisions and calculating cost-based access prices of regulated telecommunications services, taking into account the demand and technological uncertainties in telecommunications networks.

The proposed model and methodology are built on five pillars:

(i) Different network elements are subject to different demand and technological uncertainties so that an option value multiple should be calculated for each main network element (or at least one for each main part of the telecommunications network: access; switching; transport).

(ii) Retail costs and revenues should be excluded from the markup calculations for (wholesale) network services.

(iii)Technological uncertainty should be modeled through two complementary approaches: one for the technology obsolescence of used equipment and another for the technology evolution of new modern equivalent asset.

(iv)Network costs should be assigned to network services on the basis of how much each service uses each network element.

(v) The cost base used for calculating cost-based access prices should consider not only the cost of investment, but also the net value of the real options involved; i.e., the value of the delay option that is extinguished at the time of investment and the value of the option to invest in the modern equivalent equipment of resized/adjusted capacity.

These pillars led to the definition of the investment project as the purchase, 
installation and operation of a single network element, where each network element provides a hypothetical network service, and the services provided by a number of network elements are combined to form a network service (e.g., interconnection, local loop unbundling, etc). I calculate the option value multiples to be applied to three main network elements, each representing a different part of the Brazilian fixed telecommunications network. After applying the markup factors, network costs should be assigned to services on the basis of how much each service uses each network element.

Working at the network element level allows correctly calculating the costbased price of the hypothetical service provided by each network element, and thus the cost-based price of any network service. All of the needed inputs are either available or can be easily estimated - e.g., operational data (number of access lines in service, minutes of local traffic, minutes of long distance traffic, number of call setups, etc), procurement data (prices of modern equivalent assets/equipment) and average economic asset lives. In the end, the impact of real options on the cost-based price of a regulated telecommunications service will depend on the network elements used by that service and the option value multiple calculated for each network investment decision.

In this thesis, I also investigate the interest rate uncertainty in Brazil for different maturities/terms and propose a method for constructing the Brazilian inflation coupon curve (using a combination of traditional nonlinear optimization algorithm and a genetic algorithm specifically developed for that purpose), although the impact of interest rate uncertainty on the option value multiples has been left as a future research topic.

The proposed model and methodology can be easily applied on top of existing cost studies. By applying them: (i) regulators are able to set cost-based prices for access to the network infrastructure so as to promote service-based (retail) competition without reducing incentives to build new networks and/or upgrade existing ones; and (ii) telecommunications carriers are able to make better investment decisions, considering not only the cost of investment, but also the net value of the real options involved; i.e., the value of the delay option that is extinguished at the time of investment and the value of the option to invest in the 
modern equivalent equipment of resized/adjusted capacity.

\section{2}

\section{Suggestions for future studies}

Some research perspectives can be highlighted.

(a). Other sources of uncertainty can be added to the real options model, such as the uncertainties over interest rates. In a volatile interest rate environment, it is important to evaluate the impact of interest rate uncertainty on the option value multiples derived considering the demand and technological uncertainties in telecommunications networks, and to see whether it is better to use a real options valuation tool with a stochastically modeled risk-free interest rate or if a tool that uses a constant risk-free rate is sufficient, or even if Hull's implied forward rates approach is more appropriate.

(b). Statistical models can be built to estimate the drift and volatility parameters of each geometric Brownian motion (flow of total variable profit and cost of new investment), taking a forward-looking perspective (as opposed to using backward-looking estimates), considering the impact of new entry and/or new technologies that may not be captured using historical data.

(c). The market completeness assumption can be investigated and models for incomplete markets (i.e., when the stochastic fluctuations in $\Pi_{t}$ and $I_{t}$ are not spanned by other assets in the economy) can be built for deriving an interval of option value multiples for each network investment decision. 


\section{References}

Alleman, J., \& Noam, E. (1999). The New Investment Theory of Real Options and Its Implications for Telecommunications Economics. Dordrecht: Kluwer Academic Publishers.

Alleman, J. (2002). A new view of telecommunications economics. Telecommunications Policy, 26(1-2), 87-92.

Alleman, J., \& Rappoport, P. (2002). Modelling regulatory distortions with real options. The Engineering Economist, 47(4), 390-417.

Allen, S. L., \& Kleinstein, A. D. (1991). Valuing Fixed-Income Investments and Derivative Securities: Cash-Flow Analysis and Calculations. New York Institute of Finance.

Alvarez, L. H. R., \& Koskela, E. (2002). Irreversible investment and interest rate variability, Working Paper, Turku School of Economics and Business Administration, Turku, Finland, May 6, 2002.

Anatel (2005a). General regulation of interconnection. Anatel's resolution $n^{\circ}$ 410-2005. Retrieved from http://legislacao.anatel.gov.br/resolucoes (in Portuguese). Consulted 05 January 2013.

Anatel (2005b). Regulation of industrial exploration of leased lines. Anatel's resolution $\mathrm{n}^{\circ}$ 402-2005. Revoked by Anatel's resolution $\mathrm{n}^{\circ}$ 590-2012.

Anatel (2005c). Regulation of account separation and allocation. Anatel's resolution $\mathrm{n}^{\circ}$ 396-2005. Retrieved from http://legislacao.anatel.gov.br/resolucoes (in Portuguese). Consulted 05 January 2013.

Anatel (2006). Regulation of mobile interconnection tariffs. Anatel's resolution $\mathrm{n}^{\circ}$ 438-2006. Retrieved from http://legislacao.anatel.gov.br/resolucoes (in Portuguese). Consulted 05 January 2013.

Anatel (2007). Regulation of fixed interconnection tariffs. Anatel's resolution $\mathrm{n}^{\circ}$ 458-2007. Modified by Anatel's resolution n ${ }^{\circ}$ 588-2012.

Anatel (2012a). Regulation of fixed interconnection tariffs. Anatel's resolution 
$\mathrm{n}^{\circ}$ 588-2012. Retrieved from http://legislacao.anatel.gov.br/resolucoes (in Portuguese). Consulted 05 January 2013.

Anatel (2012b). Regulation of industrial exploration of leased lines. Anatel's resolution $\mathrm{n}^{\circ}$ 590-2012. Retrieved from http://legislacao.anatel.gov.br/resolucoes (in Portuguese). Consulted 05 January 2013.

Anatel (2012c). Telecommunications market statistics. Retrieved from http://www.anatel.gov.br/Portal/exibirPortalInternet.do (in Portuguese). Consulted 01 December 2012.

Anbima (2010). Estrutura a termo das taxas de juros estimada e inflação implícita. Retrieved from http://www.andima.com.br/est_termo/arqs/esttermo_metodologia.pdf (in Portuguese). Consulted 01 July 2012.

Angelou, G. N., \& Economides, A. A. (2009). A multi-criteria game theory and real-options model for irreversible ICT investment decisions. Telecommunications Policy, 33(10-11), 686-705.

Arifovic, J., \& Gencay, R. (2000). Statistical properties of genetic learning in a model of exchange rate. Journal of Economic Dynamics and Control, 24(5-7), 981-1005.

Armstrong, M. (2002). The theory of access pricing and interconnection. In Cave, M. E., Majumdar, S. K. \& Vogelsang, I. (Eds.), Handbook of Telecommunications Economics, vol. 1, Amsterdam: North-Holland.

Banerjee, A., Dolado, J. J., Galbraith, J. W., \& Hendry, D. F. (1993). CoIntegration, Error-Correction, and the Econometric Analysis of Non-Stationary Data. Oxford University Press, USA.

Barrie, \& Hibbert (2008). A framework for estimating and extrapolating the term structure of interest rates. Retrieved from http://www.barrhibb.com/documents/downloads/A_Framework_for_Estimating_a nd_Extrapolating_the_Term_Structure.pdf. Consulted 15 March 2011.

Bertsekas, D. P. (1999). Nonlinear Programming, 2nd edition, Athena Scientific. 
Bourreau, M., Dogan, P., \& Manant, M. (2009). A critical review of the 'ladder of investment' approach. Telecom ParisTech Working Paper No. ESS-09-06.

Bragança, G. G. F. (2005). A remuneração de redes nas telecomunicações e a nova orientação a custos: Avaliação e perspectivas para a telefonia fixa brasileira. Instituto de Pesquisa Econômica Aplicada - IPEA Discussion Paper No. 1104. Retrieved from http://www.ipea.gov.br/pub/td/2005/td_1104.pdf (in Portuguese). Consulted 05 January 2013.

Brandão, L. E. T., \& Gomes, L. L. (2011). Investimentos em Infraestrutura, 1a edição, Mauad X (in Portuguese).

BT Group (2011). Long Run Incremental Cost Model: Relationships and Parameters. Retrieved from http:/www.btplc.com/Thegroup/RegulatoryandPublicaffairs/Financialstatements/ 2011/LongRunIncrementalCostModel2011.pdf. Consulted 05 January 2013.

Camacho, F. T., \& Menezes, F. M. (2009). Access pricing and investment: A real options approach. Journal of Regulatory Economics, 36(2), 107-126.

Cave, M. (2006). Encouraging infrastructure competition via the ladder of investment. Telecommunications Policy, 30 (3-4), 223-237.

Chambers, D. R., Carleton, W. T., \& Waldman, D. M. (1984). A new approach to estimation of the term structure of interest rates. Journal of Financial and Quantitative Analysis, 19(33), 233-252.

Clark, E., \& Easaw, J. Z. (2007). Optimal access pricing for natural monopoly networks when costs are sunk and revenues are uncertain. European Journal of Operational Research, 178(2), 595-602.

Clarke, R. N., Hassett, K. A., Ivanova, Z., \& Kotlikoff, L. J. (2004). Assessing the economic gains from telecom competition. NBER Working Paper No. 10482.

Cooper, R., \& Kaplan, R. S. (1991). Profit priorities from activity-based costing. Harvard Business Review, 69(3), 130-135.

Crandall, R. W., Ingraham, A. T., \& Singer, H. J. (2004). Do unbundling policies discourage CLEC facilities-based investment? B.E. Journals in Economic 
Analysis and Policy, vol. topics.4(1), 14-14.

Crandall, R. W. (2005). Competition and Chaos: U.S. Telecommunications Since the 1996 Telecom Act. The Brookings Institution Press.

Davis, L. (1989). Adapting operator probabilities in genetic algorithms. In J. David Schaffer (Ed.), Proceeding of the Third International Conference on Genetic Algorithms, Morgan Kaufmann Publishers, San Mateo.

Davis, L. (1991). Handbook of Genetic Algorithms, Van Nostrand Reinhold, New York.

Dawid, H. (1999). Adaptative Learning by Genetic Algorithms: Analytical Results and Applications to Economic Models, 2nd edition. Springer, Berlin.

Diebold, F. X., \& Li, C. (2006). Forecasting the term structure of government bond yields. Journal of Econometrics, 130(2), 337-364.

Dias, M. A. G. (2005). Opções Reais Híbridas com Aplicações em Petróleo. Tese de Doutorado - Departamento de Engenharia Industrial, Pontifícia Universidade Católica do Rio de Janeiro (in Portuguese).

Dias, M. A. G. (2013). Análise de Investimentos com Opções Reais: Teoria e Prática. Manuscript in preparation (in Portuguese).

Dixit, A. X., \& Pindyck, R. S. (1994). Investment Under Uncertainty. Princeton University Press, Princeton, NJ.

Dobbs, I. M. (2004), Intertemporal price cap regulation under uncertainty. The Economic Journal, 114, 421-440.

Economides, N., Viard, V. B., \& Seim, K. (2008). Quantifying the benefits of entry into local phone service. RAND Journal of Economics, 39(3), 699-730.

EPT Luxembourg (2007). EPT: Current Cost Accounting. Retrieved from http://www.pt.lu/webdav/site/portailEPT/groups/DT_operators_redacteurs/public/ Regulatory/Costing\%20Model/EPT_CCA_calculation_methodology_20071023.p df. Consulted 10 August 2012.

Eshelman, L., \& Shaffer, J. (1993). Real-coded genetic algorithms and interval 
schemata. In D. L. Whitley (Ed.), Foundations of Genetic Algorithms 2, Morgan Kaufmann Publishers, San Mateo.

Evans, L., \& Guthrie, G. (2006). Incentive regulation of prices when costs are sunk. Journal of Regulatory Economics, 29(3), 239-264.

Fabozzi, J. F. (2006). Bond Markets, Analysis and Strategies, 6th edition. Prentice Hall.

Fisher, M., Nychka D., \& Zervos, D. (1995). Fitting the term structure of interest rates with smoothing splines. Working Paper No. 95-1, Finance and Economics Discussion Series, Federal Reserve Board.

Ford, G. S., \& Pelcovits, M. D. (2002). Unbundling and facilities-based entry by CLECs: Two empirical tests. Retrieved from http://www.aestudies.com/library/twotest.pdf. Consulted 05 January 2013.

Fraletti, P. B. (2004). Ensaios Sobre Taxas de Juros em Reais e Sua Aplicação na Análise Financeira. Tese de Doutorado - FEA, Universidade de São Paulo (in Portuguese).

Franklin Jr., S. L., \& Diallo, M. (2010). Cost-based access pricing and regulatory challenges. Brazilian Journal of Operations \& Production Management, 7(1), 37-51.

Franklin Jr., S. L., \& Diallo, M. (2012). Valuing real options for network investment decisions and cost-based access pricing. The Engineering Economist, $57(4), 223-246$.

Franklin Jr., S. L., Duarte, T. B., Neves, C. R., \& Melo, E. F. L. (2012). A estrutura a termo de taxas de juros no Brasil: Modelos, estimação e testes. Economia Aplicada, 16(2), 255-290 (in Portuguese).

Franklin Jr., S. L., \& Diallo, M. (2013). Real options and cost-based access pricing: Model and methodology. Telecommunications Policy.

Gimeno, R., \& Nave, J. M. (2006). Genetic algorithm estimation of interest rate term structure, Madrid, Banco de España. Documentos de Trabajo, No. 0634. 
Greenstein, S., \& Mazzeo, M. (2003). Differentiation strategy and market deregulation: Local telecommunications entry in the late 1990s. NBER Working Paper No. 9761.

Harmantzis, F., \& Tanguturi, V. P. (2007). Investment decisions in the wireless industry applying real options. Telecommunications Policy, 31(2), 107-123.

Hausman, J. (1999). The effect of sunk costs in telecommunications. In J. Alleman \& E. Noam (Eds.), The New Investment Theory of Real Options and Its Implications for Telecommunications Economics, Dordrecht: Kluwer Academic Publishers.

Hausman, J., \& Myers, S. (2002). Regulating the US railroads: The effects of sunk costs and asymmetric risk. Journal of Regulatory Economics, 22(3), 287310.

Herrera, F., Lozano, M., \& Verdegay, J. L. (1998). Tackling real-coded genetic algorithms: Operators and tools for behavioural analysis. Artificial Intelligence Review, 12(4), 265-319.

Ho, T. S. Y., Stapleton, R., \& Subrahmanyam, M. (1997). The valuation of American options with stochastic interest rates: A generalization of the GeskeJohnson technique. The Journal of Finance, 52(2), 827-840.

Holland, J. (1975). Adaptation in Natural and Artificial Systems. Ann Arbor: The University of Michigan Press.

Hori, K., \& Mizuno, K. (2006). Access pricing and investment with stochastically growing demand. International Journal of Industrial Organization, 24(4), 795-808.

Hull, J. C. (1997). Options, Futures, and Other Derivatives, 3rd edition. Pretince Hall.

Ingersoll Jr., J. E., \& Ross, S. A. (1992). Waiting to Invest: Investment and uncertainty. Journal of Business, 65(1), 1-29.

Jorde, T., Sidak, G, \& Teece, D. (2000). Innovation, investment, and unbundling. Yale Journal on Regulation, 17(1), 1-37. 
Knittel, C. R. (2004). Regulatory restructuring and incumbent price dynamics: The case of US local telephone markets. Review of Economics and Statistics, $86(2), 614-625$.

Krouse, C. G. (2000). LRIC pricing, dynamically competitive markets and incentives to invest in telecommunications. The Antitrust Bulletin/Winter 2000, 45(4), 921-934.

Laffont, J., \& Tirole, J. (2001). Competition in Telecommunications. The MIT Press.

Litzenberger, R. H., \& Rolfo, J. (1984). An international study of tax effects on government bonds. Journal of Finance, 39(1), 1-22.

Marathe, R. R., \& Ryan, S. M. (2005). On the validity of the geometric Brownian motion assumption. The Engineering Economist, 50(2), 159-192.

Miltersen, K. R. (2000). Valuation of natural resource investments with stochastic convenience yields and interest rates. In M.J.Brennan \& L.Trigeorgis (Eds.), Project Flexibility, Agency, and Competition, Oxford University Press.

McCulloch, J. H. (1975). The tax-adjusted yield curve. Journal of Finance, 30(3) 811-830.

McDonald, R., \& Siegel, D. (1986). The value of waiting to invest. The Quarterly Journal of Economics, 101(4), 707-728.

Mitchell, M. (1998). An Introduction to Genetic Algorithms, 1st edition. The MIT Press, Cambridge (MA).

National Congress (1997). General Law of Telecommunications - Law n 9.472 of July 16, 1997. Retrieved from http://www.planalto.gov.br/ccivil_03/leis/L9472.htm (in Portuguese). Consulted 05 January 2013.

Nelson, C. R., \& Siegel, A. F. (1987). Parsimonious modeling of yield curves. The Journal of Business, University of Chicago Press, 60(4), 473-489.

Noam, E. M. (2002). Interconnection practices. In Cave, M., Majumdar, S. \& 
Vogelsang, I. (Eds.), Handbook of Telecommunications Economics, vol. 1, Amsterdam: North-Holland.

Ozorio, L. M., Bastian-Pinto, C. L., \& Brandao, L. E. T. (2012). The choice of stochastic process in real option valuation. In Proceeding of the $14^{\text {th }}$ Annual International Conference on Real Options: Theory Meets Practice, London, UK, June 28-30.

Pelcovits, M. (1999). Application of real options theory to TELRIC models: Real trouble or red herring. In J. Alleman \& E. Noam (Eds.), The New Investment Theory of Real Options and Its Implications for Telecommunications Economics, Dordrecht: Kluwer Academic Publishers.

Pindyck, R. S. (2005). Pricing capital under mandatory unbundling and facilities sharing. NBER Working Paper No. 11225. Retrieved from http://www.nber.org/papers/w11225. Consulted 05 January 2013.

Pindyck, R. S. (2007). Mandatory unbundling and irreversible investment in telecom networks. Review of Network Economics, 6(3), 274-298.

Presidency (2003). Public policies in telecommunications. Brazilian Democratic Republic Presidency decree $\mathrm{n}^{\circ}$ 4733/03. Retrieved from http://www.planalto.gov.br/ccivil_03/decreto/2003/d4733.htm (in Portuguese). Consulted 05 January 2013.

PricewaterhouseCoopers (2001). Analysis of published data. Retrieved from http://tel_archives.ofca.gov.hk/en/report-paperguide/paper/consultation/1027_12.pdf. Consulted 05 January 2013.

Prieger, J. E., \& Heil, D. (2009). Is regulation a roadblock on the information highway? In I. Lee (Ed.), Handbook of Research on Telecommunications Planning and Management for Business, Hershey, PA: IGI Global.

Ray, I. C. (1992). The Bond Market: Trading and Risk Management, McGrawHill.

Salinger, M. A. (1998). Regulating prices to equal forward-looking costs: Costbased prices or price-based costs? Journal of Regulatory Economics, 14(2), 149- 
163.

Sandmann, K. (1993). The pricing of options with an uncertain interest rate: A discrete time approach. Mathematical Finance, 3(2), 201-216.

Schulmerich, M. (2010). Real Options Valuation: The Importance of Interest Rate Modelling in Theory and Practice, 2nd edition. Springer.

Scott, E. C. (2009). Evolution vs. Creationism: An Introduction, 2nd edition. University of California Press.

Small, J. P., \& Ergas, H. (1999). The rental cost of sunk and regulated capital. Econometrics Working Paper No. 9908, Department of Economics, University of Victoria.

Smith, A., \& Wilson, T. (2001). Fitting yield curves with long term constraints. Research Notes, Bacon and Woodrow.

Svensson, L. E. O. (1994). Estimating and interpreting forward interest rates: Sweden 1992-1994. International Monetary Fund Working Paper, No. 114, Washington DC.

Teisberg, E. O. (1993). Capital investment strategies under uncertain regulation. RAND Journal of Economics, 24(4), 591-604.

Telebrasil, \& Teleco (2011). O desempenho do setor de telecomunicações no Brasil - Séries temporais. Retrieved from http://www.telebrasil.org.br/saibamais/o_desempenho_do_setor_de_telecom_-_series_temporais_1t11_f.pdf (in Portuguese). Consulted 10 April 2012.

Teleco (2012). Telecommunications market statistics. Retrieved from http://www.teleco.com.br/ (in Portuguese). Consulted 01 December 2012.

Trigeorgis L. (1996). Real Options: Managerial Flexibility and Strategy in Resource Allocation. Cambridge (MA): MIT Press; 1996.

Valletti, T. M., \& Estache, A. (1999). The theory of access pricing: An overview for infrastructure regulators. World Bank Working Paper No. 2133. Washington, D.C. 
Varga, G. (2009). Teste de modelos estatísticos para a estrutura a termo no Brasil. Revista Brasileira de Economia, 63(4), 361-394 (in Portuguese).

Vasicek, O. (1977). An equilibrium characterization of the term structure. Journal of Financial Economics, 5(8), 177-188.

WikiWealth (2012). Telecom industry WACC. Retrieved from http://www.wikiwealth.com/wacc. Consulted 01 August 2012.

Willig, R. D., Lehr, W. H., Bigelow, J. P., \& Levinson, S. B. (2002). Stimulating investment and the Telecommunications Act of 1996. Unpublished.

Wright, A. (1991). Genetic algorithms for real parameter optimization. In G. J. E. Rawlin (Ed.), Foundations of Genetic Algorithms 1, Morgan Kaufmann Publishers, San Mateo. 


\section{Appendix A - Testing for the GBM model and estimating the drift and volatility parameters of each stochastic process}

If $Y_{t}$ follows geometric Brownian motion with drift and volatility parameters respectively given by $\alpha_{Y}$ and $\sigma_{Y}$, then

$$
\ln \left(Y_{t}\right)=\left(\alpha_{Y}-\sigma_{Y}^{2} / 2\right) t+\ln \left(Y_{0}\right)+\sigma_{Y} N(0,1) \sqrt{t}
$$

Writing the above equation for discrete intervals of time of length $\Delta t=1 / \mathrm{N}$ year(s), leads to

$$
\ln \left(\frac{Y_{i}}{Y_{i-1}}\right)=\frac{a_{Y}}{N}+\frac{\sigma_{Y}}{\sqrt{N}} \varepsilon_{i}, \text { where } a_{Y}=\left(\alpha_{Y}-\sigma_{Y}^{2} / 2\right) \text { and } \varepsilon_{i} \sim N(0,1)
$$

I performed the Dickey-Fuller test running the linear regression model on $\ln \left(Y_{i} / Y_{i-1}\right)=a_{Y} / N+\left(b_{Y}-1\right) \ln \left(Y_{i-1}\right)+\sigma_{Y} / \sqrt{N} \varepsilon_{i}$, and testing whether $b_{Y}=1$. The null hypothesis, $H_{0}$, was $\left(b_{Y}-1\right)=0$, and the alternative hypothesis, $H_{A}$, was $\left(b_{Y}-1\right)<0$.

The regressions were based on quarterly time-series data on the demand stochastic variables (i.e., number of access lines in service, minutes of local traffic and minutes of transport traffic) over a period of 8 to 10 years, and on quarterly time-series data on the cost of new investment stochastic variables (i.e., switching and transmission equipment prices and local loop investment costs, under the modern equivalent asset approach) over a period of 7 to 9 years.

The following estimates and standard errors (reported in parentheses below the estimates) were obtained:

$$
\ln \left(x a_{i} / x a_{i-1}\right)=1.187-0.073 \ln \left(x a_{i-1}\right)+\sigma_{x a} / 2 \varepsilon_{i}
$$




$$
\ln \left(x b_{i} / x b_{i-1}\right)=1.043-0.064 \ln \left(x b_{i-1}\right)+\sigma_{x b} / 2 \varepsilon_{i} ;
$$

$$
\ln \left(x c_{i} / x c_{i-1}\right)=-0.041+0.002 \ln \left(x c_{i-1}\right)+\sigma_{x c} / 2 \varepsilon_{i} ;
$$

$$
\ln \left(I A_{i} / I A_{i-1}\right)=3.276-0.200 \ln \left(I A_{i-1}\right)+\sigma_{I A} / 2 \varepsilon_{i} ;
$$

$$
\text { (1.596) (0.097) }
$$

$$
\begin{aligned}
\ln \left({ }^{I B_{i}} / I B_{i-1}\right)= & -0.310+0.017 \ln \left(I B_{i-1}\right)+\sigma_{I B} / 2 \varepsilon_{i} ; \\
& (0.483) \quad(0.030) \\
\ln \left({ }^{I C_{i}} / I C_{i-1}\right)= & -0.208+0.013 \ln \left(I C_{i-1}\right)+\sigma_{I C} / 2 \varepsilon_{i} . \\
& (0.501) \quad(0.034)
\end{aligned}
$$

The $t$-statistics on the demand stochastic variables are in the range from -1.18 to 0.04 , and the $t$-statistics on the cost of new investment stochastic variables are in the range from -2.05 to 0.58 . In all tests, one cannot reject the null hypothesis (i.e., the assumption that the stochastic variables follow geometric Brownian motion) even at mid to high percentage levels.

Table 13 contains the critical values of the Dickey-Fuller test for various significance levels and sample sizes, taken from Banerjee et al. (1993). 
Table 13: Empirical cumulative distribution of the $t$-student statistic under $H_{0}$

\begin{tabular}{ccccccccc}
\hline \multirow{2}{*}{$\begin{array}{l}\text { Sample } \\
\text { size }\end{array}$} & \multicolumn{7}{l}{ Probability of a smaller value } \\
\cline { 2 - 9 } & 0.01 & 0.025 & 0.05 & 0.10 & 0.90 & 0.95 & 0.975 & 0.99 \\
\hline 25 & -3.75 & -3.33 & -3.00 & -2.63 & -0.37 & 0.00 & 0.34 & 0.72 \\
50 & -3.58 & -3.22 & -2.93 & -2.60 & -0.40 & -0.03 & 0.29 & 0.66 \\
100 & -3.51 & -3.17 & -2.89 & -2.58 & -0.42 & -0.05 & 0.26 & 0.63 \\
250 & -3.46 & -3.14 & -2.88 & -2.57 & -0.42 & -0.06 & 0.24 & 0.62 \\
500 & -3.44 & -3.13 & -2.87 & -2.57 & -0.43 & -0.07 & 0.24 & 0.61 \\
$\infty$ & -3.43 & -3.12 & -2.86 & -2.57 & -0.44 & -0.07 & 0.23 & 0.60
\end{tabular}

Although the Dickey-Fuller test is widely used in the real options practice, the failure to reject $H_{0}$ only means that the data do not provide evidence against $H_{0}$. Further discussion about the choice of stochastic process in real options valuation and the main tests used to support that task can be found in Ozorio et al. (2012).

I followed the procedure in Marathe and Ryan (2005) and also checked for the GBM process fit, testing the assumptions of normality of $\log$ ratios and independence of log ratios from past data:

- The Jarque-Bera $(J B)$ test was used to check for the normality of log ratios. The $J B$ test is a goodness-of-fit test of whether sample data have the skewness and kurtosis matching a normal distribution. If the data come from a normal distribution, the $J B$ statistic asymptotically has a chi-squared distribution with two degrees of freedom. However, for small samples the chi-squared approximation is overly sensitive, often rejecting the null hypothesis when it is true. In fact, the sample sizes in the range between 28 and 38 observations are too small, so that the results of the normality test are very sensitive to one or two outliers.

- The Ljung-Box $(L B)$ test was used to check for the serial independence of $\log$ ratios. The $L B$ test is a statistical test of whether the time-series data are independently distributed (i.e., the correlations in the population from which 
the sample is taken are zero, so that any observed correlations in the data result from randomness of the sampling process). For all stochastic processes modeled (demand and cost of new investment), the p-values varied in the range from $37 \%$ to $94 \%$.

The sample mean and sample variance of $\ln \left(Y_{i} / Y_{i-1}\right)$ were used to estimate the drift and volatility parameters of each stochastic process.

From equation (A.1):

$$
\left\{\begin{array}{l}
E\left[\ln \left(Y_{i} / Y_{i-1}\right)\right]=a_{Y} / N=\left(\alpha_{Y}-\sigma_{Y}^{2} / 2\right)(1 / N), \\
\operatorname{Var}\left[\ln \left(Y_{i} / Y_{i-1}\right)\right]=\sigma_{Y}^{2} / N
\end{array}\right.
$$

Therefore:

$$
\left\{\begin{array}{l}
\hat{\sigma}_{Y}^{2}=N\left\{\text { sample variance of } \ln \left(Y_{i} / Y_{i-1}\right)\right\}, \\
\hat{\alpha}_{Y}=\hat{a}_{Y}+\hat{\sigma}_{Y}^{2} / 2=N\left\{\text { sample mean of } \ln \left(Y_{i} / Y_{i-1}\right)+\frac{\text { sample variance of } \ln \left(Y_{i} / Y_{i-1}\right)}{2}\right\} .
\end{array}\right.
$$




\section{Appendix B - Actual cost and volume data}

The cost and volume data used in this thesis were based on the actual cost study of an incumbent telecommunications carrier for the project to build an IP/NGN network in a small metropolitan area.

The network components modeled in the IP network included:

- The access network, which is based around a copper cable infrastructure containing the following components: copper multi-pair cables; joints; manholes; poles; ducts; distribution points, dropwires and network interface devices.

- The core transmission network, which is based around optical fiber cables (either underground in ducts or aerial, supported on poles) containing the following components: fiber cables; fiber joints; ducts, poles and manholes. The transmission network is based on traditional SDH equipment, in a resilient ring configuration providing a minimum of 1 STM1 link to each remote service unit.

- Media Gateways (MG) connecting to the copper access network and providing the functionality for provision of voice calls. ADSL services are provided via a collocated DSLAM unit.

- Softswitch/Multi-Service Edge and Voice Packet Gateway routing calls between the Media Gateways and providing the link between the carrier's network and outside networks. The two softswitches modeled are capable of handling all the international and national traffic, so there is no separate international switching element.

The IP network was dimensioned to meet the forecast demand for voice and data services over the next three years. Table 14 shows the cost and volume information of three network elements - Local Access Loop $\left(\mathrm{NE}_{\mathrm{A}}\right)$, PSTN Host Switch/Duration Sensitive $\left(\mathrm{NE}_{\mathrm{B}}\right)$, and Host-Host Transmission $\left(\mathrm{NE}_{\mathrm{C}}\right)-$ taken from the actual cost study, suitably modified to preserve the carrier's anonymity. 
Table 14: Cost and volume information of $\mathrm{NE}_{\mathrm{A}}, \mathrm{NE}_{\mathrm{B}}$, and $\mathrm{NE}_{\mathrm{C}}$

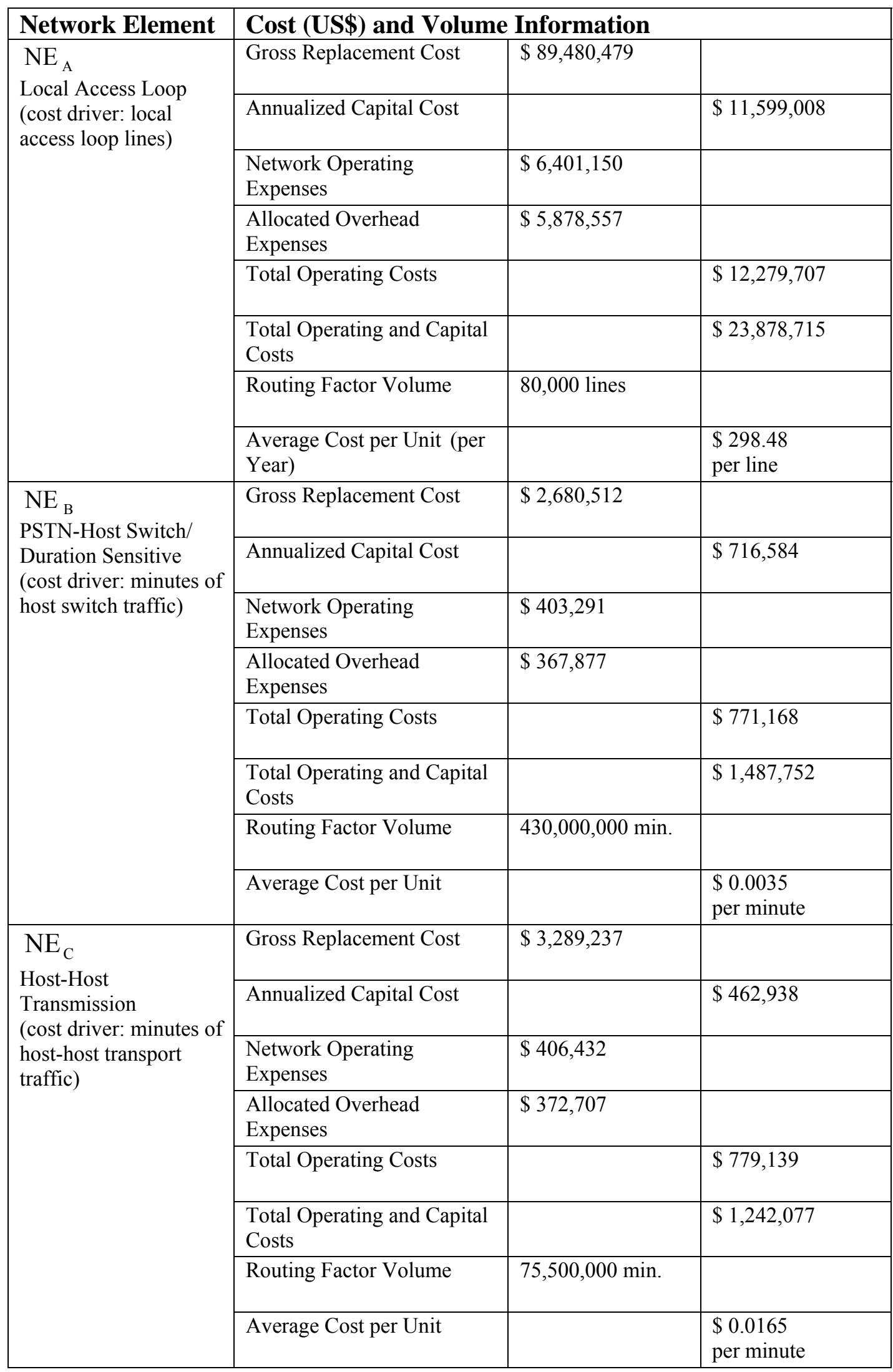




\section{Appendix C - A note on exponential/Poisson decay}

The assumption that the economic depreciation is exponential/Poisson decay at rate $\lambda$ (so that the asset's lifetime $T_{I O}$ has exponential distribution with rate $\lambda$ ) can be thought of as the expected value of the used asset (e.g., the network element) declining exponentially at rate $\lambda$.

To see this, let's represent the value at $t+u$, of a used asset bought at $t$, as a random variable $I O_{u}^{t}(u \geq 0)$; its value at time $t$ is $I O_{0}^{t}=I_{t}$, so that the value of the used asset at $t$ (the moment the asset is purchased) is equal to the value of a new one.

If the asset's economic depreciation is exponential/Poisson decay at rate $\lambda$, the change in value of the used asset in the infinitesimal interval of time $[t+u, t+u+d u)$ is a random variable that can take either the value zero or $I_{t}$ :

$$
-d I O_{u}^{t}=\left\{\begin{array}{l}
I_{t}, \text { if } T_{I O} \notin[u, u+d u), \text { what happens with probability } \lambda e^{-\lambda u} d u, \\
0, \text { if } T_{I O} \notin[u, u+d u), \text { what happens with probability } 1-\lambda e^{-\lambda u} d u
\end{array}\right.
$$

Therefore, the expected change in value of the used asset is $E\left[-d I O_{u}^{t}\right]=I_{t} \lambda e^{-\lambda u} d u$, and the expected value of used asset itself is

$$
\begin{aligned}
& E\left[I O_{u}^{t}\right]=E\left[I_{t}-\int_{0}^{u} d I O_{s}^{t}\right]=I_{t}-\int_{0}^{u} E\left[d I O_{s}^{t}\right]=I_{t}-\int_{0}^{u} I_{t} \lambda e^{-\lambda s} d s=I_{t}-I_{t}\left(1-e^{-\lambda u}\right) . \\
& \left.\Rightarrow E\left[I O_{u}^{t}\right]=I_{t} e^{-\lambda u} \text { (which declines exponentially at rate } \lambda\right) .
\end{aligned}
$$

Taking a different perspective, the assumption that the expected value of the used asset declines exponentially at rate $\lambda$ can be written as $E\left[I O_{u}^{t}\right]=I_{t} e^{-\lambda u}$, so that $\frac{d E\left[I O_{u}^{t}\right]}{d u}=-I_{t} \lambda e^{-\lambda u}$. During the infinitesimal interval of time $[t+u, t+u+d u)$, the change in the expected value of the used asset is $-d E\left[I O_{u}^{t}\right]=I \lambda e^{-\lambda u} d u$. 
Define the random variable $T_{I O}$ with exponential probability density function of $f_{T_{I O}}(u)=\left\{\begin{array}{l}\lambda e^{-\lambda u}, \text { for } u \geq 0, \\ 0, \text { for } u<0,\end{array}\right.$ so that $P\left(T_{I O} \in[u, u+d u)\right)=\lambda e^{-\lambda u} d u$, for $u \geq 0$.

The change in the expected value of the used asset in the infinitesimal interval of time $[t+u, t+u+d u)$ is equal to the product of $I_{t}$ and $P\left(T_{I O} \in[u, u+d u)\right)$, which is the expected value of a random variable that can take either the value zero or $I_{t}$ :

$$
-d I O_{u}^{t}=\left\{\begin{array}{l}
I_{t}, \text { if } T_{I O} \notin[u, u+d u), \text { what happens with probability } \lambda e^{-\lambda u} d u, \\
0, \text { if } T_{I O} \notin[u, u+d u), \text { what happens with probability } 1-\lambda e^{-\lambda u} d u .
\end{array}\right.
$$

Thus, $T_{I O}$ can be interpreted as the random lifetime of the used asset (a random variable with exponential distribution of parameter $\lambda$ ), so that the event asset death follows a Poisson process with parameter $\lambda$. 


\section{Appendix D - Proof that $\mu_{I \Delta}>\mu_{\Pi \Delta}$ (for $\Delta=A, B, C$ )}

From equation (5.1), the demand for $\mathrm{NE}_{\mathrm{i}}$ 's hypothetical network service, $x_{t}$, follows geometric Brownian motion with drift and volatility parameters given by $\alpha_{x}$ and $\sigma_{x}$.

From equation (5.2), the flow of total variable profit from the provision of $\mathrm{NE}_{\mathrm{i}}$ 's hypothetical network service, $\Pi_{t}=p_{t} x_{t}$, follows geometric Brownian motion with drift and volatility parameters given by $\alpha_{\Pi}=\alpha_{x}+\alpha_{p}$ and $\sigma_{\Pi}=\sigma_{x}$.

From equations (5.3) and (5.4), the cost of new investment in $\mathrm{NE}_{\mathrm{i}}$ (i.e., the cost of a new modern equivalent asset of resized/adjusted capacity), $I_{t}$, follows geometric Brownian motion with drift and volatility parameters given by $\alpha_{I}$ and $\sigma_{I}$, where $\rho_{\Pi, I}=\operatorname{Corr}\left(\varepsilon_{\Pi}, \varepsilon_{I}\right)$ and $d z_{\Pi} d z_{I}=\rho_{\Pi, I} d t$.

From equations (5.5) and (5.6): $\mu_{\Pi}=r+\phi_{M} \sigma_{\Pi} \rho_{\Pi, M} ; \mu_{I}=r+\phi_{M} \sigma_{I} \rho_{I, M}$.

The cost of new investment in $\mathrm{NE}_{i}$ depends on two variables: (i) the stochastic price per-unit of capacity of $\mathrm{NE}_{\mathrm{i}}$ 's modern equivalent asset; (ii) the capacity required to meet the stochastic demand for $\mathrm{NE}_{\mathrm{i}}{ }^{\prime} \mathrm{s}$ hypothetical network service. Let $q_{t}$ denote the stochastic price per-unit of capacity of $\mathrm{NE}_{\mathrm{i}}$ 's modern equivalent asset, and $x_{t}$ denote the resized/adjusted capacity measured in terms of $\mathrm{NE}_{\mathrm{i}}{ }^{\prime} \mathrm{s}$ cost driver volume, so that $I_{t}=q_{t} x_{t}$.

The correlations between $q_{t}$ and $x_{t}$, and between $q_{t}$ and the market portfolio are assumed to be positive, so that $\rho_{q, x}=\operatorname{Corr}\left(\varepsilon_{q}, \varepsilon_{x}\right)>0$ and $\rho_{q, M}=\operatorname{Corr}\left(\varepsilon_{q}, \varepsilon_{M}\right)>0$.

I show bellow that $\sigma_{I} \rho_{I, M}>\sigma_{x} \rho_{x, M}=\sigma_{\Pi} \rho_{\Pi, M}$, so that $\mu_{I}=r+\phi_{M} \sigma_{I} \rho_{I, M}$ is greater than $\mu_{\Pi}=r+\phi_{M} \sigma_{\Pi} \rho_{\Pi, M}=r+\phi_{M} \sigma_{x} \rho_{x, M}$ (i.e., $\mu_{I}>\mu_{\Pi}$ ). 
Firstly, I write $\sigma_{I}$ in terms of the GBM parameters of $x_{t}$ and $q_{t}$, as shown below.

$$
\begin{aligned}
& d I=(q+d q)(x+d x)-q x=q x+q d x+x d q+d q d x-q x \\
& =q \cdot d x+x \cdot d q+\sigma_{q} \cdot \sigma_{x} \cdot q \cdot x \cdot \rho_{q, x} \cdot d t \\
& \text { where } \rho_{q, x}=\operatorname{Corr}\left(\varepsilon_{q}, \varepsilon_{x}\right)=\operatorname{Coef} . \operatorname{Corr}(d q, d x)=\operatorname{Coef} . \operatorname{Corr}\left(d z_{q}, d z_{x}\right) . \\
& d I=q\left(\alpha_{x} x d t+\sigma_{x} x d z_{x}\right)+x\left(\alpha_{q} q d t+\sigma_{q} q d z_{q}\right)+\sigma_{q} \sigma_{x} q x \rho_{q, x} d t \\
& =\left(\alpha_{x} q x+\alpha_{q} q x+\sigma_{q} \sigma_{x} q x \rho_{q, x}\right) d t+\sigma_{x} q x d z_{x}+\sigma_{q} q x d z_{q} \\
& =\left(\alpha_{x}+\alpha_{q}+\sigma_{q} \sigma_{x} \rho_{q, x}\right) I d t+\left(\sigma_{x} d z_{x}+\sigma_{q} d z_{q}\right) I .
\end{aligned}
$$

Note that:

$E\left[\sigma_{x} d z_{x}+\sigma_{q} d z_{q}\right]=0 ;$

$\operatorname{Var}\left(\sigma_{x} d z_{x}+\sigma_{q} d z_{q}\right)=E\left[\left(\sigma_{x} d z_{x}+\sigma_{q} d z_{q}\right)^{2}\right]=\left(\sigma_{x}^{2}+\sigma_{q}^{2}+2 \sigma_{q} \sigma_{x} \rho_{q, x}\right) d t ;$

$\operatorname{Std}\left(\sigma_{x} d z_{x}+\sigma_{q} d z_{q}\right)=\sqrt{\sigma_{x}^{2}+\sigma_{q}^{2}+2 \sigma_{q} \sigma_{x} \rho_{q, x}} \sqrt{d t}$.

If $\left\lfloor\varepsilon_{x}, \varepsilon_{q}\right\rfloor$ forms a Gaussian vector, then $\sigma_{x} d z_{x}+\sigma_{q} d z_{q} \sim N\left(0, \sigma_{I}^{2} d t\right)=\sigma_{I} d z_{I}$, where

$$
\left\{\begin{array}{l}
\sigma_{I}=\sqrt{\sigma_{x}^{2}+\sigma_{q}^{2}+2 \sigma_{q} \sigma_{x} \rho_{q, x}}, \\
d z_{I} \text { is a Wiener increment; } d z_{I}=\varepsilon_{I} \sqrt{d t} ; \varepsilon_{I} \sim N(0,1) .
\end{array}\right.
$$

Therefore, $I_{t} \sim G B M$ and $d I=\alpha_{I} I d t+\sigma_{I} I d z_{I}$, where

$$
\left\{\begin{array}{l}
\alpha_{I}=\alpha_{x}+\alpha_{q}+\sigma_{q} \sigma_{x} \rho_{q, x}, \\
\sigma_{I}=\sqrt{\sigma_{x}^{2}+\sigma_{q}^{2}+2 \sigma_{q} \sigma_{x} \rho_{q, x}}
\end{array}\right.
$$

Secondly, I compare $\sigma_{I} \rho_{I, M}$ with $\sigma_{x} \rho_{x, M}=\sigma_{\Pi} \rho_{\Pi, M}$, as shown below.

$$
\begin{aligned}
& \rho_{I, M}=\operatorname{Coef} . \operatorname{Cor}(d I, d M)=\frac{\operatorname{Cov}(d I, d M)}{\operatorname{StD}(d I) \operatorname{StD}(d M)}=\frac{\operatorname{Cov}\left(\sigma_{x} I d z_{x}+\sigma_{q} I d z_{q}, d M\right)}{\sigma_{I} \sigma_{M} I M d t} \\
& =\frac{\operatorname{Cov}\left(\sigma_{x} d z_{x}+\sigma_{q} d z_{q}, d M\right)}{\sigma_{I} \sigma_{M} M d t} . \\
& \Rightarrow \sigma_{I} \rho_{I, M}=\frac{\operatorname{Cov}\left(\sigma_{x} d z_{x}, d M\right)}{\sigma_{M} M d t}+\frac{\operatorname{Cov}\left(\sigma_{q} d z_{q}, d M\right)}{\sigma_{M} M d t} .
\end{aligned}
$$


$\rho_{\Pi, M}=\operatorname{Coef} . \operatorname{Corr}(d \Pi, d M)=\rho_{x, M}=\operatorname{Coef} . \operatorname{Corr}(d x, d M)$

$=\frac{\operatorname{Cov}(d x, d M)}{\operatorname{StD}(d x) \operatorname{StD}(d M)}=\frac{\operatorname{Cov}\left(\sigma_{x} x d z_{x}, d M\right)}{\sigma_{x} \sigma_{M} x M d t}$.

$\Rightarrow \sigma_{x} \rho_{x, M}=\frac{\operatorname{Cov}\left(\sigma_{x} d z_{x}, d M\right)}{\sigma_{M} M d t}$

As a result:

$\sigma_{I} \rho_{I, M}=\sigma_{x} \rho_{x, M}+\frac{\operatorname{Cov}\left(\sigma_{q} d z_{q}, d M\right)}{\sigma_{M} M d t}$, where $\frac{\operatorname{Cov}\left(\sigma_{q} d z_{q}, d M\right)}{\sigma_{M} M d t}>0$

$\left(\right.$ since $\left.\operatorname{Coef} . \operatorname{Corr}(d q, d M)=\operatorname{Corr}\left(\varepsilon_{q}, \varepsilon_{M}\right)>0\right)$.

Finally:

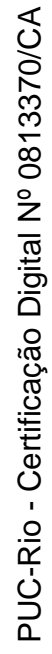

$\sigma_{I} \rho_{I, M}>\sigma_{x} \rho_{x, M}$

$\Rightarrow \mu_{I}=r+\phi_{M} \sigma_{I} \rho_{I, M}>\mu_{\Pi}=\mu_{x}=r+\phi_{M} \sigma_{x} \rho_{x, M}$. 


\section{Annex A - Operational data and calculations for the demand stochastic variables}

Publicly available quarterly time-series data on number of access lines in service, minutes of local traffic and minutes of transport traffic.

\begin{tabular}{|c|c|c|c|}
\hline \multicolumn{4}{|c|}{ Incumbent carrier $\left(^{\star}\right)$} \\
\hline & \multicolumn{2}{|c|}{$\begin{array}{l}\text { Minutes of traffic (million) } \\
\text { (per quarter - Q) }\end{array}$} & $\begin{array}{c}\text { Access lines } \\
\text { (end of quarter - EoQ) }\end{array}$ \\
\hline & Local traffic $\left(^{* \star}\right)$ & Long distance national & Access lines in service \\
\hline 4Q01 & $18,063,852$ & $3,583,644$ & $12,616,006$ \\
\hline 1Q02 & $17,610,798$ & $3,567,433$ & $12,576,797$ \\
\hline $2 \mathrm{Q} 02$ & $17,916,084$ & $3,574,603$ & $12,511,515$ \\
\hline 3Q02 & $17,751,178$ & $3,609,877$ & $12,560,848$ \\
\hline 4Q02 & $18,466,036$ & $4,174,964$ & $12,505,888$ \\
\hline 1Q03 & $17,669,852$ & $4,045,876$ & $12,413,480$ \\
\hline 2Q03 & $18,235,898$ & $4,110,514$ & $12,402,359$ \\
\hline 3Q03 & $17,705,198$ & $4,078,804$ & $12,353,353$ \\
\hline $4 \mathrm{QQ03}$ & $18,190,000$ & $4,141,645$ & $12,296,903$ \\
\hline 1Q04 & $17,063,638$ & $4,111,540$ & $12,227,546$ \\
\hline 2Q04 & $16,945,346$ & $3,936,645$ & $12,220,787$ \\
\hline 3Q04 & $16,770,118$ & $4,001,210$ & $12,383,565$ \\
\hline 4Q04 & $16,243,512$ & $3,819,901$ & $12,443,651$ \\
\hline 1Q05 & $15,729,648$ & $3,569,844$ & $12,344,876$ \\
\hline 2Q05 & $16,026,990$ & $3,593,171$ & $12,423,222$ \\
\hline 3Q05 & $16,078,118$ & $3,517,890$ & $12,434,277$ \\
\hline 4Q05 & $15,844,382$ & $3,455,078$ & $12,331,181$ \\
\hline 1Q06 & $15,357,246$ & $3,336,918$ & $12,362,533$ \\
\hline 2Q06 & $14,529,896$ & $3,292,161$ & $12,328,170$ \\
\hline 3Q06 & $13,766,406$ & $3,192,437$ & $12,286,772$ \\
\hline 4Q06 & $13,042,382$ & $3,207,408$ & $12,101,163$ \\
\hline 1Q07 & $12,805,659$ & $3,104,562$ & $12,020,677$ \\
\hline 2Q07 & $12,929,680$ & $3,010,806$ & $12,008,842$ \\
\hline 3Q07 & $14,581,243$ & $2,781,518$ & $12,015,558$ \\
\hline 4Q07 & $14,161,931$ & $2,979,448$ & $11,959,004$ \\
\hline 1Q08 & $13,463,208$ & $2,918,812$ & $11,931,734$ \\
\hline 2Q08 & $12,893,965$ & $3,024,398$ & $11,895,155$ \\
\hline 3Q08 & $12,802,067$ & $2,918,200$ & $10,894,861$ \\
\hline 4Q08 & $12,594,470$ & $2,902,075$ & $10,728,248$ \\
\hline 1Q09 & $11,754,539$ & $2,752,687$ & $10,641,230$ \\
\hline $2 Q 09$ & $12,563,092$ & $2,694,557$ & $11,474,532$ \\
\hline 3Q09 & $13,266,383$ & $2,645,317$ & $11,332,596$ \\
\hline 4Q09 & $13,938,186$ & $2,655,331$ & $11,250,351$ \\
\hline 1Q10 & $\mathrm{N} / \mathrm{A}$ & $\mathrm{N} / \mathrm{A}$ & $11,192,378$ \\
\hline
\end{tabular}




\begin{tabular}{|l|l|l|l|}
\hline 2Q10 & N/A & N/A & $11,259,982$ \\
\hline 3Q10 & N/A & N/A & $11,308,699$ \\
\hline 4Q10 & N/A & N/A & $11,308,564$ \\
\hline 1Q11 & N/A & N/A & $11,181,147$ \\
\hline 2Q11 & N/A & N/A & $11,133,996$ \\
\hline
\end{tabular}

Source: telecom operator

(*) Telefônica

$\left.{ }^{* *}\right)$ Includes intra-state and inter-state traffic (fixed-fixed and fixed-mobile). For timeseries data prior to July/2007, pulses were converted to minutes using a factor of two. 
Estimating the demand drift and volatility parameters (for each network element):

a) Local Access Loop $\left(\mathrm{NE}_{\mathrm{A}}\right)$

\begin{tabular}{|c|c|c|c|c|}
\hline $\begin{array}{l}\text { End of } \\
\text { quarter } \\
\text { (EoQ) }\end{array}$ & $\begin{array}{c}\text { Access lines } \\
\text { in service } \\
x a_{i}\end{array}$ & $\frac{x a_{i}}{x a_{i-1}}$ & $\ln \left(\frac{x a_{i}}{x a_{i-1}}\right)$ & $\left\{\ln \left(\frac{x a_{i}}{x a_{i-1}}\right)\right\}^{2}$ \\
\hline 4Q01 & $12,616,006$ & --- & --- & --- \\
\hline 1Q02 & $12,576,797$ & 0.99689 & -0.00311 & 0.00001 \\
\hline 2Q02 & $12,511,515$ & 0.99481 & -0.00520 & 0.00003 \\
\hline 3Q02 & $12,560,848$ & 1.00394 & 0.00394 & 0.00002 \\
\hline 4Q02 & $12,505,888$ & 0.99562 & -0.00439 & 0.00002 \\
\hline 1Q03 & $12,413,480$ & 0.99261 & -0.00742 & 0.00006 \\
\hline 2Q03 & $12,402,359$ & 0.99910 & -0.00090 & 0.00000 \\
\hline 3Q03 & $12,353,353$ & 0.99605 & -0.00396 & 0.00002 \\
\hline 4Q03 & $12,296,903$ & 0.99543 & -0.00458 & 0.00002 \\
\hline 1Q04 & $12,227,546$ & 0.99436 & -0.00566 & 0.00003 \\
\hline 2Q04 & $12,220,787$ & 0.99945 & -0.00055 & 0.00000 \\
\hline 3Q04 & $12,383,565$ & 1.01332 & 0.01323 & 0.00018 \\
\hline 4Q04 & $12,443,651$ & 1.00485 & 0.00484 & 0.00002 \\
\hline 1Q05 & $12,344,876$ & 0.99206 & -0.00797 & 0.00006 \\
\hline $2 \mathrm{Q} 05$ & $12,423,222$ & 1.00635 & 0.00633 & 0.00004 \\
\hline 3Q05 & $12,434,277$ & 1.00089 & 0.00089 & 0.00000 \\
\hline $4 \mathrm{Q} 05$ & $12,331,181$ & 0.99171 & -0.00833 & 0.00007 \\
\hline 1Q06 & $12,362,533$ & 1.00254 & 0.00254 & 0.00001 \\
\hline 2Q06 & $12,328,170$ & 0.99722 & -0.00278 & 0.00001 \\
\hline 3Q06 & $12,286,772$ & 0.99664 & -0.00336 & 0.00001 \\
\hline 4Q06 & $12,101,163$ & 0.98489 & -0.01522 & 0.00023 \\
\hline 1Q07 & $12,020,677$ & 0.99335 & -0.00667 & 0.00004 \\
\hline 2Q07 & $12,008,842$ & 0.99902 & -0.00099 & 0.00000 \\
\hline 3Q07 & $12,015,558$ & 1.00056 & 0.00056 & 0.00000 \\
\hline 4Q07 & $11,959,004$ & 0.99529 & -0.00472 & 0.00002 \\
\hline 1Q08 & $11,931,734$ & 0.99772 & -0.00228 & 0.00001 \\
\hline 2Q08 & $11,895,155$ & 0.99693 & -0.00307 & 0.00001 \\
\hline 3Q08 & $10,894,861$ & 0.91591 & -0.08784 & 0.00772 \\
\hline 4Q08 & $10,728,248$ & 0.98471 & -0.01541 & 0.00024 \\
\hline 1Q09 & $10,641,230$ & 0.99189 & -0.00814 & 0.00007 \\
\hline 2Q09 & $11,474,532$ & 1.07831 & 0.07539 & 0.00568 \\
\hline 3Q09 & $11,332,596$ & 0.98763 & -0.01245 & 0.00015 \\
\hline 4Q09 & $11,250,351$ & 0.99274 & -0.00728 & 0.00005 \\
\hline 1Q10 & $11,192,378$ & 0.99485 & -0.00517 & 0.00003 \\
\hline 2Q10 & $11,259,982$ & 1.00604 & 0.00602 & 0.00004 \\
\hline 3Q10 & $11,308,699$ & 1.00433 & 0.00432 & 0.00002 \\
\hline 4Q10 & $11,308,564$ & 0.99999 & -0.00001 & 0.00000 \\
\hline 1Q11 & $11,181,147$ & 0.98873 & -0.01133 & 0.00013 \\
\hline 2Q11 & $11,133,996$ & 0.99578 & -0.00423 & 0.00002 \\
\hline \multicolumn{2}{|c|}{$\begin{array}{l}\text { Sample mean } \\
\text { Sample variance }\end{array}$} & & $\begin{array}{r}-0.00329 \\
0.00040 \\
\end{array}$ & \\
\hline & & \multicolumn{2}{|c|}{$\hat{\alpha}_{x a}=$} & \\
\hline & & \multicolumn{2}{|c|}{$\hat{\sigma}_{x a}=$} & \\
\hline & & Linea & YReg & $X R e g$ \\
\hline
\end{tabular}




\begin{tabular}{|c|c|c|}
\hline regression & {$\left[\ln \left(\frac{x a_{i}}{x a_{i-1}}\right)\right.$} & \\
& --- & $\ln \left(x a_{i-1}\right)$ \\
\hline 4Q01 &.--- \\
1Q02 & -0.0311 & 16.35048 \\
2Q02 & -0.00520 & 16.34736 \\
3Q02 & 0.00394 & 16.34216 \\
4Q02 & -0.00439 & 16.34610 \\
1Q03 & -0.00742 & 16.34171 \\
2Q03 & -0.00090 & 16.33429 \\
3Q03 & -0.00396 & 16.33340 \\
4Q03 & -0.00458 & 16.32944 \\
1Q04 & -0.00566 & 16.32486 \\
2Q04 & -0.00055 & 16.31920 \\
3Q04 & 0.01323 & 16.31865 \\
4Q04 & 0.00484 & 16.33188 \\
1Q05 & -0.00797 & 16.33672 \\
2Q05 & 0.00633 & 16.32875 \\
3Q05 & 0.00089 & 16.33508 \\
4Q05 & -0.00833 & 16.33597 \\
1Q06 & 0.00254 & 16.32764 \\
2Q06 & -0.00278 & 16.33018 \\
3Q06 & -0.00336 & 16.32740 \\
4Q06 & -0.01522 & 16.32403 \\
1Q07 & -0.00667 & 16.30881 \\
2Q07 & -0.00099 & 16.30214 \\
3Q07 & 0.00056 & 16.30115 \\
4Q07 & -0.00472 & 16.30171 \\
1Q08 & -0.00228 & 16.29700 \\
2Q08 & -0.00307 & 16.29471 \\
3Q08 & -0.08784 & 16.29164 \\
4Q08 & -0.01541 & 16.20380 \\
1Q09 & -0.00814 & 16.18839 \\
2Q09 & 0.07539 & 16.18025 \\
3Q09 & -0.01245 & 16.25564 \\
4Q09 & -0.00728 & 16.24319 \\
1Q10 & -0.00517 & 16.23591 \\
2Q10 & 0.00602 & 16.23074 \\
3Q10 & 0.00432 & 16.23677 \\
4Q10 & -0.00001 & 16.24108 \\
1Q11 & -0.01133 & 16.24107 \\
2Q11 & -0.00423 & 16.22974 \\
& & \\
\hline
\end{tabular}

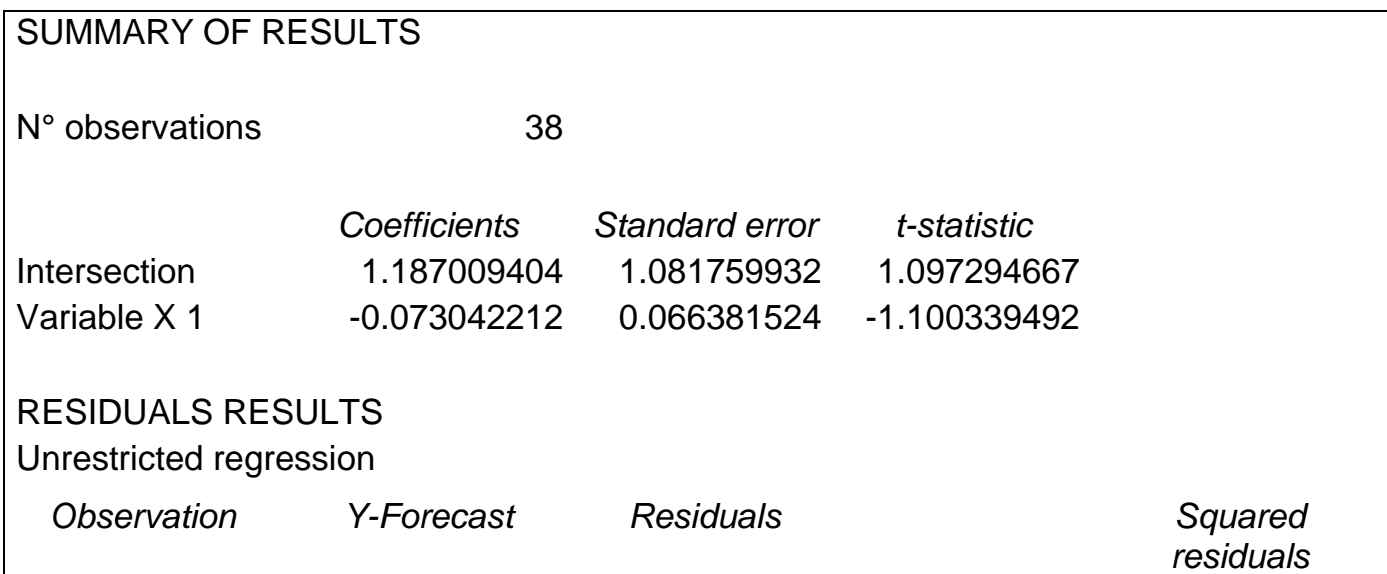




\begin{tabular}{|c|c|c|c|}
\hline 1 & -0.007265601 & 0.004152884 & 1.72464E-05 \\
\hline 2 & -0.007038241 & 0.001834053 & 3.36375E-06 \\
\hline 3 & -0.006658116 & 0.01059337 & 0.000112219 \\
\hline 4 & -0.006945555 & 0.002560454 & 6.55592E-06 \\
\hline 5 & -0.006625258 & -0.000791337 & 6.26214E-07 \\
\hline 6 & -0.006083533 & 0.005187251 & 2.69076E-05 \\
\hline 7 & -0.006018067 & 0.002058895 & 4.23905E-06 \\
\hline 8 & -0.00572888 & 0.001148798 & 1.31974E-06 \\
\hline 9 & -0.005394341 & -0.000261826 & $6.85528 \mathrm{E}-08$ \\
\hline 10 & -0.004981202 & 0.004428281 & 1.96097E-05 \\
\hline 11 & -0.004940815 & 0.018172651 & 0.000330245 \\
\hline 12 & -0.005907298 & 0.010747641 & 0.000115512 \\
\hline 13 & -0.006260847 & -0.001708608 & 2.91934E-06 \\
\hline 14 & -0.005678741 & 0.012005126 & 0.000144123 \\
\hline 15 & -0.006140834 & 0.007030304 & 4.94252E-05 \\
\hline 16 & -0.006205803 & -0.002120035 & 4.49455E-06 \\
\hline 17 & -0.005597665 & 0.008136936 & 6.62097E-05 \\
\hline 18 & -0.005783139 & 0.00299966 & 8.99796E-06 \\
\hline 19 & -0.005579827 & 0.002216176 & 4.91144E-06 \\
\hline 20 & -0.005334139 & -0.009887534 & 9.77633E-05 \\
\hline 21 & -0.004222314 & -0.002450999 & $6.0074 \mathrm{E}-06$ \\
\hline 22 & -0.003734881 & 0.002749842 & 7.56163E-06 \\
\hline 23 & -0.003662931 & 0.00422203 & 1.78255E-05 \\
\hline 24 & -0.003703769 & -0.001014073 & 1.02835E-06 \\
\hline 25 & -0.003359167 & 0.001076273 & 1.15836E-06 \\
\hline 26 & -0.00319242 & 0.000122021 & 1.48891E-08 \\
\hline 27 & -0.002968151 & -0.084871813 & 0.007203225 \\
\hline 28 & 0.003447874 & -0.018858822 & 0.000355655 \\
\hline 29 & 0.004573524 & -0.012717708 & 0.00016174 \\
\hline 30 & 0.005168393 & 0.070225499 & 0.004931621 \\
\hline 31 & -0.000338544 & -0.012108252 & 0.00014661 \\
\hline 32 & 0.000570598 & -0.007854445 & 6.16923E-05 \\
\hline 33 & 0.001102626 & -0.006268944 & 3.92997E-05 \\
\hline 34 & 0.001479986 & 0.004542028 & 2.063E-05 \\
\hline 35 & 0.001040124 & 0.003277104 & 1.07394E-05 \\
\hline 36 & 0.000724784 & -0.000736722 & $5.4276 \mathrm{E}-07$ \\
\hline 37 & 0.000725656 & -0.012056915 & 0.000145369 \\
\hline \multirow[t]{3}{*}{38} & 0.001553317 & -0.005779242 & 3.33996E-05 \\
\hline & t-statistic & -1.100339492 & \\
\hline & $\begin{array}{l}\text { Fail to reject } \mathrm{H} \\
\text { (unit root) }\end{array}$ & & \\
\hline
\end{tabular}


b) PSTN Host Switch/Duration Sensitive $\left(\mathrm{NE}_{\mathrm{B}}\right)$

\begin{tabular}{|c|c|c|c|c|}
\hline $\begin{array}{l}\text { Quarter } \\
\text { (Q) }\end{array}$ & $\begin{array}{c}\text { Minutes of local traffic } \\
\text { (registered) } \\
x_{i}\end{array}$ & $\frac{x b_{i}}{x b_{i-1}}$ & $\ln \left(\frac{x b_{i}}{x b_{i-1}}\right)$ & $\left\{\ln \left(\frac{x b_{i}}{x b_{i-1}}\right)\right\}^{2}$ \\
\hline 4001 & $18,063,852$ & --- & --- & --- \\
\hline $1 \mathrm{Q} 02$ & $17,610,798$ & 0.97492 & -0.02540 & 0.00065 \\
\hline $2 \mathrm{Q} 02$ & $17,916,084$ & 1.01734 & 0.01719 & 0.00030 \\
\hline $3 \mathrm{Q} 02$ & $17,751,178$ & 0.99080 & -0.00925 & 0.00009 \\
\hline $4 \mathrm{Q} 02$ & $18,466,036$ & 1.04027 & 0.03948 & 0.00156 \\
\hline $1 \mathrm{Q} 03$ & $17,669,852$ & 0.95688 & -0.04407 & 0.00194 \\
\hline $2 \mathrm{Q} 03$ & $18,235,898$ & 1.03203 & 0.03153 & 0.00099 \\
\hline $3 Q 03$ & $17,705,198$ & 0.97090 & -0.02953 & 0.00087 \\
\hline $4 \mathrm{Q} 03$ & $18,190,000$ & 1.02738 & 0.02701 & 0.00073 \\
\hline $1 \mathrm{Q} 04$ & $17,063,638$ & 0.93808 & -0.06392 & 0.00409 \\
\hline $2 \mathrm{Q} 04$ & $16,945,346$ & 0.99307 & -0.00696 & 0.00005 \\
\hline $3 \mathrm{Q} 04$ & $16,770,118$ & 0.98966 & -0.01039 & 0.00011 \\
\hline $4 Q 04$ & $16,243,512$ & 0.96860 & -0.03191 & 0.00102 \\
\hline $1 \mathrm{Q} 05$ & $15,729,648$ & 0.96836 & -0.03215 & 0.00103 \\
\hline 2Q05 & $16,026,990$ & 1.01890 & 0.01873 & 0.00035 \\
\hline $3 Q 05$ & $16,078,118$ & 1.00319 & 0.00319 & 0.00001 \\
\hline $4 Q 05$ & $15,844,382$ & 0.98546 & -0.01464 & 0.00021 \\
\hline $1 \mathrm{Q} 06$ & $15,357,246$ & 0.96925 & -0.03123 & 0.00098 \\
\hline 2Q06 & $14,529,896$ & 0.94613 & -0.05538 & 0.00307 \\
\hline $3 Q 06$ & $13,766,406$ & 0.94745 & -0.05398 & 0.00291 \\
\hline $4 \mathrm{Q} 06$ & $13,042,382$ & 0.94741 & -0.05403 & 0.00292 \\
\hline $1 \mathrm{Q} 07$ & $12,805,659$ & 0.98185 & -0.01832 & 0.00034 \\
\hline $2 \mathrm{Q} 07$ & $12,929,680$ & 1.00968 & 0.00964 & 0.00009 \\
\hline $3 Q 07$ & $14,581,243$ & 1.12773 & 0.12021 & 0.01445 \\
\hline 4Q07 & $14,161,931$ & 0.97124 & -0.02918 & 0.00085 \\
\hline 1Q08 & $13,463,208$ & 0.95066 & -0.05060 & 0.00256 \\
\hline $2 Q 08$ & $12,893,965$ & 0.95772 & -0.04320 & 0.00187 \\
\hline $3 Q 08$ & $12,802,067$ & 0.99287 & -0.00715 & 0.00005 \\
\hline $4 Q 08$ & $12,594,470$ & 0.98378 & -0.01635 & 0.00027 \\
\hline $1 \mathrm{Q} 09$ & $11,754,539$ & 0.93331 & -0.06902 & 0.00476 \\
\hline $2 \mathrm{Q} 09$ & $12,563,092$ & 1.06879 & 0.06652 & 0.00443 \\
\hline 3Q09 & $13,266,383$ & 1.05598 & 0.05447 & 0.00297 \\
\hline $4 Q 09$ & $13,938,186$ & 1.05064 & 0.04940 & 0.00244 \\
\hline 1Q10 & N/A & --- & --- & --- \\
\hline 2Q10 & $N / A$ & --- & --- & --- \\
\hline 3Q10 & N/A & --- & --- & --- \\
\hline 4Q10 & N/A & --- & --- & --- \\
\hline 1Q11 & N/A & --- & --- & --- \\
\hline 2Q11 & N/A & --- & --- & --- \\
\hline \multicolumn{2}{|c|}{$\begin{array}{l}\text { Sample mean } \\
\text { Sample variance }\end{array}$} & & $\begin{array}{r}-0.00810 \\
0.00183 \\
\end{array}$ & \\
\hline & & \multicolumn{2}{|l|}{$\hat{\alpha}_{x b}=$} & \\
\hline & & \multicolumn{2}{|l|}{$\hat{\sigma}_{x b}=$} & \\
\hline & & \multirow{3}{*}{$\begin{array}{l}\text { Linear } \\
\text { regression }\end{array}$} & YReg & $X R e g$ \\
\hline & & & $x b_{i}$ & $\ln (x h-1)$ \\
\hline & & & $\ln \left(\overline{x b_{i-1}}\right)$ & $111\left(\lambda D_{i-1}\right)$ \\
\hline
\end{tabular}




\begin{tabular}{|c|c|c|}
\hline 4Q01 & --- & --- \\
\hline 1Q02 & -0.02540 & 16.70942 \\
\hline 2Q02 & 0.01719 & 16.68402 \\
\hline 3Q02 & -0.00925 & 16.70121 \\
\hline 4Q02 & 0.03948 & 16.69196 \\
\hline 1Q03 & -0.04407 & 16.73144 \\
\hline 2Q03 & 0.03153 & 16.68737 \\
\hline 3Q03 & -0.02953 & 16.71890 \\
\hline $4 Q 03$ & 0.02701 & 16.68937 \\
\hline 1Q04 & -0.06392 & 16.71638 \\
\hline 2Q04 & -0.00696 & 16.65246 \\
\hline 3Q04 & -0.01039 & 16.64550 \\
\hline 4Q04 & -0.03191 & 16.63511 \\
\hline 1Q05 & -0.03215 & 16.60320 \\
\hline 2Q05 & 0.01873 & 16.57106 \\
\hline 3Q05 & 0.00319 & 16.58978 \\
\hline $4 Q 05$ & -0.01464 & 16.59297 \\
\hline 1Q06 & -0.03123 & 16.57833 \\
\hline 2Q06 & -0.05538 & 16.54710 \\
\hline 3Q06 & -0.05398 & 16.49172 \\
\hline $4 \mathrm{Q} 06$ & -0.05403 & 16.43774 \\
\hline 1Q07 & -0.01832 & 16.38371 \\
\hline 2Q07 & 0.00964 & 16.36540 \\
\hline 3Q07 & 0.12021 & 16.37504 \\
\hline 4Q07 & -0.02918 & 16.49525 \\
\hline 1Q08 & -0.05060 & 16.46607 \\
\hline 2Q08 & -0.04320 & 16.41547 \\
\hline 3Q08 & -0.00715 & 16.37227 \\
\hline $4 Q 08$ & -0.01635 & 16.36512 \\
\hline 1Q09 & -0.06902 & 16.34877 \\
\hline 2Q09 & 0.06652 & 16.27975 \\
\hline 3Q09 & 0.05447 & 16.34627 \\
\hline 4Q09 & 0.04940 & 16.40074 \\
\hline 1Q10 & --- & --- \\
\hline 2Q10 & --- & --- \\
\hline 3Q10 & --- & --- \\
\hline 4Q10 & --- & --- \\
\hline 1Q11 & --- & --- \\
\hline 2Q11 & --- & --- \\
\hline
\end{tabular}

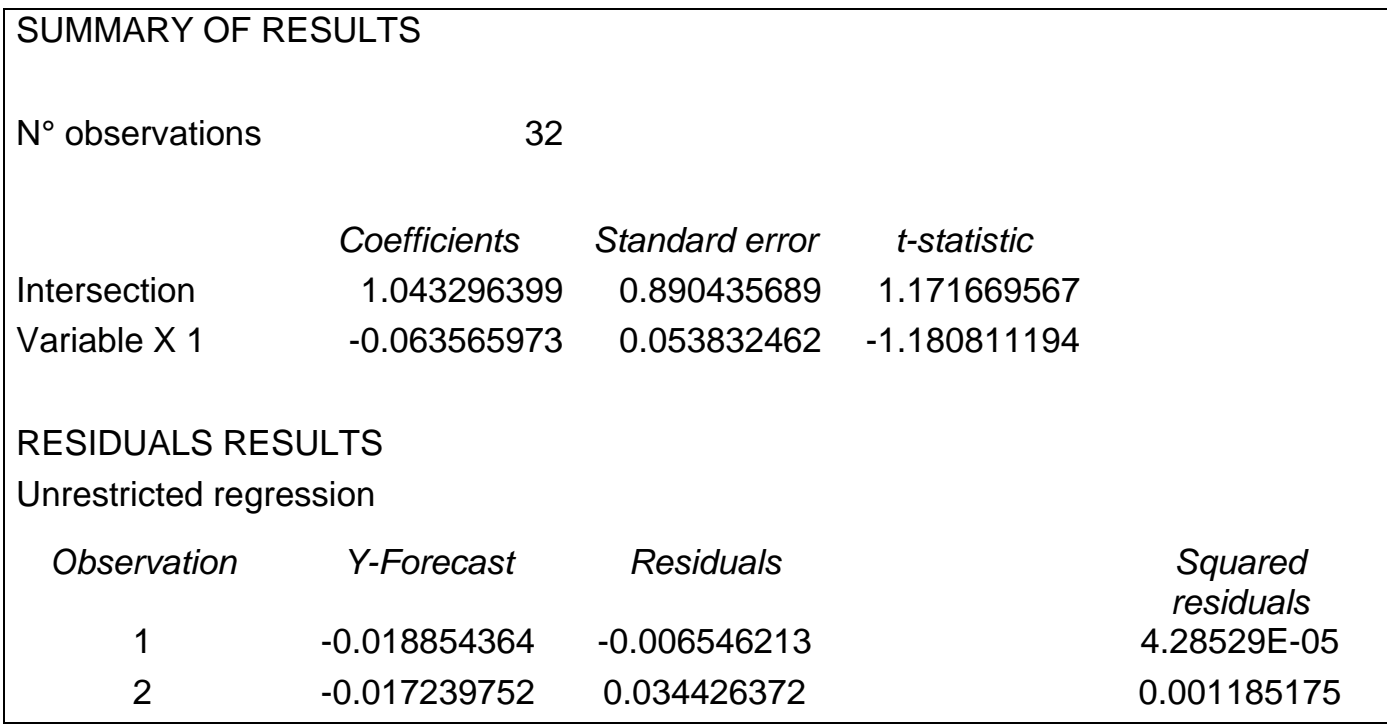




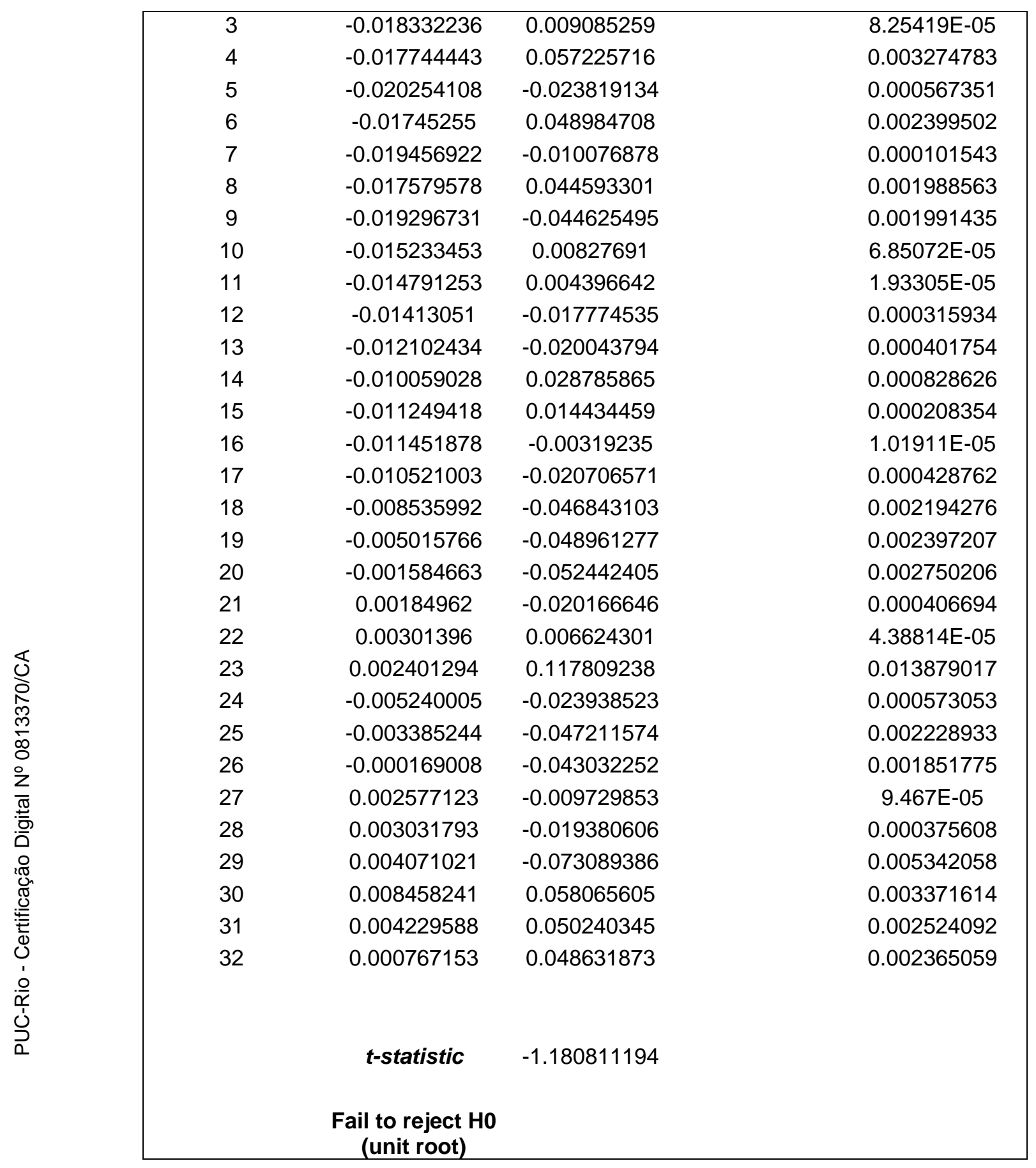


c) Host-Host Transmission $\left(\mathrm{NE}_{\mathrm{C}}\right)$

\begin{tabular}{|c|c|c|c|c|}
\hline $\begin{array}{l}\text { Quarter } \\
\text { (Q) }\end{array}$ & $\begin{array}{l}\text { Minutes of LD traffic } \\
\qquad x c_{i}\end{array}$ & $\frac{x c_{i}}{x c_{i-1}}$ & $\ln \left(\frac{x c_{i}}{x c_{i-1}}\right)$ & $\left\{\ln \left(\frac{x c_{i}}{x c_{i-1}}\right)\right\}^{2}$ \\
\hline 4Q01 & $3,583,644$ & --- & --- & -- \\
\hline $1 \mathrm{Q} 02$ & $3,567,433$ & 0.99548 & -0.00453 & 0.00002 \\
\hline $2 \mathrm{Q} 02$ & $3,574,603$ & 1.00201 & 0.00201 & 0.00000 \\
\hline 3Q02 & $3,609,877$ & 1.00987 & 0.00982 & 0.00010 \\
\hline $4 \mathrm{Q} 02$ & $4,174,964$ & 1.15654 & 0.14543 & 0.02115 \\
\hline $1 \mathrm{Q} 03$ & $4,045,876$ & 0.96908 & -0.03141 & 0.00099 \\
\hline $2 \mathrm{Q} 03$ & $4,110,514$ & 1.01598 & 0.01585 & 0.00025 \\
\hline 3Q03 & $4,078,804$ & 0.99229 & -0.00774 & 0.00006 \\
\hline $4 \mathrm{Q} 03$ & $4,141,645$ & 1.01541 & 0.01529 & 0.00023 \\
\hline 1Q04 & $4,111,540$ & 0.99273 & -0.00730 & 0.00005 \\
\hline 2Q04 & $3,936,645$ & 0.95746 & -0.04347 & 0.00189 \\
\hline $3 Q 04$ & $4,001,210$ & 1.01640 & 0.01627 & 0.00026 \\
\hline 4Q04 & $3,819,901$ & 0.95469 & -0.04637 & 0.00215 \\
\hline $1 \mathrm{Q} 05$ & $3,569,844$ & 0.93454 & -0.06770 & 0.00458 \\
\hline $2 \mathrm{Q} 05$ & $3,593,171$ & 1.00653 & 0.00651 & 0.00004 \\
\hline $3 Q 05$ & $3,517,890$ & 0.97905 & -0.02117 & 0.00045 \\
\hline $4 \mathrm{Q} 05$ & $3,455,078$ & 0.98214 & -0.01802 & 0.00032 \\
\hline $1 \mathrm{Q} 06$ & $3,336,918$ & 0.96580 & -0.03480 & 0.00121 \\
\hline $2 \mathrm{Q} 06$ & $3,292,161$ & 0.98659 & -0.01350 & 0.00018 \\
\hline $3 Q 06$ & $3,192,437$ & 0.96971 & -0.03076 & 0.00095 \\
\hline $4 Q 06$ & $3,207,408$ & 1.00469 & 0.00468 & 0.00002 \\
\hline 1Q07 & $3,104,562$ & 0.96793 & -0.03259 & 0.00106 \\
\hline $2 \mathrm{Q} 07$ & $3,010,806$ & 0.96980 & -0.03066 & 0.00094 \\
\hline 3Q07 & $2,781,518$ & 0.92384 & -0.07921 & 0.00627 \\
\hline $4 \mathrm{Q} 07$ & $2,979,448$ & 1.07116 & 0.06874 & 0.00473 \\
\hline $1 \mathrm{Q} 08$ & $2,918,812$ & 0.97965 & -0.02056 & 0.00042 \\
\hline $2 Q 08$ & $3,024,398$ & 1.03617 & 0.03554 & 0.00126 \\
\hline 3008 & $2,918,200$ & 0.96489 & -0.03575 & 0.00128 \\
\hline $4 Q 08$ & $2,902,075$ & 0.99447 & -0.00554 & 0.00003 \\
\hline $1 \mathrm{Q} 09$ & $2,752,687$ & 0.94852 & -0.05285 & 0.00279 \\
\hline 2Q09 & $2,694,557$ & 0.97888 & -0.02134 & 0.00046 \\
\hline $3 Q 09$ & $2,645,317$ & 0.98173 & -0.01844 & 0.00034 \\
\hline $4 \mathrm{Q} 09$ & $2,655,331$ & 1.00379 & 0.00378 & 0.00001 \\
\hline 1Q10 & N/A & --- & --- & --- \\
\hline 2Q10 & N/A & --- & --- & --- \\
\hline 3Q10 & $\mathrm{N} / \mathrm{A}$ & --- & --- & --- \\
\hline 4Q10 & $\mathrm{N} / \mathrm{A}$ & --- & --- & --- \\
\hline 1Q11 & $N / A$ & --- & --- & --- \\
\hline 2Q11 & $\mathrm{N} / \mathrm{A}$ & --- & --- & --- \\
\hline \multicolumn{2}{|c|}{$\begin{array}{l}\text { Sample mean } \\
\text { Sample variance }\end{array}$} & & $\begin{array}{l}-0.00937 \\
0.00167\end{array}$ & \\
\hline
\end{tabular}

\begin{tabular}{|ll|}
\hline$\hat{\alpha}_{x c}=$ & -0.034 \\
\hline$\hat{\sigma}_{x c}=$ & 0.082 \\
\hline
\end{tabular}

\begin{tabular}{|c|c|c|}
\hline $\begin{array}{c}\text { Linear } \\
\text { regression }\end{array}$ & YReg & $X R e g$ \\
& $\ln \left(\frac{x c_{i}}{x c_{i-1}}\right)$ & $\ln \left(x c_{i-1}\right)$ \\
\hline
\end{tabular}




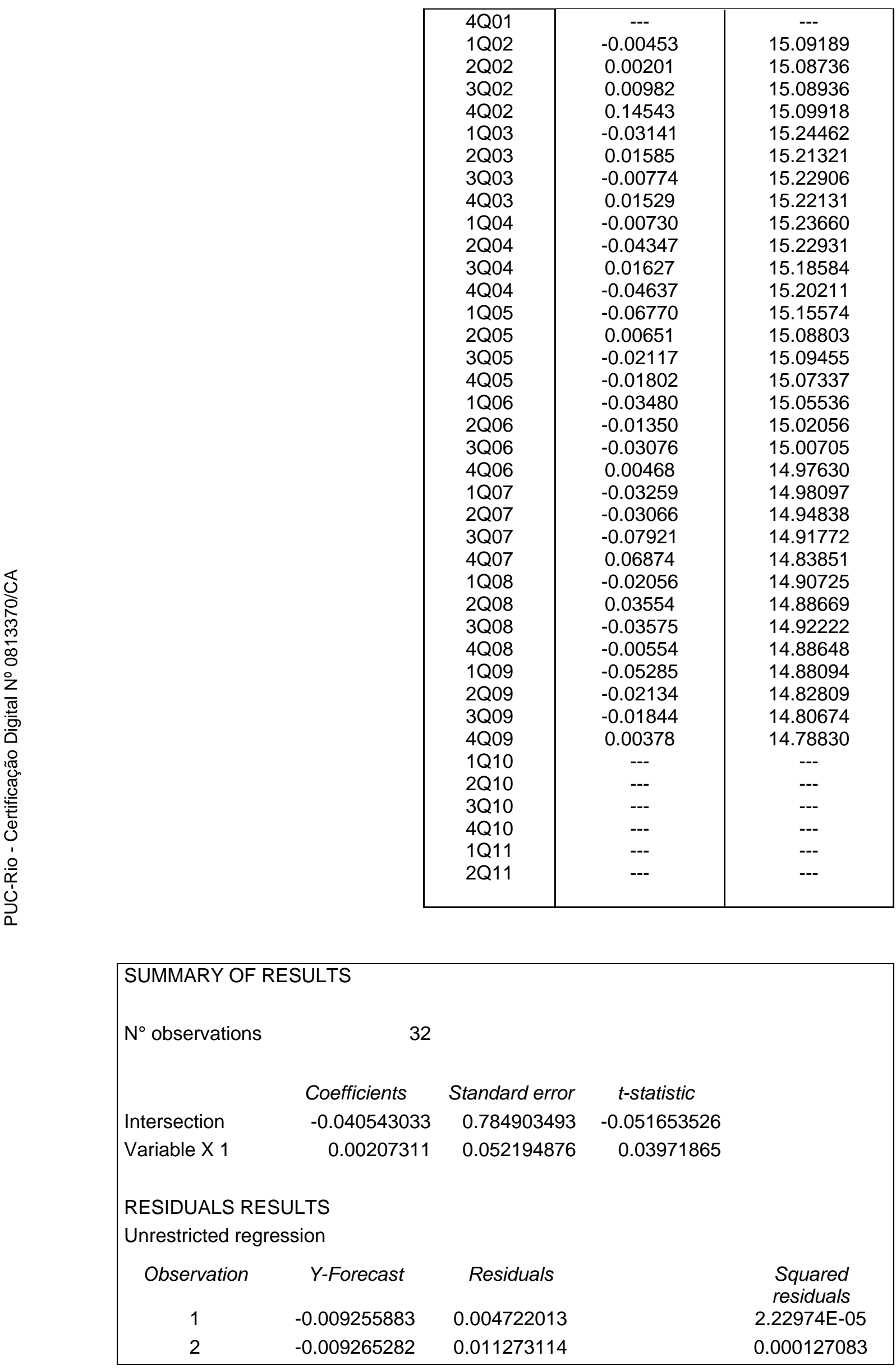




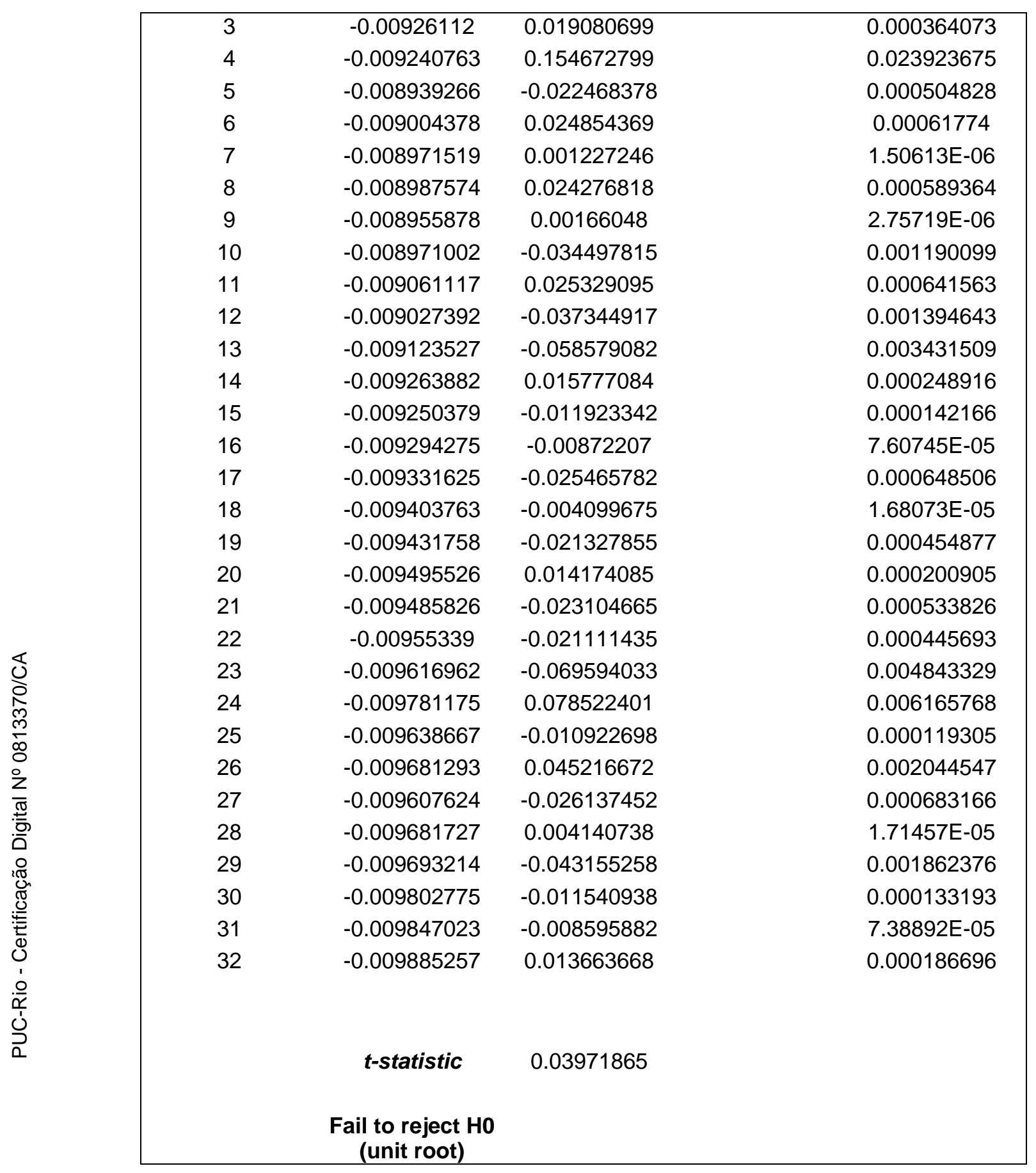




\section{Annex B - Price indices and calculations for the cost of investment stochastic variables}

The Brazilian national index for civil engineering cost, INCC-DI, and price indices for switching and transmission equipment obtained from the telecommunications equipment providers of a European incumbent carrier, using the modern equivalent asset (MEA) approach.

\begin{tabular}{|c|c|c|c|}
\hline & Local Access Loop & $\begin{array}{l}\text { PSTN Host Switch/ } \\
\text { Duration Sensitive }\end{array}$ & $\begin{array}{c}\text { Host-Host } \\
\text { Transmission }\end{array}$ \\
\hline $\begin{array}{c}\text { Year end } \\
\text { (YE) }\end{array}$ & $\begin{array}{l}\text { National index for civil } \\
\text { engineering cost } \\
\text { (INCC-DI) }\end{array}$ & $\begin{array}{c}\text { Price indices for } \\
\text { switching equipment } \\
\text { (MEA) }\end{array}$ & $\begin{array}{c}\text { Price indices for } \\
\text { transmission equipment } \\
\text { (MEA) }\end{array}$ \\
\hline YE1998 & --- & 1.000 & 1.000 \\
\hline YE1999 & --- & 0.960 & 0.960 \\
\hline YE2000 & 196,037 & 0.910 & 0.920 \\
\hline YE2001 & 213,393 & 0.840 & 0.890 \\
\hline YE2002 & 240,861 & 0.810 & 0.880 \\
\hline YE2003 & 275,594 & 0.810 & 0.840 \\
\hline YE2004 & 305,974 & 0.770 & 0.820 \\
\hline YE2005 & 326,915 & 0.690 & 0.800 \\
\hline YE2006 & 343,401 & 0.670 & 0.790 \\
\hline YE2007 & 364,525 & 0.670 & 0.730 \\
\hline YE2008 & 407,807 & 0.640 & 0.690 \\
\hline YE2009 & 421,051 & $\mathrm{~N} / \mathrm{A}$ & N/A \\
\hline YE2010 & 453,766 & N/A & N/A \\
\hline
\end{tabular}

Sources: Brazilian Institute of Economy (IBRE) for the INCC-DI, and Enterprise des Postes et Télécommunications (EPT) Luxembourg for the price indices for switching and transmission equipment (MEA approach). 
Estimating the cost of investment drift and volatility parameters (for each network element):

a) Local Access Loop $\left(\mathrm{NE}_{\mathrm{A}}\right)$

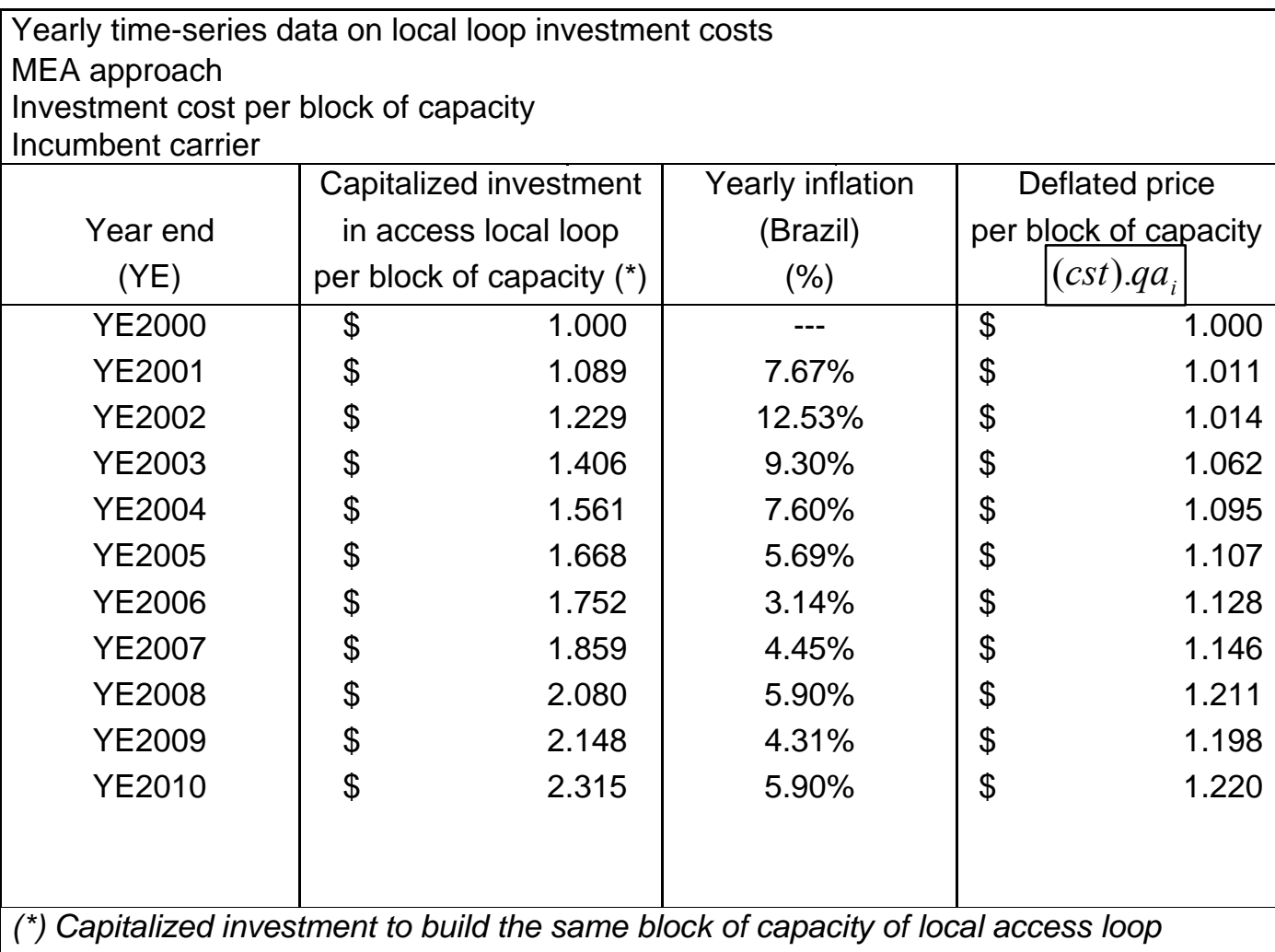

\begin{tabular}{|c|c|c|}
\hline \multicolumn{3}{|c|}{$\begin{array}{l}\text { Quarterly time-series data on local loop investment costs } \\
\text { MEA approach } \\
\text { Deflated investment cost per block of capacity } \\
\text { Incumbent carrier }\end{array}$} \\
\hline EoQ & $\begin{array}{l}\text { Deflated price } \\
\text { per block of capacity } \\
(c s t) \cdot q a_{i} \\
\end{array}$ & $\begin{array}{l}\text { Quarterly rate } \\
\text { (compounded) }\end{array}$ \\
\hline $4 \mathrm{Q} 00$ & $\$ \quad 1.000$ & 1.00274 \\
\hline 1Q01 & 1.003 & \\
\hline 2Q01 & 1.005 & \\
\hline 3Q01 & 1.008 & \\
\hline 4Q01 & 1.011 & 1.00076 \\
\hline 1Q02 & 1.012 & \\
\hline 2Q02 & 1.013 & \\
\hline 3Q02 & 1.013 & \\
\hline 4Q02 & 1.014 & 1.01151 \\
\hline 1Q03 & 1.026 & \\
\hline 2Q03 & 1.038 & \\
\hline 3Q03 & 1.049 & \\
\hline 4Q03 & 1.062 & 1.00786 \\
\hline
\end{tabular}




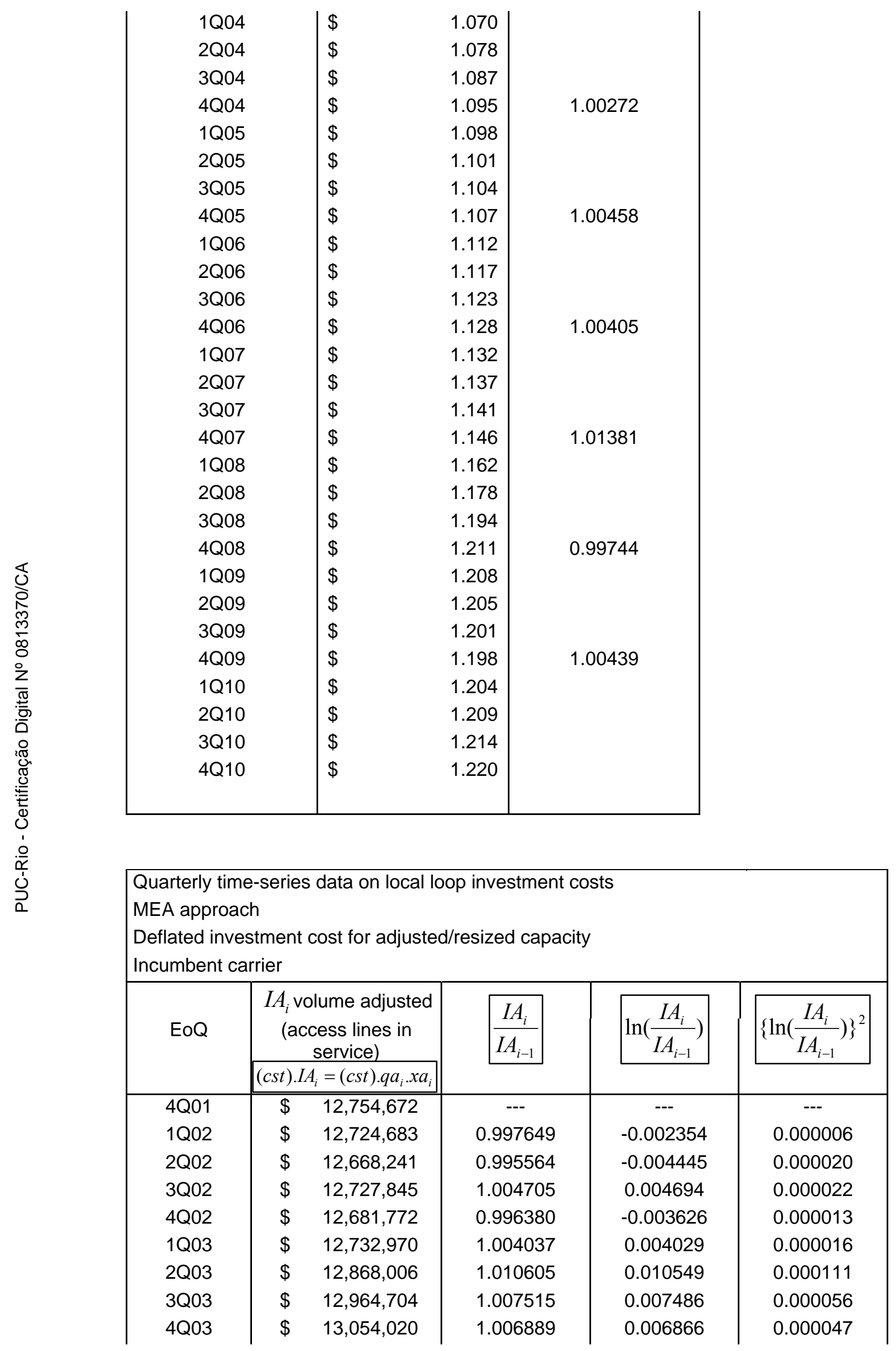




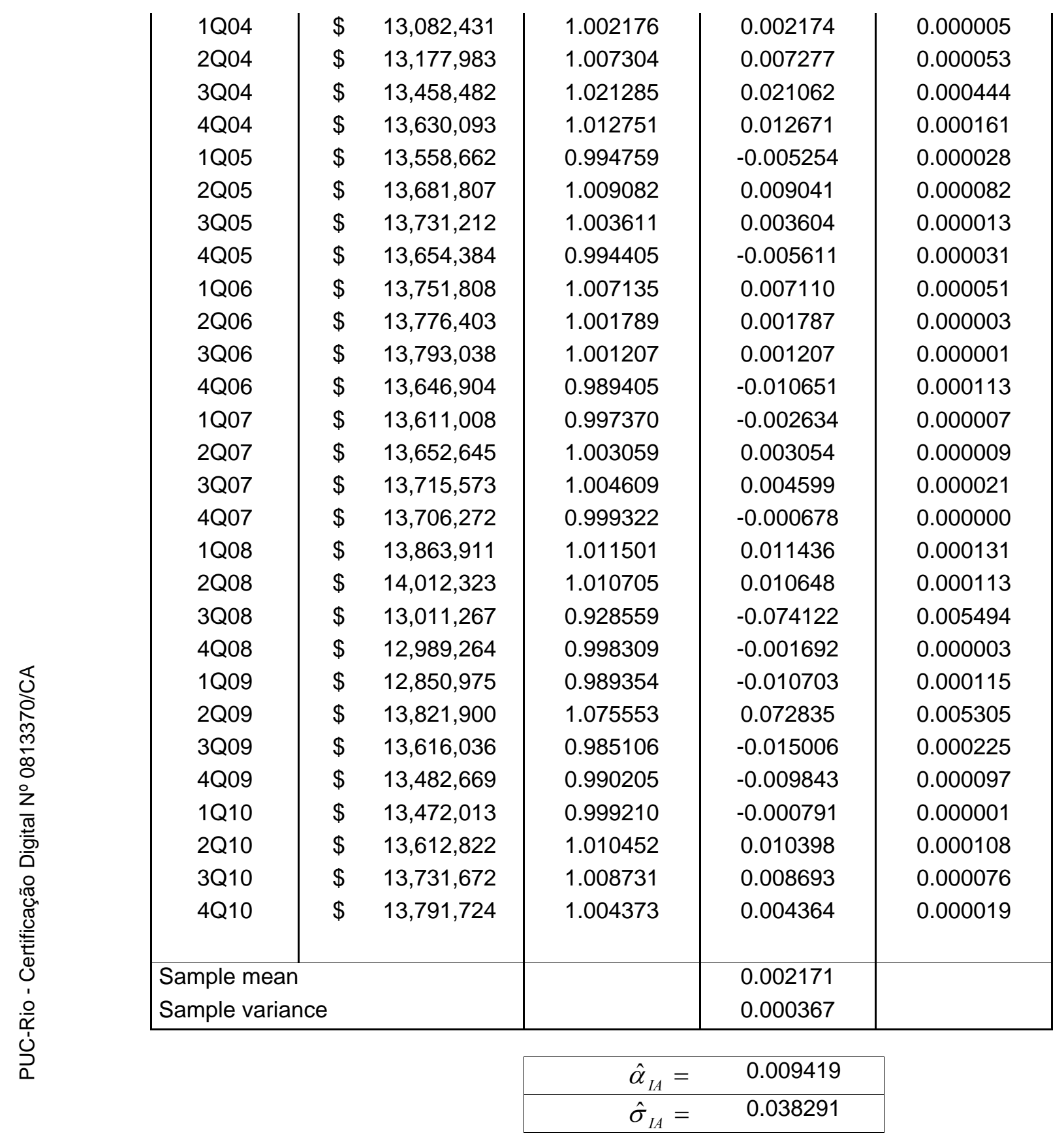

\begin{tabular}{|c|c|c|}
\hline $\begin{array}{c}\text { Linear } \\
\text { regression }\end{array}$ & \multicolumn{1}{|c|}{ YReg } & XReg \\
\cline { 2 - 3 } & $\left.\frac{I A_{i}}{I A_{i-1}}\right)$ & \\
\hline 4Q01 & --- & $\ln \left(I A_{i-1}\right)$ \\
1Q02 & -0.002354 & --- \\
2Q02 & -0.004445 & 16.361408 \\
3Q02 & 0.004694 & 16.359054 \\
4Q02 & -0.003626 & 16.354609 \\
1Q03 & 0.004029 & 16.359303 \\
2Q03 & 0.010549 & 16.355676 \\
3Q03 & 0.007486 & 16.359705 \\
4Q03 & 0.006866 & 16.370255 \\
1Q04 & 0.002174 & 16.377741 \\
2Q04 & 0.007277 & 16.384607 \\
& & 16.386781
\end{tabular}




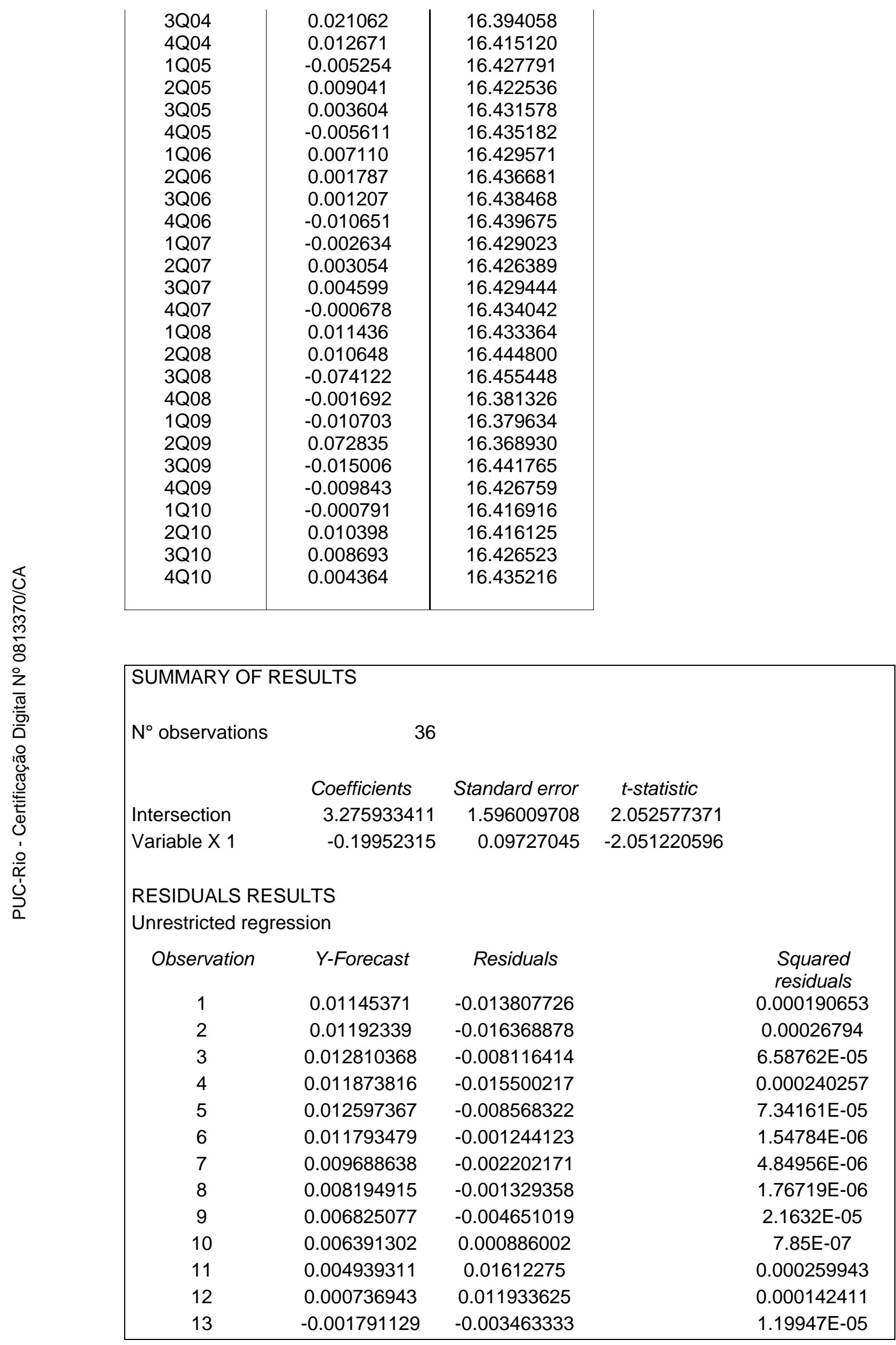




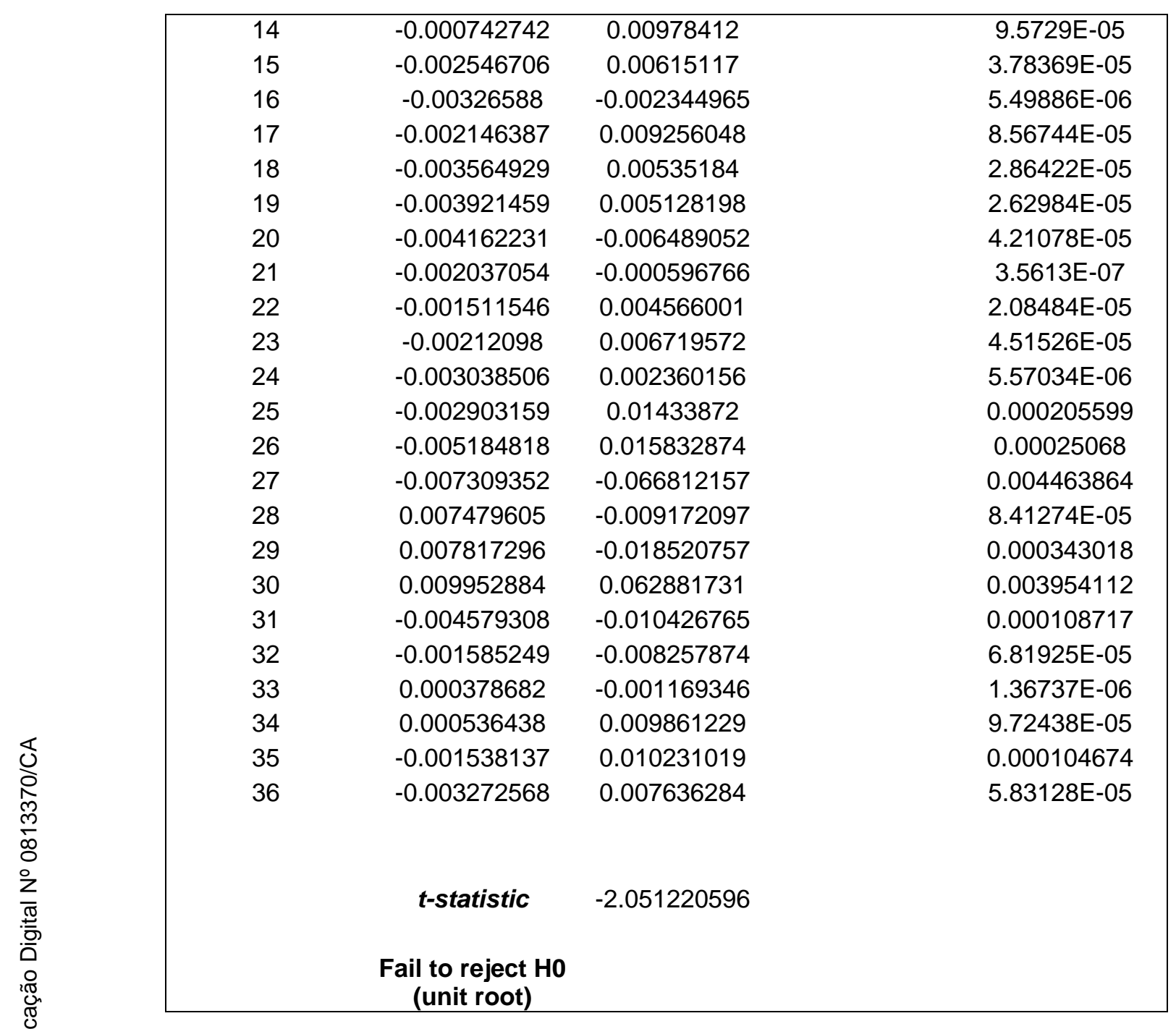


b) PSTN Host Switch/Duration Sensitive $\left(\mathrm{NE}_{\mathrm{B}}\right)$

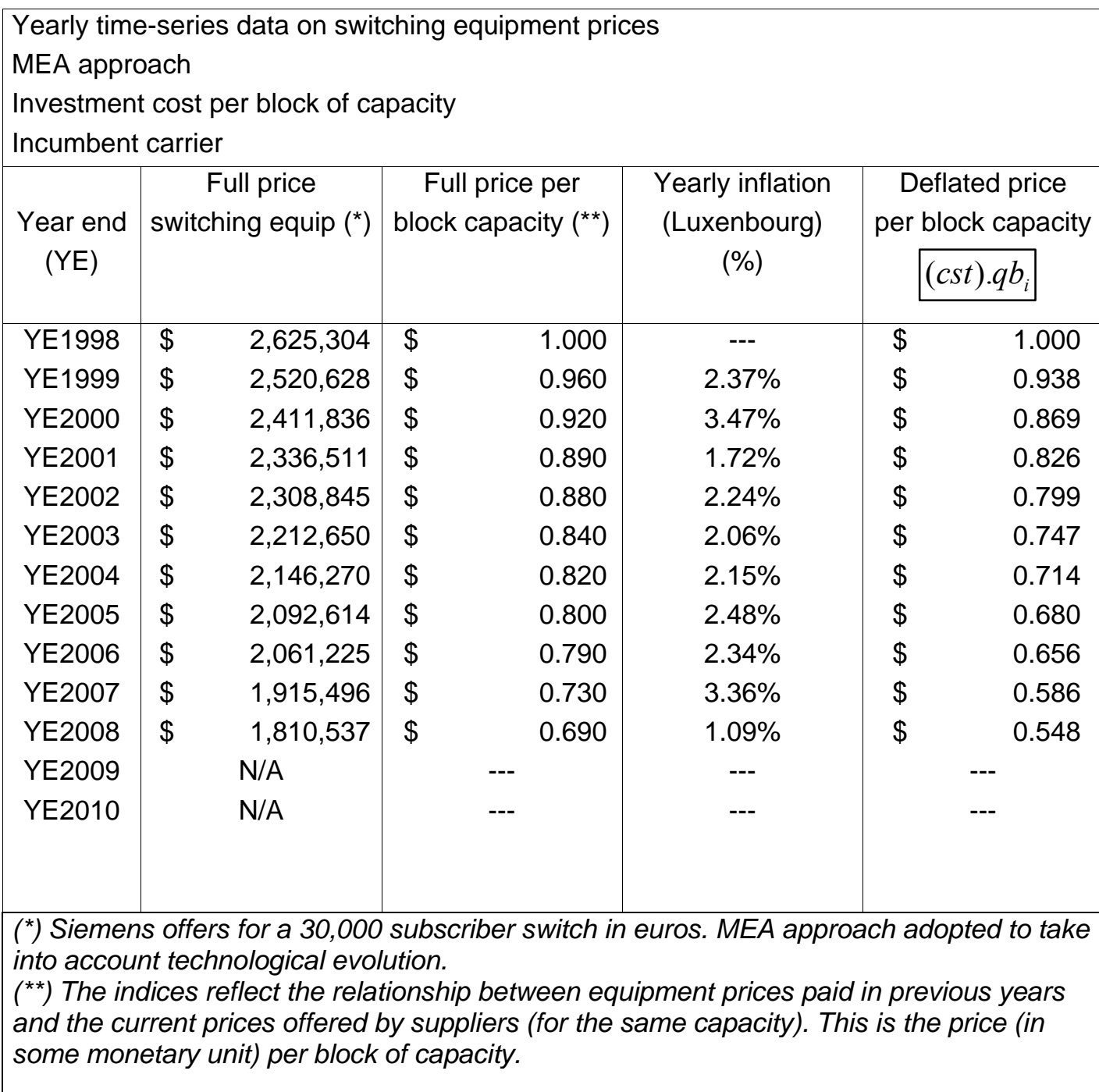

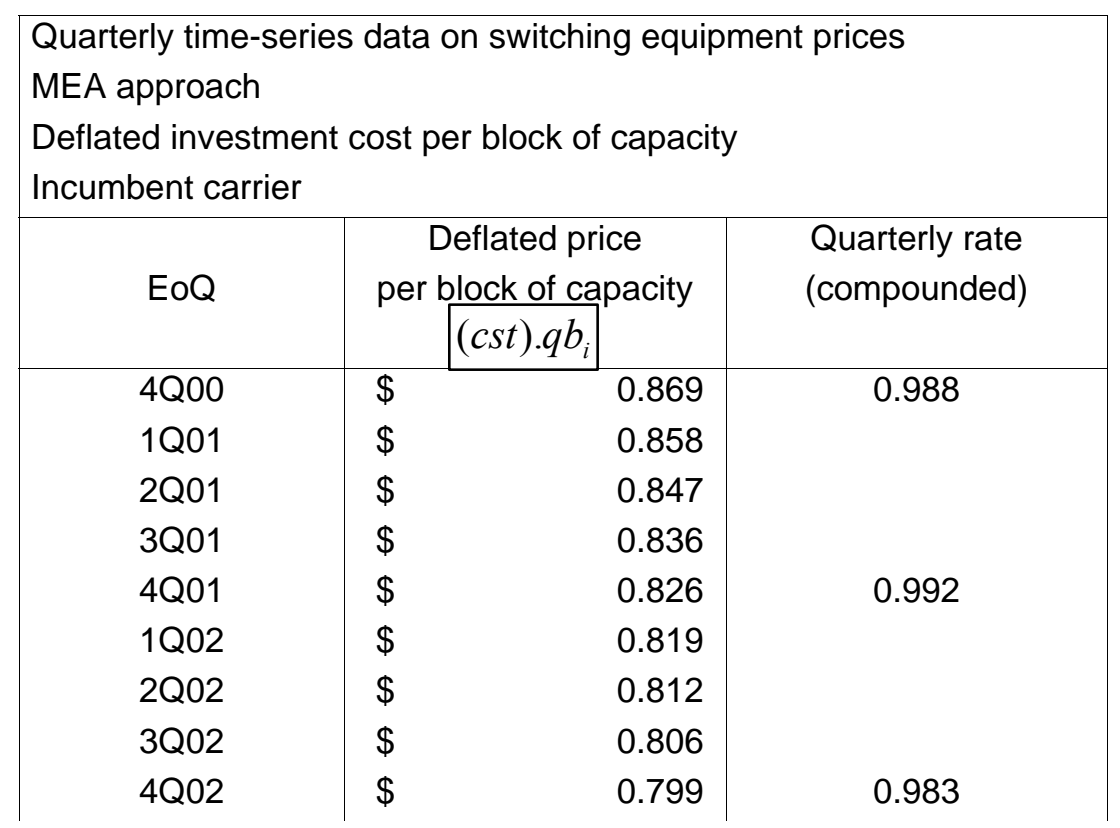




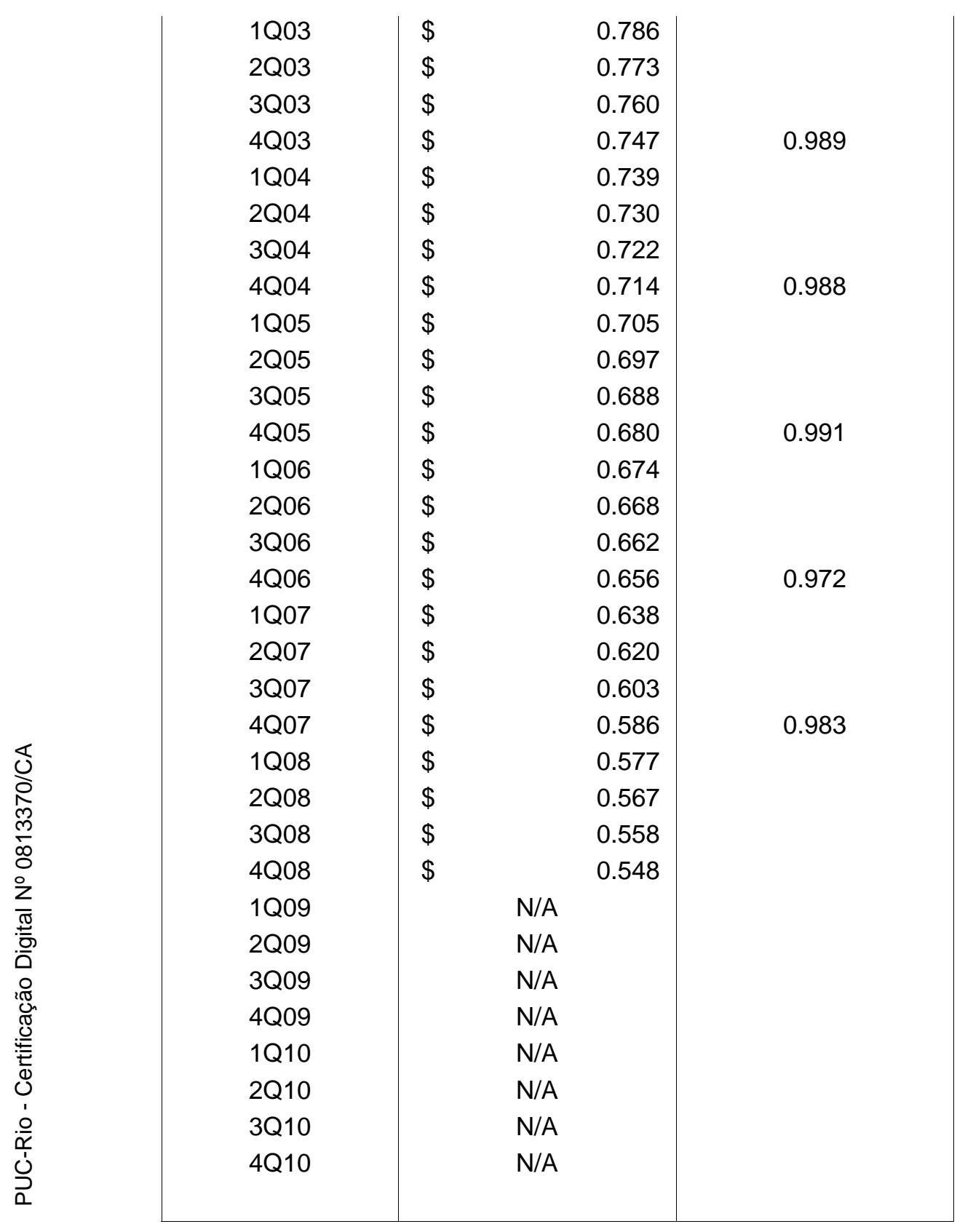

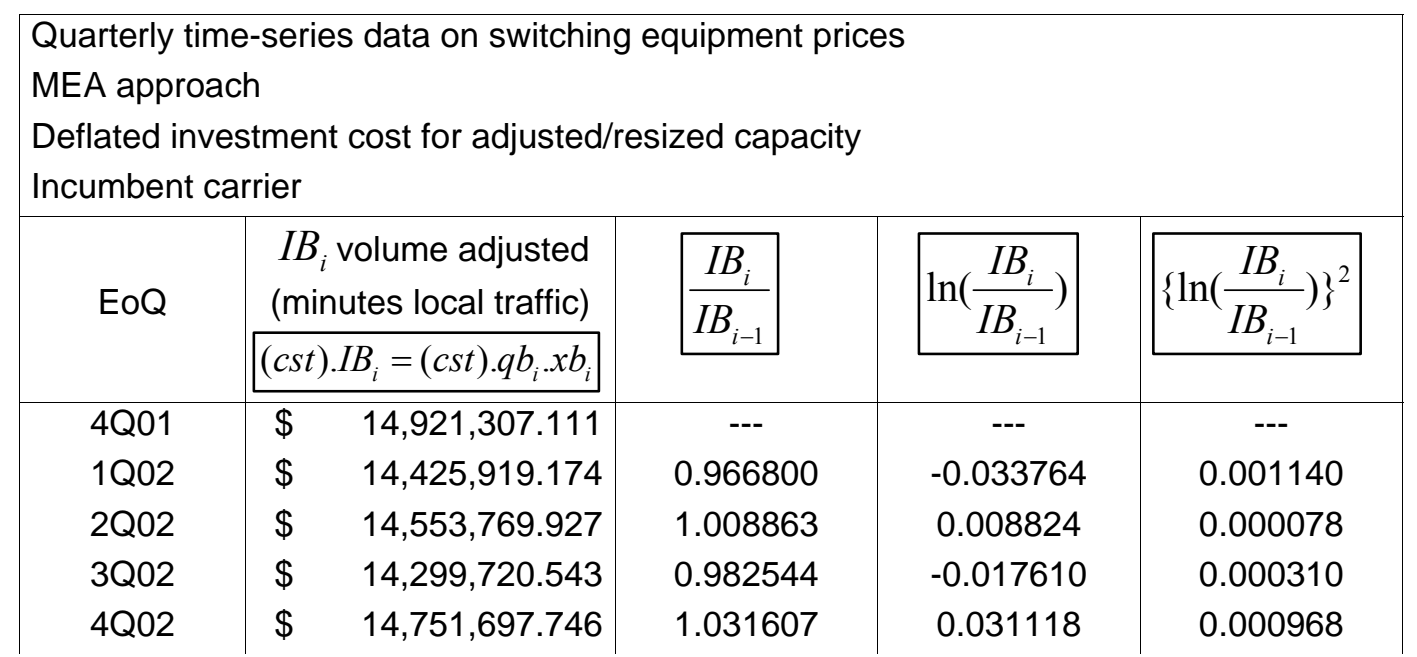




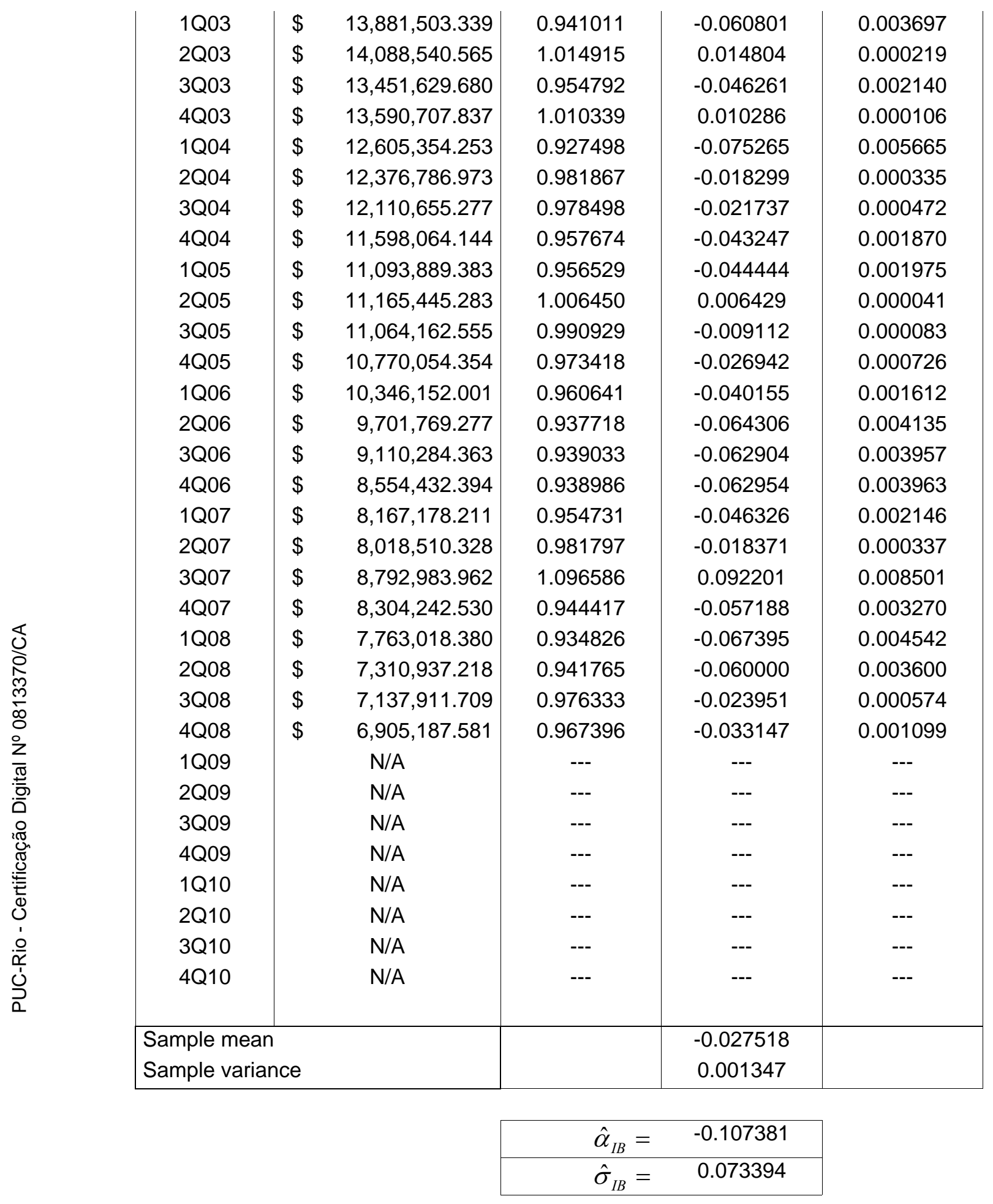

\begin{tabular}{|c|c|c|}
\hline $\begin{array}{c}\text { Linear } \\
\text { regression }\end{array}$ & YReg & XReg \\
\cline { 2 - 3 } & $\ln \left(\frac{I B_{i}}{I B_{i-1}}\right)$ & In $\left(I B_{i-1}\right)$ \\
\hline 4Q01 & --- & --- \\
1Q02 & -0.033764 & 16.518301 \\
2Q02 & 0.008824 & 16.484537 \\
3Q02 & -0.017610 & 16.493361 \\
\hline
\end{tabular}




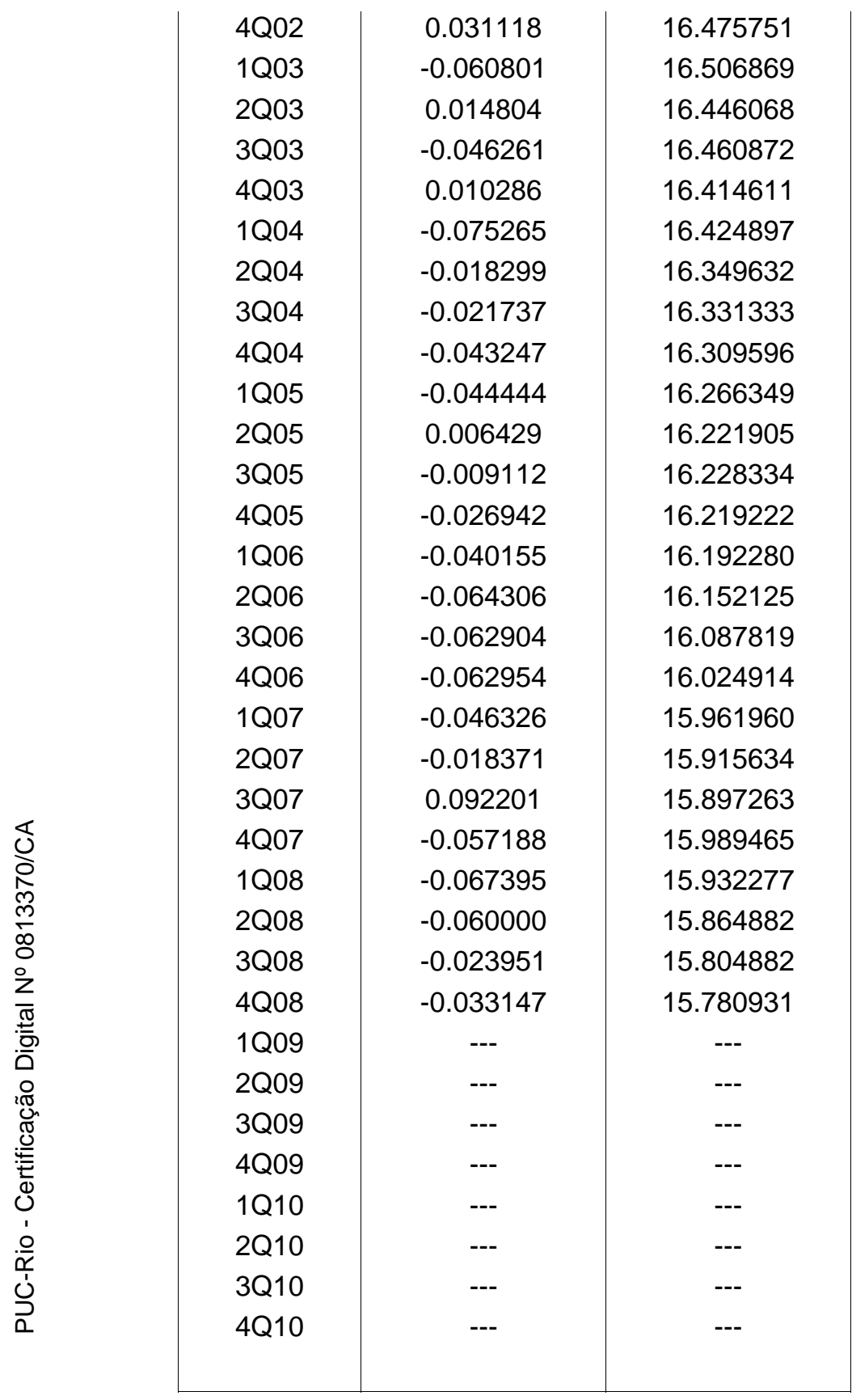

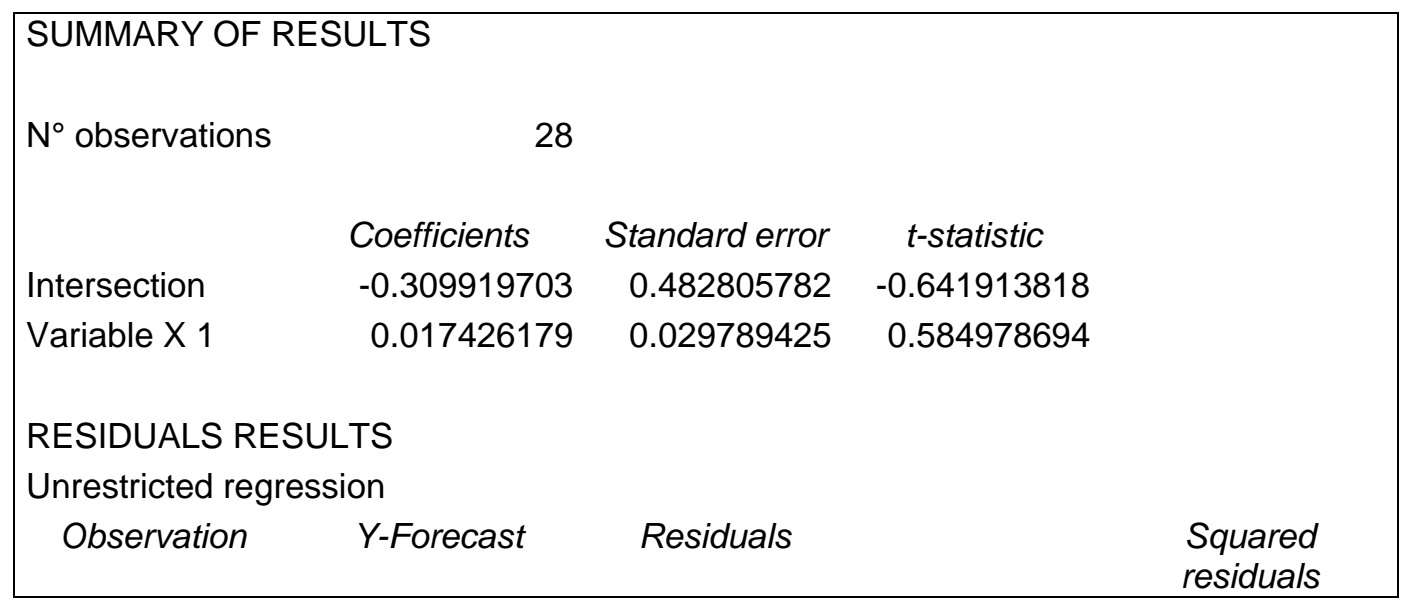




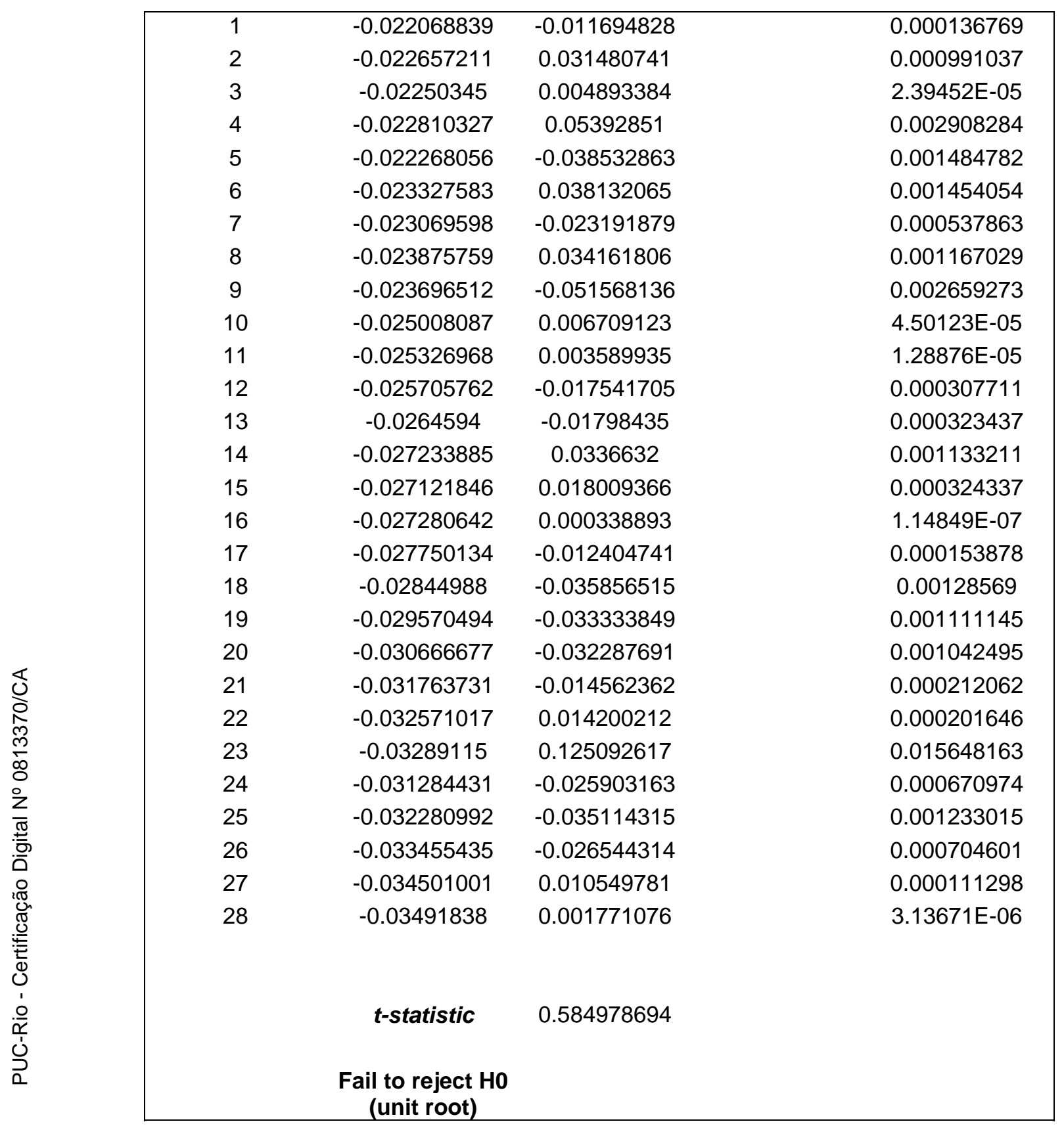


c) Host-Host Transmission $\left(\mathrm{NE}_{\mathrm{C}}\right)$

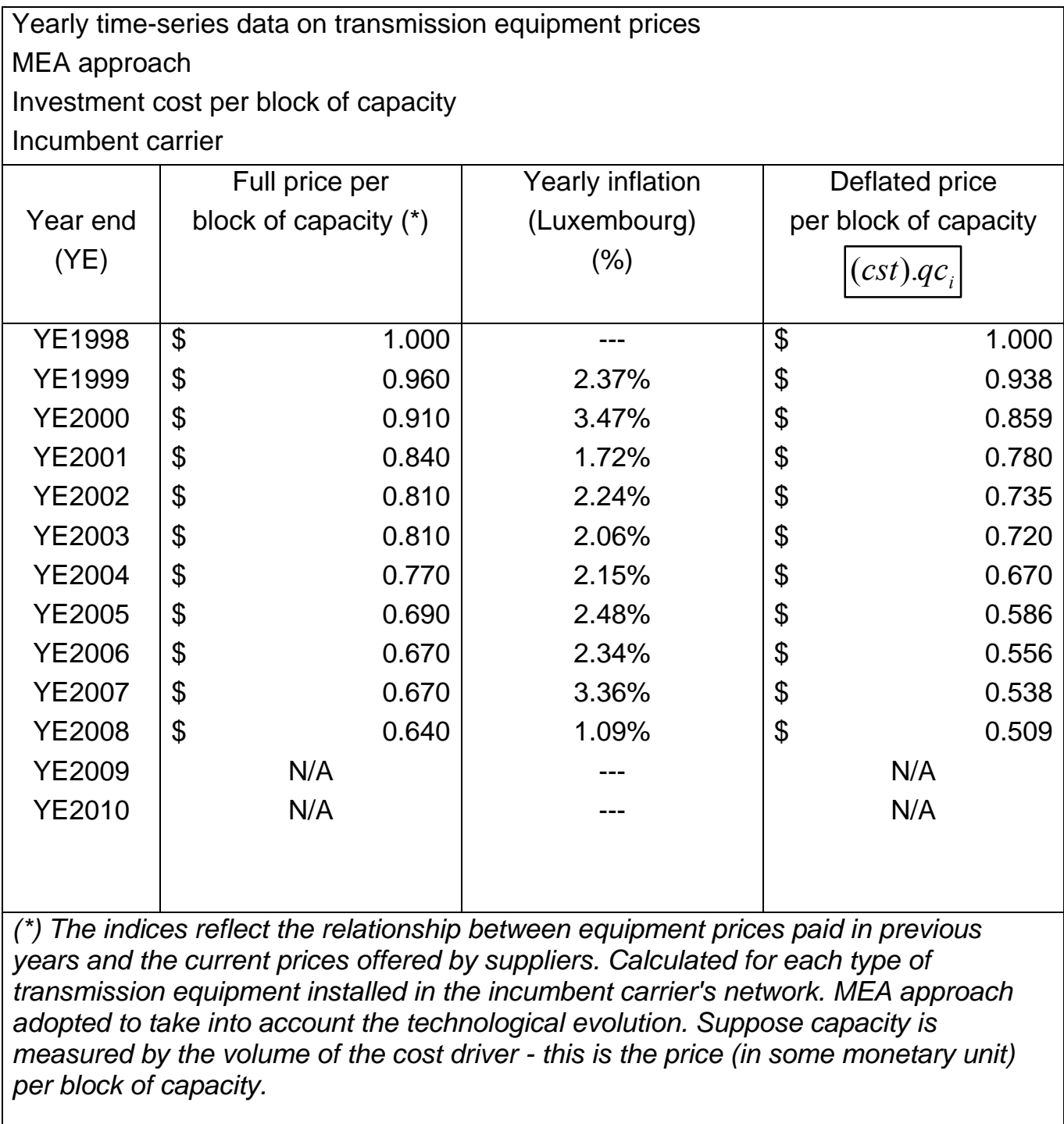

\begin{tabular}{|c|c|c|c|}
\hline \multicolumn{4}{|c|}{$\begin{array}{l}\text { Quarterly time-series data on transmission equipment prices } \\
\text { MEA approach } \\
\text { Deflated investment cost per block of capacity } \\
\text { Incumbent carrier }\end{array}$} \\
\hline EoQ & & apacity & $\begin{array}{l}\text { Quarterly rate } \\
\text { (compounded) }\end{array}$ \\
\hline 4Q00 & $\$$ & 0.859 & 0.98 \\
\hline 1Q01 & $\$$ & 0.839 & \\
\hline 2Q01 & $\$$ & 0.818 & \\
\hline 3Q01 & $\$$ & 0.799 & \\
\hline 4Q01 & $\$$ & 0.780 & 0.99 \\
\hline 1Q02 & $\$$ & 0.768 & \\
\hline 2Q02 & $\$$ & 0.757 & \\
\hline
\end{tabular}




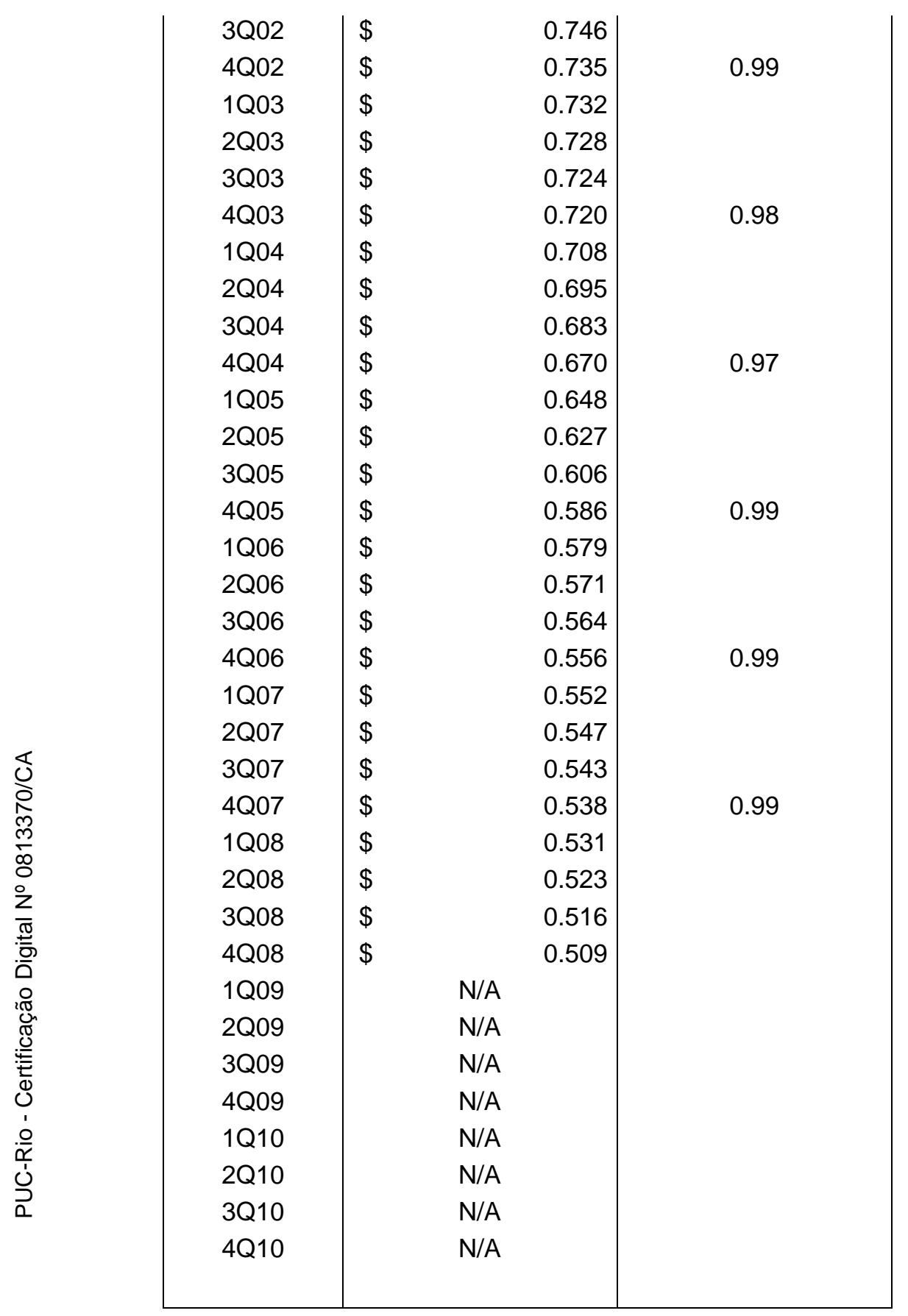

Quarterly time-series data on transmission equipment prices

MEA approach

Deflated investment cost for adjusted/resized capacity Incumbent carrier

\begin{tabular}{|c|c|c|c|c|}
\hline \multirow[t]{2}{*}{ EoQ } & $\begin{array}{l}I C_{i} \text { volume adjusted } \\
\text { (minutes LD traffic) } \\
\end{array}$ & \multirow[t]{2}{*}{$\frac{I C_{i}}{I C_{i-1}}$} & \multirow[t]{2}{*}{$\ln \left(\frac{I C_{i}}{I C_{i-1}}\right)$} & $\multirow[t]{2}{*}{\ln \left(\frac{I C_{i}}{I C_{i-1}}\right)}^{2}$ \\
\hline & $(c s t) \cdot I C_{i}=(c s t) \cdot q c_{i} \cdot x c_{i}$ & & & \\
\hline 4Q01 & $2,793,899$ & --- & --- & --- \\
\hline 1Q02 & $2,740,866$ & 0.981018 & -0.019164 & 0.000367 \\
\hline 2Q02 & $2,706,488$ & 0.987457 & -0.012622 & 0.000159 \\
\hline
\end{tabular}




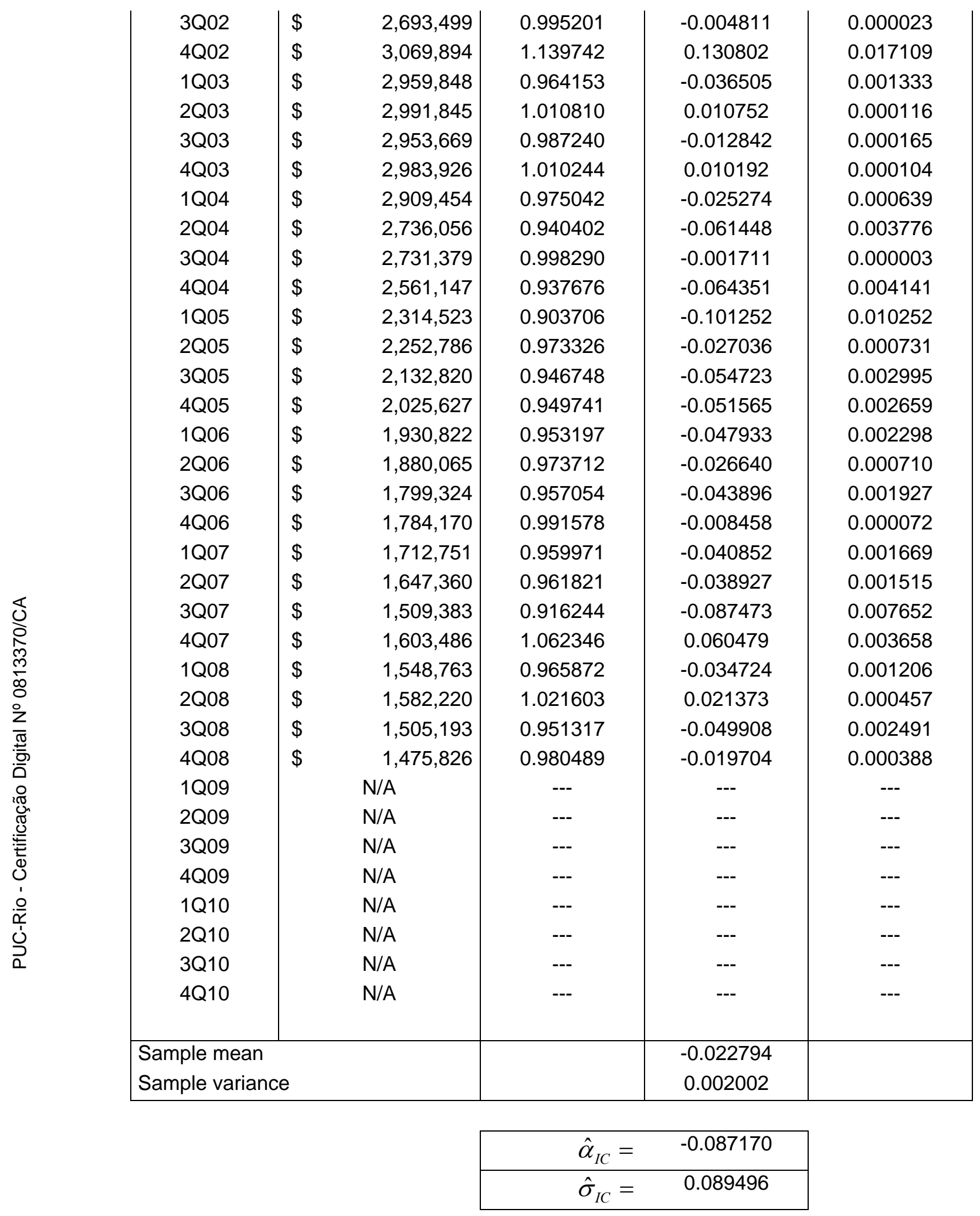

\begin{tabular}{|c|c|c|}
\hline $\begin{array}{c}\text { Linear } \\
\text { regression }\end{array}$ & YReg & XReg \\
\cline { 2 - 3 } $\ln \left(\frac{I C_{i}}{I C_{i-1}}\right)$ & $\ln \left(I C_{i-1}\right)$ \\
\hline $4 \mathrm{Q} 01$ & --- & --- \\
$1 \mathrm{Q} 02$ & -0.019164 & 14.842949 \\
\hline
\end{tabular}




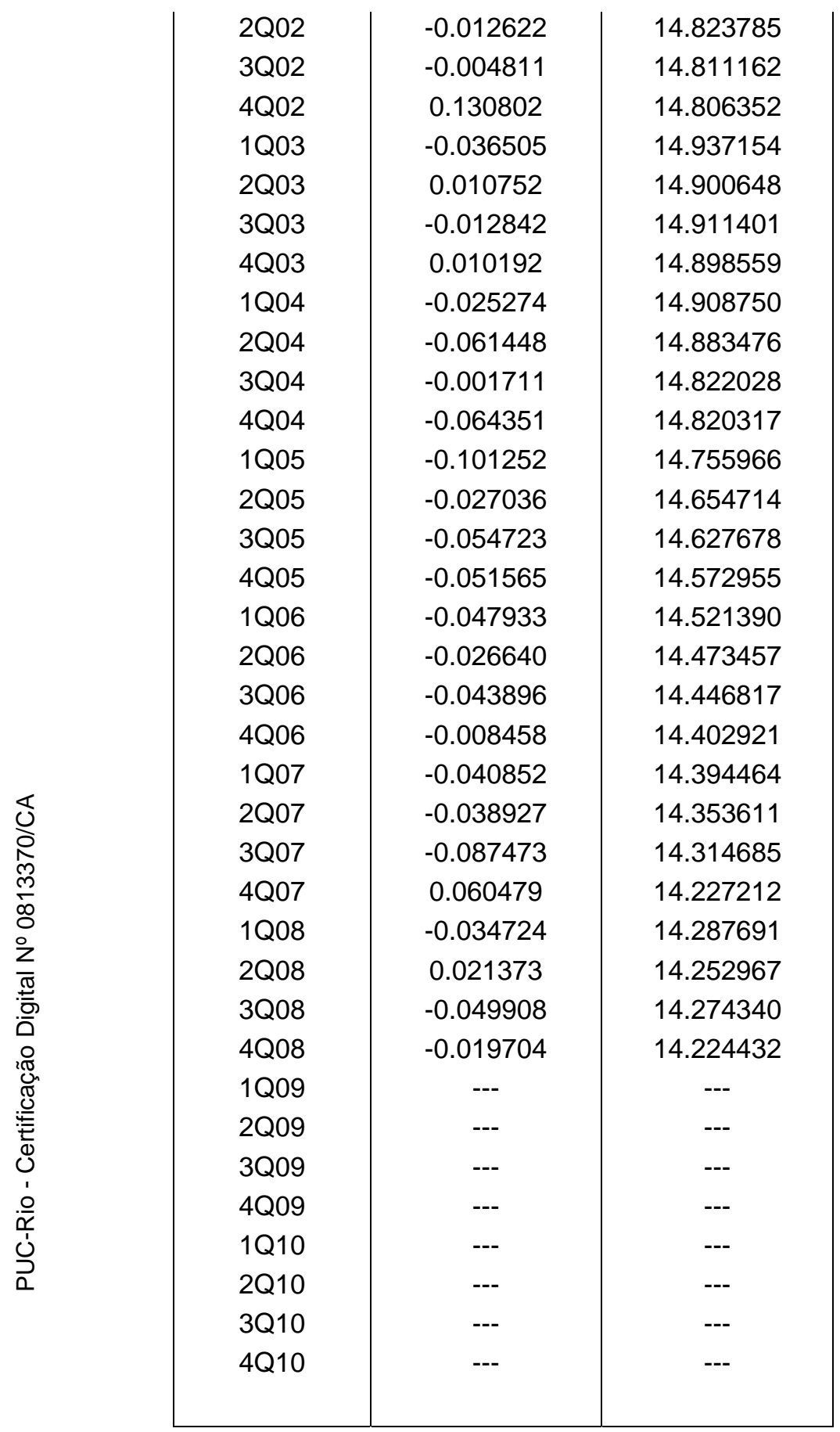

\begin{tabular}{|lrrr}
\hline SUMMARY OF RESULTS & & & \\
No observations & & & \\
& & & \\
& Coefficients & Standard error & t-statistic \\
Intersection & -0.208418292 & 0.501416909 & -0.415658682 \\
Variable X 1 & 0.012703087 & 0.034309046 & 0.370254741 \\
& & & \\
RESIDUALS RESULTS & & & \\
Unrestricted regression & & &
\end{tabular}




\begin{tabular}{|c|c|c|c|}
\hline Observation & $Y$-Forecast & Residuals & $\begin{array}{l}\text { Squared } \\
\text { residuals }\end{array}$ \\
\hline 1 & -0.019867026 & 0.000703043 & 4.9427E-07 \\
\hline 2 & -0.020110468 & 0.007488187 & $5.60729 \mathrm{E}-05$ \\
\hline 3 & -0.02027081 & 0.015460276 & 0.00023902 \\
\hline 4 & -0.020331918 & 0.151133842 & 0.022841438 \\
\hline 5 & -0.01867033 & -0.017834987 & 0.000318087 \\
\hline 6 & -0.01913406 & 0.029886379 & 0.000893196 \\
\hline 7 & -0.018997473 & 0.006155527 & 3.78905E-05 \\
\hline 8 & -0.019160605 & 0.029352176 & 0.00086155 \\
\hline 9 & -0.019031141 & -0.006243224 & 3.89778E-05 \\
\hline 10 & -0.019352203 & -0.04209558 & 0.001772038 \\
\hline 11 & -0.02013278 & 0.01842179 & 0.000339362 \\
\hline 12 & -0.020154514 & -0.044196762 & 0.001953354 \\
\hline 13 & -0.020971974 & -0.080279732 & 0.006444835 \\
\hline 14 & -0.022258183 & -0.004777712 & 2.28265E-05 \\
\hline 15 & -0.022601623 & -0.032121196 & 0.001031771 \\
\hline 16 & -0.023296772 & -0.028268671 & 0.000799118 \\
\hline 17 & -0.023951812 & -0.02398167 & 0.000575121 \\
\hline 18 & -0.024560715 & -0.002078799 & 4.32141E-06 \\
\hline 19 & -0.024899119 & -0.01899657 & 0.00036087 \\
\hline 20 & -0.02545673 & 0.016999214 & 0.000288973 \\
\hline 21 & -0.025564166 & -0.015288289 & 0.000233732 \\
\hline 22 & -0.026083119 & -0.01284367 & 0.00016496 \\
\hline 23 & -0.026577609 & -0.06089535 & 0.003708244 \\
\hline 24 & -0.027688786 & 0.088168049 & 0.007773605 \\
\hline 25 & -0.026920512 & -0.007803492 & $6.08945 \mathrm{E}-05$ \\
\hline 26 & -0.027361614 & 0.048734354 & 0.002375037 \\
\hline 27 & -0.027090115 & -0.022817601 & 0.000520643 \\
\hline \multirow[t]{3}{*}{28} & -0.027724097 & 0.008020467 & $6.43279 \mathrm{E}-05$ \\
\hline & t-statistic & 0.370254741 & \\
\hline & $\begin{array}{l}\text { Fail to reject } H C \\
\text { (unit root) }\end{array}$ & & \\
\hline
\end{tabular}

